\title{
CLIMATE-CHANGE EFFECTS ON THE ZAMBEZI TEAK FORESTS' PRODUCTIVITY IN ZAMBIA
}

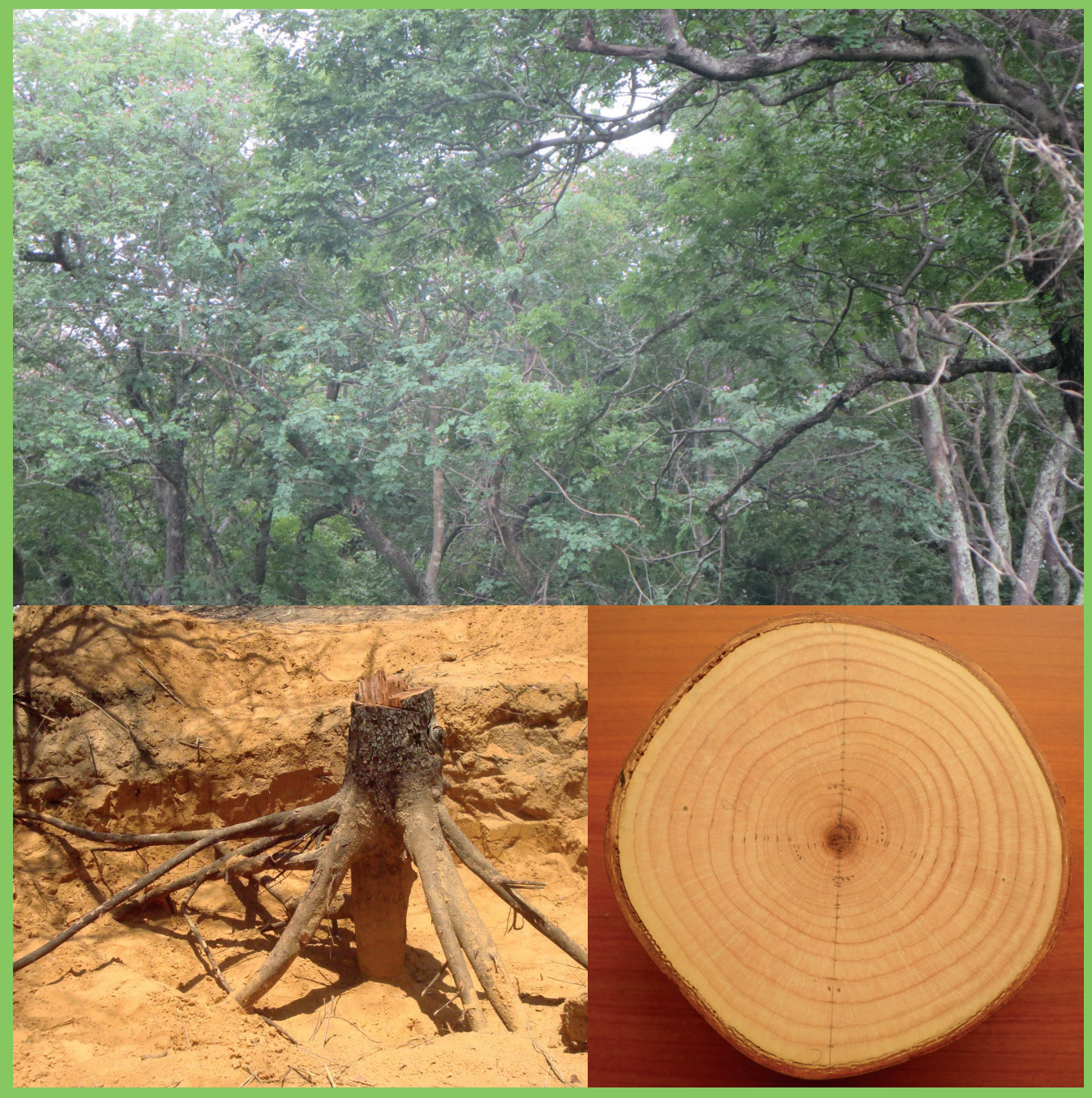

\section{Justine Ngoma}





\section{Propositions}

1. An accurate determination of climate-change effects on forests should combine different methods.

(this thesis)

2. Validating models with data from field observations is illogical to build trust in the model's performance.

(this thesis)

3. Mitigating climate change by expanding forests is impossible without involving local people and improving their livelihoods

4. In developing countries, investing in programs that reduce deforestation, is a more effective climate-change policy than investing in climate - change adaptation programs.

5. A scientist's mind is easily manipulated by a business minded person.

6. Giving people money is the quickest way to make them lazy.

Propositions belonging to the thesis:

"Climate-change effects on the Zambezi teak forests' productivity in Zambia"

Justine Ngoma

Wageningen, $11^{\text {th }}$ June, 2019 



\section{CLIMATE-CHANGE EFFECTS ON THE ZAMBEZI TEAK FORESTS' PRODUCTIVITY IN ZAMBIA}

Justine Ngoma 


\section{Thesis committee}

\section{Promotors}

Prof. dr Rik Leemans

Professor of Environmental Systems Analysis

Wageningen University and Research

Prof. dr James H. Speer

Professor of Geography and Geology

Department of Earth and Environmental Systems

Indiana State University, USA

\section{Co-promotors}

Prof. dr Eddy Moors

Rector of IHE Delft Institute for Water Education, The Netherlands

Professor at VU University Amsterdam, The Netherlands

Dr Bart Kruijt

Researcher at the Water Systems and Global Change Group

Wageningen University and Research

\section{Other members}

Dr Elmar M. Veenendaal, Nature Conservation \& Plant Ecology Group, Wageningen Univeristy and Research

Dr Marijke van Kuijk, Environmental Biology, Universiteit Utrecht

Dr C. von Randow, National Institute for Space Research (INPE), Brazil

Prof. dr Koen Kramer, Wageningen Univeristy and Research

This research was conducted under the auspices of the Graduate School for Social Economic and Natural Sciences of the Environment (SENSE) 


\section{CLIMATE-CHANGE EFFECTS ON THE ZAMBEZI TEAK FORESTS' PRODUCTIVITY IN ZAMBIA}

\section{Justine Ngoma}

\section{Thesis}

submitted in fulfilment of the requirements for the degree of doctor

$$
\text { at Wageningen University }
$$

by the authority of the Rector Magnificus

$$
\begin{aligned}
& \text { Prof. Dr A.P.J. Mol } \\
& \text { in the presence of the }
\end{aligned}
$$

Thesis Committee appointed by the Academic Board

to be defended in public

on Tuesday $11^{\text {th }}$ June 2019

at 11 a.m. in the Aula 


\section{Justine Ngoma}

Climate-change effects on the Zambezi teak forests' productivity in Zambia 194 pages

PhD thesis, Wageningen University, Wageningen, The Netherlands (2019)

With references and summary in English

ISBN: 978-94-6343-434-8

DOI: https://doi.org/10.18174/471532 


\section{Dedication}

To my family 


\section{TABLE OF CONTENTS}

CHAPTER 1: GENERAL INTRODUCTION...................................................... 1

1.1 Climate variability and change in Africa .............................................................................. 2

1.2 Climate change effects on African forests' productivity .......................................................... 2

1.3 Importance of the forests in Zambia ................................................................................. 4

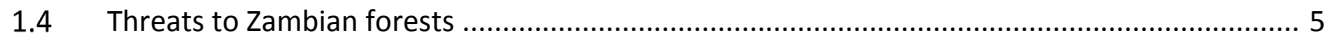

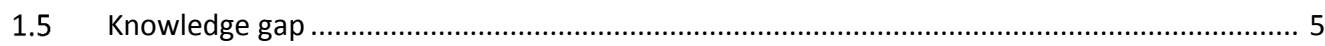

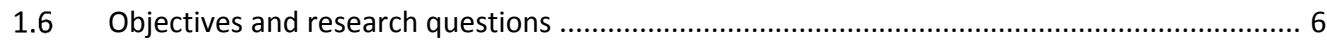

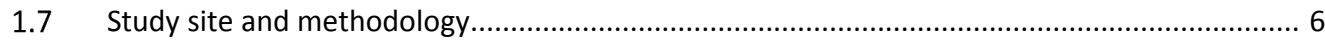

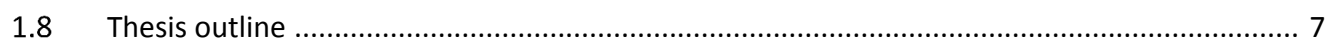

CHAPTER 2: DATA FOR DEVELOPING ALLOMETRIC MODELS AND EVALUATING CARBON STOCKS OF THE ZAMBEZI TEAK FORESTS IN ZAMBIA ....................... 11

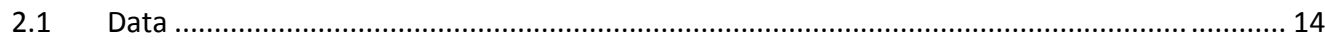

2.1.1 Parameters of trees used to develop allometric models (Tables 2.1, 2.2 and 2.3) ......... 14

2.1.2 Species Importance Value Indices of large $(\geq 5 \mathrm{~cm} \mathrm{DBH})$ and small $(<5 \mathrm{~cm} \mathrm{DBH})$ trees..... 19

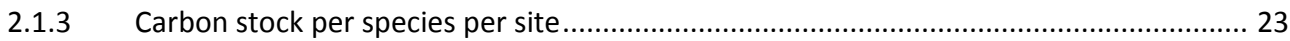

$2.2 \quad$ Experimental design, materials and methods........................................................................ 26

2.2.1 Sample collection process for developing below-ground biomass models ...................... 26

2.2.2 Sample collection process for developing above-ground biomass models ..................... 26

CHAPTER 3: BELOW AND ABOVE-GROUND CARBON DISTRIBUTION ALONG A RAINFALL GRADIENT. A CASE OF THE ZAMBEZI TEAK FORESTS, ZAMBIA......... 29

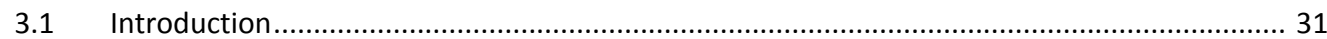

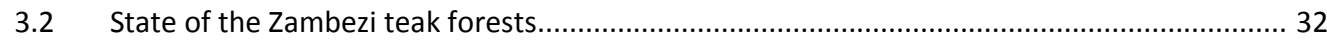

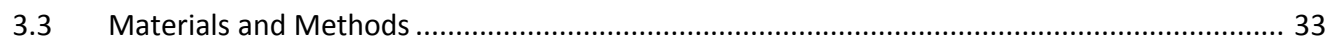

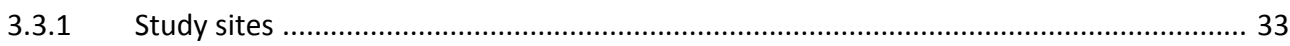

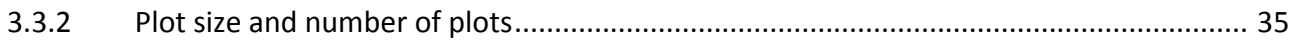

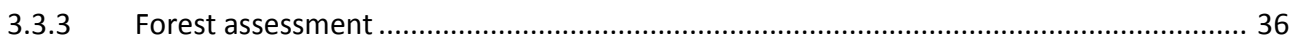

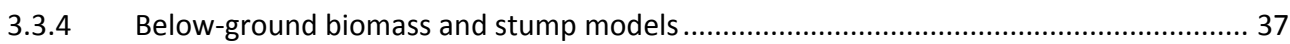

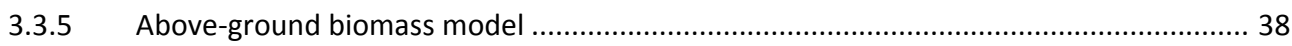

3.3.6 Carbon content of stem, branches, roots and leaves .................................................... 40

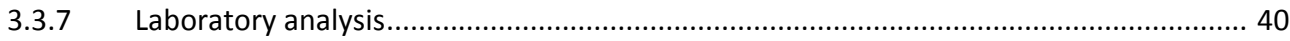

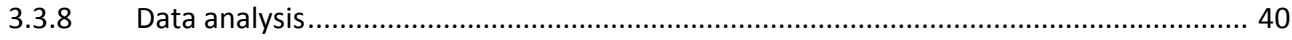

3.3.9 Model regression, selection and evaluation ................................................................... 41

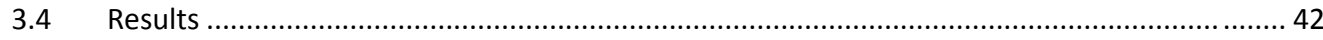

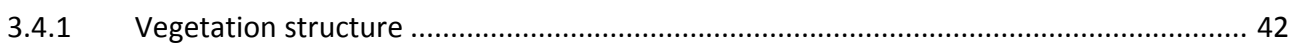

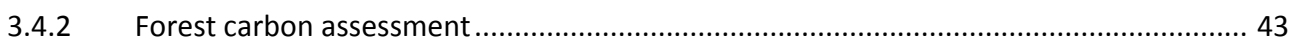

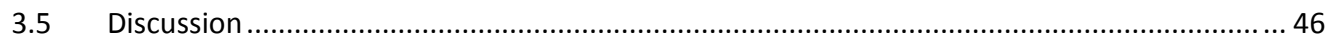

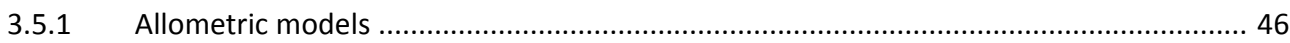




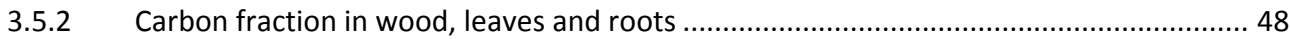

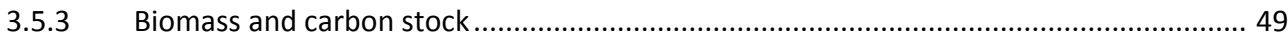

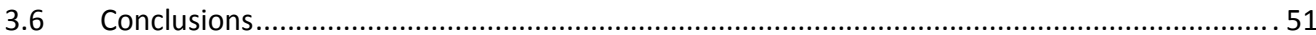

CHAPTER 4: FORESTS' RESPONSE TO CLIMATE CHANGE-A REVIEW OF NET

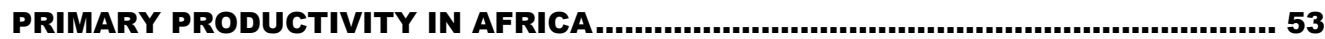

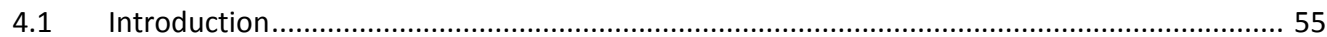

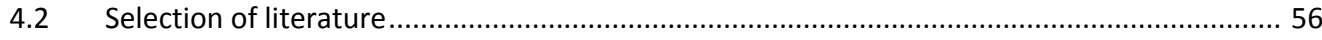

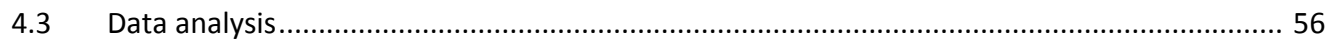

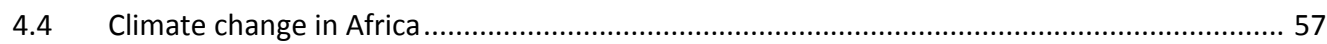

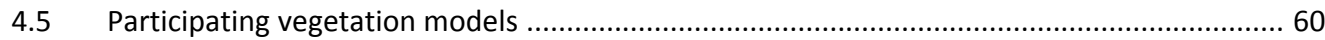

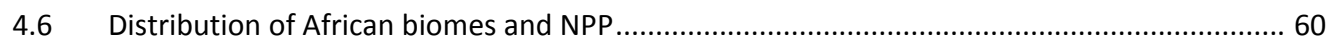

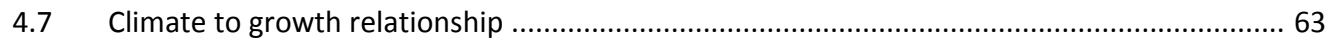

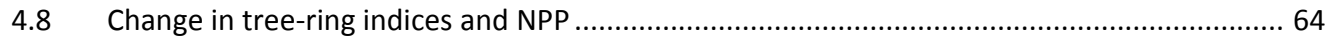

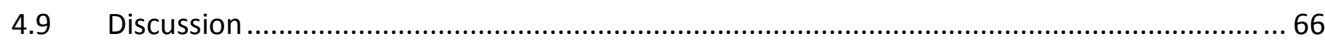

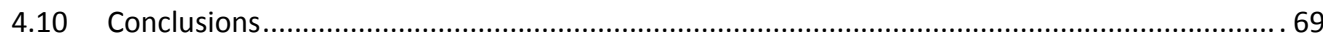

CHAPTER 5: THE DENDROCHRONOLOGICAL POTENTIAL OF BAIKIAEA PLURIJUGA

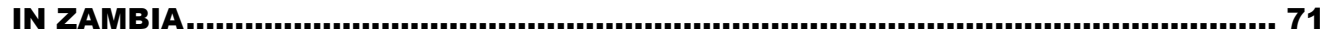

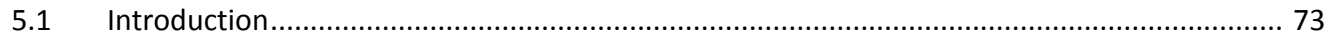

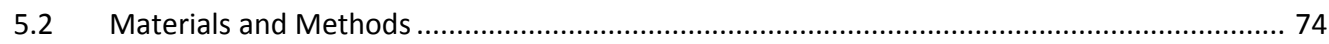

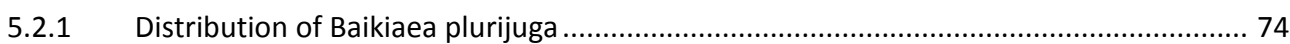

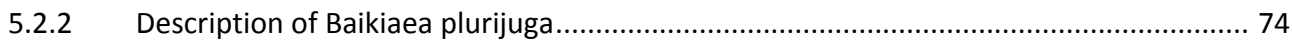

5.2.3 Composition of Baikiaea plurijuga in the Zambezi teak forest ......................................... 75

5.2.4 Topography and soil characteristics of the Zambezi teak forests .................................... 75

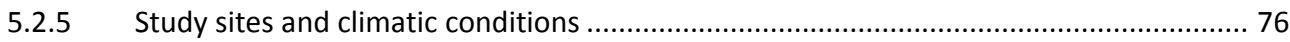

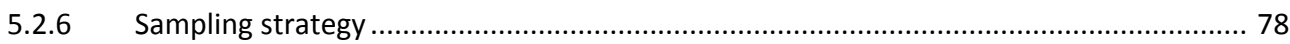

5.2.7 Sample preparation, growth-ring measurements and statistical analysis ........................ 80

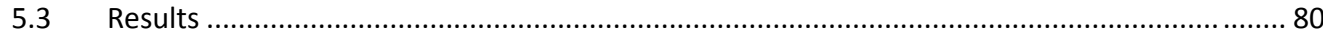

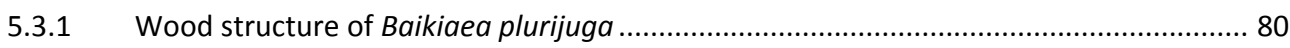

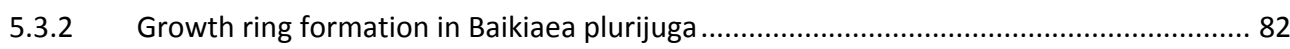

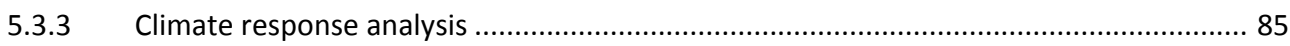

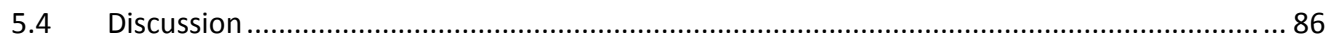

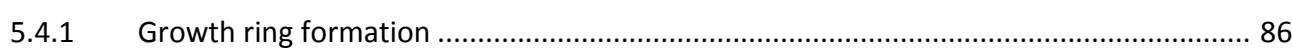

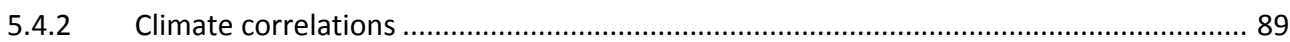

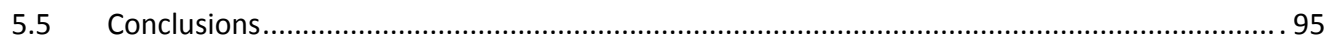

CHAPTER 6: MODELLING THE RESPONSE OF NET PRIMARY PRODUCTIVITY OF ZAMBEZI TEAK FORESTS TO CLIMATE CHANGE ALONG A RAINFALL GRADIENT IN

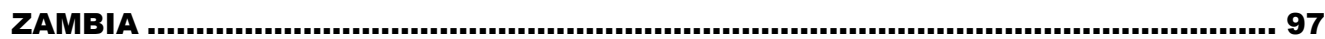

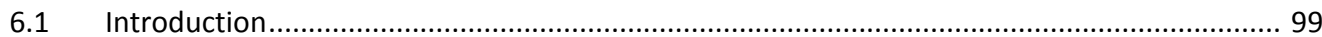

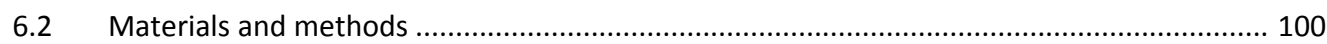

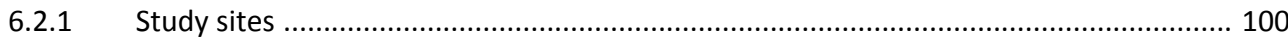




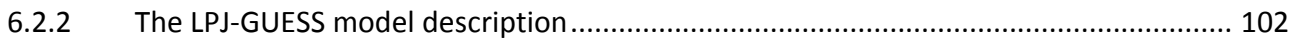

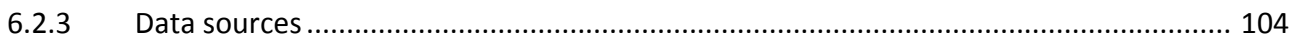

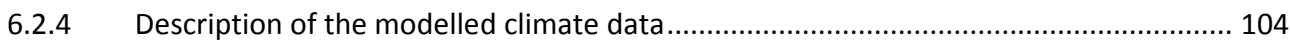

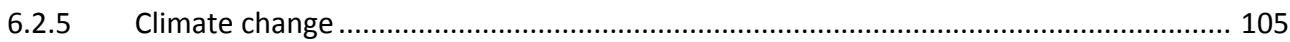

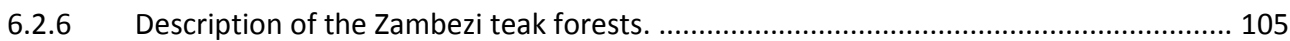

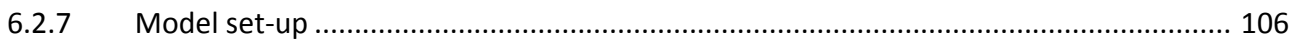

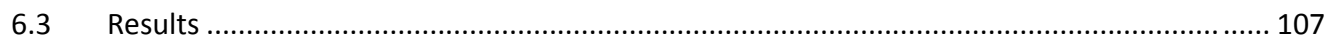

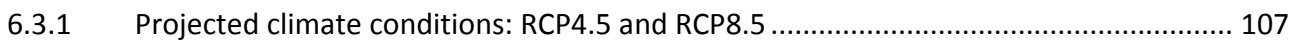

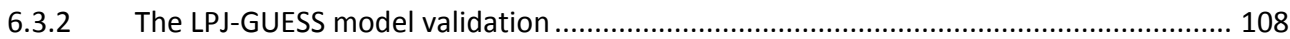

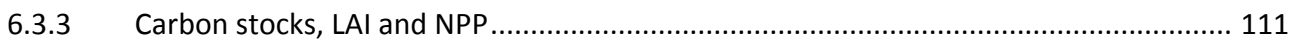

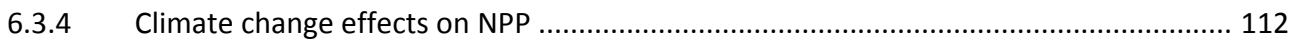

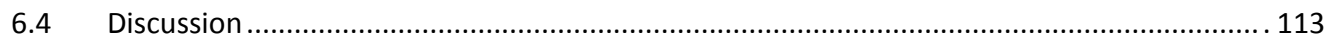

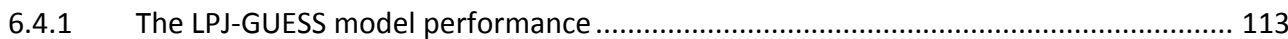

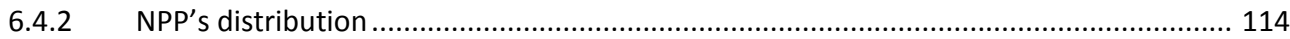

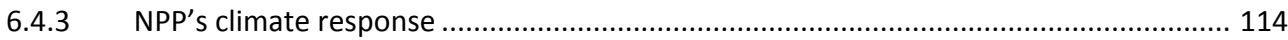

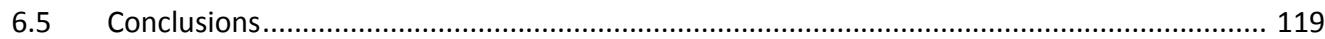

CHAPTER 7: SYNTHESIS .................................................................................121

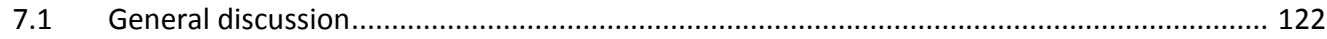

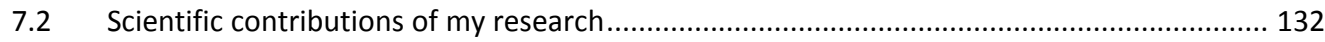

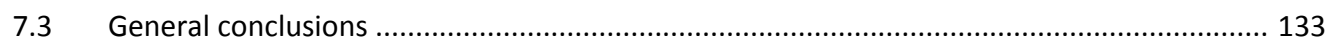

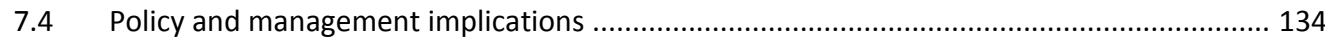

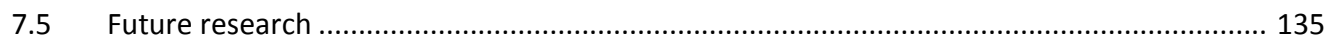

REFERENCES

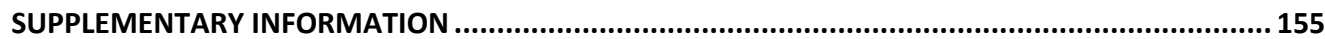

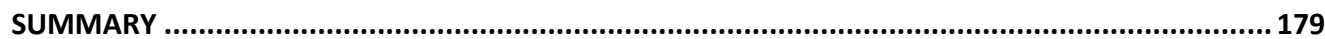

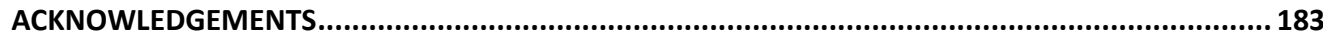

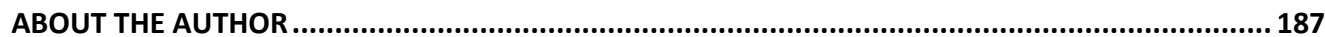

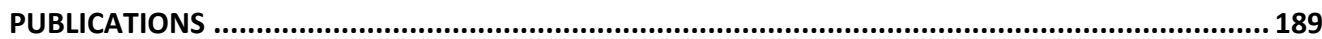

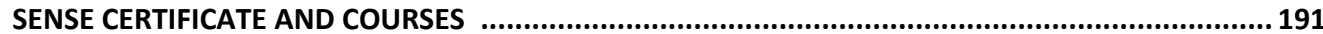

Chapters 2, 3 and 5 have been published as reviewed scientific articles. Chapter $\mathbf{6}$ is under review. This chapter received positive reviews through interractive public discussion (Biogeosciences Discussions) and we are now waiting for final decision from the journal. The text, figures and tables of the published articles and the manuscript that is under review have been adjusted to the $\mathrm{PhD}$ format (e.g. text and numbering). Chapter $\mathbf{4}$ is not published. This Chapter 4 was initially submitted to Global Change Biology and passed through the interest of the Editor-in-chief and received very helpful reviews but was rejected. The paper will soon be submitted to another journal. 


\section{GENERAL INTRODUCTION}

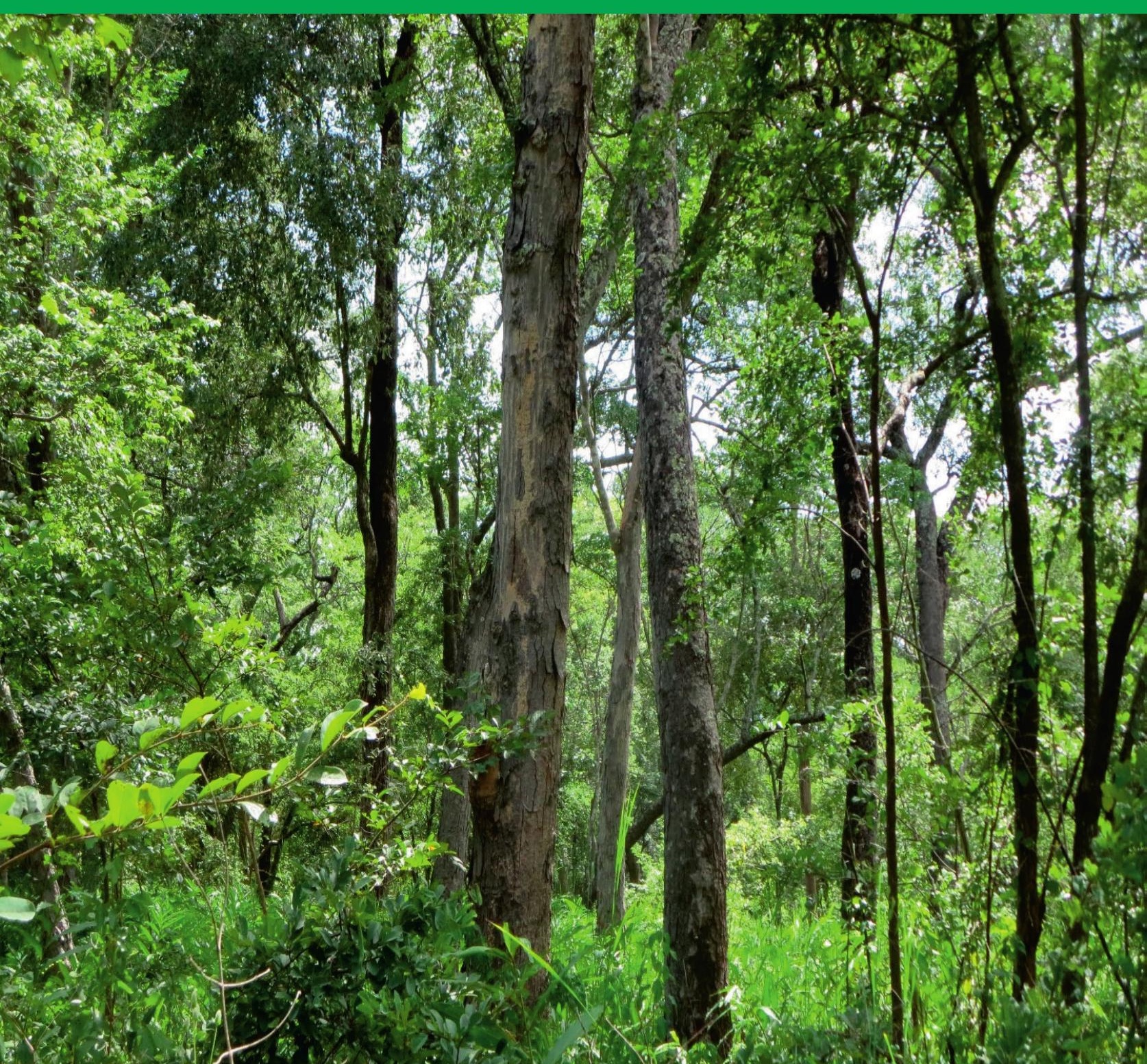




\subsection{Climate variability and change in Africa}

Climate has been demonstrated to change at a wide range of spatial and temporal scales. This change has been observed for as far back as science has been able to reconstruct it. However, climate change is now accelerated by human activities. This climate change is projected to significantly change temperature and precipitation patterns around the globe. Over the period A.D. 1880 to 2012 global temperature increased by $0.85^{\circ} \mathrm{C}$ and global temperature increase is projected to be between $1.4^{\circ} \mathrm{C}$ and $4.8^{\circ} \mathrm{C}$ by 2100 relative to $1850-1900$ (IPCC, 2014 ). Due to the cumulative greenhouse gas emissions, global climate will continue to change even beyond 2100 (Niang et al., 2014).

However, regional temperature changes differ and near surface temperatures have increased by at least $0.5^{\circ} \mathrm{C}$ during the last 50 to 100 years over most parts of Africa. Minimum temperatures have warmed more rapidly than maximum temperatures (Niang et al., 2014). Annual rainfall is reduced in this period over parts of the western and eastern Sahel region and eastern and southern Africa (Niang et al., 2014). Compared to 1986-2005, African temperatures are projected to increase by $3^{\circ} \mathrm{C}$ to $6^{\circ} \mathrm{C}$ by the end of the $21^{\text {st }}$ century. However, changes in rainfall will vary in different parts of the continent (Niang et al., 2014). This climate change has diverse effects on plant's productivity, and these effects vary with space, ecosystem types, weather conditions and human influences (Wu et al., 2011). This is elaborated in the next section.

\subsection{Climate change effects on African forests' productivity}

Though Africa is reported to be one of the most vulnerable regions to climate change, little is known about potential effects on its forests (Chidumayo et al., 2011). Researchers found a positive relationship between forest productivity and rainfall (Eshete and Ståhl, 1999; Cao et al., 2001; Fichtler et al., 2004; Schöngart et al., 2006; Therrell et al., 2007; Gebrekirstos et al., 2008; Trouet et al., 2010; Pan et al., 2015; Mohammed et al., 2018). The relationship was strong (i.e. the correlation coefficient ranges from 0.54 to 0.79 ) in areas receiving between 400 and 700 $\mathrm{mm} \mathrm{yr}^{-1}$ (Stahle et al., 1999; Gebrekirstos et al., 2008; Nicolini et al., 2010) and weak (i.e. between 0.00 and 0.38 ) in regions receiving between 800 and $1500 \mathrm{~mm} \mathrm{yr}^{-1}$ (Trouet, 2004; Trouet et al., 2006; Couralet et al., 2010; Ridder et al., 2013). However, temperature correlated negatively with trees' productivity (Cao et al., 2001; Trouet, 2004; Trouet et al., 
2006; Nicolini et al., 2010; Ilmen et al., 2016) though this negative influence occurs when temperature rises beyond the tree's optimal temperature limit (Wu et al., 2011).

Following the above outlined relationships, some efforts have been made to understand the response of forests' productivity to climate change. Thus, from 1900 to 2000, Cao et al. (2001) simulated an NPP increase of between 2.3 and 6.3Gt C year ${ }^{-1}$ in north, central and southern Africa, due to changes in temperature and rainfall without taking into consideration any change in $\mathrm{CO}_{2}$ concentrations. However, with increased $\mathrm{CO}_{2}$ concentrations, NPP increased by 2.4 to $6.6 \mathrm{Gt} \mathrm{C}_{\text {year }}{ }^{-1}$ due to the fertilization effect in the same regions over the the same period (Cao et al., 2001). In the 1970s and 1980s, NPP was reduced in northern Africa due to drought and in the 1990s, NPP was enhanced when precipitation increased. In southern Africa, NPP was high during the period from 1961 to 1970 but reduced since the 1980s because of reduced precipitation (Cao et al., 2001). For the whole of Africa, NPP reduced by $6 \%$ over the period between 1911 and 2000 following increased rainfall by $14.4 \mathrm{~mm}$ and temperature by $0.2^{\circ} \mathrm{C}$ (Gang et al., 2013). NPP in Africa increased by $0.013 \mathrm{Gt} \mathrm{C}$ year ${ }^{-1}$ in the period from 1900 to 2000 due to increased $\mathrm{CO}_{2}$ concentrations (Cao et al., 2001). Pan et al. (2015) estimated an African NPP increase of 10.4-11.7\% during the period from 1980 to 2010 covering the biomes grasslands, shrublands and deserts. Projections show that per unit area, NPP will increase by $253 \mathrm{~g} \mathrm{C} \mathrm{m}^{-2}$ year $^{-1}$ over the period from 1989-2000 to 2080-2099 following increased rainfall by $0.3 \mathrm{~mm} \mathrm{day}^{-1}$ and temperature by $3.4^{\circ} \mathrm{C}$ in east Africa (Doherty et al., 2010).

My analysis of all individual studies (See Chapter 4) showed that the combined NPP of all biomes in Africa increased by $4.8 \%$ from 1900 to 2011 though by the end of the $21^{\text {st }}$ century, NPP will reduce by $8 \%$ from 1950 . This analysis further showed that trees growing in low rainfall receiving regions respond more strongly to changes in rainfall than those growing in high-rainfall receiving regions and that changes in temperature have more effects on trees' productivity in hotter regions than in colder ones. However, most of the studies were conducted at either regional or continental levels, with limited studies conducted at the local level. I therefore focused my study at the local level in Zambia, where more than half of the population depends on the forest resources for their livelihoods (The Government of the Republic of Zambia, 2011b). The next section presents the importance of the forests in Zambia. 


\subsection{Importance of the forests in Zambia}

Zambia has a variety of natural resources and the forests cover two-thirds of the country's total area (The Government of the Republic of Zambia, 2008; The Government of the Republic of Zambia, 2011b). These forests include closed types, open (or wodlands) types, antihills (or termitaria) and grasslands (Storrs et al., 1979; The Government of the Republic of Zambia, 2008). They consist of more than 500 tree species (The Government of the Republic of Zambia, 2008). The Zambian forests have a total biomass of just over six billion metric tonnes. About 7\% of this biomass is deadwood (The Government of the Republic of Zambia, 2008). In 2017, Zambia had about 1,520 million $\mathrm{m}^{3}$ of wood in stock and 403 million $\mathrm{m}^{3}$ of this available stock represented the stock for the commercial species (Ng'andwe et al., 2017). The diversity of tree species enables the forests to provide various products and services in Zambia, ranging from economic, social and ecological. Economically, the forests are important because of various products that they provide and supply to local, national and international markets (Mubita, 1986; Musokotwane, 1986; Peele, 1986; Piearce, 1986a; The Government of the Republic of Zambia, 2008; The Government of the Republic of Zambia, 2011b). The forestry sector contributed 6.2\% to Zambia's Gross Domestic Product (GDP) annually since 1980 (Ng'andwe et al., 2012; Ng'andwe et al., 2015). These Zambian forests contribute about US\$197 million annually to rural household incomes (The Government of the Republic of Zambia, 2011b). Two thirds of the Zambian people live in rural areas and their livelihoods are tied to the land and forests (The Government of the Republic of Zambia, 2011b). In recent years, the Zambian population rose from 13 million to 15 million (The Government of the Republic of Zambia, 2016), estimated at the growth rate of $2.8 \%$ annually (The Government of the Republic of Zambia, 2011a). This also indicates an increasing demand for various environmental products and services to cater for this growing population. In addition to the economic contributions, the forests provide employment through woodbased industries (Piearce, 1986a). Ecologically, the forests conserve biological diversity (FAO, 2007) and provide natural habitats for fauna and flora (Mubita, 1986; Kwashirai, 2007). Forests also help to protect catchment areas (FAO, 2007). Other benefits include scientific, educational and aesthetic values (Piearce, 1986a). In addition to all these valuable benefits is the forests' role in carbon sequestration to curb the problem of climate change. The terrestrial biosphere (ecosystems including plants, soils and atmosphere) sequesters substantial amounts of $\mathrm{CO}_{2}$ and thereby act as carbon sinks (Sarmiento and Gruber, 2002). 
However, despite that the Zambia forests are so important to various stakeholders, these forests are threatened by climate change as explained in the next section.

\subsection{Threats to Zambian forests}

The Zambia's forests have been threatened by various forms of degradation and deforestation. This is driven by agricultural expansion, mining and infrastructural development (Ng'andwe et al., 2012; Matakala et al., 2015). Climate change is another threat to Zambia's forests. This change varies with locality (See Section 1.1). For example, over the period 1976 and 2016, maximum temperature increased by $1{ }^{\circ} \mathrm{C}$ in the southern part of Zambia (Dube and Nhamo, 2018) and over the past thirty years, temperature has increased by $0.6^{\circ} \mathrm{C}$ (Bwalya, 2010). Thirty one years of temperature records showed a substantial increase in average seasonal temperatures (October-April) (Mulenga et al., 2017). By the year 2070, Zambia's temperatures are projected to increase by $2.9^{\circ} \mathrm{C}$ with reference to 1880 (The Government of the Republic of Zambia et al., 2007). Rainfall reduced by $47 \mathrm{~mm}$ between 1976 and 2016 in Southern Zambia (Dube and Nhamo, 2018). Magadza (2011) reported a declining trend in rainfall beginning in the early 1980's though other studies did not find significant changes in Zambia's rainfall (Kampata et al., 2008; Stern and Cooper, 2011; Mulenga et al., 2017).

Drought and seasonal floods have increased in Zambia and the worst drought was experienced in 1991/92 (The Government of the Republic of Zambia et al., 2007). The latest drought was recorded in 2007/08 rainy season (Bwalya, 2010). During the 1978/79 season, Zambia experienced the wettest conditions ever (Bwalya, 2010). Projections show that by the year 2070, the amount of rainfall in Zambia will increase with reference to 2010 (The Government of the Republic of Zambia et al., 2007).

These climatic changes are likely to have various effects on forests resources in different parts of Zambia. To get an in depth understanding on these potential affects, I focused my study on the Zambezi teak forests. These forests are found across a south-north rainfall gradient in Zambia. The next section, highlights the knowledge gap that exists following the studies that have so far been conducted in the Zambian forests.

\subsection{Knowledge gap}

Though Zambia has different forest types, it is mainly covered by the Miombo woodlands (Storrs et al., 1979; The Government of the Republic of Zambia, 2008). The Zambezi teak forests cover about 9\% of the total forest extent in Zambia (Matakala et al., 2015). These teak 
forests are two storeyed (The Government of the Republic of Zambia, 1969; Mulolwa, 1986) with either a closed or open canopy (Mulolwa, 1986). The trees are deciduous (Piearce, 1986b) and belong to various species (The Government of the Republic of Zambia, 1969). The Baikiaea plurijuga Harms is the most dominant species in the Zambezi teak forests (Mbughi, 1986; Mulolwa, 1986; Piearce, 1986a). This B. plurijuga is the main source of hardwood timber that is supplied to local, national and international markets (Mubita, 1986; Musokotwane, 1986; Peele, 1986; Piearce, 1986a).

Timber production requires an accurate estimation of biomass stocks by using biomass allometric models that are developed using tree species growing in the same locality. Currently, accurate biomass stock values for the Zambezi teak forests are unavailable in Zambia. This is caused by the lack of biomass allometric models that results from limited data to develop these models. How climate change will affect the Zambezi teak forests is also poorly known since no study has so far been carried out to determine their responses to climate change. Similar studies have been conducted in the vast Miombo woodlands (Trouet, 2004; Chidumayo, 2005; Trouet et al., 2006; The Government of the Republic of Zambia et al., 2007) but extrapolating such knowledge to the Zambezi teak forests is challenging because of the differences in species composition. This research gap motivated me to conduct my study in the Zambezi teak forests, which are equally important to people and the environment as the Miombo woodlands.

\subsection{Objectives and research questions}

Following the knowledge gap outlined above, my study aims to determine the effects of climate change on the productivity of the Zambezi teak forests in Zambia. I formulated six research questions (RQs) to accommodate this aim and to guide my studies. Each of these RQs were addressed in various chapters of this study. The first two questions focus on biomass allometric models and estimation of forests' carbon stocks, while the last four questions relate to NPP's response to contemporary and future climates. These RQs are outlined in Table 1.1. The next section describes the study site and the applied methods.

\subsection{Study site and methodology}

The study was carried out in the Zambian Zambezi teak forests, though the forests are also found in the tropical zones of Angola, Botswana, Namibia and Zimbabwe (Chisumpa, 1986; Piearce, 1986a; Piearce, 1986b; Selander, 1986). These forests are distributed in various Zambian provinces which include: the western, southern and north-western provinces 
(Chisumpa, 1986; Mbughi, 1986). The forests occur across a south-north climatic gradient with annual rainfall ranging from $700 \mathrm{~mm}$ in the south to $1100 \mathrm{~mm}$ in the north. Following this rainfall pattern, Zambia is divided into three ecological zones ${ }^{1}$ (Figure 1.1). The driest zone I, receives less than $700 \mathrm{~mm}$ and the intermediate zone II receives between $800 \mathrm{~mm}$ and $1000 \mathrm{~mm}$. The wettest Zone III recieves more than 1000mm (The Government of the Republic of Zambia and UNDP, 2009). My research was carried out at sites in the Sesheke $\left(17^{\circ} 21.278 \mathrm{~S}, 24^{\circ} 22.560 \mathrm{E}\right)$, Kabompo $\left(14^{\circ} 00.551 \mathrm{~S}, 023^{\circ} 35.106 \mathrm{E}\right)$ and Namwala $\left(15^{\circ} 50.732 \mathrm{~S}\right.$, $026^{\circ} 28.927 \mathrm{E}$ ) areas. The Sesheke study site is part of the Masese Forest Reserve, which is located in Zone I. In Kabompo, the study was carried out in Kabompo and Zambezi Forest Reserves, which are part of Zone II. The Namwala study site is part of the Ila Forest Reserve on the transition between Zones I and II (Figure 1.1). Temperatures in these sites differ with the lowest values recorded in the Namwala site (Figure 1.2). To address the six RQs, different methods were applied and details of each method are presented in the respective chapters as indicated in Table 1.1.

\subsection{Thesis outline}

This thesis consists of seven chapters (Figure 1.3). I first present all the relevant data on tree heights, DBH, wood density, carbon fraction and carbon stocks of each surveyed tree in the forest (Chapter 2). This data was initially included and described in Chapter 3, but the editor of Acta Oecologica suggested to publish it seperately in Data in Brief. This journal ( Data in Brief) solely publishes long data sets used and explained in other studies, hence the tabular format of the paper. The data are thus used as input to Chapter 3, where I developed biomass allometric equations and estimated total vegetation carbon stock (below and above-ground carbon stock) of the study plots.

To analyse forests' response to climate change, I first reviewed literature on modelling and tree-ring studies (Chapter 4). This review helped me to have an in-depth understanding of the relationships between forests' productivity and climatic variables (rainfall and temperature), and also to determine the effects of climate change on NPP in Africa in general (Chapter 4). I, then, correlated climatic variables (temperature and rainfall) and evaporation with tree-ring indices of the most common species in my study sites (Chapter 5). I projected NPPs'

\footnotetext{
${ }^{1}$ Zone II is sub-divided into IIa and IIb. Zone IIa consists of a sub-region of the plateau including the main farming areas on the plateau of central, eastern and southern provinces, whereas zone Ilb comprises the Kalahari (Barotse) sand plateau and the Zambezi flood plains. Both zones receive the same amount of rainfall $(800-1000 \mathrm{~mm} /$ year) (Wamunyima, 2014)
} 
response to climate change using the LPJ-GUESS vegetation model (Chapter 6). This model was validated using the vegetation carbon-stock values generated in Chapter $\mathbf{3}$ and tree-ring indices determined in Chapter 5. Finaly, I synthesize my research by presenting the general discussion, scientific contributions, general conclusions, policy and management implications and needed future research (Chapter 7).

Table 1.1:Research questions, applied methods and chapters that addressed the questions.

\begin{tabular}{|c|c|c|c|}
\hline $\begin{array}{l}\text { Research } \\
\text { question (RQ) } \\
\text { number }\end{array}$ & Research question & Applied method & $\begin{array}{l}\text { Chapter that } \\
\text { addresses the } \\
\text { question }\end{array}$ \\
\hline RQ 1 & $\begin{array}{l}\text { Are biomass models available for the } \\
\text { Zambezi teak forests and, if so, what data are } \\
\text { needed to develop these models? }\end{array}$ & Field survey & Chapters 2 and 3 \\
\hline RQ 2 & $\begin{array}{l}\text { How are forests' carbon stocks distributed in } \\
\text { the wetter, intermediate and drier sites of the } \\
\text { Zambezi teak forests? }\end{array}$ & Field survey & Chapters 2 and 3 \\
\hline RQ 3 & $\begin{array}{l}\text { How do contemporaneously and future } \\
\text { climate affect the productivity of the forests } \\
\text { in Africa? }\end{array}$ & Literature review & Chapter 4 \\
\hline RQ 4 & $\begin{array}{l}\text { What is the relationship between forest } \\
\text { productivity and climatic variables in the } \\
\text { wetter, intermediate and drier sites of the } \\
\text { Zambezi teak forests? }\end{array}$ & $\begin{array}{l}\text { Tree ring analysis and } \\
\text { Application of LPJ- } \\
\text { GUESS vegetation model }\end{array}$ & Chapters 5 and 6 \\
\hline RQ 5 & $\begin{array}{l}\text { Can the forests' carbon stock be realistically } \\
\text { reproduced for current climate conditions at } \\
\text { the wetter, intermediate and drier sites? }\end{array}$ & $\begin{array}{l}\text { Application of LPJ- } \\
\text { GUESS model }\end{array}$ & Chapter 6 \\
\hline RQ 6 & $\begin{array}{l}\text { How will climate change affect the } \\
\text { productivity of the Zambezi teak forests in the } \\
\text { wetter, intermediate and drier sites, and what } \\
\text { are the main drivers of change? }\end{array}$ & $\begin{array}{l}\text { Application of LPJ- } \\
\text { GUESS model }\end{array}$ & Chapter 6 \\
\hline
\end{tabular}




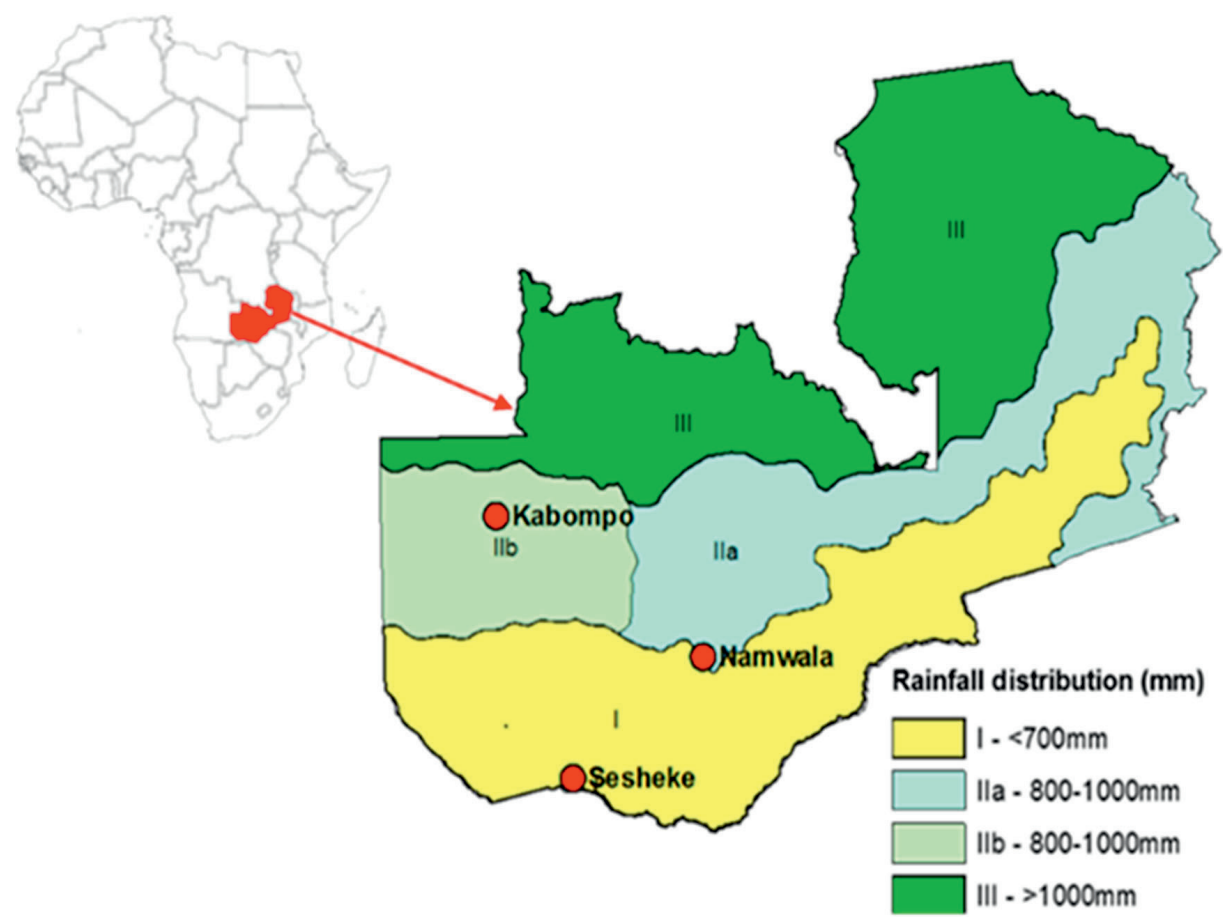

Figure 1.1 Study sites.

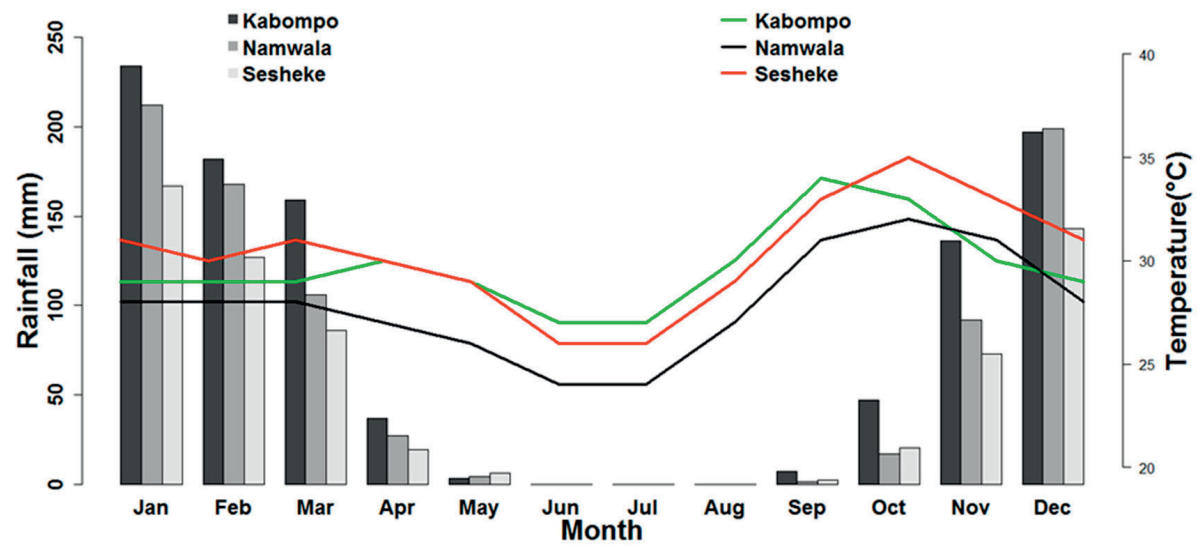

Figure 1.2 Total annual rainfall (bars) and mean annual temperature (lines) distribution at the Sesheke (1975 - 2011), Namwala (1975 - 2011) and Kabompo (1971 - 2007 for rainfall and 1957- 1989 for temperature) study sites. Climatic data for Sesheke site were drawn from Sesheke and Livingstone meteorological stations, while for Namwala site, data were drawn from Choma meteorological station. For Kabompo site, climatic data were taken from Zambezi and Kabompo meteorological stations. 


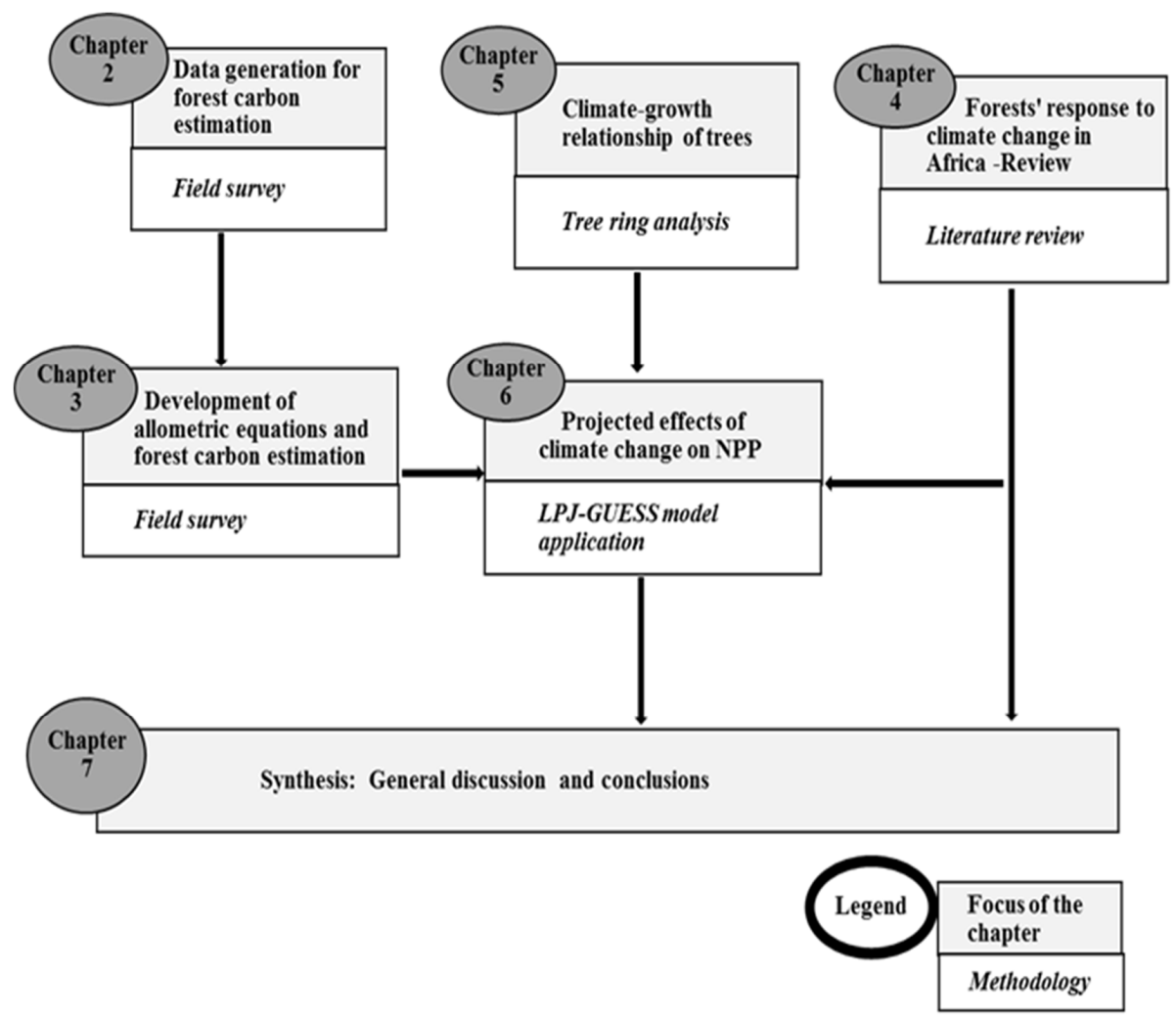

Figure 1.3 An overview of thesis structure, focus of each chapter and the respective methods applied. 


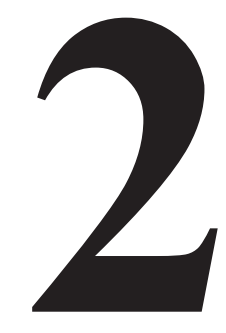

\section{DATA FOR DEVELOPING ALLOMETRIC MODELS AND EVALUATING CARBON STOCKS OF THE ZAMBEZI TEAK FORESTS IN ZAMBIA}

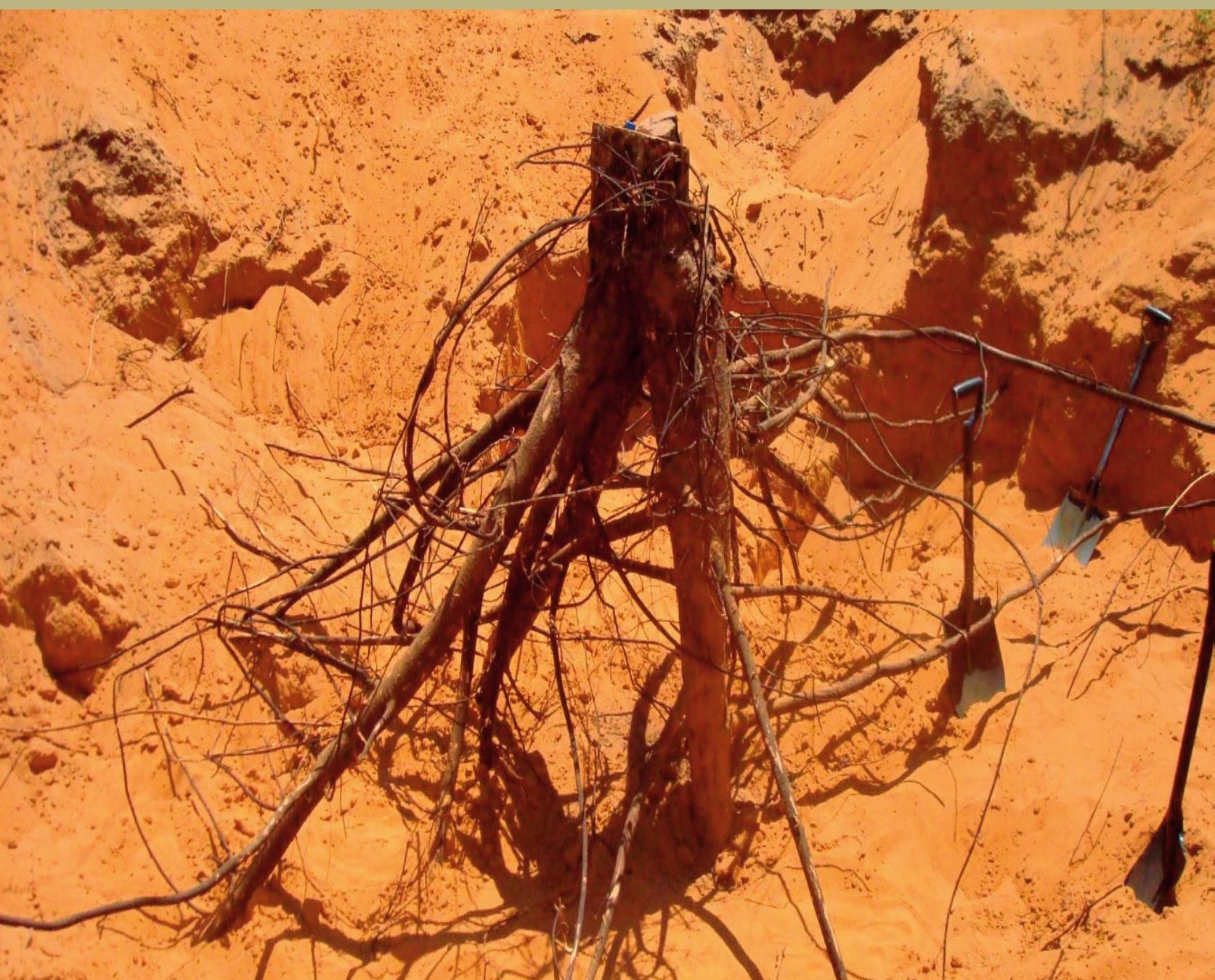




\section{Abstract}

This paper presents data on carbon stocks of tropical tree species along a rainfall gradient.

The data was generated from the Sesheke, Namwala and Kabompo sites in Zambia. Though above-ground data was generated for all these three sites, we uprooted trees to determine below-ground biomass from the Sesheke site only. The vegetation was assessed in all three sites. The data includes tree diameter at breast height $(\mathrm{DBH})$, total tree height, wood density, wood dry weight and root dry weight for large $(\geq 5 \mathrm{~cm} \mathrm{DBH})$ and small $(<5 \mathrm{~cm} \mathrm{DBH})$ trees. We further presented Root-to-Shoot Ratios of uprooted trees. Data on the importance-value indices of various species for large and small trees are also determined. Below and aboveground carbon stocks of the surveyed tree species are presented per site. This data were used by Ngoma et al. (2018a) to develop above and below-ground biomass models and the reader is refered to this study for additional information, interpretation and reflection on applying this data.

\section{Published as:}

Ngoma J, Moors E, Kruijt B, Speer JH, Vinya R, Chidumayo EN, Leemans R. 2018. Data for developing allometric models and evaluating carbon stocks of the Zambezi Teak Forests in Zambia. Data in Brief 17:13611373 . 
Specifications Table

\begin{tabular}{|c|c|}
\hline Subject area & Ecology \\
\hline $\begin{array}{l}\text { More specific subject } \\
\text { area }\end{array}$ & Carbon stocks of the Zambezi teak forests. \\
\hline Type of data & Tables and Figures. \\
\hline $\begin{array}{l}\text { How data was } \\
\text { acquired }\end{array}$ & $\begin{array}{l}\text { We generated data to develop above-ground and below-ground biomass } \\
\text { models by respectively cutting down trees and uprooting trees. We } \\
\text { assessed vegetation characteristics by generating data to determine carbon } \\
\text { stocks. We determined the carbon fractions in leaves, branches, stems and } \\
\text { roots from all cut and uprooted trees. These carbon fractions were } \\
\text { measured in the laboratory using a Fisons EA1108 CHN-0 elemental } \\
\text { analyser (See Ngoma et al. (2018a) for details). }\end{array}$ \\
\hline Data format & Analyzed and Raw. \\
\hline Experimental factors & $\begin{array}{l}\text { Root and wood samples were immediately weighed whilst in the field. } \\
\text { Samples taken to develop allometric models were then oven dried for } 24 \\
\text { hours at } 105^{\circ} \mathrm{C} \text { to obtain their dry weight after determining their volume } \\
\text { through the water-displacement approach in the 'as received condition' } \\
\text { (ASTM, 2007; Ngoma et al., 2018a). Stem, branches, roots and leaves } \\
\text { were ground into fine powder before analyzing them for their C fraction. } \\
\text { Wood volume was not measured for the disk samples that were taken to } \\
\text { determine their carbon fraction. }\end{array}$ \\
\hline $\begin{array}{l}\text { Experimental } \\
\text { features }\end{array}$ & $\begin{array}{l}\text { Data were collected along a rainfall gradient covering high, intermediate } \\
\text { and low rainfall areas (See Ngoma et al. (2018a) for details). }\end{array}$ \\
\hline Data source location & $\begin{array}{l}\text { We collected data from Kabompo }\left(14^{\circ} 00.551 \mathrm{~S}, 023^{\circ} 35.106 \mathrm{E}\right) \text {, Namwala } \\
\left(15^{\circ} 50.732 \mathrm{~S}, 026^{\circ} 28.927 \mathrm{E}\right) \text { and Sesheke }\left(17^{\circ} 21.278 \mathrm{~S}, 24^{\circ} 22.560 \mathrm{E}\right) \text { in } \\
\text { Zambia. }\end{array}$ \\
\hline Data accessibility & $\begin{array}{l}\text { Data are provided in this paper to improve data accessibility and } \\
\text { further data at the tree-level are available online in excel format } \\
\text { (Supplementary information S2.1 and S2.2) }\end{array}$ \\
\hline
\end{tabular}




\subsection{Data}

We present data on various tree parameters (e.g. diameter at breast height (DBH), total tree height, wood density and dry weight). The data presented in Section 2.1 were used to determine carbon fraction in leaves, stem, branches and roots, and to develop above and below-ground biomass models. Root-to-Shoot ratios of the uprooted trees were also calculated. Section 2.1.2 provides the species-importance-value (SIV) indices of all surveyed trees, which are categorized as large $(\geq 5 \mathrm{~cm} \mathrm{DBH})$ or small $(<5 \mathrm{~cm} \mathrm{DBH})$ trees. In Section 2.1.3, data on carbon stocks of various surveyed tree species per study site are presented.

\subsubsection{Parameters of trees used to develop allometric models (Tables 2.1, 2.2 and 2.3)}

Table 2.1: Diameter (DBH), total tree height, wood density and wood dry weight of sampled small trees $(<5 \mathrm{~cm} \mathrm{DBH})$.

\begin{tabular}{|l|l|l|l|l|}
\hline Species & $\begin{array}{l}\text { Diameter } \\
(\mathbf{D B H}, \mathbf{c m})\end{array}$ & $\begin{array}{l}\text { Total tree } \\
\text { height } \mathbf{( m )}\end{array}$ & $\begin{array}{l}\text { Wood density } \\
\left(\mathbf{g} / \mathbf{m}^{3}\right)\end{array}$ & $\begin{array}{l}\text { Wood dry } \\
\text { weight } \mathbf{( k g})\end{array}$ \\
\hline Baphia massaiensis & 2.30 & 3.00 & 0.77 & 0.66 \\
\hline Baphia massaiensis & 1.10 & 2.00 & 0.56 & 0.24 \\
\hline Baphia massaiensis & 3.50 & 3.95 & 0.66 & 2.10 \\
\hline Baphia massaiensis & 2.50 & 2.35 & 0.67 & 0.69 \\
\hline Baphia massaiensis & 1.80 & 3.20 & 0.70 & 0.72 \\
\hline Baphia massaiensis & 3.50 & 4.70 & 0.70 & 3.04 \\
\hline Baphia massaiensis & 4.50 & 7.00 & 0.73 & 5.58 \\
\hline Baphia massaiensis & 4.50 & 4.90 & 0.70 & 4.10 \\
\hline Baphia massaiensis & 1.10 & 2.50 & 0.79 & 3.32 \\
\hline Baphia massaiensis & 1.20 & 3.40 & 0.93 & 3.01 \\
\hline Baphia massaiensis & 2.50 & 4.40 & 0.95 & 0.91 \\
\hline Baphia massaiensis & 3.00 & 4.90 & 0.92 & 0.36 \\
\hline Baphia massaiensis & 3.70 & 5.50 & 0.88 & 1.75 \\
\hline Baphia massaiensis & 3.40 & 5.30 & 0.76 & 2.12 \\
\hline Baphia massaiensis & 4.60 & 4.00 & 0.89 & 2.07 \\
\hline Baphia massaiensis & 4.50 & 4.50 & 0.94 & 0.60 \\
\hline Baphia massaiensis & 1.80 & 3.70 & 0.73 & 0.86 \\
\hline Baphia massaiensis & 2.40 & 3.80 & 1.07 & 0.33 \\
\hline Baphia massaiensis & 1.50 & 3.70 & 1.04 & 0.23 \\
\hline Baphia massaiensis & 3.10 & 4.90 & 0.72 & 4.79 \\
\hline Baphia massaiensis & 2.80 & 4.00 & 0.62 & 0.28 \\
\hline Baphia massaiensis & 1.50 & 3.90 & 0.86 & 0.35 \\
\hline Baphia massaiensis & 2.00 & 3.50 & 0.88 & 0.40 \\
\hline Baphia massaiensis & 1.60 & 3.58 & 0.73 & 0.26 \\
\hline Baphia massaiensis & 2.40 & 3.80 & 0.75 & 0.14 \\
\hline Baphia massaiensis & 1.60 & 3.20 & 1.01 & 0.35 \\
\hline Baphia massaiensis & 1.10 & 2.50 & 0.71 & 0.17 \\
\hline & & & & \\
\hline & & & \\
\hline
\end{tabular}




\begin{tabular}{|c|c|c|c|c|}
\hline Species & $\begin{array}{l}\text { Diameter } \\
(\mathrm{DBH}, \mathrm{cm})\end{array}$ & $\begin{array}{l}\text { Total tree } \\
\text { height }(\mathrm{m})\end{array}$ & $\begin{array}{l}\text { Wood density } \\
\left(\mathrm{g} / \mathrm{m}^{3}\right)\end{array}$ & $\begin{array}{l}\text { Wood dry } \\
\text { weight (kg) }\end{array}$ \\
\hline Combretum celastroides & 2.20 & 2.10 & 0.08 & 2.07 \\
\hline Combretum celastroides & 2.00 & 3.85 & 0.93 & 1.66 \\
\hline Combretum celastroides & 1.30 & 3.10 & 0.99 & 2.49 \\
\hline Combretum celastroides & 3.10 & 4.40 & 0.93 & 3.60 \\
\hline Combretum celastroides & 4.50 & 5.00 & 0.97 & 2.82 \\
\hline Combretum celastroides & 4.20 & 4.70 & 0.90 & 0.97 \\
\hline Combretum celastroides & 2.80 & 3.30 & 0.83 & 2.04 \\
\hline Combretum celastroides & 3.80 & 8.40 & 0.97 & 3.82 \\
\hline Diplorhynchus candylocarpon & 4.50 & 4.20 & 0.53 & 0.91 \\
\hline Diplorhynchus candylocarpon & 4.70 & 5.30 & 0.46 & 0.33 \\
\hline Diplorhynchus candylocarpon & 2.80 & 8.90 & 0.47 & 2.04 \\
\hline Diplorhynchus candylocarpon & 1.40 & 4.15 & 0.65 & 7.22 \\
\hline Diplorhynchus candylocarpon & 3.40 & 4.30 & 0.76 & 6.16 \\
\hline Diplorhynchus candylocarpon & 3.50 & 5.70 & 0.69 & 0.42 \\
\hline Diplorhynchus candylocarpon & 1.60 & 3.40 & 0.70 & 0.58 \\
\hline Diplorhynchus candylocarpon & 2.80 & 5.40 & 0.54 & 3.71 \\
\hline Friesodielsia obovata & 1.60 & 3.10 & 0.51 & 0.38 \\
\hline Friesodielsia obovata & 1.20 & 2.80 & 0.84 & 9.57 \\
\hline Friesodielsia obovata & 4.80 & 8.80 & 0.70 & 2.32 \\
\hline Friesodielsia obovata & 3.20 & 4.00 & 0.81 & 0.64 \\
\hline Friesodielsia obovata & 2.70 & 4.00 & 0.72 & 0.72 \\
\hline Friesodielsia obovata & 2.70 & 3.00 & 0.85 & 2.78 \\
\hline Friesodielsia obovata & 4.00 & 3.60 & 0.78 & 0.25 \\
\hline Friesodielsia obovata & 1.20 & 3.40 & 0.70 & 0.55 \\
\hline Friesodielsia obovata & 2.40 & 4.70 & 0.68 & 0.39 \\
\hline Friesodielsia obovata & 2.60 & 5.01 & 0.63 & 1.03 \\
\hline Friesodielsia obovata & 3.10 & 5.05 & 0.72 & 1.30 \\
\hline Friesodielsia obovata & 3.10 & 4.10 & 0.67 & 5.63 \\
\hline Friesodielsia obovata & 1.60 & 4.04 & 0.89 & 0.26 \\
\hline Friesodielsia obovata & 4.90 & 6.90 & 0.75 & 3.01 \\
\hline Pteleopsis anisoptera & 3.20 & 6.10 & 0.68 & 6.28 \\
\hline Pteleopsis anisoptera & 2.60 & 5.20 & 0.72 & 0.35 \\
\hline Pteleopsis anisoptera & 2.40 & 2.90 & 0.68 & 4.35 \\
\hline Pteleopsis anisoptera & 1.20 & 3.20 & 0.73 & 0.48 \\
\hline Pteleopsis anisoptera & 1.10 & 3.40 & 0.87 & 0.37 \\
\hline Pteleopsis anisoptera & 4.90 & 5.60 & 0.75 & 3.03 \\
\hline Pteleopsis anisoptera & 3.10 & 5.80 & 0.70 & 1.92 \\
\hline Pteleopsis anisoptera & 4.70 & 6.50 & 0.81 & 3.70 \\
\hline Pterocarpus antunesii & 4.30 & 8.00 & 0.79 & 0.40 \\
\hline Pterocarpus antunesii & 4.40 & 7.00 & 0.89 & 0.88 \\
\hline Pterocarpus antunesii & 1.40 & 4.10 & 0.50 & 0.39 \\
\hline Pterocarpus antunesii & 3.80 & 5.80 & 0.80 & 1.14 \\
\hline Pterocarpus antunesii & 2.30 & 5.40 & 1.19 & 0.49 \\
\hline Pterocarpus antunesii & 1.70 & 5.20 & 0.79 & 0.32 \\
\hline Pterocarpus antunesii & 4.00 & 7.40 & 0.69 & 0.77 \\
\hline Pterocarpus antunesii & 3.80 & 7.25 & 0.78 & 4.54 \\
\hline Pterocarpus antunesii & 4.30 & 5.30 & 0.73 & 5.97 \\
\hline
\end{tabular}


Table 2.2: Diameter (DBH), total tree height, wood density and wood dry weight of sampled large trees $(\geq 5 \mathrm{~cm} \mathrm{DBH})$.

\begin{tabular}{|c|c|c|c|c|}
\hline Species & $\begin{array}{l}\text { Diameter (DBH, } \\
\text { cm) }\end{array}$ & $\begin{array}{l}\text { Total height } \\
\text { (m) }\end{array}$ & $\begin{array}{l}\text { Wood density } \\
\left(\mathrm{g} / \mathrm{m}^{3}\right)\end{array}$ & $\begin{array}{l}\text { Wood dry weight } \\
\text { (kg) }\end{array}$ \\
\hline Baikiaea plurijuga & 32.50 & 12.44 & 0.83 & 459.99 \\
\hline Baikiaea plurijuga & 34.00 & 15.32 & 0.96 & 619.83 \\
\hline Baikiaea plurijuga & 21.00 & 11.95 & 0.78 & 129.50 \\
\hline Baikiaea plurijuga & 7.00 & 8.20 & 0.92 & 14.80 \\
\hline Baikiaea plurijuga & 26.70 & 14.90 & 1.00 & 271.89 \\
\hline Baikiaea plurijuga & 33.00 & 9.80 & 0.94 & 493.30 \\
\hline Baikiaea plurijuga & 48.70 & 17.55 & 0.88 & 1031.10 \\
\hline Baikiaea plurijuga & 43.70 & 16.90 & 0.91 & 944.59 \\
\hline Baikiaea plurijuga & 55.50 & 16.90 & 0.94 & 2043.49 \\
\hline Baikiaea plurijuga & 51.00 & 17.85 & 0.89 & 1020.93 \\
\hline Baikiaea plurijuga & 69.50 & 21.90 & 0.91 & 2355.53 \\
\hline Baikiaea plurijuga & 39.50 & 39.50 & 0.85 & 949.69 \\
\hline Baikiaea plurijuga & 22.20 & 11.95 & 0.80 & 204.77 \\
\hline Baikiaea plurijuga & 33.10 & 14.00 & 0.85 & 423.57 \\
\hline Baikiaea plurijuga & 41.00 & 15.19 & 1.01 & 744.65 \\
\hline Baikiaea plurijuga & 43.00 & 14.20 & 0.91 & 689.72 \\
\hline Baikiaea plurijuga & 8.50 & 6.70 & 0.92 & 13.30 \\
\hline Baikiaea plurijuga & 12.00 & 9.80 & 0.94 & 55.06 \\
\hline Baikiaea plurijuga & 12.00 & 10.05 & 0.85 & 54.89 \\
\hline Baikiaea plurijuga & 8.00 & 7.65 & 0.69 & 17.60 \\
\hline Baikiaea plurijuga & 50.00 & 15.37 & 0.83 & 1321.92 \\
\hline Baikiaea plurijuga & 25.00 & 10.80 & 0.98 & 310.46 \\
\hline Baikiaea plurijuga & 44.00 & 14.90 & 0.90 & 1201.18 \\
\hline Baikiaea plurijuga & 35.00 & 6.20 & 1.02 & 427.83 \\
\hline Baikiaea plurijuga & 21.20 & 10.30 & 0.75 & 181.39 \\
\hline Baikiaea plurijuga & 25.00 & 11.37 & 0.89 & 307.05 \\
\hline Baikiaea plurijuga & 26.00 & 12.40 & 1.15 & 489.81 \\
\hline Baikiaea plurijuga & 41.00 & 12.50 & 0.85 & 947.46 \\
\hline Baikiaea plurijuga & 29.00 & 10.30 & 0.73 & 169.89 \\
\hline Baikiaea plurijuga & 13.70 & 13.20 & 0.78 & 63.18 \\
\hline Baikiaea plurijuga & 42.20 & 12.12 & 0.88 & 892.87 \\
\hline Baikiaea plurijuga & 33.00 & 10.17 & 1.15 & 917.50 \\
\hline Baikiaea plurijuga & 23.70 & 12.10 & 0.83 & 232.91 \\
\hline Baikiaea plurijuga & 51.50 & 11.80 & 0.93 & 1294.72 \\
\hline Baikiaea plurijuga & 16.50 & 10.40 & 0.94 & 29.27 \\
\hline Baikiaea plurijuga & 46.30 & 10.42 & 0.97 & 961.39 \\
\hline Baikiaea plurijuga & 62.00 & 19.30 & 0.86 & 2659.55 \\
\hline Baphia massaiensis & 10.00 & 7.85 & 0.77 & 17.80 \\
\hline
\end{tabular}




\begin{tabular}{|c|c|c|c|c|}
\hline Species & $\begin{array}{l}\text { Diameter (DBH, } \\
\text { cm) }\end{array}$ & $\begin{array}{l}\text { Total height } \\
\text { (m) }\end{array}$ & $\begin{array}{l}\text { Wood density } \\
\left(\mathrm{g} / \mathrm{m}^{3}\right)\end{array}$ & $\begin{array}{l}\text { Wood dry weight } \\
\text { (kg) }\end{array}$ \\
\hline Baphia massaiensis & 16.00 & 9.05 & 0.89 & 64.46 \\
\hline Baphia massaiensis & 13.00 & 9.25 & 0.78 & 65.57 \\
\hline Baphia massaiensis & 35.00 & 12.70 & 0.86 & 467.63 \\
\hline Baphia massaiensis & 20.00 & 8.47 & 0.84 & 63.11 \\
\hline Baphia massaiensis & 16.00 & 7.80 & 1.02 & 38.65 \\
\hline Baphia massaiensis & 7.50 & 8.60 & 0.98 & 16.79 \\
\hline Combretum hereroense & 24.00 & 18.40 & 0.88 & 201.16 \\
\hline Combretum hereroense & 25.00 & 6.62 & 0.67 & 212.95 \\
\hline Combretum hereroense & 41.50 & 12.22 & 0.79 & 805.12 \\
\hline Combretum hereroense & 11.00 & 34.50 & 0.65 & 25.63 \\
\hline Combretum hereroense & 16.00 & 9.08 & 0.70 & 36.96 \\
\hline Combretum hereroense & 5.00 & 6.60 & 0.62 & 6.52 \\
\hline Combretum hereroense & 36.50 & 13.50 & 0.81 & 361.30 \\
\hline Combretum hereroense & 9.00 & 20.90 & 0.62 & 20.09 \\
\hline Combretum hereroense & 38.40 & 15.35 & 0.88 & 556.10 \\
\hline $\begin{array}{l}\text { Diplorhynchus } \\
\text { candylocarpon }\end{array}$ & 10.00 & 6.30 & 0.67 & 27.49 \\
\hline $\begin{array}{l}\text { Diplorhynchus } \\
\text { candylocarpon }\end{array}$ & 14.40 & 6.50 & 0.75 & 61.05 \\
\hline $\begin{array}{l}\text { Diplorhynchus } \\
\text { candylocarpon }\end{array}$ & 28.50 & 8.55 & 0.92 & 161.07 \\
\hline $\begin{array}{l}\text { Diplorhynchus } \\
\text { candylocarpon }\end{array}$ & 22.00 & 7.56 & 0.72 & 117.92 \\
\hline $\begin{array}{l}\text { Diplorhynchus } \\
\text { candylocarpon }\end{array}$ & 33.00 & 7.60 & 0.73 & 274.79 \\
\hline $\begin{array}{l}\text { Diplorhynchus } \\
\text { candylocarpon }\end{array}$ & 15.00 & 5.65 & 0.83 & 38.07 \\
\hline $\begin{array}{l}\text { Diplorhynchus } \\
\text { candylocarpon }\end{array}$ & 9.70 & 4.85 & 0.80 & 19.32 \\
\hline $\begin{array}{l}\text { Diplorhynchus } \\
\text { candylocarpon }\end{array}$ & 22.00 & 8.90 & 0.76 & 296.68 \\
\hline $\begin{array}{l}\text { Diplorhynchus } \\
\text { candylocarpon }\end{array}$ & 5.10 & 4.25 & 0.48 & 5.53 \\
\hline $\begin{array}{l}\text { Diplorhynchus } \\
\text { candylocarpon }\end{array}$ & 5.50 & 4.70 & 0.63 & 3.27 \\
\hline $\begin{array}{l}\text { Entandrophragma } \\
\text { caudatum }\end{array}$ & 36.00 & 17.30 & 0.64 & 563.02 \\
\hline $\begin{array}{l}\text { Entandrophragma } \\
\text { caudatum }\end{array}$ & 46.50 & 16.07 & 0.65 & 193.80 \\
\hline Ficus sycomorus & 17.00 & 7.75 & 0.70 & 95.26 \\
\hline Ficus sycomorus & 15.70 & 6.70 & 0.78 & 76.48 \\
\hline Ficus sycomorus & 23.00 & 5.65 & 0.56 & 193.80 \\
\hline Ficus sycomorus & 16.50 & 7.48 & 0.99 & 103.44 \\
\hline Ficus sycomorus & 17.00 & 5.56 & 0.68 & 56.30 \\
\hline Lonchocarpus nelsii & 9.50 & 6.40 & 0.99 & 19.54 \\
\hline
\end{tabular}




\begin{tabular}{|c|c|c|c|c|}
\hline Species & $\begin{array}{l}\text { Diameter (DBH, } \\
\text { cm) }\end{array}$ & $\begin{array}{l}\text { Total height } \\
\text { (m) }\end{array}$ & $\begin{array}{l}\text { Wood density } \\
\left(\mathrm{g} / \mathrm{m}^{3}\right)\end{array}$ & $\begin{array}{l}\text { Wood dry weight } \\
\text { (kg) }\end{array}$ \\
\hline Lonchocarpus nelsii & 29.00 & 11.30 & 1.11 & 300.64 \\
\hline Lonchocarpus nelsii & 16.00 & 8.75 & 0.80 & 75.21 \\
\hline Lonchocarpus nelsii & 16.20 & 6.60 & 0.69 & 59.37 \\
\hline Pteleopsis anisoptera & 5.00 & 7.50 & 0.99 & 6.57 \\
\hline Pteleopsis anisoptera & 10.00 & 9.00 & 0.86 & 37.04 \\
\hline Pteleopsis anisoptera & 9.00 & 9.20 & 0.83 & 16.57 \\
\hline Pteleopsis anisoptera & 15.20 & 11.30 & 0.66 & 57.46 \\
\hline Pteleopsis anisoptera & 27.00 & 14.75 & 0.95 & 315.11 \\
\hline Pteleopsis anisoptera & 28.00 & 16.45 & 0.97 & 543.42 \\
\hline Pteleopsis anisoptera & 31.70 & 13.60 & 0.98 & 365.56 \\
\hline Pteleopsis anisoptera & 34.00 & 16.63 & 0.85 & 590.86 \\
\hline Pteleopsis anisoptera & 33.00 & 18.30 & 1.13 & 422.99 \\
\hline Pterocarpus angolensis & 19.00 & 8.09 & 0.56 & 66.13 \\
\hline Pterocarpus angolensis & 6.30 & 4.85 & 0.42 & 6.16 \\
\hline Pterocarpus angolensis & 10.00 & 5.85 & 0.68 & 27.08 \\
\hline Pterocarpus angolensis & 13.50 & 7.55 & 0.47 & 39.09 \\
\hline Pterocarpus angolensis & 24.00 & 10.15 & 0.59 & 159.04 \\
\hline Pterocarpus angolensis & 21.60 & 10.80 & 0.64 & 169.62 \\
\hline Pterocarpus angolensis & 31.50 & 9.48 & 0.56 & 365.62 \\
\hline Pterocarpus angolensis & 12.00 & 6.19 & 0.76 & 43.72 \\
\hline Pterocarpus angolensis & 50.30 & 11.88 & 0.70 & 1488.17 \\
\hline Pterocarpus angolensis & 32.50 & 11.75 & 0.62 & 199.30 \\
\hline Pterocarpus angolensis & 43.00 & 14.44 & 0.65 & 803.22 \\
\hline Pterocarpus antunesii & 39.00 & 14.05 & 0.95 & 895.36 \\
\hline Pterocarpus antunesii & 19.00 & 16.55 & 0.72 & 182.70 \\
\hline Pterocarpus antunesii & 20.00 & 18.55 & 0.93 & 160.68 \\
\hline Pterocarpus antunesii & 10.00 & 11.50 & 0.76 & 28.62 \\
\hline Pterocarpus antunesii & 6.50 & 10.40 & 0.67 & 9.50 \\
\hline Pterocarpus antunesii & 32.00 & 11.87 & 0.69 & 630.64 \\
\hline Pterocarpus antunesii & 23.00 & 12.23 & 0.80 & 401.37 \\
\hline Pterocarpus antunesii & 44.00 & 18.81 & 0.83 & 651.66 \\
\hline Pterocarpus antunesii & 41.00 & 15.26 & 0.83 & 1170.64 \\
\hline Pterocarpus antunesii & 25.00 & 13.60 & 0.73 & 205.56 \\
\hline
\end{tabular}


Table 2.3: Diameter (DBH), total tree height, wood density, wood dry weight and root dry weight of sampled uprooted trees.

\begin{tabular}{|l|l|l|l|l|l|l|}
\hline Species & $\begin{array}{l}\text { DBH } \\
(\mathbf{c m})\end{array}$ & $\begin{array}{l}\text { Total tree } \\
\text { height }(\mathbf{m})\end{array}$ & $\begin{array}{l}\text { Above-ground } \\
\text { biomass }(\mathbf{K g})\end{array}$ & $\begin{array}{l}\text { Root } \\
\mathbf{d e n s i t y} \\
\left(\mathbf{g} / \mathbf{m}^{\mathbf{3}}\right)\end{array}$ & $\begin{array}{l}\text { Root } \\
\text { biomass } \\
(\mathbf{K g})\end{array}$ & $\begin{array}{l}\text { Root-to- } \\
\text { Shoot ratio }\end{array}$ \\
\hline Baikiaea plurijuga & 25 & 11 & 310 & 0.89 & 56 & 0.18 \\
\hline Baikiaea plurijuga & 44 & 18 & 1201 & 0.85 & 295 & 0.25 \\
\hline Baikiaea plurijuga & 35 & 6 & 428 & 0.67 & 151 & 0.35 \\
\hline Ficus sycomorus & 17 & 8 & 95 & 0.53 & 27 & 0.28 \\
\hline Lonchocarpus nelsii & 10 & 6 & 20 & 0.76 & 9 & 0.47 \\
\hline Lonchocarpus nelsii & 29 & 11 & 301 & 0.80 & 199 & 0.66 \\
\hline Ficus sycomorus & 16 & 7 & 76 & 0.48 & 35 & 0.46 \\
\hline Average & & & & & & 0.38 \\
\hline
\end{tabular}

\subsubsection{Species Importance Value Indices of large $(\geq 5 \mathrm{~cm} \mathrm{DBH})$ and small $(<5 \mathrm{~cm}$ DBH) trees}

This section provides the SIV indices of all surveyed trees and tree species (Ngoma et al., 2018a). Indices were calculated following the Cottam and Curtis (1956) method.

Supplementary information S2.1 (small trees) and S2.2 (large trees) provide list of all trees and tree species surveyed. The information are excel files and available in electronic format.

Table 2.4: Species Importance Value (SIV) Indices of small trees $(<5 \mathrm{~cm} \mathrm{DBH})$ per site. (Note: A dash means that a species was not found at the site.)

\begin{tabular}{|c|c|c|c|c|}
\hline Species & Kabompo & Namwala & Sesheke & $\begin{array}{l}\text { Language of the } \\
\text { species name }\end{array}$ \\
\hline Acacia ataxacantha & - & - & 11.01 & Botanical \\
\hline Afzelia quanzensis & 3.07 & - & - & Botanical \\
\hline Baikiaea plurijuga & - & 4.82 & - & Botanical \\
\hline Baphia massaiensis & 70.37 & 69.68 & 27.08 & Botanical \\
\hline Bauhinia petersiana & - & - & 0.00 & Botanical \\
\hline Brachystegia speciformis & 8.27 & - & - & Botanical \\
\hline Cassia abbreviata & - & 4.90 & - & Botanical \\
\hline Combretum celastroides & - & 30.96 & 0.00 & Botanical \\
\hline Combretum hereroense & - & - & 15.51 & Botanical \\
\hline Combretum molle & - & 9.07 & - & Botanical \\
\hline Combretum zeyheri & - & 1.37 & - & Botanical \\
\hline Commiphora mollis & - & 3.57 & - & Botanical \\
\hline Croton gratissimus & - & - & 0.00 & Botanical \\
\hline Dichrostachys cinerea & - & 1.35 & - & Botanical \\
\hline Diplorhynchus candylocarpon & 49.44 & 26.78 & 4.82 & Botanical \\
\hline Eucalyptus (exotic species) & - & - & 0.00 & Botanical \\
\hline Friesodielsia obovata & 3.01 & 45.03 & 42.71 & Botanical \\
\hline Hippocratea africana & - & - & 5.09 & Botanical \\
\hline Hymenocardia acida & - & 1.37 & - & Botanical \\
\hline
\end{tabular}




\begin{tabular}{|c|c|c|c|c|}
\hline Species & Kabompo & Namwala & Sesheke & $\begin{array}{l}\text { Language of the } \\
\text { species name }\end{array}$ \\
\hline Ibu & - & 1.32 & - & Ila \\
\hline Kapasa ka lyongono & 1.54 & - & - & Luvale \\
\hline Lonchocarpus nelsii & - & - & 12.23 & Botanical \\
\hline Mang'omba & - & 3.19 & - & Tonga \\
\hline Markhamia obtusifolia & 2.06 & 17.95 & - & Botanical \\
\hline Markhamia zanzibarica & - & - & 12.47 & Botanical \\
\hline Mbungeimo & - & - & 0.00 & Lozi \\
\hline Mubangabanga & 6.64 & - & - & Luvale \\
\hline Mubeba & 1.65 & - & - & Luvale \\
\hline Mubwabwa & - & 2.77 & - & Luvale \\
\hline Muhoho & 1.35 & - & - & Luvale \\
\hline Muhuhu & 12.67 & - & - & Luvale \\
\hline Mukube & 5.56 & - & - & Luvale \\
\hline Mumbukushu & 10.84 & - & - & Luvale \\
\hline Mumbumelenge & - & - & 0.00 & Lozi \\
\hline Mutungambabala & - & 1.70 & - & Tonga \\
\hline Mwingili & - & 1.34 & - & Tonga \\
\hline Namulomo & - & - & 25.73 & Lozi \\
\hline Pseudolachnostylis maprouneifolia & - & 3.22 & 43.67 & Botanical \\
\hline Pteleopsis anisoptera & 22.28 & - & - & Botanical \\
\hline Pterocarpus angolensis & - & 1.34 & - & Botanical \\
\hline Pterocarpus angolensis & - & 40.17 & - & Botanical \\
\hline Pterocarpus antunesii & - & - & 66.93 & Botanical \\
\hline Rhus longipes & - & 5.84 & - & Botanical \\
\hline Ricinodendron rautanenii & 2.95 & 1.55 & - & Botanical \\
\hline Stantwasokwe & - & 5.32 & - & Tonga \\
\hline Sterculia quinqueloba & 12.03 & - & - & Botanical \\
\hline Strychnos innocua & - & 2.79 & - & Botanical \\
\hline Terminalia sericea & - & 2.05 & 4.23 & Botanical \\
\hline Uvariastrum hexaloboides & 1.71 & - & - & Botanical \\
\hline Vangueriopsis lanciflora & 2.14 & - & - & Botanical \\
\hline Ximenia americana & - & 2.59 & - & Botanical \\
\hline Zanha africana & 10.75 & 8.42 & - & Botanical \\
\hline ?1 (Not identified) & - & 1.33 & - & Not identified \\
\hline
\end{tabular}

Table 2.5: Species Importance Value Indices of large trees ( $\geq 5 \mathrm{~cm} \mathrm{DBH})$ per site. (Note: A dash means that a species was not found at the site.)

\begin{tabular}{|l|r|r|r|c|}
\hline Species & Kabompo & Namwala & Sesheke & Language of the species name \\
\hline Acacia ataxacantha & - & - & - & Botanical \\
\hline Acacia erioloba & - & - & 5.30 & Botanical \\
\hline Afzelia quanzensis & 1.97 & 1.00 & - & Botanical \\
\hline Albizia versicolor & 0.89 & 1.00 & - & Botanical \\
\hline Amblygonocarpus andongensis & 4.17 & - & - & Botanical \\
\hline Baikiaea plurijuga & 48.39 & 163 & 149.33 & Botanical \\
\hline Baphia massaiensis & 33.09 & 16.00 & - & Botanical \\
\hline Bauhinia petersiana & - & - & 2.30 & Botanical \\
\hline Brachystegia boehmii & - & - & - & Botanical \\
\hline Brachystegia longifolia & 8.31 & - & - & Botanical \\
\hline
\end{tabular}


Data for developing allometric models and evaluating carbon stocks

\begin{tabular}{|c|c|c|c|c|}
\hline Species & Kabompo & Namwala & Sesheke & Language of the species name \\
\hline Brachystegia speciformis & 18.98 & - & - & Botanical \\
\hline Burkea africana & 8.98 & - & 2.00 & Botanical \\
\hline Cassia abbreviata & - & 6.19 & - & Botanical \\
\hline Combretum celastroides & - & 13.00 & - & Botanical \\
\hline Combretum hereroense & - & - & 30.99 & Botanical \\
\hline Combretum imberbe & - & 1.07 & - & Botanical \\
\hline Combretum molle & - & 6.54 & - & Botanical \\
\hline Commiphora mollis & - & 7.63 & - & Botanical \\
\hline Dialium engleranum & 2.94 & - & - & Botanical \\
\hline Dichrostachys cinerea & - & - & 2.55 & Botanical \\
\hline Diospyros batocana & 3.99 & - & - & Botanical \\
\hline Diplorhynchus candylocarpon & 14.09 & 27.00 & 8.00 & Botanical \\
\hline Erythrophleum africanum & - & - & 10.95 & Botanical \\
\hline Eucalyptus (Exotic species) & - & - & - & Botanical \\
\hline Ficus sycomorus & - & - & 8.14 & Botanical \\
\hline Guibourtia coleosperma & 3.00 & 2.00 & - & Botanical \\
\hline Hymenocardia acida & 0.63 & 2.00 & - & Botanical \\
\hline Khaya nyasica & - & 1.65 & - & Botanical \\
\hline Lannea discolor & - & - & - & Botanical \\
\hline Lannea stuhlmannii & - & 6.26 & - & Botanical \\
\hline Leza & - & 0.91 & - & Tonga \\
\hline Lonchocarpus nelsii & - & - & 18.29 & Botanical \\
\hline Magwilinti & - & 1.99 & - & Chewa \\
\hline Markhamia obtusifolia & 6.98 & - & - & Botanical \\
\hline Markhamia obtusifolia & - & 4.36 & - & Botanical \\
\hline Markhamia zanzibarica & - & - & - & Botanical \\
\hline Matu & - & 2.21 & - & Tonga \\
\hline Mubangabanga & - & 2.22 & - & Tonga \\
\hline Mubeba & 1.72 & - & - & Luvale \\
\hline Muhaswa & 4.46 & - & - & Luvale \\
\hline Muhuhu & 24.65 & - & - & Luvale \\
\hline Mukamba & - & 4.19 & - & Tonga \\
\hline Mukenge & 12.80 & - & - & Luvale \\
\hline Mukube & 2.12 & - & - & Luvale \\
\hline Muleyambezo & - & 3.04 & - & Tonga \\
\hline Mumbukushu & 1.05 & - & - & Luvale \\
\hline Musenene & 0.70 & - & - & Luvale \\
\hline Musungwa & 0.83 & - & - & Luvale \\
\hline Nankhala & - & - & - & Tonga \\
\hline Ochna pulchra & - & - & 2.08 & Botanical \\
\hline Pseudolachnostylis maprouneifolia & 19.75 & 3.00 & 5.00 & Botanical \\
\hline Pteleopsis anisoptera & 35.45 & - & - & Botanical \\
\hline Pterocarpus angolensis & 4.42 & 22.00 & 5.00 & Botanical \\
\hline Pterocarpus antunesii & - & - & 25.34 & Botanical \\
\hline Ricinodendron rautanenii & 21.20 & 2.00 & 4.00 & Botanical \\
\hline Sclerocarya caffra & - & - & - & Botanical \\
\hline Securidaca longepedunculata & 0.62 & - & - & Botanical \\
\hline
\end{tabular}




\begin{tabular}{|l|r|r|r|r|}
\hline Species & Kabompo & Namwala & Sesheke & Language of the species name \\
\hline Sterculia quinqueloba & 1.92 & - & - & Botanical \\
\hline Strophanthus welwitschii & - & - & 6.71 & Botanical \\
\hline Strychnos potatorum & - & 6.16 & - & Botanical \\
\hline Strychnos pungens & 0.70 & - & - & Botanical \\
\hline Terminalia sericea & - & - & 8.42 & Botanical \\
\hline Uvariastrum hexaloboides & 4.29 & - & - & Botanical \\
\hline Vangueriopsis lanciflora & 0.78 & - & - & Botanical \\
\hline Ximenia americana & - & - & - & Botanical \\
\hline Zanha africana & 5.45 & 13.00 & - & Botanical \\
\hline ?1 (Not identified) & 0.66 & - & - & Not identified \\
\hline ?2 (Not identified) & - & 2.73 & - & Not identified \\
\hline ?3 (Not identified) & - & 7.65 & - & Not identified \\
\hline ?4 (Not identified) & - & - & 5.34 & Not identified \\
\hline
\end{tabular}




\subsubsection{Carbon stock per species per site}

See Table 2.6 and Supplementary Information Table S2.1 and Table S2.2.

Table 2.6: Carbon stock $\left(\mathrm{t} \mathrm{C} \mathrm{ha}^{-1}\right)$ per species per site.

\begin{tabular}{|c|c|c|c|c|c|}
\hline \multirow[t]{2}{*}{ Site } & \multirow[t]{2}{*}{ Species name } & \multicolumn{2}{|c|}{$\begin{array}{l}\text { Carbon stock of standing } \\
\text { dead and live trees }\end{array}$} & \multirow{2}{*}{$\begin{array}{l}\text { Number } \\
\text { of trees } \\
\text { recorded } \\
(\%) \\
\end{array}$} & \multirow{2}{*}{$\begin{array}{l}\text { Species } \\
\text { name's } \\
\text { language }\end{array}$} \\
\hline & & $\begin{array}{l}\text { Above-ground } \\
\text { carbon stock }\end{array}$ & $\begin{array}{l}\text { Species } \\
\text { name's } \\
\text { language }\end{array}$ & & \\
\hline Kabompo & Afzelia quanzensis & 0.031 & 0.011 & 0.29 & Botanical \\
\hline Kabompo & Albizia verscolor & 0.075 & 0.025 & 0.07 & Botanical \\
\hline Kabompo & $\begin{array}{l}\text { Amblygonocarpus } \\
\text { andongensis }\end{array}$ & 0.485 & 0.161 & 0.72 & Botanical \\
\hline Kabompo & Baikiaea plurijuga & 7.928 & 2.637 & 10.96 & Botanical \\
\hline Kabompo & Baphia massaiensis & 0.923 & 0.344 & 21.27 & Botanical \\
\hline Kabompo & Brachystegia longifolia & 0.865 & 0.291 & 1.59 & Botanical \\
\hline Kabompo & Brachystegia speciformis & 2.861 & 0.940 & 4.33 & Botanical \\
\hline Kabompo & Burkea africana & 0.751 & 0.254 & 1.59 & Botanical \\
\hline Kabompo & Dialium engleranum & 0.203 & 0.072 & 0.94 & Botanical \\
\hline Kabompo & Diospyros batocana & 0.185 & 0.066 & 1.37 & Botanical \\
\hline Kabompo & Diplorhynchus candylocarpon & 0.195 & 0.075 & 6.85 & Botanical \\
\hline Kabompo & Friesodielsia obovata & 0.001 & 0.000 & 0.14 & Botanical \\
\hline Kabompo & Guibourtia coleosperma & 0.094 & 0.033 & 0.43 & Botanical \\
\hline Kabompo & Hymenocardia acida & 0.003 & 0.001 & 0.07 & Botanical \\
\hline Kabompo & Kabompol? (Not identified) & 0.010 & 0.004 & 0.07 & Not identified \\
\hline Kabompo & Kapasa ka lyongono & 0.000 & 0.000 & 0.07 & Luvale \\
\hline Kabompo & Markhamia obtusifolia & 0.069 & 0.026 & 1.73 & Botanical \\
\hline Kabompo & Mubangabanga & 0.001 & 0.000 & 0.36 & Luvale \\
\hline Kabompo & Mubeba & 0.052 & 0.019 & 0.43 & Luvale \\
\hline Kabompo & Muhaswa & 0.062 & 0.023 & 0.87 & Luvale \\
\hline Kabompo & Muhoho & 0.000 & 0.000 & 0.07 & Luvale \\
\hline Kabompo & Muhuhu & 1.832 & 0.641 & 9.08 & Luvale \\
\hline Kabompo & Mukenge & 0.558 & 0.201 & 4.83 & Lunda \\
\hline Kabompo & Mukube & 0.019 & 0.007 & 0.43 & Luvale \\
\hline Kabompo & Mumbukushu & 0.013 & 0.005 & 0.65 & Luvale \\
\hline Kabompo & Musenene & 0.018 & 0.007 & 0.07 & Luvale \\
\hline Kabompo & Musungwa & 0.032 & 0.011 & 0.14 & Luvale \\
\hline Kabompo & $\begin{array}{l}\text { Pseudolachnostylis } \\
\text { maprouneifolia }\end{array}$ & 1.783 & 0.618 & 5.62 & Botanical \\
\hline Kabompo & Pteleopsis anisoptera & 1.959 & 0.697 & 15.79 & Botanical \\
\hline Kabompo & Pterocarpus angolensis & 0.166 & 0.057 & 0.50 & Botanical \\
\hline Kabompo & Ricinodendron rautanenii & 2.654 & 0.893 & 5.55 & Botanical \\
\hline Kabompo & Securidaca longepedunculata & 0.001 & 0.001 & 0.07 & Botanical \\
\hline
\end{tabular}




\begin{tabular}{|c|c|c|c|c|c|}
\hline \multirow{2}{*}{ Site } & \multirow{2}{*}{ Species name } & \multicolumn{2}{|c|}{$\begin{array}{l}\text { Carbon stock of standing } \\
\text { dead and live trees }\end{array}$} & \multirow{2}{*}{$\begin{array}{l}\text { Number } \\
\text { of trees } \\
\text { recorded } \\
(\%)\end{array}$} & \multirow{2}{*}{$\begin{array}{l}\text { Species } \\
\text { name's } \\
\text { language }\end{array}$} \\
\hline & & $\begin{array}{l}\text { Above-ground } \\
\text { carbon stock }\end{array}$ & $\begin{array}{l}\text { Species } \\
\text { name's } \\
\text { language }\end{array}$ & & \\
\hline Kabompo & Sterculia quinqueloba & 0.024 & 0.009 & 0.58 & Botanical \\
\hline Kabompo & Strychnos pungens & 0.003 & 0.001 & 0.14 & Botanical \\
\hline Kabompo & Uvariastrum hexaloboides & 0.029 & 0.011 & 0.94 & Botanical \\
\hline Kabompo & Vangueriopsis lanciflora & 0.003 & 0.001 & 0.29 & Botanical \\
\hline Kabompo & Zanha africana & 0.038 & 0.014 & 1.08 & Botanical \\
\hline Namwala & Afzelia quanzensis & 0.000 & 0.000 & 0.07 & Botanical \\
\hline Namwala & Albizia verscolor & 0.019 & 0.007 & 0.07 & Botanical \\
\hline Namwala & Baikiaea plurijuga & 12.835 & 4.421 & 32.60 & Botanical \\
\hline Namwala & Baphia massaiensis & 0.203 & 0.074 & 13.55 & Botanical \\
\hline Namwala & Cassia abbreviata & 0.055 & 0.020 & 0.86 & Botanical \\
\hline Namwala & Combretum celastroides & 0.236 & 0.084 & 6.77 & Botanical \\
\hline Namwala & Combretum imberbe & 0.007 & 0.003 & 0.13 & Botanical \\
\hline Namwala & Combretum molle & 0.108 & 0.039 & 1.99 & Botanical \\
\hline Namwala & Combretum zeyheri & 0.000 & 0.000 & 0.07 & Botanical \\
\hline Namwala & Commiphora mollis & 0.149 & 0.053 & 1.20 & Botanical \\
\hline Namwala & Dichrostachys cinerea & 0.000 & 0.000 & 0.07 & Botanical \\
\hline Namwala & Diplorhynchus candylocarpon & 0.389 & 0.147 & 11.29 & Botanical \\
\hline Namwala & Friesodielsia obovata & 0.032 & 0.011 & 9.16 & Botanical \\
\hline Namwala & Guibourtia coleosperma & 0.067 & 0.024 & 0.40 & Botanical \\
\hline Namwala & Hymenocardia acida & 0.018 & 0.007 & 0.33 & Botanical \\
\hline Namwala & $I b u$ & 0.000 & 0.000 & 0.07 & Ila \\
\hline Namwala & Lannea stuhlmannii & 0.036 & 0.013 & 0.73 & Botanical \\
\hline Namwala & Leza & 0.001 & 0.001 & 0.07 & Tonga \\
\hline Namwala & Mang'omba & 0.001 & 0.000 & 0.07 & Tonga \\
\hline Namwala & Markhamia obtusifolia & 0.023 & 0.009 & 2.32 & Botanical \\
\hline Namwala & Matu & 0.022 & 0.008 & 0.40 & Tonga \\
\hline Namwala & Moonze & 0.000 & 0.000 & 0.07 & Tonga \\
\hline Namwala & Mubangabanga & 0.059 & 0.020 & 0.13 & Tonga \\
\hline Namwala & Mugwirinti & 0.009 & 0.003 & 0.20 & Tonga \\
\hline Namwala & Mukamba & 0.011 & 0.004 & 0.40 & Tonga \\
\hline Namwala & Muleyambezo & 0.038 & 0.013 & 0.33 & Tonga \\
\hline Namwala & Mung'omba & 0.000 & 0.000 & 0.07 & Tonga \\
\hline Namwala & Mutungambabala & 0.000 & 0.000 & 0.13 & Tonga \\
\hline Namwala & Mutwamaila & 0.000 & 0.000 & 0.07 & Tonga \\
\hline Namwala & Mwingili & 0.000 & 0.000 & 0.07 & Tonga \\
\hline Namwala & Namwalal? (Not identified) & 0.139 & 0.046 & 0.20 & Not identified \\
\hline Namwala & Namwala2?(Not identified) & 0.009 & 0.003 & 0.13 & Not identified \\
\hline Namwala & Pericorpsis angolensis & 0.065 & 0.023 & 0.20 & Botanical \\
\hline Namwala & $\begin{array}{l}\text { Pseudolachnostylis } \\
\text { maprouneifolia }\end{array}$ & 0.030 & 0.011 & 0.73 & Botanical \\
\hline
\end{tabular}




\begin{tabular}{|c|c|c|c|c|c|}
\hline \multirow{2}{*}{ Site } & \multirow{2}{*}{ Species name } & \multicolumn{2}{|c|}{$\begin{array}{l}\text { Carbon stock of standing } \\
\text { dead and live trees }\end{array}$} & \multirow{2}{*}{$\begin{array}{l}\text { Number } \\
\text { of trees } \\
\text { recorded } \\
(\%)\end{array}$} & \multirow{2}{*}{$\begin{array}{l}\text { Species } \\
\text { name's } \\
\text { language }\end{array}$} \\
\hline & & $\begin{array}{l}\text { Above-ground } \\
\text { carbon stock }\end{array}$ & \begin{tabular}{|l|} 
Species \\
name's \\
language \\
\end{tabular} & & \\
\hline Namwala & Pterocarpus angolensis & 0.429 & 0.155 & 9.63 & Botanical \\
\hline Namwala & Rhus longipes & 0.002 & 0.001 & 0.53 & Botanical \\
\hline Namwala & Ricinodendron rautanenii & 0.040 & 0.014 & 0.27 & Botanical \\
\hline Namwala & Stantwasokwe & 0.003 & 0.001 & 0.86 & Tonga \\
\hline Namwala & Strychnos innocua & 0.002 & 0.001 & 0.13 & Botanical \\
\hline Namwala & Strychnos potatorum & 0.195 & 0.067 & 0.93 & Botanical \\
\hline Namwala & Terminalia sericea & 0.001 & 0.000 & 0.13 & Botanical \\
\hline Namwala & Ximenia americana & 0.001 & 0.000 & 0.27 & Botanical \\
\hline Namwala & Zanha africana & 0.205 & 0.074 & 2.32 & Botanical \\
\hline Sesheke & Acacia ataxacantha & 0.001 & 0.000 & 0.75 & Botanical \\
\hline Sesheke & Acacia erioloba & 0.074 & 0.026 & 0.60 & Botanical \\
\hline Sesheke & Baikiaea plurijuga & 8.200 & 2.784 & 35.04 & Botanical \\
\hline Sesheke & Baphia massaiensis & 0.005 & 0.002 & 3.16 & Botanical \\
\hline Sesheke & Bauhinia petersiana & 0.002 & 0.001 & 0.30 & Botanical \\
\hline Sesheke & Burkea africana & 0.046 & 0.016 & 0.15 & Botanical \\
\hline Sesheke & Combretum hereroense & 0.510 & 0.182 & 10.38 & Botanical \\
\hline Sesheke & Dichrostachys cinerea & 0.005 & 0.002 & 0.45 & Botanical \\
\hline Sesheke & Diplorhynchus candylocarpon & 0.039 & 0.015 & 2.86 & Botanical \\
\hline Sesheke & Erythrophleum africanum & 0.316 & 0.112 & 2.71 & Botanical \\
\hline Sesheke & Ficus sycomorus & 0.168 & 0.058 & 0.75 & Botanical \\
\hline Sesheke & Friesodielsia obovata & 0.029 & 0.010 & 7.07 & Botanical \\
\hline Sesheke & Hippocratea africana & 0.001 & 0.000 & 0.30 & Botanical \\
\hline Sesheke & Lonchocarpus nelsii & 0.114 & 0.042 & 4.21 & Botanical \\
\hline Sesheke & Markhamia zanzibarica & 0.007 & 0.002 & 1.05 & Botanical \\
\hline Sesheke & Namulomo & 0.010 & 0.003 & 2.71 & Lozi \\
\hline Sesheke & Ochna pulchra & 0.003 & 0.001 & 0.15 & Botanical \\
\hline Sesheke & $\begin{array}{l}\text { Pseudolachnostylis } \\
\text { maprouneifolia }\end{array}$ & 0.048 & 0.017 & 6.47 & Botanical \\
\hline Sesheke & Pterocarpus angolensis & 0.050 & 0.018 & 0.60 & Botanical \\
\hline Sesheke & Pterocarpus antunesii & 0.303 & 0.112 & 15.34 & Botanical \\
\hline Sesheke & Ricinodendron rautanenii & 0.076 & 0.027 & 0.75 & Botanical \\
\hline Sesheke & Sesheke1?(Not identified) & 0.031 & 0.012 & 0.90 & Not identified \\
\hline Sesheke & Strophanthus welwitschii & 0.016 & 0.006 & 0.45 & Botanical \\
\hline Sesheke & Terminalia sericea & 0.060 & 0.023 & 2.86 & Botanical \\
\hline
\end{tabular}




\subsection{Experimental design, materials and methods}

Our sampling strategy and methods are fully described in Ngoma et al. (2018a) and its cited references. This section only presents the pictorial processes that we followed to collect our samples to develop below-ground (Section 2.2.1) and above-ground biomass (Section 2.2.2) models.

\subsubsection{Sample collection process for developing below-ground biomass models}

Before felling a tree, we first measured total tree height, bole height, DBH and crown diameters. The uprooting process started by first exposing all roots connecting directly to the taproot (Figures 2.1A and B). We followed both lateral and taproots till they tapered to $\leq 5 \mathrm{~mm}$ in diameter (Figure 2.1C). We recorded rooting distance and depth for each recorded root. Big root mid-diameters ( $\geq 5 \mathrm{~cm}$ diameter) and their lengths were also measured (Figure 2.1D). All roots were weighed immediately after excavation to get their green weight (Figure 2.1E).
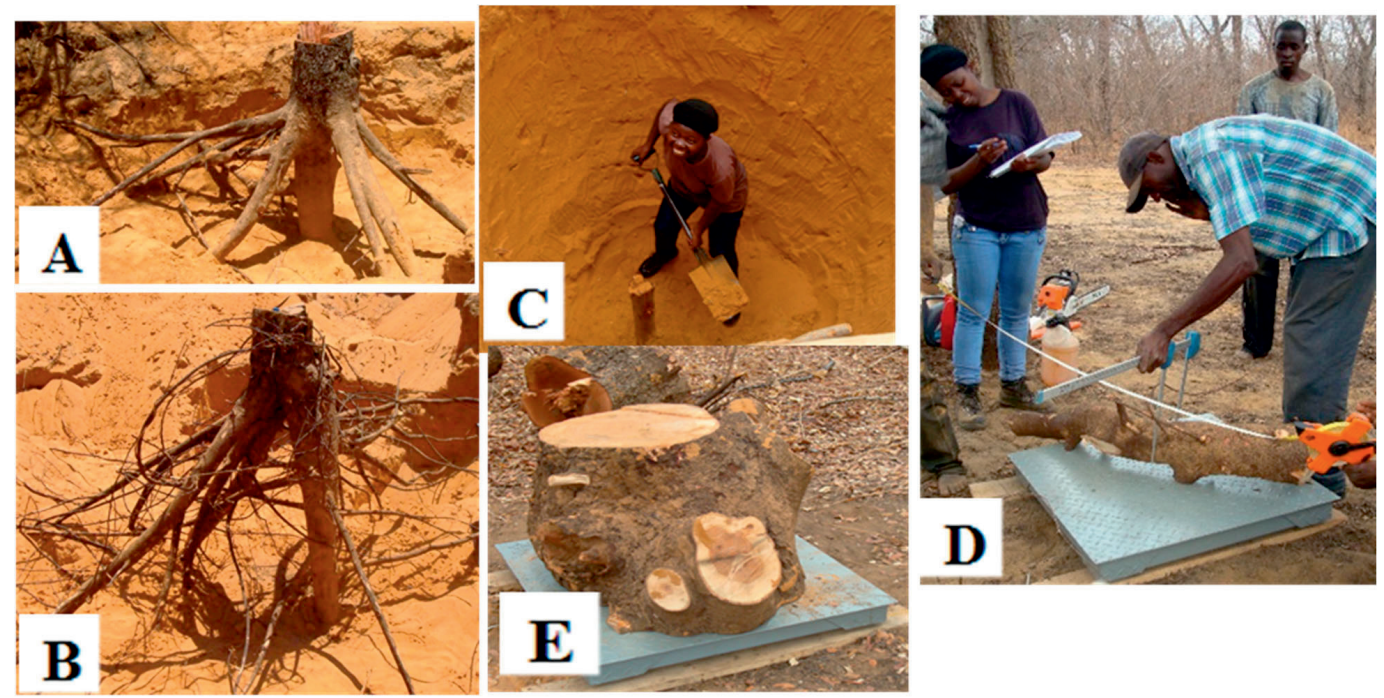

Figure 2.1 Below-ground sample collection process. Exposed roots are shown in (A) and (B), a taproot is followed in (C), the root's mid-diameter and length are measured in (D) and the root is weighed in (E).

\subsubsection{Sample collection process for developing above-ground biomass models}

The felled tree was then cross cut (Figure 2.2B) into small billets (Figure 2.2C) to unable lifting (Figure 2.2D) of the pieces for weighing. However, before weighing, the scale had to be calibrated (Figure 2.2E). Large pieces ( $\geq 10 \mathrm{~cm}$ mid diameter) were weighed individually 
(Figure 2.2F) while small pieces $(<10 \mathrm{~cm}$ mid-diameter) were weighed as batches together with their twigs and leaves (Figure 2.2G).

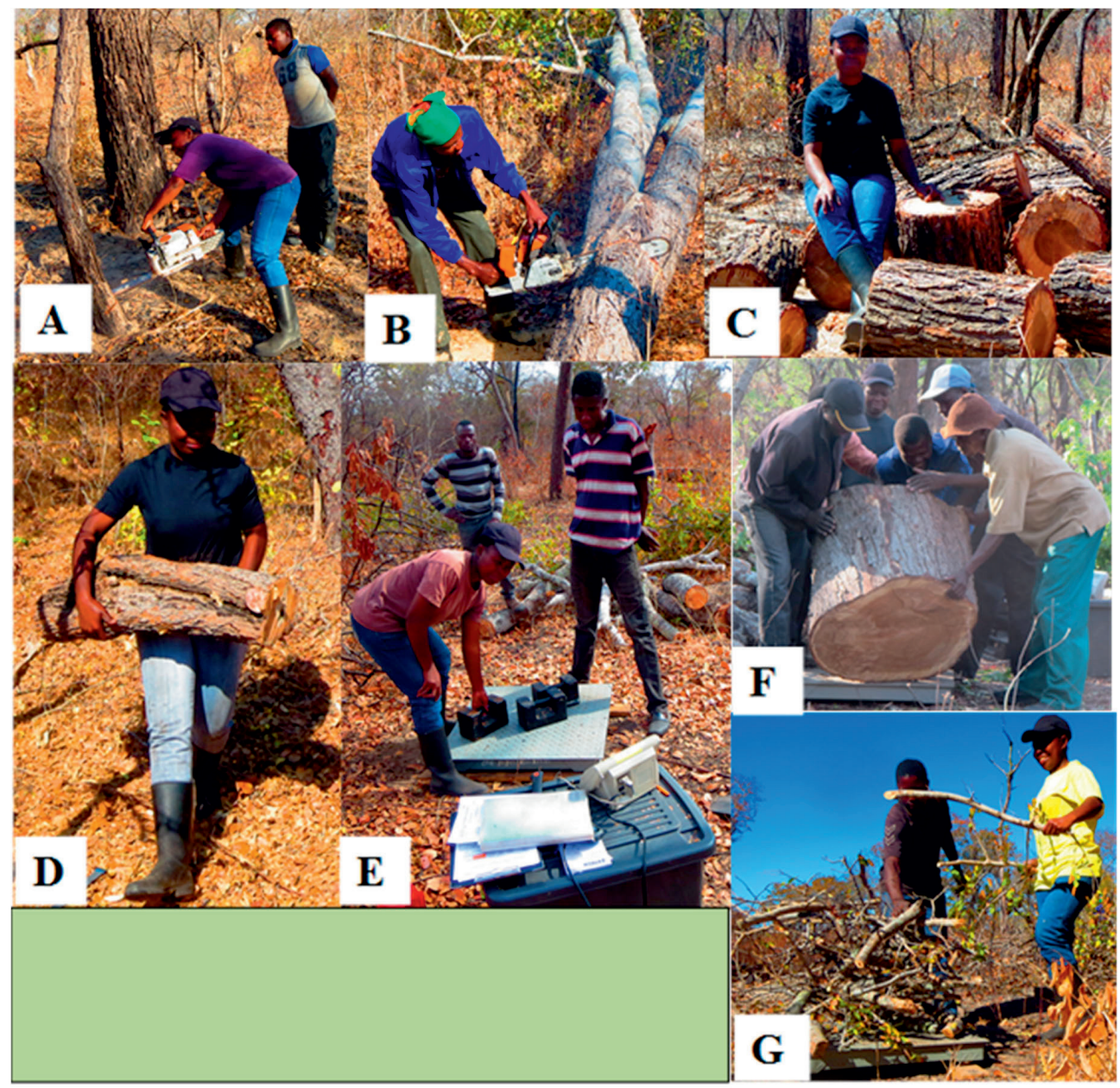

Figure 2.2 Above-ground sample collection process. Trees are felled (A), cross-cuts (B) and billets (C) are prepared and taken for weighing (D) but, first, the scale is calibrated (E). Large billets (F) and small billets $(<10 \mathrm{~cm}$ mid-diameter) including twigs and leaves $(\mathrm{G})$ are weighed. 
Chapter 2 


\section{BELOW AND ABOVE-GROUND CARBON DISTRIBUTION ALONG A RAINFALL GRADIENT. A CASE OF THE ZAMBEZI TEAK FORESTS, ZAMBIA}

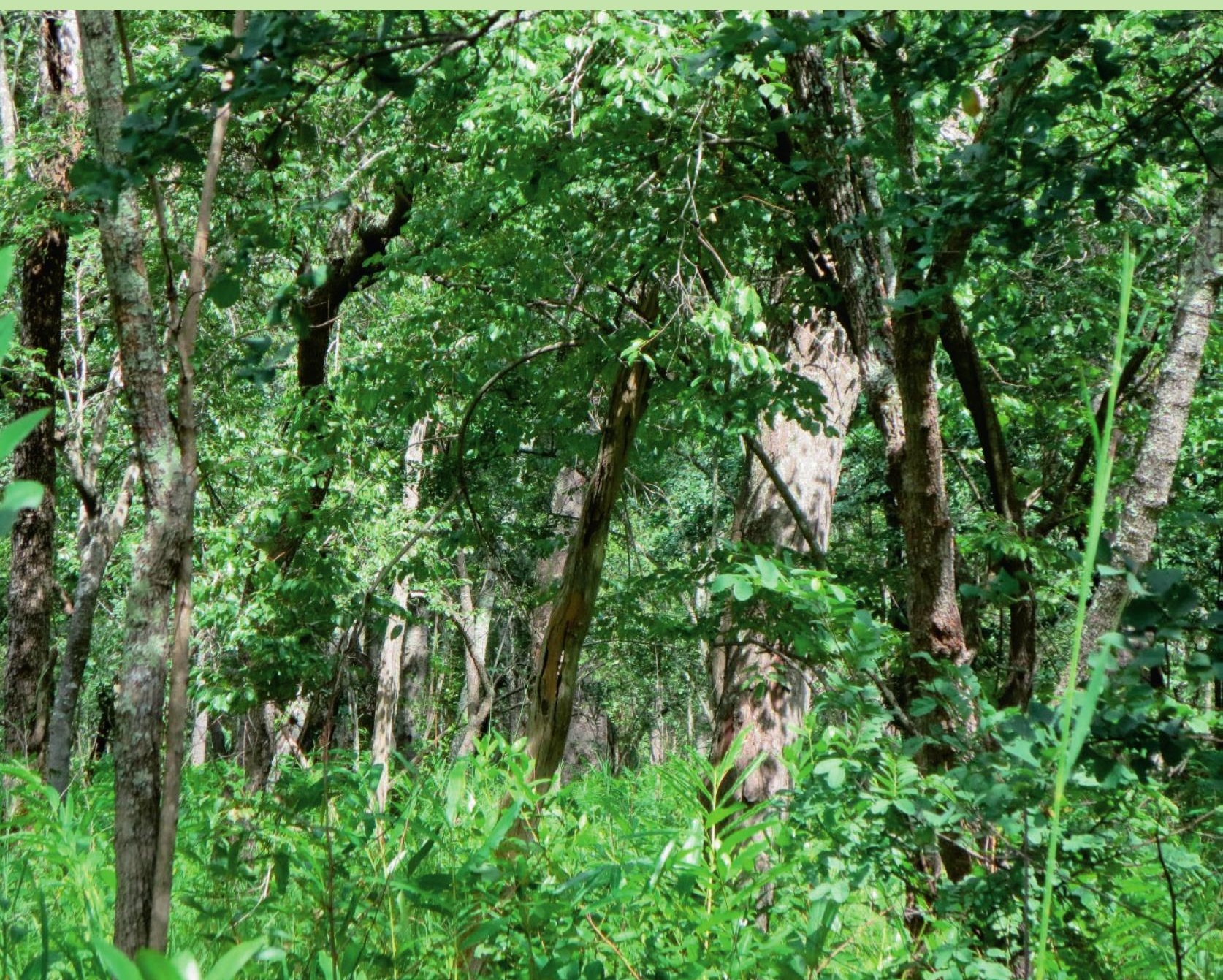




\section{Abstract}

Understanding carbon (C) stocks or biomass in forests is important to examine how forests mitigate climate change. To estimate biomass in stems, branches and roots takes intensive fieldwork to uproot, cut and weigh the mass of each component. Different models or equations are also required. Our research focussed on the dry tropical Zambezi teak forests and we studied their structure at three sites following a rainfall gradient in Zambia. We sampled 3558 trees at 42 plots covering a combined area of 15 ha. Using data from destructive tree samples, we developed mixed-species biomass models to estimate above ground biomass for small ( $<5 \mathrm{~cm}$ diameter at breast height (DBH, $1.3 \mathrm{~m}$ above-ground)) and large ( $\geq 5 \mathrm{~cm} \mathrm{DBH})$ trees involving 90 and 104 trees respectively, that belonged to 12 species. A below-ground biomass model was developed from seven trees of three species (16 to $44 \mathrm{~cm} \mathrm{DBH}$ ) whose complete root systems were excavated. Three stump models were also derived from these uprooted trees. Finally, we determined the C fractions from 194 trees that belonged to 12 species. The analysis revealed that DBH was the only predictor that significantly correlated to both above-ground and below-ground biomass. We found a mean root-to-shoot ratio of 0.38:0.62. The $\mathrm{C}$ fraction in leaves ranged from $39 \%$ to $42 \%$, while it varied between $41 \%$ and $46 \%$ in wood. The $\mathrm{C}$ fraction was highest at the Kabompo site that received the highest rainfall and lowest at the intermediate Namwala site. The $\mathrm{C}$ stocks varied between 15 to 36 ton $\mathrm{C} \mathrm{ha}^{-1}$ and these stocks where highest at the wetter Kabompo site and lowest at the drier Sesheke site. Our results indicate that the projected future rainfall decrease for southern Africa, will likely reduce the $\mathrm{C}$ storage potential of the Zambezi teak forests, thereby adversely affecting their mitigating role in climate change.

Published as:

Ngoma J, Moors E, Kruijt B, Speer JH, Vinya R, Chidumayo EN, Leemans R. 2018. Below and above-ground carbon distribution along a rainfall gradient. A case of the Zambezi teak forests, Zambia. Acta Oecologica 87:4557 


\subsection{Introduction}

The Zambezi teak forests form part of the dry tropical forests of southern Africa and cover about $265000 \mathrm{~km}^{2}$ in north-western Zimbabwe, north-east Botswana, south-west Zambia, north-east Namibia and south-east Angola. These forests are found at elevations of between $900 \mathrm{~m}$ and $1100 \mathrm{~m}$ on the gently undulating plateau overlain by deep Kalahari sands (Timberlake et al., 2010). About 2.6\% (of $265000 \mathrm{~km}^{2}$ ) of these forests are found in central, north-western, southern and western provinces of Zambia (Chidumayo, 1997) across a southnorth climatic gradient with annual rainfall ranging from $700 \mathrm{~mm}$ in the south to $1100 \mathrm{~mm}$ in the north. The Zambezi teak forests cover $9 \%$ of the total forest extent of $453000 \mathrm{~km}^{2}$ in Zambia (Matakala et al., 2015). Baikiaea plurijuga Harms is the dominant tree species in these teak forests (Mbughi, 1986; Mulolwa, 1986; Piearce, 1986a; Ngoma et al., 2017) and the forests' ground layer is covered by herbs and grasses that normally facilitate the spread of fire during the dry season (Mulolwa, 1986).

Because of the species diversity, the benefits from the Zambezi teak forests are also many, ranging from economic, social and ecological. Economically, the forests are important because of valuable commercial timber coming from the Baikiaea Plurijuga that supply local, national and international markets (Mubita, 1986; Musokotwane, 1986; Peele, 1986; Piearce, 1986a). In Zambia, logging in the Zambezi teak forests is dated back to 1911 when the first sawmill began operating in Livingstone. Between 1964 to $1970,450,000 \mathrm{~m}^{3}$ of Baikiaea plurijuga and other species were removed annually from the forests for both commercial and domestic usage (Musokotwane, 1986). By 1986, there were five sawmills utilizing the Zambezi teak forests mainly producing railway sleepers, mining sleepers, parquet battens and sawn timber from the Baikiaea plurijuga Harm (Piearce, 1986a).

The Zambezi teak forests provide social benefits to the local people through providing food, medicine and firewood (Kwashirai, 2007). People are also provided with employment through wood based industries (Piearce, 1986a). Ecologically, the forests conserve biological diversity (FAO, 2007) and provide natural habitat for fauna and flora (Mubita, 1986; Kwashirai, 2007). Catchment areas are also protected (FAO, 2007). Scientific, educational and aesthetic values are some of the additional benefits of the Zambezi teak forests (Piearce, 1986a). In addition to these benefits is the role the forests play in mitigating climate change. Plants take up significant amount of $\mathrm{CO}_{2}$, thereby acting as carbon sinks (Sarmiento and Gruber, 2002). However, despite the forests being so important, deforestation and climate change are 
some of the threats of the Zambezi teak forests. If these forests disappeared, the whole genetic pool would be lost as these forests are only found in southern Africa. It is therefore important that carbon stocks of these forests are established. Literature (Brown and Lugo, 1984; Chidumayo, 1990; Brown et al., 1991; Malimbwi et al., 1994; Beaty et al., 2001; Chave et al., 2003; Baccini et al., 2008; Henry et al., 2009; Hertel et al., 2009; Kamelarczyk, 2009; Shirima et al., 2011; Gautam and Pietsch, 2012; Ullah and Al-Amin, 2012) shows that tropical forests hold different amounts of biomass and carbon stocks. Unfortunately, these biomass and C stocks have not been accurately quantified. Quantification of biomass requires the use of allometric models, which are currently lacking for these forests despite similar models being available for other forest types (e.g. Henry et al. (2011)). Thus, developing ecosystem-specific biomass models for the Zambezi teak forests is crucial to reduce uncertainties and achieve more accurate results in $\mathrm{C}$ accounting in dry tropical forests. The objectives of our study were (1) to develop allometric equations for estimating component biomass of the Zambezi teak forests; (2) to evaluate the $\mathrm{C}$ fraction in component biomass of these teak forests; and (3) to assess $\mathrm{C}$ stocks along a rainfall gradient in these teak forests.

\subsection{State of the Zambezi teak forests}

The Zambezi teak forests have experienced various forms of forest degradation and deforestation. Apart from timber production, deforestation and forest degradation have also been caused by agricultural expansion, wood fuel collection, bush fires and infrastructure development underpinned by demographic and economic changes (Theilade et al., 2001; Matakala et al., 2015; Musgrave, 2016). The Zambezi teak forests have lost half of their area since 1975 due to logging and agricultural activities among others (Musgrave, 2016) and this trend has increased since 1984 (Figure 3.1). This indicates that, with the recent increase in Zambian population from about 13 million to 15 million (The Government of the Republic of Zambia, 2016), coupled with poor implementation of forestry monitoring programs, the extent of these forests will probably reduce even further. 

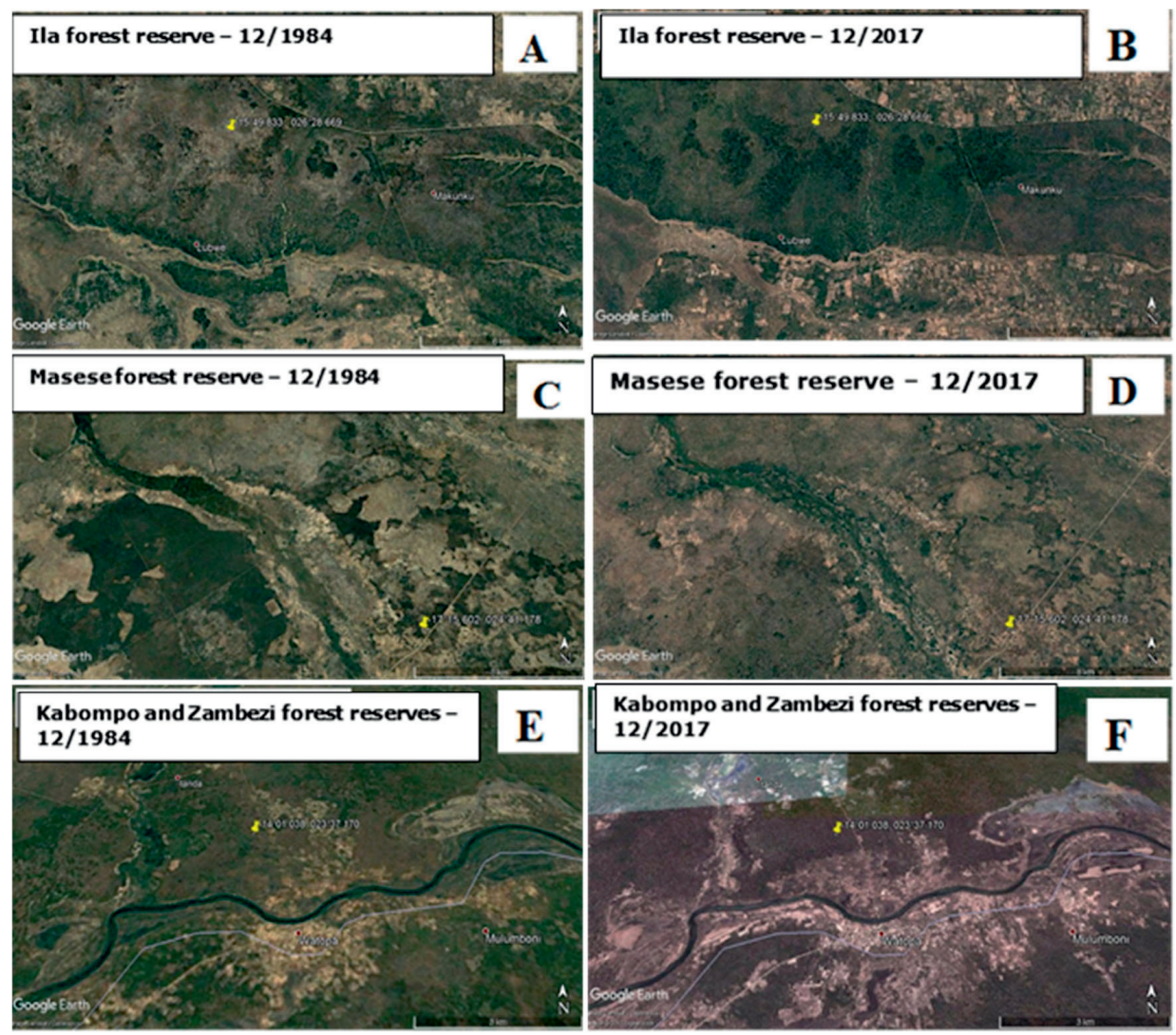

Figure 3.1 Status of the Zambezi teak forests in some of the reserves. Ila forest reserve in December 1984 (A) and in December 2017 (B). The Masese forest reserve in December 1984 (C) and in December 2017 (D). Kabompo and Zambezi forest reserves in December 1984 (E) and in December 2017 (F) (Masese Forest Reserve et al. (2017).

\subsection{Materials and Methods}

\subsubsection{Study sites}

Zambia is divided into three ecological zones defined by the amount of annual rainfall (Figure 3.2). Zone I receives less than $700 \mathrm{~mm}$ and zone II receives between $800 \mathrm{~mm}$ and $1000 \mathrm{~mm}$.

The wetter Zone III recieves more than 1000mm (The Government of the Republic of Zambia and UNDP, 2009). Our research was carried out at sites in the Kabompo (1400.551S, $\left.023^{\circ} 35.106 \mathrm{E}\right)$, Namwala $\left(15^{\circ} 50.732 \mathrm{~S}, 026^{\circ} 28.927 \mathrm{E}\right)$ and Sesheke $\left(17^{\circ} 21.278 \mathrm{~S}, 4^{\circ} 22.560 \mathrm{E}\right)$ 
areas (The KML file is available online: Study sites). In Kabompo, the study was carried out in Kabompo and Zambezi Forest Reserves, which are part of Zone II. The Sesheke study site is part of the Masese Forest Reserve, which is located in Zone I. The Namwala study site is part of the Ila Forest Reserve on the transition between Zones I and II (Figures 3.2 and 3.3).
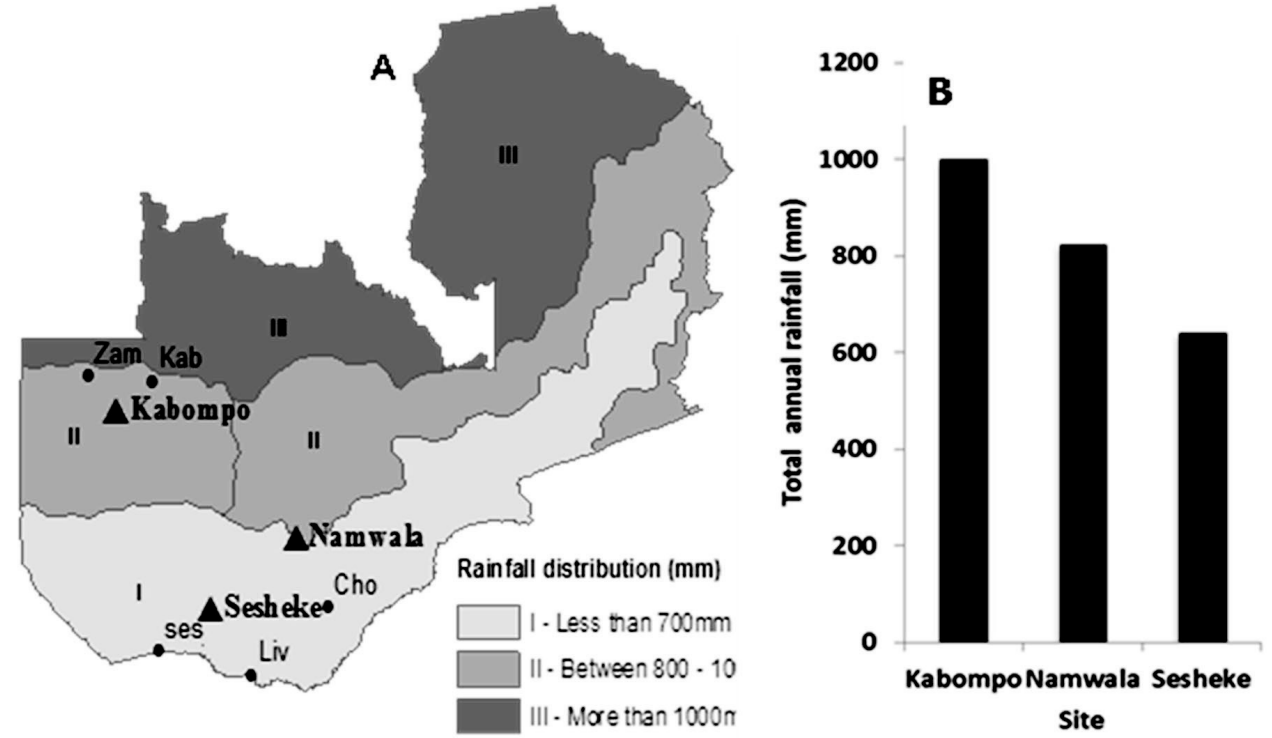

Figure 3.2 (A) Ecological zones, distribution of study sites and meteorological stations. (B) Total annual rainfall received at Kabompo, Namwala and Sesheke sites. The total annual rainfall figures cover the period 1973-1989 (Kabompo), 19702011(Namwala) and 1958-2011 (Sesheke) based on available data. The black triangles show study sites, while black dots show locations of meteorological stations. 'Zam' is Zambezi meteorological station and 'Kab' stands for Kabompo meteorological station. 'Cho', 'Ses' and 'Liv' represent Choma, Sesheke and Livingstone meteorological stations respectively. (Source of agro-ecological zones map:Wamunyima (2014))

We used rainfall figures from local meteorological stations that where within a $200 \mathrm{~km}$ radius, but in the same ecological zones as the respective forest reserves where our vegetation assessments were conducted. All rainfall figures for the respective local meteorological stations were provided by the head meteorological office in Lusaka. We used rainfall values from Kabompo and the Zambezi meteorological stations for Kabompo site, while rainfall data for the Sesheke site came from the Sesheke and Livingstone meteorological stations.

Namwala site was supplied with rainfall data from the Choma meteorological station. We averaged rainfall figures from various meteorologocal stations to allow us to fill data gaps 
from individual site records. In addition to their geographical locations, their accessibility through existing roads was another criterion we used to choose these study sites.

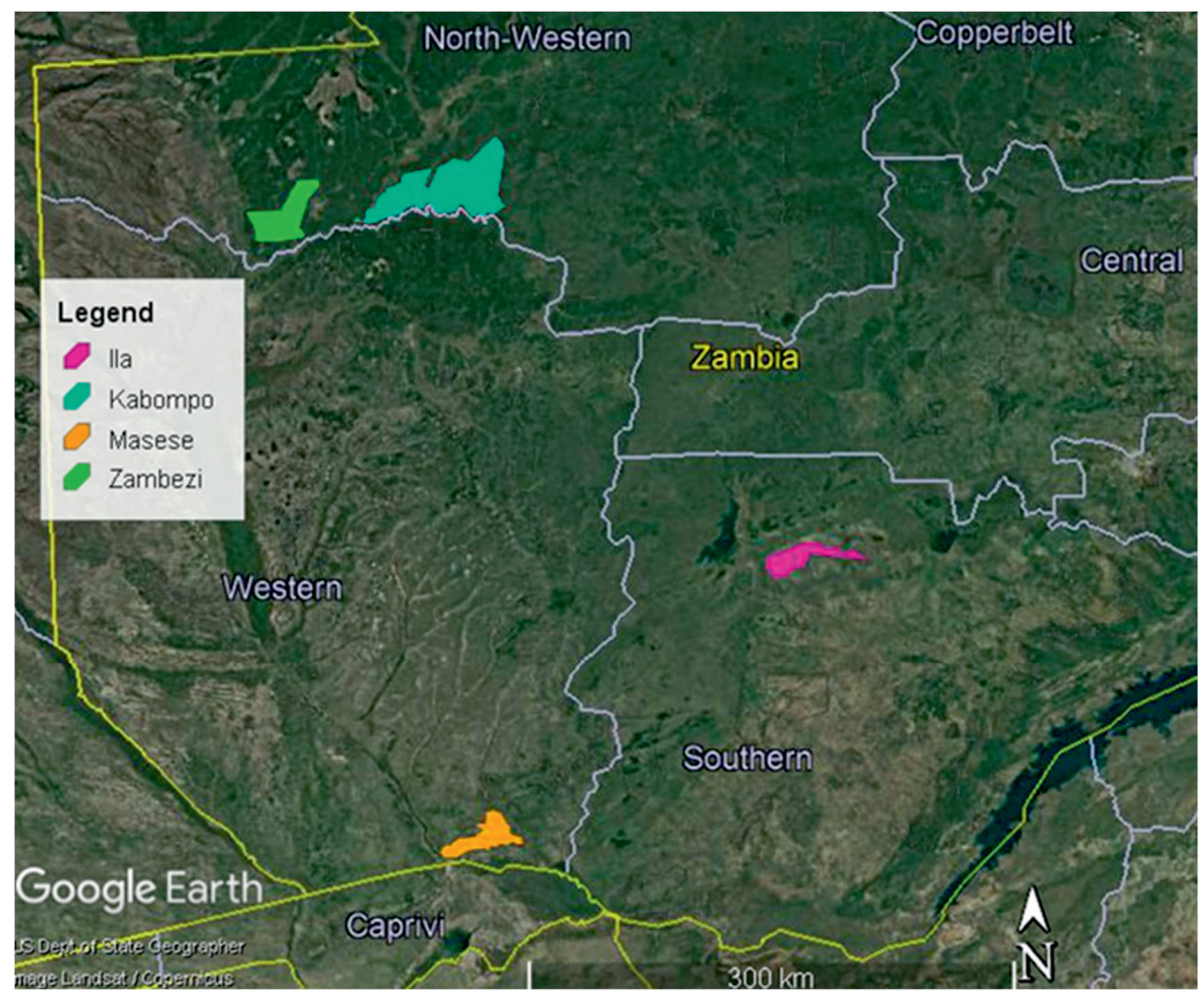

Figure 3.3 Surveyed reserves of the Zambezi teak forests (Masese Forest Reserve et al. (2017)

\subsubsection{Plot size and number of plots}

Optimal plot size was determined by assessing the maximum variation in stem density as a function of plot area. We implemented the plot size that gave maximum variation in stem density. A $3600 \mathrm{~m}^{2}$ (60m by $\left.60 \mathrm{~m}\right)$ square plot size was adopted (Barker, 2001) (Figure 3.4A). The total number of plots required was taken from the variability in stem densities as a function of the number of plots. The optimal number of plots were taken as the maximum variation in stem density as a function of the number of plots (Figure 3.4B). This is the point at which the relationship between the number of plots and the variation in stem density flattened (Figure 3.4B). Thus, a total of fifteen plots (i.e. 5 plots per site) sufficed to capture the maximum variability in all sites. However, to secure a broader understanding of the 
forests, an additional nine plots were surveyed in each study site. Both the optimal plot size and the required number of plots were established by applying Google Earth Pro along with ArcGIS and by counting individual trees in the satellite images.
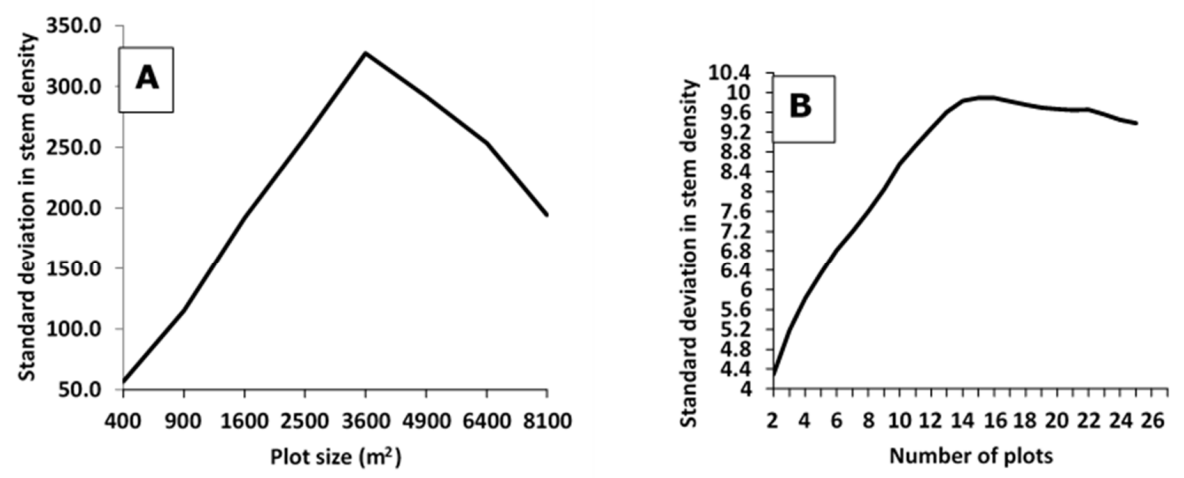

Figure 3.4 (A) Plot size (B) Number of plots.

\subsubsection{Forest assessment}

A total of 42 plots were sampled for the complete forest assessment in all the sites. This covered an area of just over $15 \mathrm{ha}$ in which the DBH and total heights of all trees were measured. The protocol used in this research was based on the field manual prepared for the Integrated Land Use Assessment (ILUA) project of the Zambian Forestry Department (Branthomme, 2006). Figure 3.5 represents the sampling design and Table 3.1 provides a more detailed sampling description. In each study site, the main plots were established to measure large diameter trees ( $\geq 5 \mathrm{~cm} \mathrm{DBH}$ ), $20 \mathrm{~m}$ by $20 \mathrm{~m}$ sub-plots to assess smaller diameter trees $(<5 \mathrm{~cm} \mathrm{DBH}), 5 \mathrm{~m}$ by $5 \mathrm{~m}$ sub-plots to assess dead wood of less than $10 \mathrm{~cm}$ in diameter on the forest floor and $1 \mathrm{~m}$ by $1 \mathrm{~m}$ sub-plots for the sampling of tree regeneration (plants of less than $1 \mathrm{~m}$ height). We based the $60 \mathrm{~m}$ by $60 \mathrm{~m}$ plot size on our statistical analysis (Figure 3.4; See Section 3.3.2) and all our sample plots were square (See Figure 3.5). We classified small trees as trees smaller than $5 \mathrm{~cm}$ in DBH and taller than $1.3 \mathrm{~cm}$ in height, and regeneration as woody plants of less than $1 \mathrm{~m}$ height. We measured both live and dead trees including stumps. Trees were identified using local names in the respective study sites. The survey crew at each site included one elderly local person who was familiar with these local trees and helped to identify species. The local names were later linked to their botanical names using Storrs et al. (1979) and if no botanical name was found, these species were only specified by their local names. 


\subsubsection{Below-ground biomass and stump models}

We sampled trees from the Masese Forest Reserve in Sesheke to develop below-ground biomass and stump models. This reserve is located near a local community from which we drew labour to help in uprooting of trees. In total, seven trees of the species Baikiaea plurijuga, Ficus sycomorus and Lonchocarpus nelsii with diameter size ranging from $15.7 \mathrm{~cm}$ to $44.0 \mathrm{~cm}$ were uprooted. Total tree height, $\mathrm{DBH}$, crown heights and crown diameters were measured before felling each tree (See Table 3 in Ngoma et al. (2018b)).

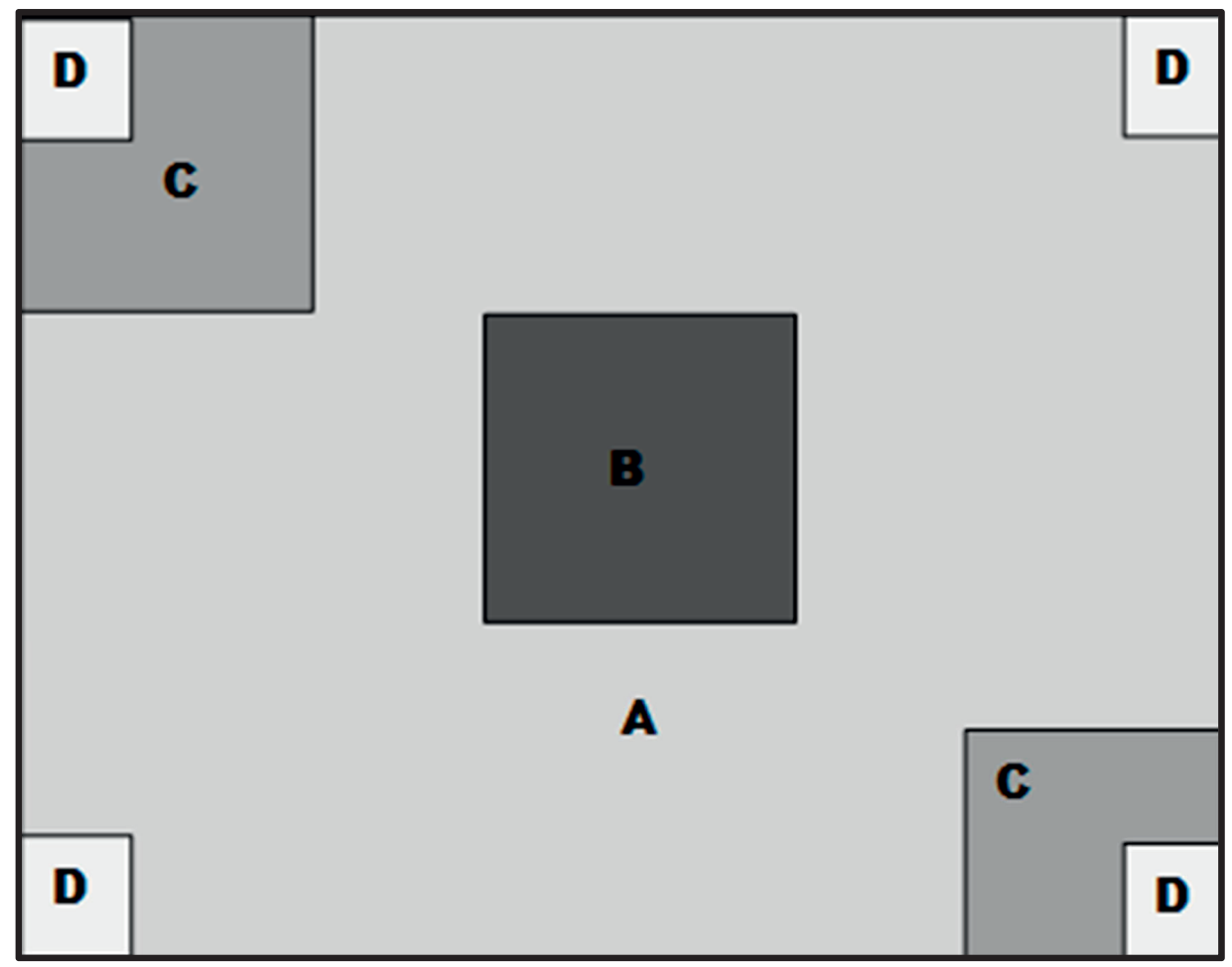

Figure 3.5 Schematic representation of the sampling design. Main plots of $60 \mathrm{~m}$ by $60 \mathrm{~m}$ size (A) were established to measure large trees ( $\geq 5 \mathrm{~cm} \mathrm{DBH}), 20 \mathrm{~m}$ by $20 \mathrm{~m}$ sub-plot (B) to assess small trees (1-4.9 DBH), 5m by $5 \mathrm{~m}$ sub-plot (C) to assess dead wood of less than $10 \mathrm{~cm}$ mid-diameter lying on the ground and $1 \mathrm{~m}$ by $1 \mathrm{~m}$ subplots (D) to assess regeneration. All sub-plots were established systematically to avoid sampling bias. The data recorded at each plot and sub-plot are described in Table 3.1. 
After felling a tree and measuring the above-ground biomass, roots were excavated by first exposing all the main roots that connect directly to the taproot. From this taproot, all roots were followed until they tapered to $\leq 5 \mathrm{~mm}$ in diameter. Roots were cut into smaller parts by a chainsaw and the soil was carefully removed by brushing. The roots were then weighed immediately to avoid water loss. Root mid-diameter and length were also measured (c.f. Figure 1 in Ngoma et al. (2018b) for the whole sampling process). A pre-weighed root disc was taken to the laboratory for dry weight determination. From the excavated trees, their stumps (measured at $30 \mathrm{~cm}$ above ground level), were cut and weighed separately to get stump fresh weight. All stumps had the same height of $30 \mathrm{~cm}$ cut above ground level.

\subsubsection{Above-ground biomass model}

Trees and their respective species were selected after executing a DBH-based forest survey and calculating Cottam and Curtis (1956) Importance Value Indices (IVI). The IVI indicates the distribution of tree species in the reserves. The indices take into account not just the diversity or number of trees available in an area, but also the size of trees. Tree species with the highest IVI values were selected to regress the above-ground biomass models. The first three species with the highest IVI (in each category of large and smaller diameter trees) were selected at each site to collect their above-ground biomass (See Tables 4 and 5 in Ngoma et al. (2018b)). Ten trees per category and species were targeted. However, when felling a targeted tree, this tree could hit and fell a nearby tree. Both, the targeted and the injured trees were then weighed and include in our analysis. Three injured Namwala trees and four Sesheke trees were included in our above-ground samples. We also included the seven excavated tree samples from the Sesheke site.

To have a balanced tree size distribution in our regression analysis, trees of each species were grouped in five DBH classes for large trees (i.e. $5-10 \mathrm{~cm}, 11-20 \mathrm{~cm}, 21-30 \mathrm{~cm}, 31-40 \mathrm{~cm}$ and $>40 \mathrm{~cm}$ in DBH) and four classes for small trees $(1.1-2.0 \mathrm{~cm}, 2.1-3.0 \mathrm{~cm}, 3.1-4.0 \mathrm{~cm}$ and $4.1-$ $4.9 \mathrm{~cm}$ in $\mathrm{DBH})$. Trees were distributed almost equally per diameter class per species. A total of 104 large trees (See Table 2 in Ngoma et al. (2018b)) and 90 small trees (See Table 1 in Ngoma et al. (2018b)) were cut and weighed to develop the above-ground biomass models. All samples were immediately weighed in the field to avoid the effect of moisture loss (c.f. Figure 2 in Ngoma et al. (2018b) for the whole sampling process). One pre-weighed stem (or trunk) disc from each felled tree was taken to the laboratory to determine its dry weight. We took trunk discs of smaller trees $(<5 \mathrm{~cm} \mathrm{DBH})$ and larger trees of up to $20 \mathrm{~cm} \mathrm{DBH}$ at $30 \mathrm{~cm}$ above ground level. As for larger trees of more than $20 \mathrm{~cm} \mathrm{DBH}$, we sampled discs of $20 \mathrm{~cm}$ 
diameter from the branches of the respective trees. Diameters of discs sampled from the trunks differed with tree size. All discs were $3 \mathrm{~cm}$ to $5 \mathrm{~cm}$ thick. We avoided getting very large discs because ovens in the laboratory were too small to accommodate these large discs.

Table 3.1: Description of the sampling design (See also Figure 3.5).

\begin{tabular}{|c|c|c|c|c|}
\hline Plot & Plot size & Samples measured & $\begin{array}{l}\text { Parameters measured in the } \\
\text { field }\end{array}$ & Comments \\
\hline \multirow[t]{4}{*}{$\bar{A}$} & \multirow[t]{4}{*}{$\begin{array}{l}60 \mathrm{~m} \text { by } \\
60 \mathrm{~m}\end{array}$} & $\begin{array}{l}\text { Standing live trees } \\
(\geq 5 \mathrm{~cm} \mathrm{DBH})\end{array}$ & $\begin{array}{l}\text { Total tree height, bole height, } \\
\text { DBH, crown height and crown } \\
\text { diameter. }\end{array}$ & $\begin{array}{l}\text { Crown diameter was measured at the widest and } \\
\text { thinnest parts of the crown (Schreuder et al., } \\
\text { 1993). Tree heights, bole heights and DBH were } \\
\text { measured following Branthomme (2006) }\end{array}$ \\
\hline & & $\begin{array}{l}\text { Standing dead trees } \\
(\geq 5 \mathrm{~cm} \mathrm{DBH})\end{array}$ & Total tree height and DBH & $\begin{array}{l}\text { Trees were measured in the same way as standing } \\
\text { live trees }\end{array}$ \\
\hline & & Stumps & Stump height and diameter & $\begin{array}{l}\text { We measured stump diameter at the top of the } \\
\text { stump for all stumps that had heights of up to } \\
30 \mathrm{~cm} \text { above ground level. For stumps with } \\
\text { heights of more than } 30 \mathrm{~cm} \text { above ground level, } \\
\text { but less than } 1.3 \mathrm{~m} \text { above ground level, we } \\
\text { measured their diameters at } 30 \mathrm{~cm} \text { above ground } \\
\text { level. For stumps that were longer than } 1.3 \mathrm{~m} \\
\text { above ground level, their diameters were } \\
\text { measured at } 1.3 \mathrm{~m}(\mathrm{DBH}) .\end{array}$ \\
\hline & & $\begin{array}{l}\text { Dead wood lying on } \\
\text { the ground }(\geq 10 \mathrm{~cm} \\
\text { mid-diameter) }\end{array}$ & $\begin{array}{l}\text { For whole lying tree, we } \\
\text { measured total height and DBH. } \\
\text { For lying pieces of wood, } \\
\text { diameters were measured at } \\
\text { base, mid and the top. Total } \\
\text { length was also measured. }\end{array}$ & $\begin{array}{l}\text { Fallen trees were measured following } \\
\text { Branthomme (2006). Hollow wood was noted } \\
\text { and length and diameters of the holes were } \\
\text { measured (Harmon and Sexton, 1996; Brown et } \\
\text { al., 2004). From each lying wood, a sample was } \\
\text { taken and immediately weighed to determine its } \\
\text { 'fresh' weight. The pre-weighed sub-sample was } \\
\text { taken to the laboratory for dry weight } \\
\text { determination. }\end{array}$ \\
\hline \multirow[t]{2}{*}{ B } & \multirow[t]{2}{*}{$\begin{array}{l}20 \mathrm{~m} \text { by } \\
20 \mathrm{~m}\end{array}$} & $\begin{array}{l}\text { Live and standing } \\
\text { smaller trees }(<5 \mathrm{~cm} \\
\text { DBH })\end{array}$ & Total tree height and DBH & $\begin{array}{l}\text { Smaller trees were measured the same way as the } \\
\text { larger trees (Branthomme, 2006) }\end{array}$ \\
\hline & & $\begin{array}{l}\text { Dead and standing } \\
\text { small trees }(<5 \mathrm{~cm} \\
\text { in } \mathrm{DBH})\end{array}$ & Total tree height and DBH & $\begin{array}{l}\text { Smaller trees were measured the same way as the } \\
\text { larger trees (Branthomme, 2006) }\end{array}$ \\
\hline $\mathbf{C}$ & $5 \mathrm{~m}$ by $5 \mathrm{~m}$ & $\begin{array}{l}\text { Dead wood lying on } \\
\text { the ground }(<10 \mathrm{~cm} \\
\text { mid-diameter } \\
\text { including twigs })\end{array}$ & Wood 'fresh' weight & $\begin{array}{l}\text { Samples were harvested and immediately } \\
\text { weighed. The pre-weighed sub-samples were } \\
\text { taken to the laboratory for dry weight } \\
\text { determination. }\end{array}$ \\
\hline D & $1 \mathrm{~m}$ by $1 \mathrm{~m}$ & Regeneration & Fresh weight. & $\begin{array}{l}\text { We harvested the plants of less than } 1 \mathrm{~m} \text { height } \\
\text { from the ground level and green weight weighed. } \\
\text { Pre-weighted sub-samples were taken to the } \\
\text { laboratory for dry weight determination. }\end{array}$ \\
\hline
\end{tabular}




\subsubsection{Carbon content of stem, branches, roots and leaves}

We collected stem, branches, roots and leaf samples from all trees that were harvested (See Tables 1 and 2, and Table 3 in Ngoma et al. (2018b)) to determine their C fractions. One root disc (in the case of the Sesheke site) and one stem (or trunk) disc were taken from each felled tree (Details of wood discs were as described in Section 3.3.5). Root discs were taken from the taproot of each uprooted tree. Samples were taken from different locations in different tree components (e.g. some wood samples were taken from the trunks while other samples were taken from the branches of the sampled trees) which could affect comparability. To reduce this bias, we made composite samples from trunks and branches at the respective sites. Leaf samples were taken from the branches of each felled tree. Following the number of felled trees and species (See Tables 1 and 2, and Table 3 in Ngoma et al. (2018b)), 194 stem discs and 7 root discs were collected from all sites. An A4-size envelope was filled with leaves from each felled tree and 194 leaf samples (envelopes) were taken. A total of 395 samples from twelve tree species were collected to determine their $\mathrm{C}$ fractions in various tree components (i.e. stem, branches, roots and leaves).

\subsubsection{Laboratory analysis}

Fresh wood and root samples were weighed in the field to avoid moisture loss. We then determined the volume of these pre-weighed samples in the laboratory before oven drying them for 24 hours at $105^{\circ} \mathrm{C}$ to get their dry weight. Due to the irregular nature of the samples, volume was determined by water displacement in the 'as received condition' since the samples were partially dry by the time they reached the laboratory from the study sites. Sample volume was taken as the amount of water displaced following mode IV in the ASTM (2007). We determined density $\left(\mathrm{g} \mathrm{cm}^{-3}\right)$ from the dry mass $(\mathrm{g})$ and sample volume $\left(\mathrm{cm}^{3}\right)$. To quicken the laboratory process, we analysed half of the samples at the Copperbelt University and another half at the Zambian Forestry Department's Division of the Forestry Research. We ground stem, branches, roots and leaves into fine powder before analysing them for their $\mathrm{C}$ fraction. $\mathrm{C}$ fractions were determined by Fisons EA1108 CHN-0 elemental analyser at the Ecosystem Laboratory of Wageningen University and Research. The analyser was monitored for accuracy of reading every ten samples with the Atropina standard $(70.56 \% \mathrm{C}, 4.84 \% \mathrm{~N})$.

\subsubsection{Data analysis}

The data were analysed in R environment (R Core Team, 2017). We used NLSTOOLS package (Baty et al., 2015) to fit non-linear regressions and we determined the Leave-One- 
Out Cross Validation (LOOCV) of these non-linear regressions using the MASS package (Venables and Ripley, 2002). Linear regressions were fitted using the STATS package (R Core Team, 2017) and the LOOCV of these linear regressions were determined using the BOOT package (Davison and Hinkley, 1997). We applied these models in this study (Table 3.3), to estimate biomass stock. To determine the volume of dead pieces of wood lying on the ground (>10cm mid-diameter), we used Newton's formula (Kershaw et al., 2016):

$$
\mathrm{V}=\frac{\mathrm{L}}{6}\left(A_{b}+4 A_{m}+A_{t}\right)
$$

(Equation 3.1)

where, $\mathrm{V}$ is Volume $\left(\mathrm{m}^{3}\right)$, $\mathrm{L}$ is Length of $\log (\mathrm{m}), A_{b}$ is Area at the base $\left(\mathrm{m}^{2}\right), A_{m}$ is area at the middle $\left(\mathrm{m}^{2}\right)$ and $A_{t}$ is Area at the top $\left(\mathrm{m}^{2}\right)$ of the wood lying on the ground.

This volume was used together with wood density of the sampled trees to determine the biomass of dead wood. Dry weight of small dead wood material $(<10 \mathrm{~cm}$ mid-diameter) lying on the ground and regeneration were estimated by direct weighing.

\subsubsection{Model regression, selection and evaluation}

The most common model types developed for dry tropical forests range from exponential, power, linear, logarithmic, to polynomial models (Henry et al., 2011). These models are based on single species and multiple species using one variable or multiple variables. However, we tested the power model following the different allometry theory that predict universal scaling relationships between the dependent variable (Y) and independent variable (x) (Niklas, 1995; West et al., 1999; Sileshi, 2014). We also tested the log-log model (Niklas and Spatz, 2004; Sileshi, 2014):

Power model: $\mathrm{Y}=\mathrm{a} \cdot \mathrm{X}^{\mathrm{b}}$

(Equation 3.2)

Log-log model: $\operatorname{Ln}(Y)=a+b \cdot \operatorname{Ln}(X)$

(Equation 3.3)

We first ran a multiple regression to determine the predictor (independent) variables that had significant influence on the response (or dependent) variable $(\mathrm{p}<0.05)$. For the two categories of large and smaller trees, we further conducted a Shapiro-Wilk Normality Test (p $<0.05$ ) to check whether the population (combined data of large and small trees) was normally distributed. Following the results of multiple regression and a Shapiro-Wilk Normality Test, we developed models using predictor variables that significantly influenced the response variables.

We selected the best-fit models based on Mean Absolute Percentage Error (MAPE) (Sileshi, 2014). Models with lower values of MAPE were recommended. We reported values of Akaike Information Criteria (AIC) (Sakamoto et al., 1986; Symonds and Moussalli, 2011; 
Gareth et al., 2013; Sileshi, 2014) and Residual Standard Error (RSE) (Gareth et al., 2013) for information. The AIC estimates the relative information lost when a given model is used to represent the process that generated the data. Thus, for competing model candidates, the best model is the candidate model that minimises information loss. For models with more than one predictor variable, the AIC also imposes a penalty and acts as a guard against overfitting of parameters. We further carried out a LOOCV (Gareth et al., 2013) to provide more information on how the models would perform on independent data. Coefficient of determination $\left(r^{2}\right)$ values were reported for linear models (Spiess and Neumeyer, 2010) only. The AIC, RSE and LOOCV can also be used individually or in combination to measure the performance of the models by selecting the best fit models with the lowest values. However, we did not use these values as criteria for model selection in our study since the reported AIC, RSE and LOOCV values could not be compared for power-law models in the arithmetic (Y= $\left.\mathrm{a} \cdot \mathrm{X}^{\mathrm{b}}\right)$ and logarithmic $(\ln (\mathrm{Y})=\mathrm{a}+\mathrm{b} \cdot \ln (\mathrm{X}))$ domains.

\subsection{Results}

\subsubsection{Vegetation structure}

A total of 3558 trees of diameter class from $1.1 \mathrm{~cm}$ to $70.0 \mathrm{~cm}$ were surveyed. This enabled us determine vegetation and biomass structures at the Sesheke, Namwala and Kabompo sites. Thus, tree density was highest at the Namwala $\left(265\right.$ trees ha $\left.^{-1}\right)$ and the least number of trees were surveyed at the Sesheke site (119 trees ha ${ }^{-1}$ ). Kabompo had 248 trees ha ${ }^{-1}$. Of the 80 species recorded, Namwala had the highest diversity of 43 species (c.f. Table 3.2).

Table 3.2: Number of species and trees inventoried per site.

* The total number of species in all sites is NOT the summation of species in the respective sites as

\begin{tabular}{|c|c|c|c|c|c|c|c|c|c|c|}
\hline \multirow[b]{2}{*}{ Site } & \multicolumn{3}{|c|}{ Total number of species } & \multicolumn{3}{|c|}{$\begin{array}{l}\text { Total number of trees } \\
\text { surveyed per site }\end{array}$} & \multicolumn{3}{|c|}{$\begin{array}{l}\text { Tree density (Number } \\
\text { of trees per hectare) }\end{array}$} & \multirow{2}{*}{$\begin{array}{l}\text { Tree basal } \\
\text { area }\left(\mathrm{m}^{\mathbf{2}} \mathbf{h a}^{-1}\right) \\
\text { Large trees }\end{array}$} \\
\hline & $\begin{array}{l}\text { Large } \\
\text { trees }\end{array}$ & $\begin{array}{l}\text { Small } \\
\text { trees }\end{array}$ & $\begin{array}{l}\text { Large } \\
\text { plus } \\
\text { small } \\
\end{array}$ & $\begin{array}{l}\text { Large } \\
\text { trees }\end{array}$ & $\begin{array}{l}\text { Small } \\
\text { trees }\end{array}$ & $\begin{array}{l}\text { Large } \\
\text { plus } \\
\text { small } \\
\end{array}$ & $\begin{array}{l}\text { Large } \\
\text { trees }\end{array}$ & $\begin{array}{l}\text { Small } \\
\text { trees }\end{array}$ & $\begin{array}{l}\text { Large } \\
\text { plus } \\
\text { small } \\
\end{array}$ & \\
\hline Kabompo & 33 & 19 & 37 & 1287 & 100 & 1387 & 255 & 179 & 248 & 10.01 \\
\hline Namwala & 28 & 30 & 43 & 958 & 548 & 1506 & 190 & 979 & 269 & 7.36 \\
\hline Sesheke & 18 & 13 & 25 & 457 & 208 & 665 & 91 & 371 & 119 & 4.55 \\
\hline All sites & $70 *$ & $55^{*}$ & $80 *$ & 2702 & 856 & 3558 & 179 & 510 & 235 & 7.31 \\
\hline
\end{tabular}

some species were common among sites. Large trees had $\mathrm{DBH} \geq 5 \mathrm{~cm}$ and small trees fall between $1.1-4.9 \mathrm{~cm}$ DBH. Note that small and large trees were respectively surveyed in $400 \mathrm{~m}^{2}$ and $3600 \mathrm{~m}^{2}$ plot sizes.

${ }^{2} R S E=\sqrt{R S S /(n-2)}$, where RSE $=$ Residual standard Error, RSS $=$ Residual Sum of Squares and $\mathrm{n}=$ sample size (Gareth et al., 2013) 
Using the criteria from Section 3.3.9, we recommended Models 2 and 4 (Table 3.3) to estimate above-ground biomass of large and small trees respectively. While Model 6 was recommended to estimate biomass in roots, we recommended Model 8 to estimate biomass in stumps and Model 10 to estimate above-ground biomass of trees that have been harvested from the forest (See Table 3.3). Model 12 fitted well in estimating DBH of trees that have been harvested already from the forests. We found an average root-to-shoot ratio of 0.38:0.62 (See Table 3 in Ngoma et al. (2018b)).
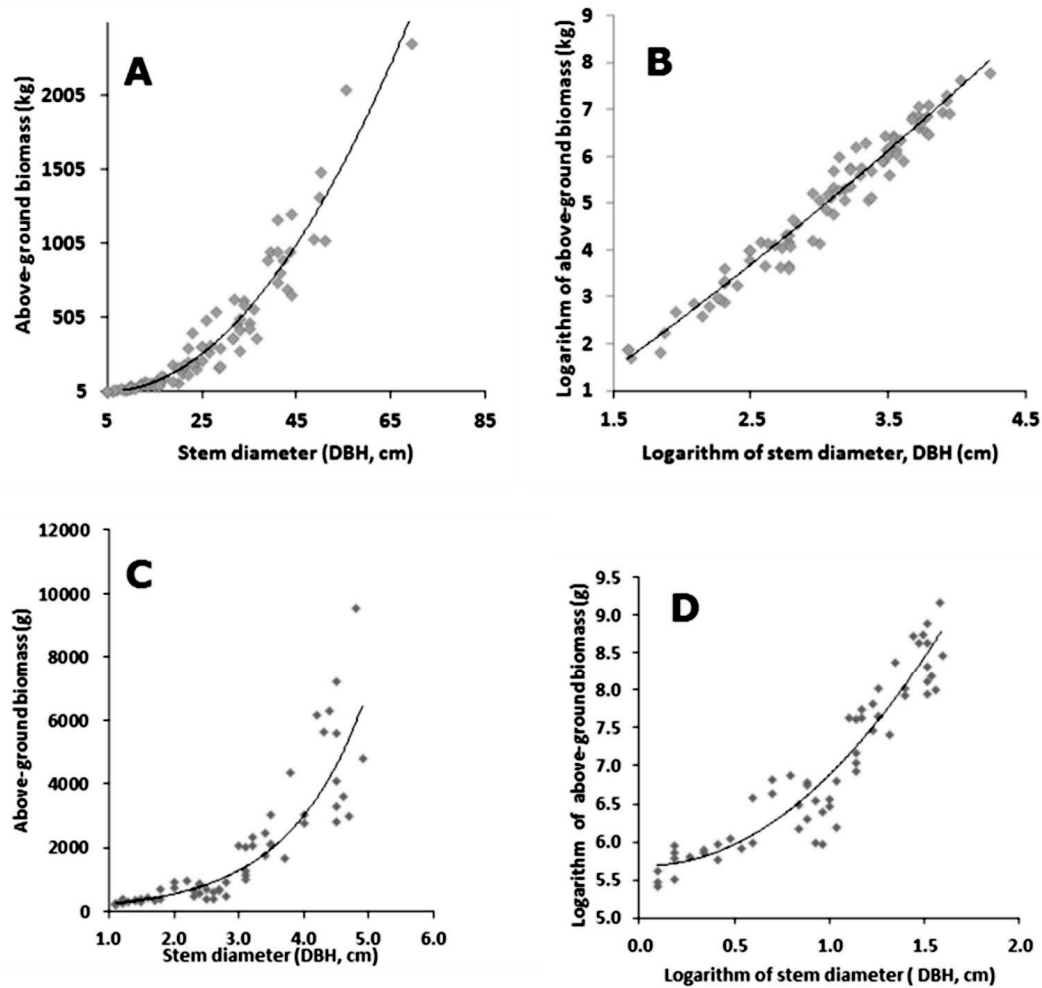

Figure 3.6 Regression plots and lines of best fit on above-ground biomass models data sets of: (A) large trees before log transformation; (B) large trees after log transformation; (C) small trees before log transformation; and (D) small trees after $\log$ transformation.

\subsubsection{Forest carbon assessment}

\subsubsection{Carbon fraction in wood, roots and leaves}

The twelve tree species assessed in the Zambezi teak forests had an average $\mathrm{C}$ fraction of $42 \%$ with the highest fraction recorded at the Kabompo site (Table 3.4). The $\mathrm{C}$ fraction was highest 
in Pteleopsis anisoptera (45\%) while Ficus sycomorus recorded the lowest C fraction (40\%) (Figure 3.7 and Table 3.4) for the carbon distribution per species per site). Wood (i.e. Stem and branches) stored the most $\mathrm{C}$ compared to leaves and roots (Figure 3.7). The ANOVA showed that wood $\mathrm{C}$ and leaf $\mathrm{C}$ strongly differed and this difference was significant at the Kabompo $(p=0.006)$ and Namwala $(p=0.022)$ sites, and insignificant at the Sesheke $(p=$ 0.644 ) site. The $\mathrm{C}$ fraction in wood differed significantly between Kabompo and Namwala ( $\mathrm{p}$ $=0.010$ ). We did not find any significant difference in $\mathrm{C}$ fractions of leaves among sites.

Roots had an average $\mathrm{C}$ fraction of $36 \%$ with the highest fraction recorded in Ficus syncomorous (37\%) (Figure 3.7A).
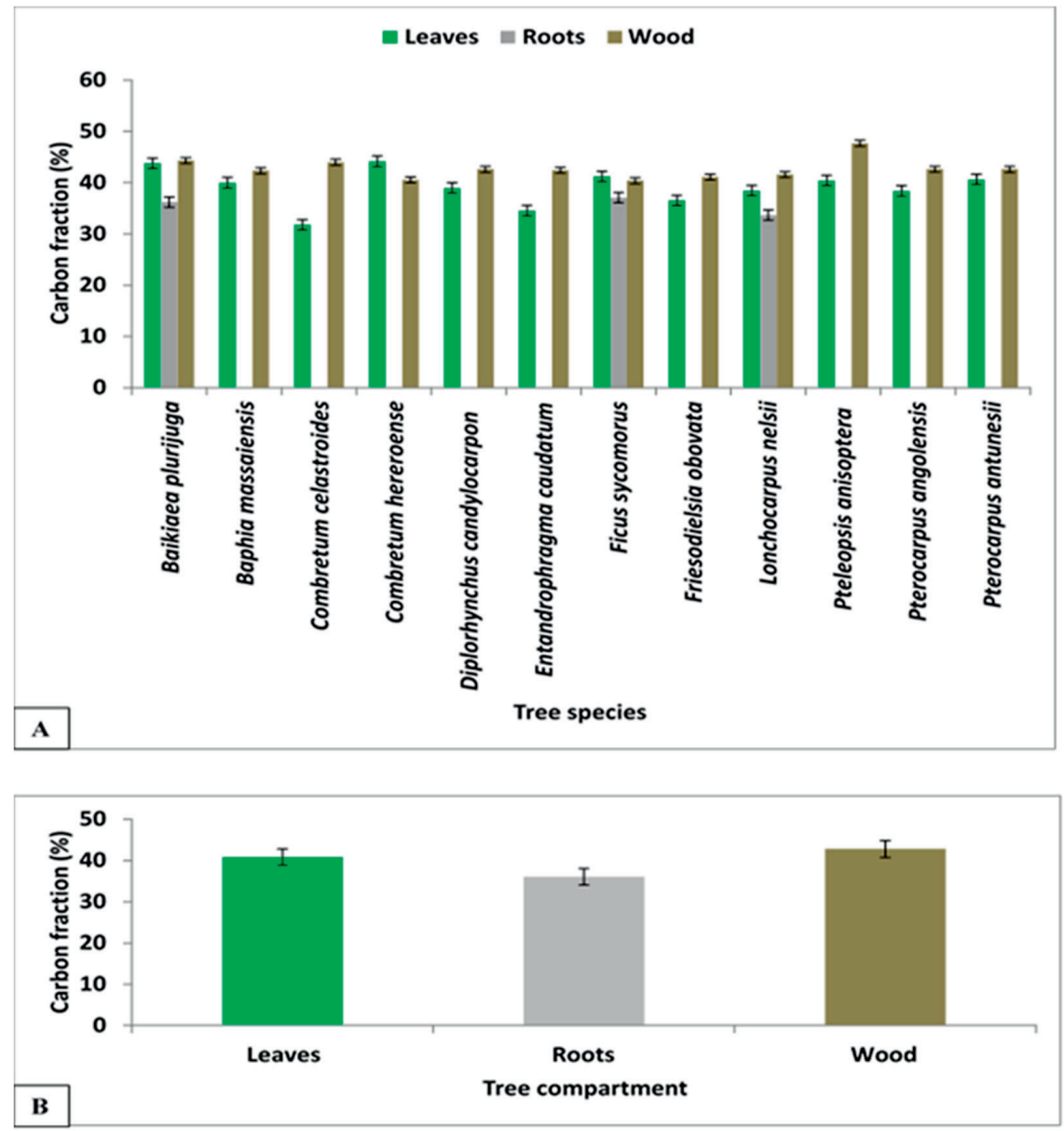

Figure 3.7 Carbon fraction as a percentage of total molecular weight of all elements in wood (i.e. stem and branches), leaves and roots. (A) presents the Carbon fraction per species per compartment and (B) summarizes the carbon fraction per compartment. 


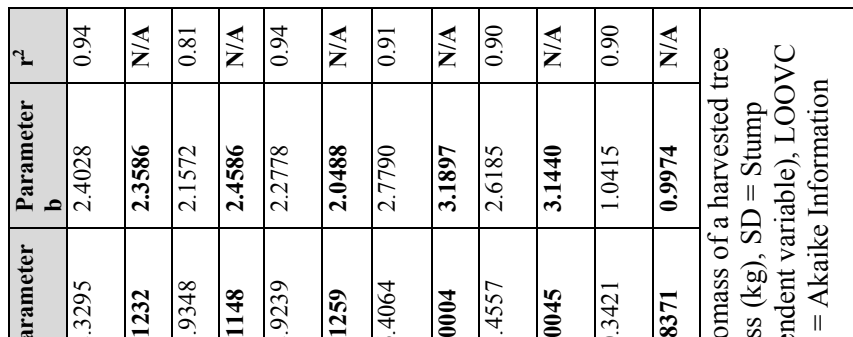

L...

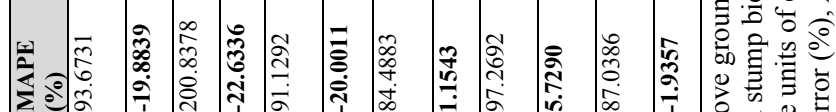

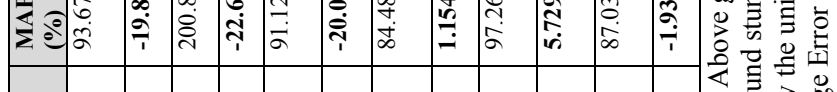

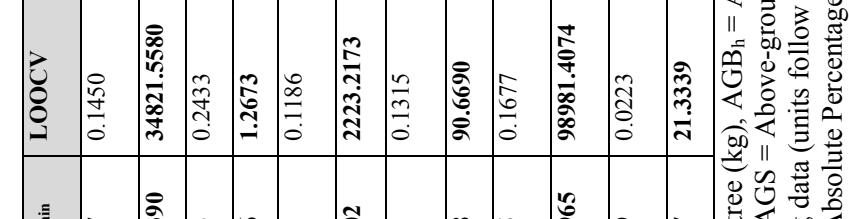

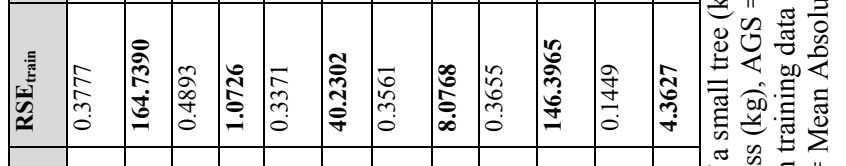

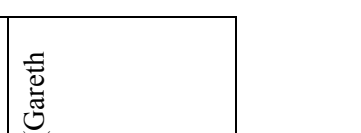

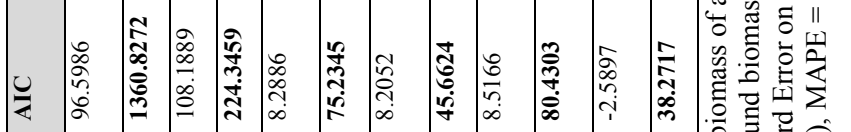

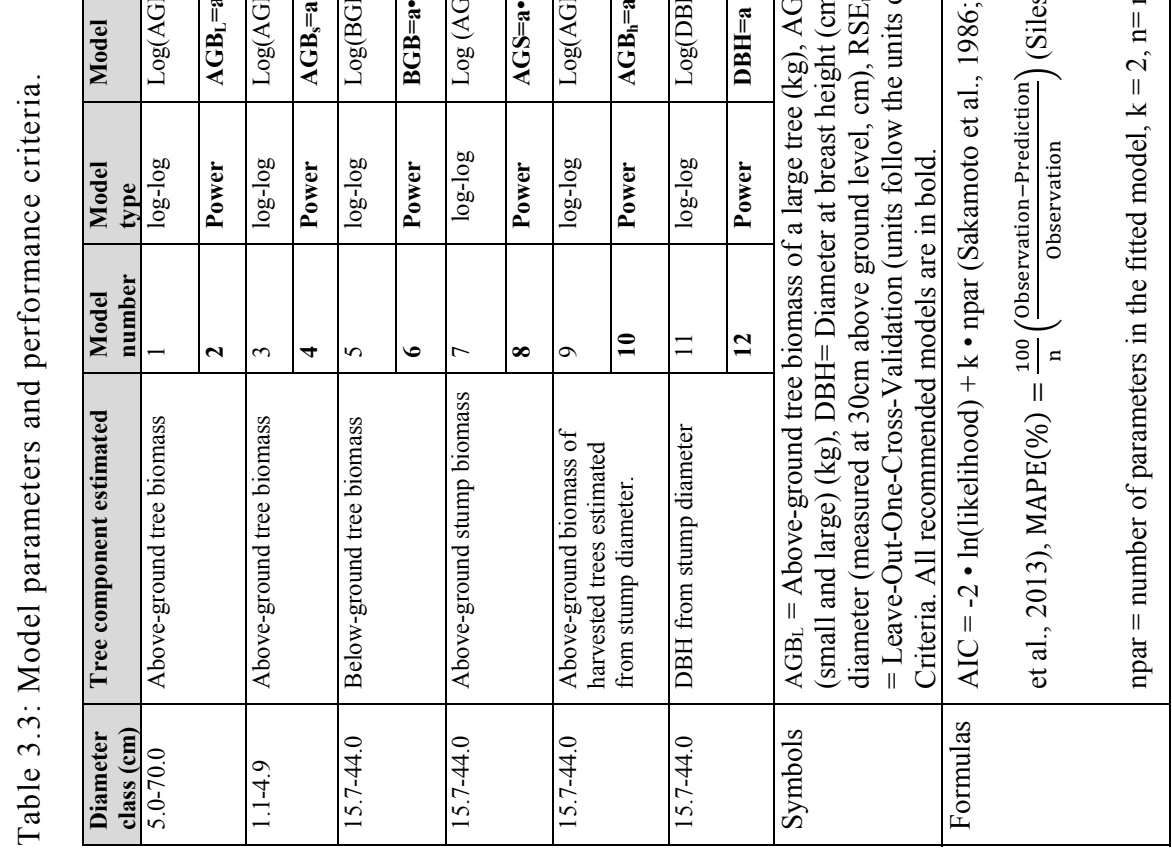


Table 3.4: Mean $\mathrm{C}$ fraction as a percentage of total molecular weight of all elements in tree biomass per site per species. Figures in brackets are the standard deviations.

\begin{tabular}{|l|l|l|l|}
\hline Species & Kabompo (\%) & Namwala(\%) & Sesheke (\%) \\
\hline Baikiaea plurijuga & $44.4(3.9)$ & $42.8(4.3)$ & $42.5(5.1)$ \\
\hline Baphia massaiensis & $43.4(3.4)$ & $35.4(4.5)$ & $43.3(2.3)$ \\
\hline Combretum celastroides & - & $41.5(7.8)$ & - \\
\hline Combretum hereroense & - & - & $42.6(4.3)$ \\
\hline Diplorhynchus candylocarpon & $43.6(1.2)$ & $38.5(5.5)$ & - \\
\hline Entandrophragma caudatum & - & - & $39.8(4.7)$ \\
\hline Ficus sycomorus & - & - & $39.7(3.0)$ \\
\hline Friesodielsia obovata & & $41.2(3.1)$ & $40.1(3.5)$ \\
\hline Lonchocarpus nelsii & - & - & $39.6(3.6)$ \\
\hline Pterocarpus angolensis & & $40.8(4.2)$ & - \\
\hline Pteleopsis anisoptera & $44.5(4.4)$ & - & - \\
\hline Pterocarpus antunesii & - & - & $41.6(2.7)$ \\
\hline Average & $44.0(3.2)$ & $40.5(4.9)$ & $41.3(4.0)$ \\
\hline
\end{tabular}

Biomass stock $\left(\mathrm{t} \mathrm{ha}^{-1}\right)$ was converted to $\mathrm{C}$ stock $\left(\mathrm{t} \mathrm{C} \mathrm{ha}^{-1}\right)$ by average site specific $\mathrm{C}$ factors of 43.98, 40.47 and $41.31 \%$ at the Kabompo, Namwala and Sesheke sites respectively. Kabompo had 36t C ha-1 compared to Namwala and the Sesheke sites, which had $25 \mathrm{t} \mathrm{C} \mathrm{ha}^{-1}$ and $15 \mathrm{t} \mathrm{C}$ ha $^{-1}$ respectively (Figure 3.8). We found the highest C stock in Baikiaea plurijuga at all sites (c.f. Table 6 in Ngoma et al. (2018b)).

\subsection{Discussion}

\subsubsection{Allometric models}

The power model in an arithmetic domain performed better than the log-log model for both large and small trees including stumps. However, the performance of these models could not easily be compared with similar models (Henry et al., 2011) due to the different indicators used to measure their performances. While we used MAPE (Sileshi, 2014), other researchers (Henry et al., 2011) used other indicators such as the Mean Square Error (Chave et al., 2005) and Root Mean Square Error (Jibrin and Abdulkadir, 2015). Although no standard performance criteria have been created to compare different models, some of our models' results were significantly better. For example, Model 2 performed best for above-ground biomass of large trees. The high influence of DBH on tree biomass that we found, is consistent with many other studies on tropical trees (Brown et al., 1989; Chidumayo, 1990; Deans et al., 1996; Brown, 1997; Chamshama et al., 2004; Chave et al., 2005; Basuki et al., 2009; Lima et al., 2012). 
Most studies (Henry et al., 2011) have reported coefficient of determination $\left(\mathrm{r}^{2}\right)$ values for non-linear models. This indicator can be used to measure the performance of linear models, but cannot be used in the same capacity for nonlinear models since the total sum of squares (TSS) is not equal to the summation of the regression sum-of squares (REGSS) and the residual sum-of-squares (RSS) (Spiess and Neumeyer, 2010). We therefore did not report $\mathrm{r}^{2}$ values for the non-linear power models in this study. Moreover, the $r^{2}$ - value increases when polynomial terms are added (Sileshi, 2014) and also when sample size is reduced. This makes $\mathrm{r}^{2}$ a weak indicator to use as a criteria in model selection. Although we used 12 species only to develop the models out of the 80 species we recorded during our vegetation assessments, we included the most common and dominant species in an effort to reduce bias. We developed below-ground biomass models using trees from the driest Sesheke site due to limited resources. Excavation of trees is extremely expensive and labour intensive. Moreover, roots of the studied trees grow very deep and wide (Högberg, 1984; Childes, 1988). For example, the lateral roots of the uprooted trees spread $28 \mathrm{~m}$ away from the taproot base. The taproots tapered to $5 \mathrm{~mm}$ diameter at about $6 \mathrm{~m}$ depth.

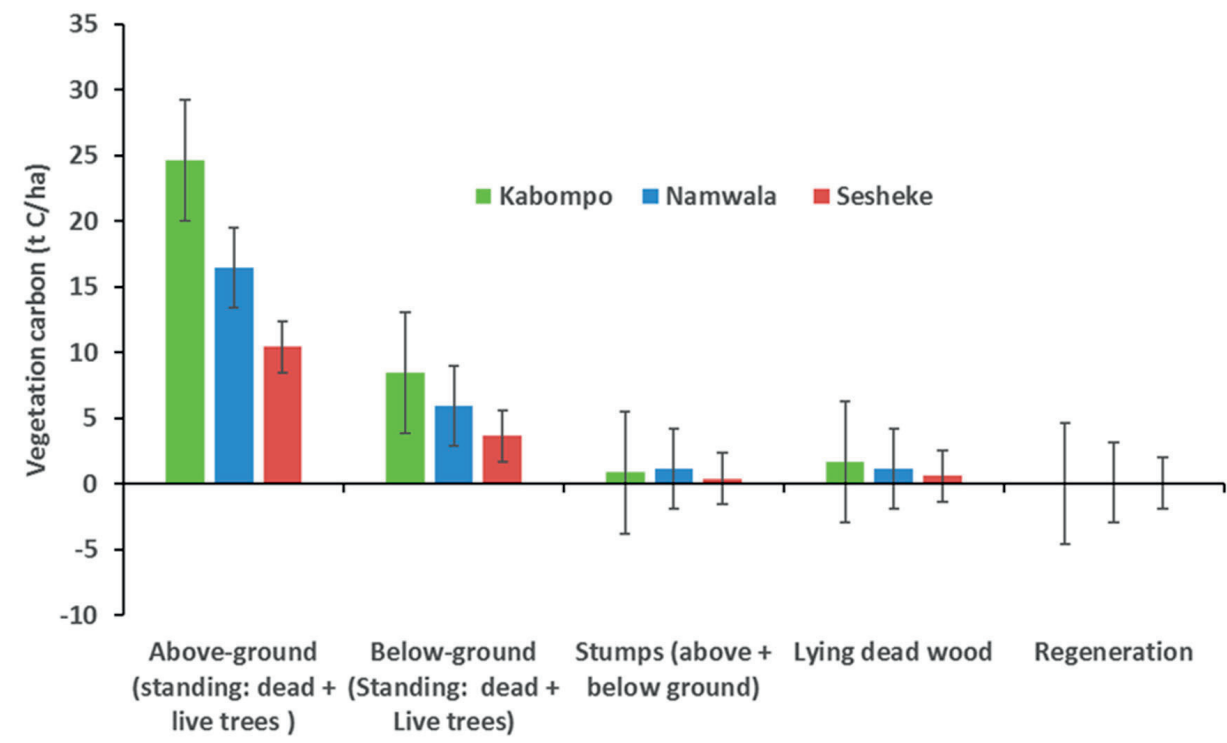

Figure 3.8 Carbon Stock distribution within and among sites.

Both above and below-ground samples were generated through destructive sampling (See Ngoma et al. (2018b)). These sampling processes introduce errors through the loss of wood and root material when cutting. However, measures were taken to reduce this error by using a chain saw with a narrow kerf size and correcting for width of the cut. 
The root-to-shoot ratio of 0.38:0.62 was in line with other dry tropical tree studies. For example, while Malimbwi et al. (1994) found a root-to-shoot ratio of 0.25:0.75, Castellanos et al. (1991) reported 0.42:0.58, Mugasha et al. (2013) 0.40:0.60 and Kraenzel et al. (2003) 0.16:0.84. Ryan et al. (2011) reported a root-to-shoot ratio of 0.42:0.58 for dry tropical forests. Differences in actual root-to-shoot ratios could be due to differences in the species studied, the sample size, the size of the trees sampled, sampling methods and the minimum diameter of the roots that were included in the ratio calculations. For example, Deans et al. (1996) included roots of $10 \mathrm{~mm}$ as a minimum diameter while Castellanos et al. (1991) included roots of $5 \mathrm{~mm}$ diameter. This study included roots of minimally $5 \mathrm{~mm}$ diameter. While we completely excavated all roots of the sampled trees, other researchers (e.g. Mugasha et al. (2013)) relied on sampling of the roots. The root-to-shoot ratio of our study decreased with increasing $\mathrm{DBH}(\mathrm{r}=-0.26)$. This means that, even though the ratio can be applied on smaller trees, some bias in the results of the small trees will occur.

The developed stump models require that stump diameter is measured at a height of $30 \mathrm{~cm}$ above-ground level or below. For stumps with sprouts, only biomass of stumps is estimated by these models. This indicates that stump biomass is under-estimated by these models. Stump models also facilitate biomass estimates of trees that have been removed through timber extraction. This is often not done because appropriate models are unavailable. We carefully measured a stump height of $30 \mathrm{~cm}$ and this increased the reliability of our models.

\subsubsection{Carbon fraction in wood, leaves and roots}

The $\mathrm{C}$ fraction is a function of different factors including species, tree age, climate, soil conditions and chemical composition (Elias and Potvin, 2003; Bert and Danjon, 2006; Koss et al., 2007). High lignin content in wood, for example, increases the $\mathrm{C}$ fraction (Bert and Danjon, 2006). We found higher $C$ fraction in wood than in leaves. This was also reported by other studies (Table 3.5). For example, Kraenzel et al. (2003) found a C fraction of 50\% in wood and $47 \%$ in leaves. The C fraction was highest in Pteleopsis anisoptera and lowest in Lonchocarpus nelsii. Following the rainfall gradient, the $\mathrm{C}$ fraction increased with increasing rainfall (Figure 3.9). This was most evident in Baikiaea plurijuga and Baphia massaiensis, which were both found in all the three sites. The C fraction in Baikiaea plurijuga was $4 \%$ higher at the wetter Kabompo site than at the drier Sesheke site The $\mathrm{C}$ fraction at the Kabompo and Sesheke sites shows a clear difference in $\mathrm{C}$ storage potential of trees with changes in rainfall (Figure 3.9). Our results show the lowest $\mathrm{C}$ fraction at the Namwala site. The Namwala's Ila forest reserve stretches both in the dry and wetter 
zones. Here, trees are likely affected more by the local drier conditions than the wetter conditions. Comparing the reported annual rainfall and $\mathrm{C}$ fraction figures, trees at the Namwala site do not seem to store as much C. The Choma meteorological station probably reported rainfall values that do not represent the actual amount of rainfall received by the Ila forest reserve due to the $200 \mathrm{~km}$ distance between the meteorological station and the forest reserve.

The reported $\mathrm{C}$ fractions were within the values reported by other studies on tropical trees (Table 3.5). The variability in actual numbers (See Table 3.5) are probably due to differences in species, sample size, sampling strategy (e.g. heartwood, sapwood, small trees and large trees), variability in environmental conditions and laboratory methodologies (Table 3.5).

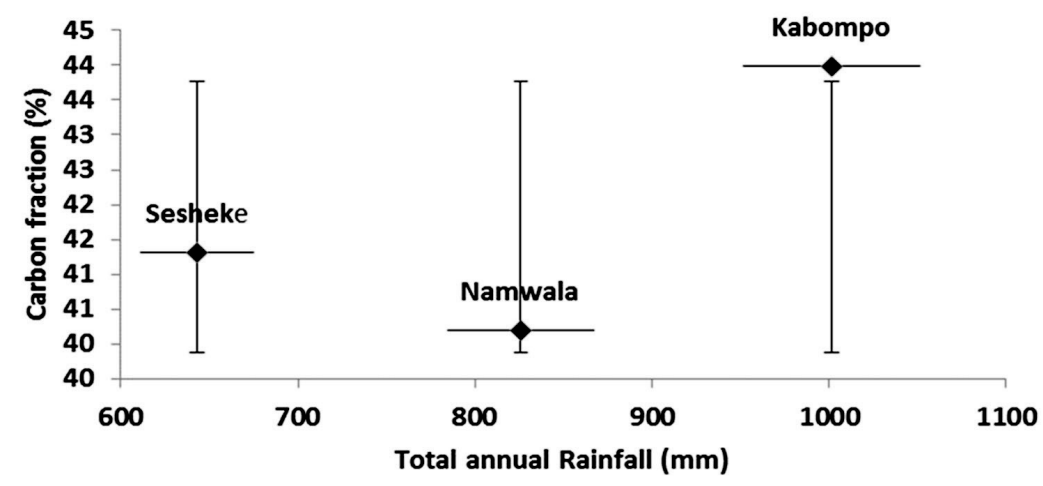

Figure 3.9 Inter-site carbon fraction as a percentage of total molecular weight of elements in tree biomass in relation to rainfall.

\subsubsection{Biomass and carbon stock}

Above-ground biomass was highest at Kabompo, despite having lost $5 \mathrm{t} \mathrm{ha}^{-1}$ of wood from logging activities. Increased biomass at Kabompo is due to high tree density. This increased tree density probably resulted from higher regeneration after the logging activities and then further stimulated by the higher rainfall.

A total of $7 \mathrm{t} \mathrm{ha}^{-1}$ was lost at Namwala from logging activities, but its biomass stock was still higher than at Sesheke that lost only $2 \mathrm{tha}^{-1}$ from logging. The higher rainfall at Namwala as compared to Sesheke, increased tree basal area and tree density. The lower biomass at Sesheke correlated well with low rainfall, tree density and low tree basal area. 
Table 3.5: Carbon fraction as a percentage of total molecular weight of all elements in various tree components of tropical trees for this and other studies.

\begin{tabular}{|c|c|c|c|c|}
\hline Study & $\begin{array}{l}\text { Stem or } \\
\text { trunk wood } \\
(\%)\end{array}$ & $\begin{array}{l}\text { Leaf } \\
(\%)\end{array}$ & $\begin{array}{l}\text { Wood } \\
\text { roots } \\
(\%)\end{array}$ & Laboratory method and equipment used \\
\hline This study & $34-53$ & $31-51$ & $34-40$ & $\begin{array}{l}\text { Gas chromatography on a CHN-0 Elemental } \\
\text { analyser, EA1108 (Fisons instruments). }\end{array}$ \\
\hline IPCC (2006) & $46-49$ & $43-47$ & & Various methods \\
\hline Kraenzel et al. (2003) & $47-51$ & $46-48$ & $45-49$ & $\begin{array}{l}\text { Gas chromatography on a CHN Elemental } \\
\text { analyser, EA1108 (Fisons instruments) }\end{array}$ \\
\hline Arias et al. (2011) & $47-50$ & $41-50$ & & Carlo Erba Analyser 1500 \\
\hline Negi (2003) & $41-46$ & $26-44$ & & $\begin{array}{l}\text { Ash content method and by regression } \\
\text { equation derived between carbon and } \\
\text { Calcium content }(\%) \text {. }\end{array}$ \\
\hline Hughes et al. (2000) & $45-49$ & $43-47$ & & $\begin{array}{l}\text { Induction- furnace method using a Carlo- } \\
\text { Erba NA Series } 1500 \text { CNS analyzer (Fisons } \\
\text { Instruments, Danvers, Massa- chusetts, USA }\end{array}$ \\
\hline Bert and Danjon (2006) & $52-54$ & & $51-52$ & $\begin{array}{l}\text { Dumas method with a Leco CN2000 } \\
\text { analyser }\end{array}$ \\
\hline $\begin{array}{l}\text { Thomas and Martin } \\
\text { (2012) }\end{array}$ & $47-49$ & & & Literature review \\
\hline Becker et al. (2012) & $47-50$ & & & Elementary-analyzer, Elementar Vario EL \\
\hline Elias and Potvin (2003) & $42-51$ & & & $\begin{array}{l}\text { Automated elemental analyzer (model EA } \\
1108, \text { FISONS Instruments, Milan, Italy). }\end{array}$ \\
\hline $\begin{array}{l}\text { Martin and Thomas } \\
\text { (2011) }\end{array}$ & $45-50$ & & & $\begin{array}{l}\text { ECS } 4010 \text { CN analyzer (Costech Analytical } \\
\text { Technologies Inc., Valencia, CA, USA) }\end{array}$ \\
\hline Chambers et al. (2001) & 49 & & & Fisons $\mathrm{C} / \mathrm{N}$ auto-analyzer \\
\hline Rana et al. (2010) & $47-48$ & & & CNS analyser (Vario L, Hanau, Germany). \\
\hline
\end{tabular}

The above-ground biomass stock values reported in this study are generally within the range reported by other studies on tropical dry forests (Table 3.6). Conversion of total biomass stock $\left(\mathrm{t} \mathrm{ha}^{-1}\right)$ to total $\mathrm{C}$ stock $(\mathrm{t} \mathrm{C} \mathrm{ha-1})$ led to the highest $\mathrm{C}$ stock at the Kabompo site compared to the Namwala and Sesheke sites. The total $\mathrm{C}$ stock per hectare is a function of total biomass per hectare and the average $\mathrm{C}$ fraction. Both biomass stock and average $\mathrm{C}$ fraction were highest at the Kabompo site. This explained in the highest $\mathrm{C}$ stock. Though the $\mathrm{C}$ fraction was lowest at the Namwala site, its C stock was higher than at the Sesheke site. This high Namwala C stock was explained by its high biomass stock, which is likely a consequence of increased tree density more than high basal area. In general, Baikiaea plurijuga had the highest $\mathrm{C}$ stock. This most abundant tree species represents a quarter of all surveyed trees of the 80 species. Comparably, carbon stock values reported in this study are within the range of values reported for Zambian forests (Kamelarczyk, 2009).

So far, we have done a one-time forest assessment which could define a baseline. To obtain trends in $\mathrm{C}$ storage potential of these forests, such assessments should be carried out 
repeatedly (e.g. after every ten years). The Zambian Forestry Department should stimulate such developing monitoring program and should work with local communities to better manage these forests and their reserves.

Table 3.6: Above-ground biomass stock in tropical dry forests. Dry forests receive less than $1000 \mathrm{~mm}$ rainfall annually (IPCC, 1996).

\begin{tabular}{|l|l|l|l|}
\hline Study & $\begin{array}{l}\text { Above-ground biomass } \\
\text { stock (t ha-1) }\end{array}$ & DBH range (cm) & Place of study \\
\hline This study & $25-56$ & $\geq 1 \mathrm{~cm}$ & Zambia \\
\hline Kamelarczyk (2009) & $32-51$ & $\geq 7 \mathrm{~cm}$ & Zambia \\
\hline Chidumayo (1993) & $49-91$ & $\geq 1 \mathrm{~cm}$ & Zambia \\
\hline Chidumayo (1990) & $78-107$ & $>5 \mathrm{~cm}$ & Zambia \\
\hline Chamshama et al. (2004) & $23-44$ & $\geq 5 \mathrm{~cm}$ & Tanzania \\
\hline Shirima et al. (2011) & $19-27$ & $\geq 10 \mathrm{~cm}$ & Tanzania \\
\hline Brown (1997) & $20-175$ & $\geq 10 \mathrm{~cm}$ & Africa \\
\hline Brown (1997) & $16-70$ & $\geq 10 \mathrm{~cm}$ & Asia \\
\hline
\end{tabular}

\subsection{Conclusions}

The power-law models in arithmetic domain performed better that the log-log models for large and small trees including stumps. DBH was the most important factor in developing both below and above-ground biomass models, thereby reducing the need to measure other parameters, such as total tree heights, in forest inventories. Stump biomass models helped to capture biomass in stumps and thereby improved the total forest biomass estimates.

Generally, mature trees in the Zambezi teak forests have more $\mathrm{C}$ stock above-ground than below-ground. We recorded the highest $\mathrm{C}$ stock at the Kabompo site followed by the Namwala and Sesheke sites respectively. However, more C stock was lost due to logging at the Namwala site than at the Kabompo and Sesheke sites. The $\mathrm{C}$ fraction was highest at the Kabompo site, closely followed by the Sesheke site and lowest at the Namwala site.

Pteleopsis anisoptera had the highest $\mathrm{C}$ fraction whilst Lonchocarpus nelsii had the lowest C fraction. This indicates differences in $\mathrm{C}$ storage potential of trees of dry tropical forests. Of the 80 species surveyed, the dominant Baikiaea plurijuga had the highest $\mathrm{C}$ stock. However, both $\mathrm{C}$ fraction and $\mathrm{C}$ stock increased with increasing rainfall. This study therefore suggests that a rainfall decrease for southern Africa, as projected by Niang et al. (2014) for future climate change could negatively affect carbon stock of the Zambezi teak forests through its effects on forest productivity. These negative effects, coupled with forest degradation and deforestation ((Musgrave, 2016), also as observed in our sites), will likely reduce the $\mathrm{C}$ 
stocks. The reduced carbon stock will negatively affect the $\mathrm{C}$ storage potential of the studied Zambezi teak forests resulting in decreased mitigating role in climate change. 


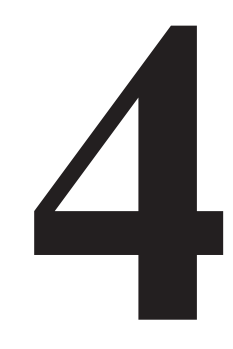

\section{FORESTS' RESPONSE TO CLIMATE CHANGE-A REVIEW OF NET PRIMARY PRODUCTIVITY IN AFRICA}

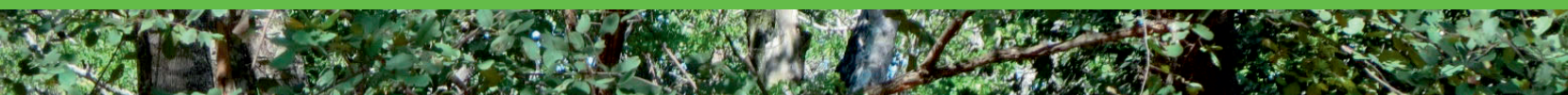

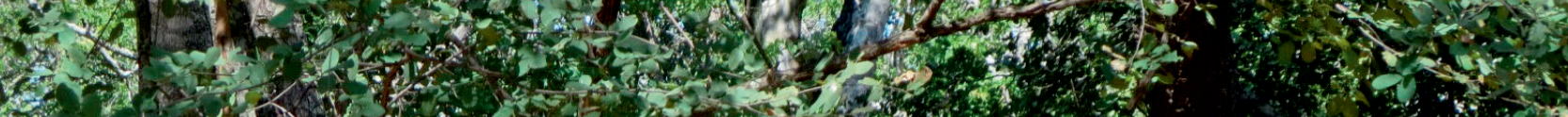
(1)

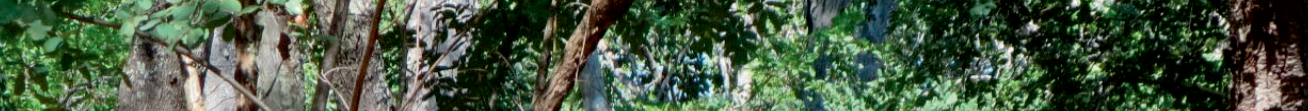

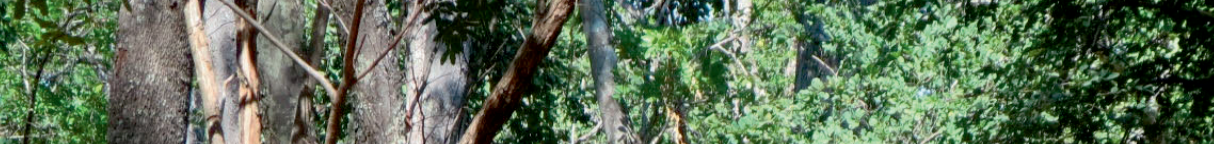
4.

.

entoris
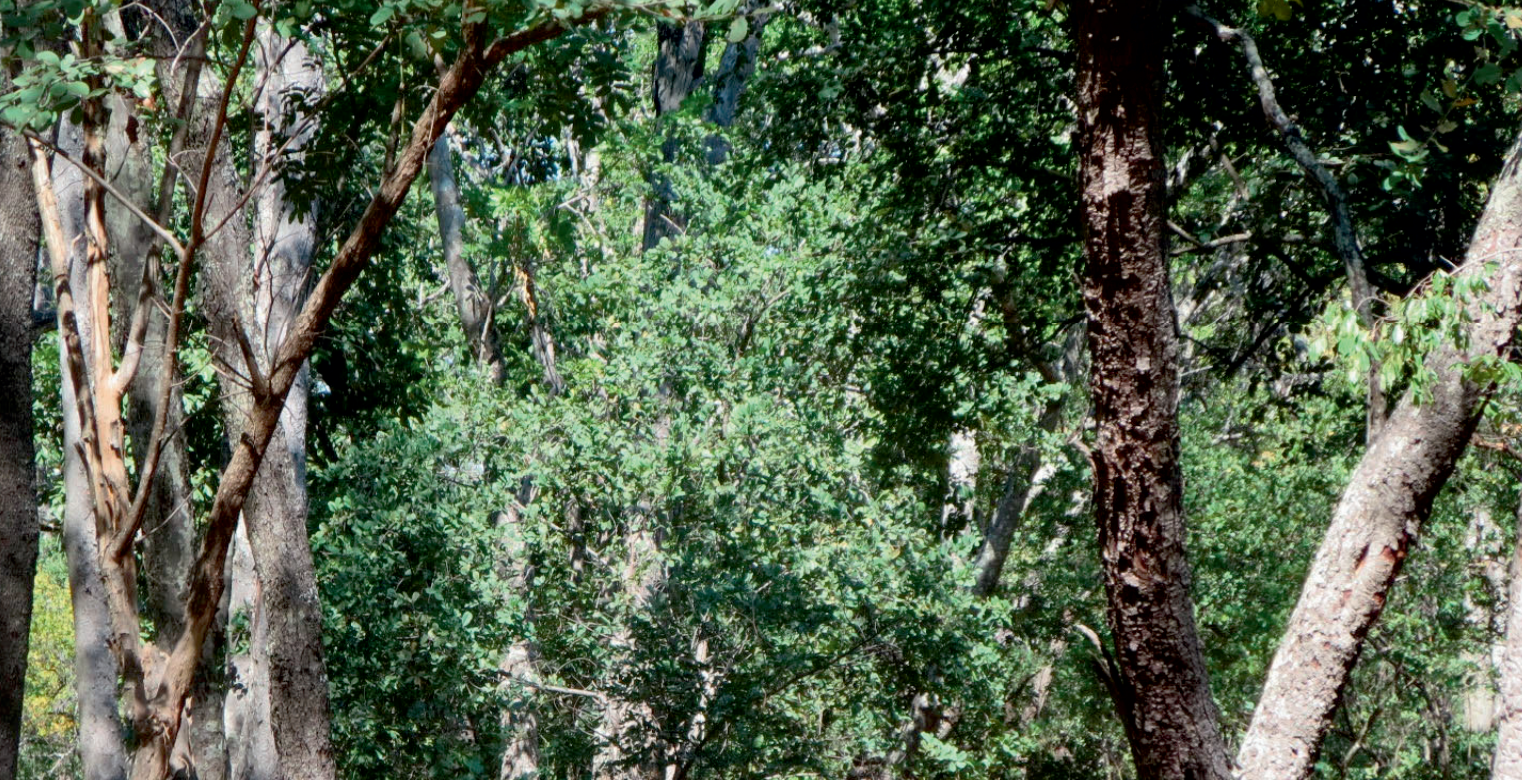

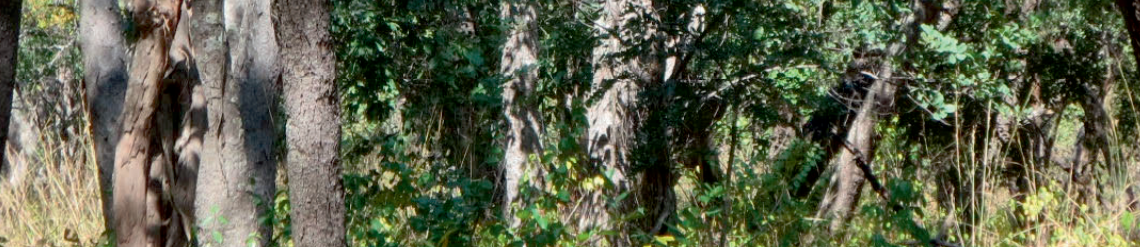

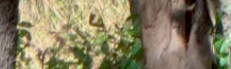
V.

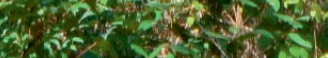

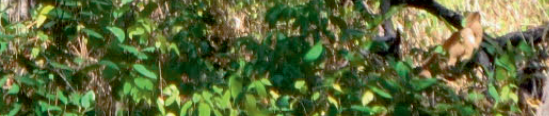

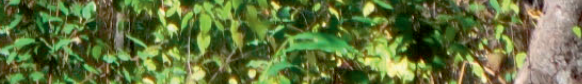

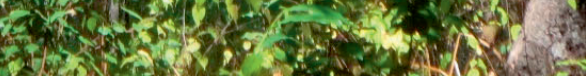
we

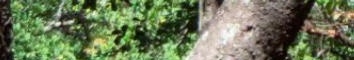

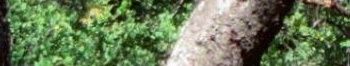

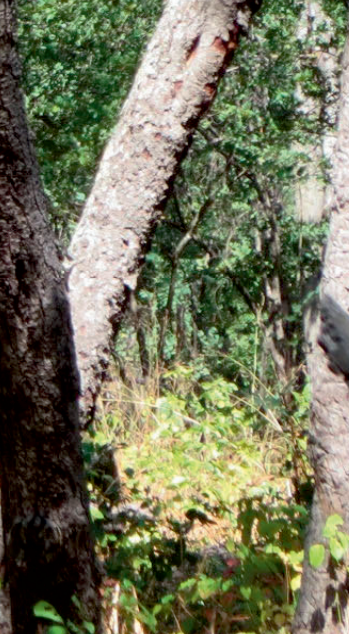

a 


\section{Abstract}

Africa holds about $17 \%$ of the world's total forests. More than half of African forests are found in Central Africa and are dominantly tropical rain forests. Forests are important for local people economically, socially and ecologically as carbon sinks. Unfortunately, these forests are vulnerable to climate change, which likely has substantial effects on forests' growth and peoples' livelihoods. We reviewed the literature (1) to assess the contemporary response of tree species in Africa to climate from dendrochronological studies and (2) to determine contemporary and projected climate change effects on African forest's biomes from modelling studies. We analysed a total of 19 tree-ring and 6 modelling studies in our review. We found that rainfall increase positively affected forest's productivity and temperature increase had negative effects on forest productivity. Both dendrochronological and modelling studies showed that by the year 2000, the productivity of the savanna woodlands increased. The modelling studies showed that the combined NPP of all biomes in Africa will reduce by $8 \%$ by the end of the $21^{\text {st }}$ century from 1950 . This review showed that trees growing in low rainfall receiving areas respond more strongly to changes in rainfall than those growing in high rainfall receiving regions, and that changes in temperature have more effects on tree's productivity in hotter regions than in colder areas.

Unpublished. This manuscript was submitted to Global Change Biology but it was rejected. We are currently preparing it to submit to another journal.

Ngoma J, Moors E, Speer JH, Kruijt B, Vinya R, Leemans R. 2019. Forest response to climate change - A review of net primary productivity in Africa. 


\subsection{Introduction}

The world is estimated to have 3.0 trillion trees of which almost half are found in tropical and subtropical forests, a quarter in boreal forests, and another quarter in temperate forests (Crowther et al., 2015). In total, African forests extend to 650 million hectares (FAO, 2001b). This is one sixth of the world's total forest extent. More than half of these forests are tropical rain forests in central Africa, while the African deserts' trees' extent is small (FAO, 2001b). Cao et al. (2001) showed that Africa holds a total carbon stock of $275 \mathrm{Gt}$ C, of which two thirds is in soils. African forests are important to the local people as they provide many ecosystem services (Chidumayo and Gumbo, 2010) ranging from economic (Musokotwane, 1986; Peele, 1986; Piearce, 1986a), food, medicine, energy and building material (FAO, 2007; Kwashirai, 2007; Chidumayo and Gumbo, 2010). The forests also provide employment to many local people (Piearce, 1986a). These forests enhance soil fertility (Kwashirai, 2007), protect the catchment areas, and incorporate biological diversity (Mubita, 1986; FAO, 2007). The forests are also important for their scientific, educational, and aesthetic values (Piearce, 1986a). Just like other forests in the world (Ciais et al., 1995), African forests play a significant role in removing atmospheric $\mathrm{CO}_{2}$. However, despite the forests being so important, they are currently threatened by climate change. Climate change is accelerating substantially due to anthropogenic activities. For example, annual rainfall decreased over the past century in the western and eastern Sahel and in eastern and southern Africa (Niang et al., 2014). Though not uniform, rainfall is projected to change in various parts of Africa with increased amounts over central and eastern Africa, and will decrease in northern and southern Africa (Niang et al., 2014). Temperature has already increased in the past decades. For example, west Africa and the Sahel region recorded a temperature increase of between $0.5^{\circ} \mathrm{C}$ and $0.8^{\circ} \mathrm{C}$ between 1970 and 2010 (Niang et al., 2014). Such changes had significant effects on forestry resources. Unfortunately only few studies (Cao et al., 2001; Weber et al., 2009; Pan et al., 2015) have contributed to understanding how African forests respond to climate change. This limit in studies possess a challenge in understanding how the projected climate change likely affects these forests across this continent. We review the potential effects of changes in climate on forests productivity across Africa. The main objectives are (1) to assess the contemporary response of tree species in Africa to climate from dendrochronological studies and (2) to determine contemporary and projected climate change effects on African forest biomes from modelling studies. Though our discussion focusses on climate change 
effects, results of effects of other factors (e.g. $\mathrm{CO}_{2}$ concentration) were also presented due to difficulties in separating the effects of different factors in the reviewed papers.

\subsection{Selection of literature}

In this paper, we followed FAO (2000) for the definition of a forest as 'land with tree crown cover (or equivalent stocking level) of more than ten percent and area of more than 0.5 hectares (ha)'. Thus, following this definition of the forest (FAO, 2000), deserts were excluded from the focus of our study. We reviewed both old and recent literature on climate change and on how changes in climate are affecting forests' productivity in Africa. Literature was searched from online accessible databases (Web of Science, Scopus, Google Scholar, and Global Search). Only articles published in English were reviewed. The search terms included: "tropical forests", "forests and climate change in Africa", "climate change effects on tropical forests", "sensitivity of tropical forests to climate change", "forests' productivity", "vegetation response to climate change", "Africa's vegetation", "tree-ring analysis", "dendrochronology in Africa", "dendrochronology in the tropical forests", and "dynamic global vegetation model (DGVM)". References in the selected papers were also checked to locate other papers that were not accessible from these international databases. From each selected and reviewed dendrochronological paper, we searched for correlation values between tree-ring indices and climatic variables (especially temperature and rainfall). We also digitised tree-ring indices from these dendrochronological papers using the 'Get Data' software. In total, we analysed tree-ring results from 19 studies . Modelling studies provided data on changes in NPP caused by changes in climatic variables, and a total of 6 studies were analysed. In the modelling studies, we focused on studies that were conducted in Africa only as these studies provided results in a form that we could isolate NPP values and re-analysed (e.g. tables) compared to global modelling studies that mainly reported NPP values in forms that could not easily be isolated and re-analysed such as maps.

\subsection{Data analysis}

We initially averaged the tree-ring indices per biome for the respective periods covered by the chronologies from the reviewed studies to get the average tree ring chronology for each biome. Biome classifications were as described in the reviewed articles. We then averaged the tree ring indices of each biome to get the continental tree ring chronology. We fitted a least square linear regression in R-environment (R Core Team, 2017) to determine trends in treering indices. 
Changes in NPP and biome classifications were extracted as presented in the reviewed articles. We determined the changes in NPP per biome by averaging the reported NPP changes of the respective biomes from the individual studies. These average figures per biome were aggregated to get an NPP change per continent. All analyses were conducted in Renvironment (R Core Team, 2017).

In this study, we used NPP and annual growth rings as measures of tree growth. Thus, annual tree growths were respectively taken as the amounts of NPP and the widths of the growthrings produced per year. Though unstandardized growth rings can be used to measure tree growth, we used standardised growth rings (also called indices) in our study. Standardised growth rings have the effects of their age removed, enabling their comparability among sites (Fritts, 1976; Speer, 2010). In literature, these tree-ring indices were related to temperature and rainfall in their respective study sites, and this enabled us to deduce the effects of contemporary climate on tree growth.

\subsection{Climate change in Africa}

Rainfall distribution in Africa is not uniform (UNEP/FAO, 1984) and is also varying between years (Hulme et al., 2001). Winter rainfall decreased in the northern regions of north Africa, and dry days per year increased during 1997-2008. There is also an increase in autumn rainfall in some parts of northern Algeria and Morocco. Small seasonal rainfall was observed in the Sahara desert, and over the $20^{\text {th }}$ century, rainfall reduced in the Sahel region with a large number of droughts in the 1970s and 1980s (Niang et al., 2014).

Rainfall reduced in east Africa in the previous three decades, between March and May/June wet season (Niang et al., 2014). Precipitation declined over much of the Great Horn of Africa during the last half century due to the shifting sea-level pressure gradient between Sudan, the southern coast of the Mediterranean sea and the southern tropical Indian Ocean region (Williams et al., 2012; Niang et al., 2014). In southern Africa, rainfall has reduced (Hoerling et al., 2006; New et al., 2006; Niang et al., 2014) and dry spells have increased (New et al., 2006) due to increased sea-surface temperatures in the tropical Indian Ocean (Niang et al., 2014). Following climate projections, total annual rainfall will decrease in northern and 
southern Africa, and increase in central and east Africa by the end of the $21^{\text {st }}$ century under RCP4.5 and RCP8.5 (See Figure 4.1).
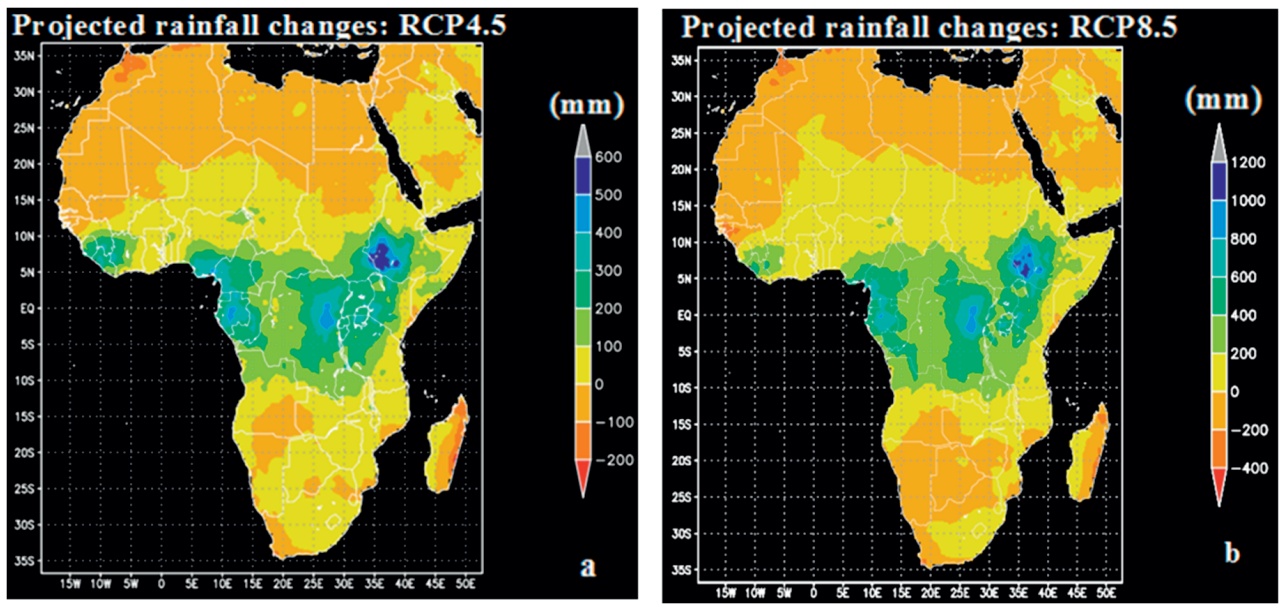

Figure 4.1 Projected rainfall changes under RCP4.5 (a) and RCP8.5 (b). Changes were projected for the period 2070-2099 with reference to 1970-1999 as baseline. Data were taken from Coupled Model Inter-comparison Project Phase 5 (CMIP5): Centre National de Recherches Météorologiques Circulation Model version 5 (CNRM-CM5.1) (Voldoire et al., 2013), European Centre Earth model (EC-Earth) (Hazeleger et al., 2011), Hadley Global Environment Model 2 Earth System (HADGEM2-ES) (Collins et al., 2011), Institute Pierre Simon Laplace Circulation Model 5A running on low resolution grid (IPSL-CM5A-LR) (Dufresne et al., 2013), and Max-Planck-Institut für Meteorologie Earth System Models Running on low resolution grid (MPI-ESM-LR) (Jungclaus et al., 2013; Giorgetta et al., 2016).

Temperature distribution in Africa differs (Weedon et al., 2014) and has been demonstrated to change at different scales. However, anthropogenic effects have increased and are projected to cause additional substantial changes around the world. During the past half century, temperature increased by $0.5^{\circ} \mathrm{C}$ in Africa. Minimum temperatures increased more than maximum temperatures. Between 1970 and 2010, temperature increased by between $0.5^{\circ} \mathrm{C}$ and $0.8^{\circ} \mathrm{C}$ in west Africa and the Sahel region. The number of cold days reduced and the number of warm days and nights increased between 1961 and 2000. Eastern, southern and northern Africa's temperatures have also increased during the past decades (Niang et al., 2014). 

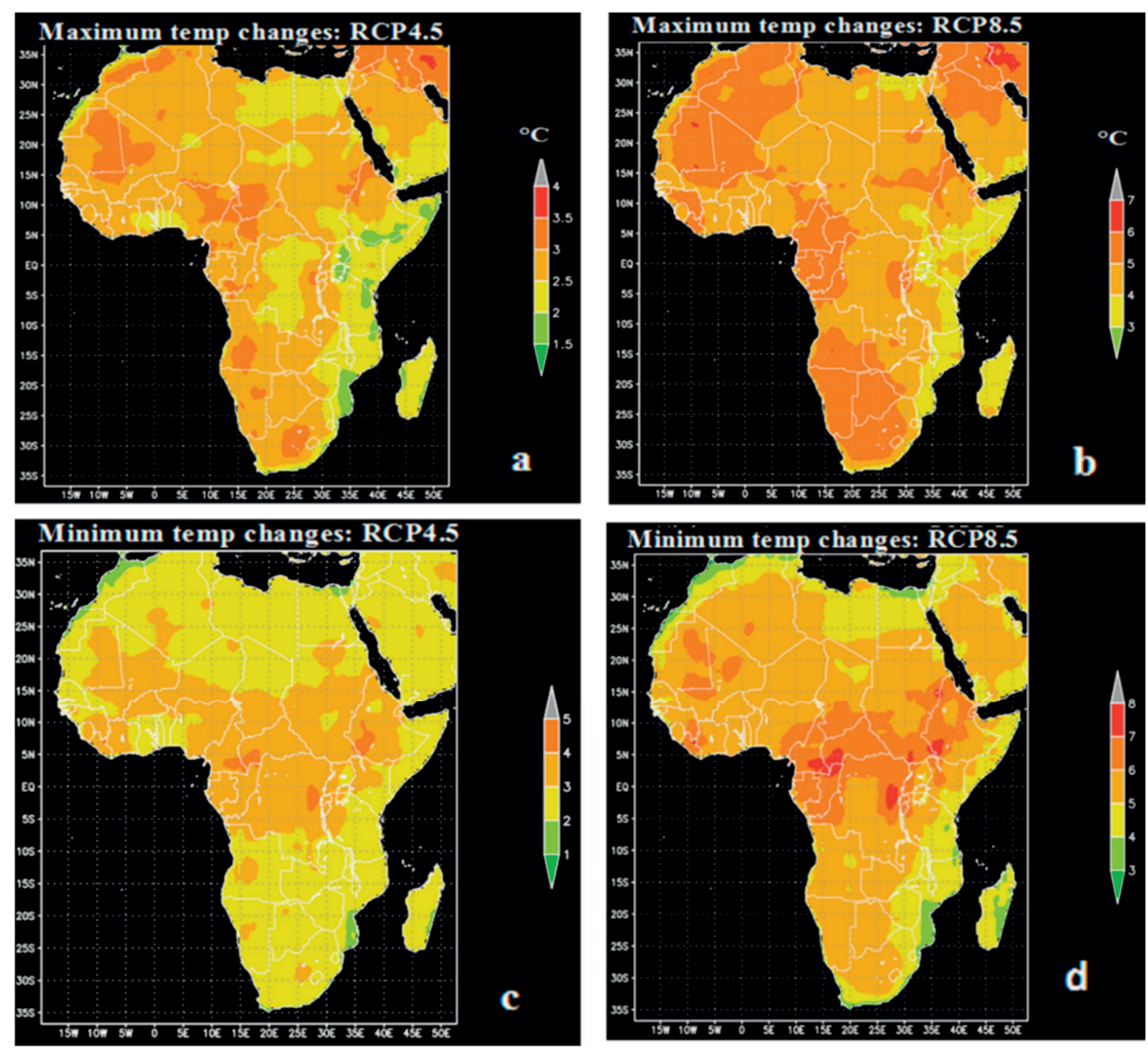

Figure 4.2 Projected maximum ( $\mathrm{a}$ and $\mathrm{b}$ ) and minimum ( $\mathrm{c}$ and $\mathrm{d}$ ) temperature changes under RCP4.5 (a and c) and RCP8.5 (b and d). Changes were projected for the period 2070-2099 with reference to 1970-1999 as baseline. Data are from CMIP5: Centre National de Recherches Météorologiques Circulation Model version 5 (CNRMCM5.1) (Voldoire et al., 2013), European Centre Earth model (EC-Earth) (Hazeleger et al., 2011), Hadley Global Environment Model 2 Earth System (HADGEM2-ES) (Collins et al., 2011), Institute Pierre Simon Laplace Circulation Model 5A running on low resolution grid (IPSL-CM5A-LR) (Dufresne et al., 2013), and Max-Planck-Institut für Meteorologie Earth System Models Running on low resolution grid (MPI-ESM-LR) (Jungclaus et al., 2013; Giorgetta et al., 2016). 
Future temperature increase for Africa is projected to be more than the projected increase in global mean temperature (Christensen, 2007). Temperatures are projected to increase by between $1^{\circ} \mathrm{C}$ and $5^{\circ} \mathrm{C}$ under RCP4.5, and by between $3^{\circ} \mathrm{C}$ and $8^{\circ} \mathrm{C}$ under RCP8.5. The minimum temperatures are projected to increase more than the maximum temperatures by the end of the $21^{\text {st }}$ century (Figure 4.2 ).

\subsection{Participating vegetation models}

The NPP review results were generated by nine vegetation models. All these models describe the interaction between the atmosphere and biosphere. Their differences lie in the way the different processes are parameterised to generate NPP (See Table 4.1). The models taken into account were the CEVSA (Cao and Woodward, 1998b), DLEM (Tian et al., 2010), IBIS (Foley et al., 1996), JULES (Best et al., 2011; Clark et al., 2011), LPJ (Sitch et al., 2003), LPJ GUESS (Smith et al., 2001), ORCHIDEE (Krinner et al., 2005), SiB3 (Sellers et al., 1986) and the FORMIX3 (Huth et al., 1997; Huth and Ditzer, 2000) (See Table 4.1 for details including model full names).

\subsection{Distribution of African biomes and NPP}

Forests' distribution follows climatic patterns (Fayolle et al., 2012). While evergreen broadleaf forests are found in the wettest regions, the deserts are found in driest areas (White, 1983; FAO, 2001a; Thomas and Baltzer, 2002) (See Figure 4.3). Evergreen broadleaf forests are the most productive $\left(1164 \mathrm{~g} \mathrm{C} \mathrm{m}^{-2}\right.$ year $^{-1}$ ) compared to other forest types (See Figure 4.4 and Supplementary information Table S4.I). 


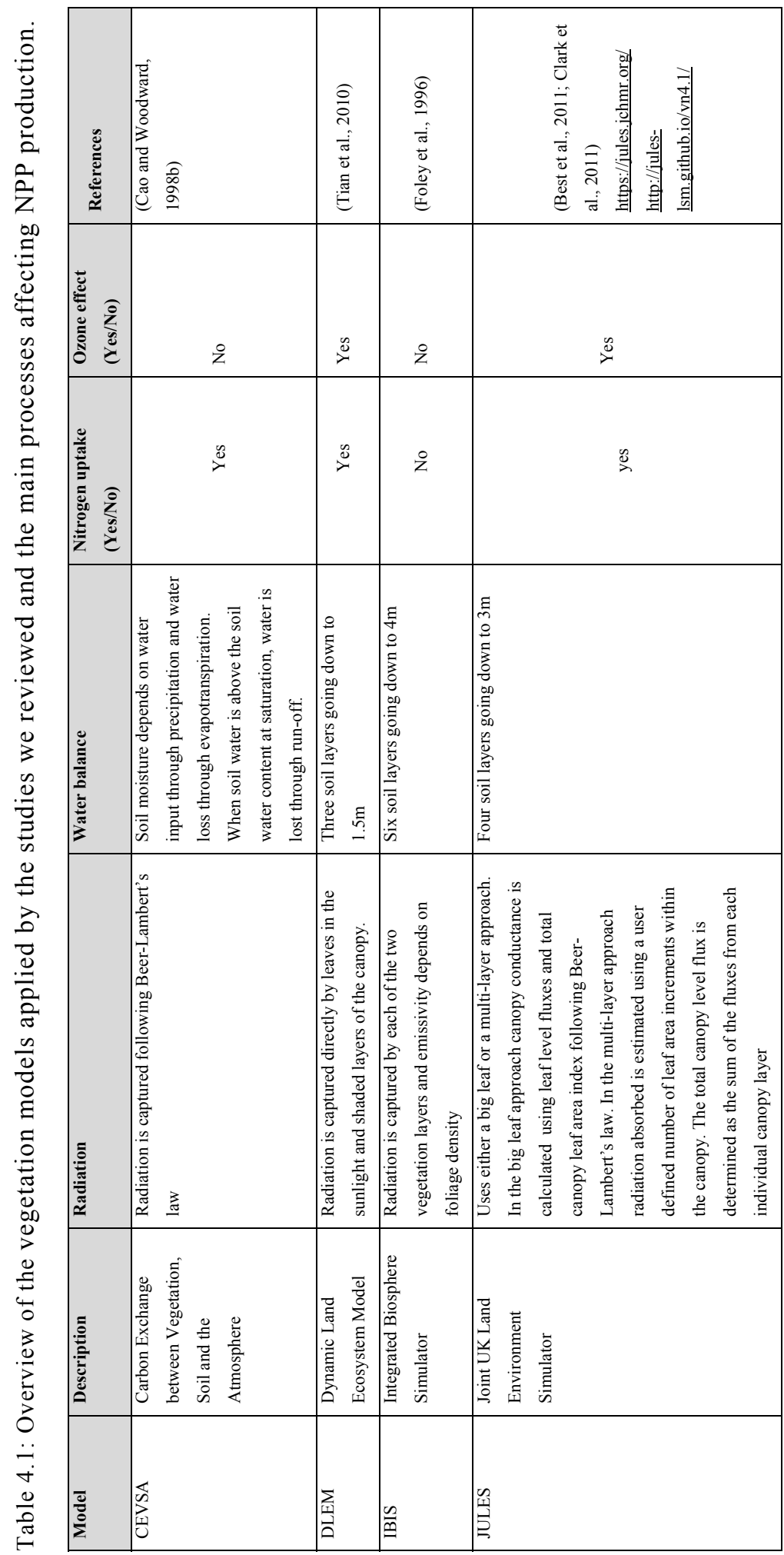




\begin{tabular}{|c|c|c|c|c|c|}
\hline 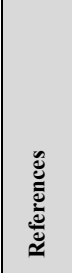 & 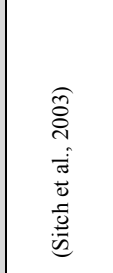 & 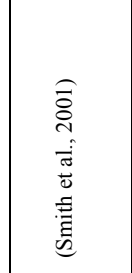 & 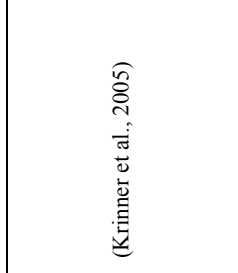 & 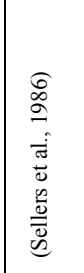 & 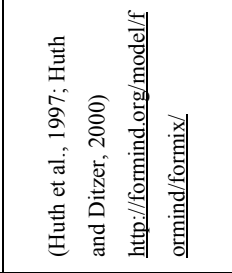 \\
\hline 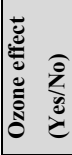 & $\stackrel{8}{z}$ & $\stackrel{\circ}{z}$ & $\stackrel{2}{z}$ & $z$ & $\stackrel{z}{z}$ \\
\hline 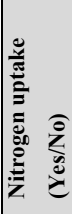 & $\stackrel{\circ}{z}$ & $\dot{z}$ & 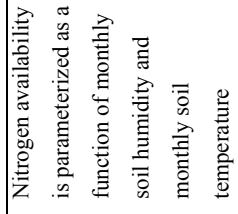 & ż & z \\
\hline 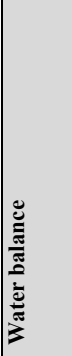 & 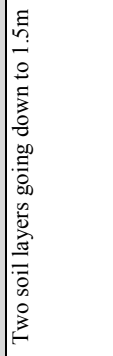 & 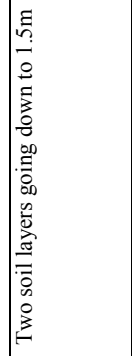 & 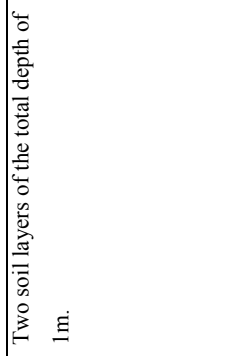 & 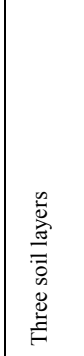 & 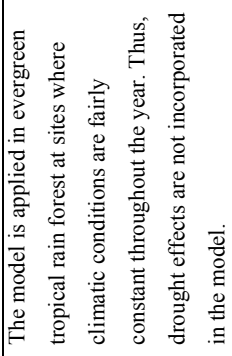 \\
\hline 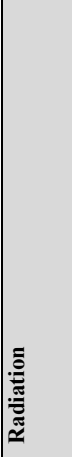 & 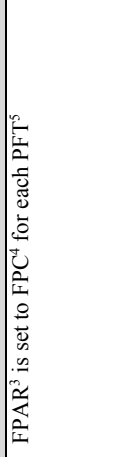 & 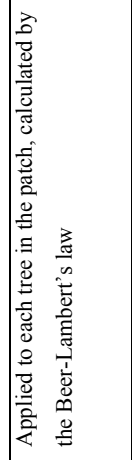 & 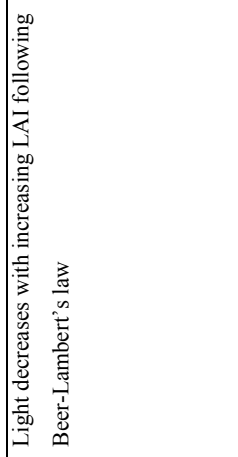 & 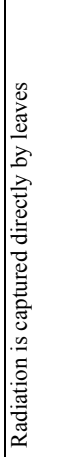 & 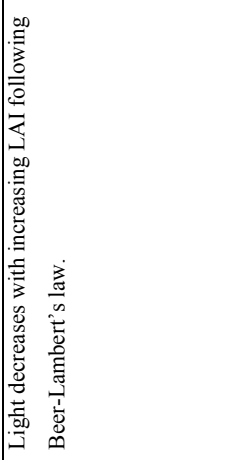 \\
\hline 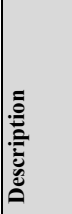 & 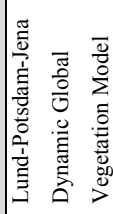 & 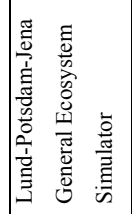 & 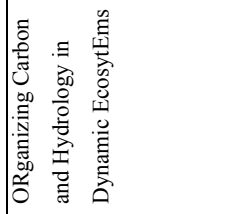 & 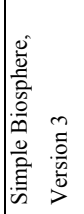 & 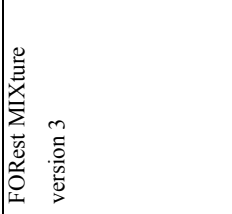 \\
\hline 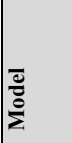 & 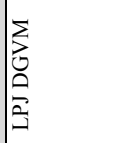 & 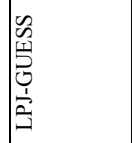 & 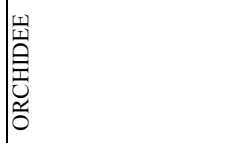 & 㩊 & 离 \\
\hline
\end{tabular}

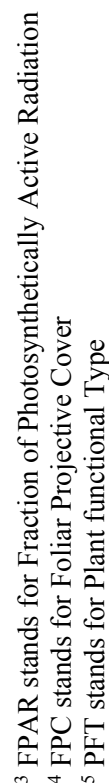




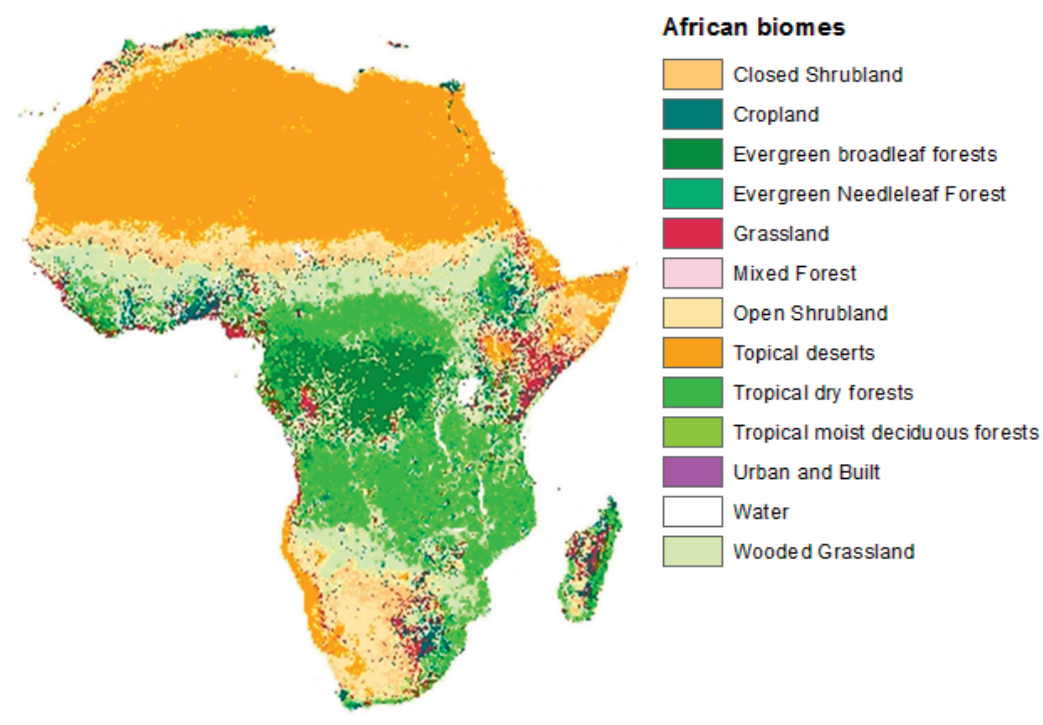

Figure 4.3 African biomes. Biome classification is based on Hansen et al. (1998) and FAO (2001a).

\subsection{Climate to growth relationship}

Trees respond positively to high rainfall $(\mathrm{r}=$ between 0.50 and 0.94$)$ as simulated by models between rainfall and NPP (Cao et al., 2001; Pan et al., 2015; Mohammed et al., 2018). This positive high rainfall influence was also observed in dendrochronological studies (Ngoma et al., 2017). Trees growing in low rainfall receiving areas respond more strongly to changes in rainfall than those growing in high rainfall receiving regions. Rainfall correlated highly (i.e. correlation coefficient ranges $0.54-0.79$ ) with tree-ring chronologies in areas receiving 400700mm yr-1 (Stahle et al., 1999; Gebrekirstos et al., 2008; Nicolini et al., 2010) while low correlations (i.e. 0.00-0.38) were recorded in regions receiving 800-1500mm yr-1 (Trouet, 2004; Trouet et al., 2006; Couralet et al., 2010; Ridder et al., 2013). Studies conducted on the same species growing in different climatic zones further confirmed the variation in a tree's responses to different environments (Ngoma et al., 2017). There is a clear trend $\left(r^{2}=0.15\right)$ between correlation coefficients of tree growth and total rainfall amounts. A similar trend was also reported by Zhu and Southworth (2013) who found that NPP-to-rainfall relationship was high and significant when mean annual rainfall was less than $850 \mathrm{~mm}$ while, with rainfall of more than $850 \mathrm{~mm}$, the relationship between NPP and rainfall was not significant. This 
indicates that changes in rainfall have more effects on trees growing in low rainfall receiving areas than those growing in high rainfall receiving regions. Thus, plants use water up-to a certain limit, and in high rainfall receiving areas, not all the water received through rainfall is used by plants, instead, most of it is lost through run off (Ping et al., 2004; Murray-Tortarolo et al., 2017).

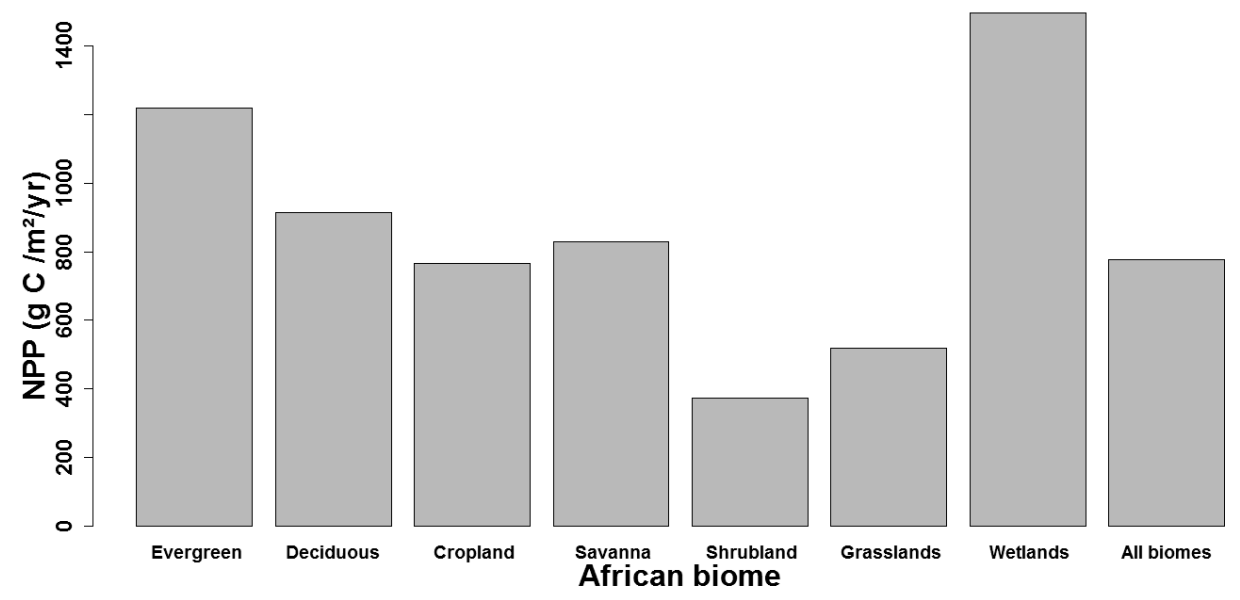

Figure 4.4 Distribution of terrestrial NPP in Africa by biome as determined by vegetation models. Data source: (Cao et al., 2001; Delire et al., 2008; Williams et al., 2008; Weber et al., 2009; Doherty et al., 2010; Pan et al., 2015; Mohammed et al., 2018). Also, see Supplementary information (Table S4.1) for more details.

High temperatures negatively influence tree growth for most species as observed in both dendrochronological (Trouet, 2004; Trouet et al., 2006; Nicolini et al., 2010; Ilmen et al., 2016; Ngoma et al., 2017) and modelling studies (Cao et al., 2001). Plants' response to temperature change increases with the rise in temperature $\left(r^{2}=0.07\right.$. However, some species respond positively to increasing temperature (Trouet, 2004; Ngoma et al., 2017), though, this positive response could just be up to the plant's optimal temperature levels (Wu et al., 2011). The positive temperature influence was also reported in modelling studies (Ciais et al., 2009; Mohammed et al., 2018; Ngoma et al., 2019a).

\subsection{Change in tree-ring indices and NPP}

From the $14^{\text {th }}$ century to the $16^{\text {th }}$ century, tree ring width of the deciduous forests were increasing while in the $17^{\text {th }}$ and $18^{\text {th }}$ centuries, tree ring width of these deciduous forests reduced. The ring width of the evergreen forests reduced highly in the $18^{\text {th }}$ century. However, 
the ring width of the savanna forests had been increasing starting from the $17^{\text {th }}$ to the $19^{\text {th }}$ century. Though the combined width of the tree-rings had been increasing starting from the $14^{\text {th }}$ to the $17^{\text {th }}$ century, they reduced by the year 2000 (See Figure 4.5 and Supplementary information Table S4.4).

From the year 1900 to 2011, the aggregated mean annual NPP increased by $4.8 \%$ in Africa. The highest increase of 14\% was recorded in shrubland though NPP of grasslands reduced by $2.4 \%$ over the same period. The combined NPP of all African biomes is projected to reduce by $8 \%$ though Grasslands' NPP will increase by $11 \%$ by the end of the $21^{\text {st }}$ century from 1950-2000 period as baseline (See Figure 4.6 and Supplementary information Table S4.5).

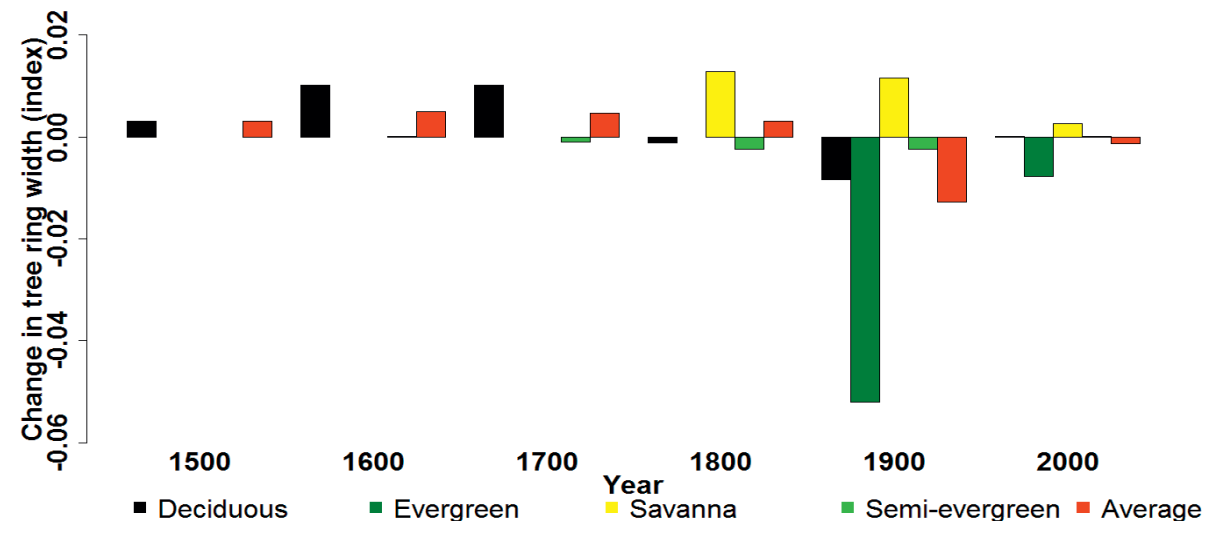

Figure 4.5 Changes in tree-ring width by biome. The reader is referred to Supplementary information (Table S4.4) for more details. We compiled data on tree-ring indices from tree-ring studies (Berger et al., 1979; Dunwiddie and LaMarche, 1980; Dutilleul and Till, 1992; Eshete and Ståhl, 1999; Stahle et al., 1999; Couralet et al., 2005; Trouet et al., 2006; Gebrekirstos et al., 2008; Sass-Klaassen et al., 2008; Couralet et al., 2010; Nicolini et al., 2010; Trouet et al., 2010; de Ridder et al., 2013; Battipaglia et al., 2015; Ilmen et al., 2016; Sanogo et al., 2016; Ngoma et al., 2017). 

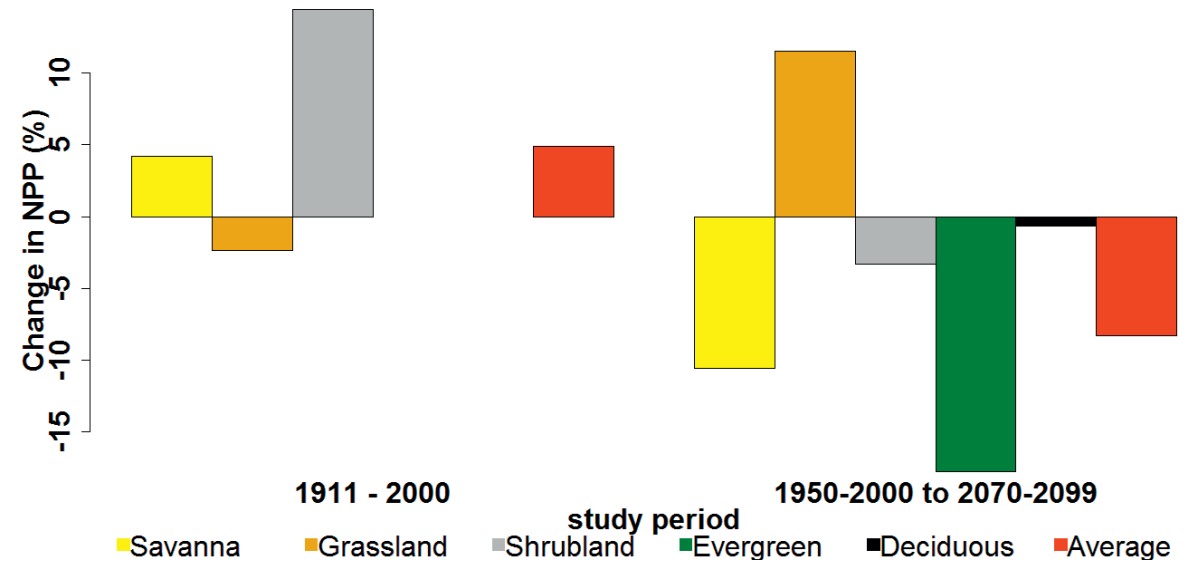

Figure 4.6 Changes in NPP by biome. The reader is referred to Supplementary information (Table S4.5) for more details. We compiled data on NPP change from studies that applied vegetation models (Cao et al., 2001; Delire et al., 2008; Doherty et al., 2010; Gang et al., 2013; Pan et al., 2015; Ngoma et al., 2019a).

\subsection{Discussion}

Our review showed that biome and NPP distributions follow rainfall distribution in Africa. For example, evergreen forests, which are more productive, are found in high rainfall receiving areas while the less productive savanna forests, are found in areas that receive lower amounts of rainfall (Figures 4.3 and 4.4). The high productivity of evergreen forests could probably be due to increased water use efficiency (Pan et al., 2015). The wetlands had the highest amounts of NPP probably due to the amount of water which is always available for plants' use. This available water enhances productivity. Differences in productivity among biomes could also be attributed to variation in species composition (Williams et al., 2007). For example, trees of the evergreen broadleaved forests do not shed their leaves, while those of the deciduous broadleaf forests are seasonal and shed their leaves during a certain period of the year (Pan et al., 2013), especially during the dry season. These seasonal trees become less productive after losing their leaves.

Following the positive relationship between rainfall and forests' productivity, NPP is affected more in low rainfall receiving areas compared to areas that receive higher amounts of rainfall when rainfall reduces. The positive high effects of rainfall on forest productivity in low rainfall receiving regions could be due to high effect of soil moisture that control tree's growth (Knapp and Smith, 2001) compared to plants growing in wetter regions. The decreased soil water causes closure of stomata and shading of leaves resulting in reduced 
carbon uptake by the plants. The reduced soil water also reduces the movements of soil nutrient (e.g. nitrogen) from the soil to the plants, resulting in low NPP (McGuire and Joyce, 2005; Fischer et al., 2014). The different plant's response to rainfall changes in low and high rainfall receiving areas was also reported by Pan et al. (2015), whose results showed that grasslands' and shrublands' NPP in arid and semiarid environments varied much (i.e. the largest coefficient of variation). Ciais et al. (2009) attributed this contrasting rainfall responses to different growth environment. They further attributed these differences to applied methodology and they explained by applying the ORCHIDEE model. According to them, their hydrology module of ORCHIDEE allows forests to access deeper water sources than grasses thereby increasing the forests' productivity. However, Pan et al. (2015) indicated that even though models can be calibrated using biome specific parameters based on field observations, certain processes (e.g. response of carbon assimilation and stomatal conductance to increasing temperature and elevated $\mathrm{CO}_{2}$ ) may change due to plant acclimation (Hui et al., 2003). This causes biomes to respond differently to environmental change. Pan et al. (2015) recommended to consider natural disturbances, such as fire and human activities (e.g. timber harvesting), when quantifying NPP responses to environmental change (including climate change).

From the two methods (dendrochronological and modelling studies) we also established that temperature correlates negatively with NPP. The negative high influence of increasing temperature is mainly due to increased respiration (Burton et al., 2008; Wu et al., 2011) and stomatal closure (Farquhar et al., 1980). High temperature stimulates evapotranspiration that eventually reduces soil water availability, and as a survival mechanism, stomata on the leaves close to reduce water loss. Closure of the stomata results in reduced carbon assimilation (Clark, 2004; Doughty and Goulden, 2008; Galbraith et al., 2010), hence reduced photosynthesis resulting in low productivity (Delire et al., 2008). For tropical trees, carbon uptake reduces with leaf temperature of above $31^{\circ} \mathrm{C}$ (Doughty and Goulden, 2008). Increased temperature also reduces NPP by inhibiting the activity of photosynthetic enzymes (Farquhar et al., 1980). Though tree ring studies showed that plants' response to temperature change increases with the rise in temperature $\left(r^{2}=0.07\right)$, we were unable to establish a clear trend between temperature distribution and biomes' response to temperature change due to a limited number of modelling studies reporting temperature effects on individual biomes. Our review established a clear trend between rainfall distribution and plants' response to rainfall changes $\left(r^{2}=0.15\right)$ at both species and biome levels. We also established a trend between temperature 
distribution and plants' response to changes in temperature at species' level, though the trend was weak $\left(r^{2}=0.07\right)$.

The model results correlating temperature and NPP were only reported either regionally (Pan et al., 2015) or for the whole continent (Cao et al., 2001) with limited studies (Ngoma et al., 2019a) relating temperature to a specific biome despite temperature having reported to have large effects on forest productivity (Delire et al., 2008). This limited to determine a trend between temperature distribution and biomes from the modelling studies.

Our study established distinct changes in NPP with biome. These changes followed forest distribution, which is determined by rainfall distribution. For example, NPP of the evergreen forests, that are found in high rainfall receiving areas, is projected to change more than NPP of the other forest types that are found in low rainfall receiving areas (Figure 4.6). However, different studies conducted in the same biomes to estimate changes in NPP produced varying results. These contrasting results could probably be due to different parameterisations in the models (See Table 4.1). For example, while Cao and Woodward (1998b) took into account nitrogen content in the parameterisation of the CEVSA model, Foley et al. (1996) did not account for nitrogen content in the parameterisation of the IBIS model. The increasing amounts of nitrogen in the soil enhances NPP production though up to an optimal $\mathrm{CO}_{2}$ levels (Norby et al., 2010). Tian et al. (2010) accounted for ozone effects on NPP in the DLEM model, while Sellers et al. (1986) did not consider the effect of ozone in the parameterisation of SiB3 model when simulating NPP. Increased exposure to high levels of ozone inhibits photosynthesis by directly damaging the cells in the leaves and reducing stomatal conductance. This results in reduced NPP (Felzer et al., 2004). The period covered by these studies also differed. For example, while Gang et al. (2013) determined the change in NPP for the period 1911 to 2000, Pan et al. (2015) reported the change in NPP for the period 1980s to 2000s for the same biomes.

We estimated changes in forest productivity from dendrochronological and modelling studies. From modelling studies, we aggregated changes in NPP per biome from individual studies to get continental changes. We determined changes in tree-ring widths per species (following the reviewed studies) which were then aggregated to biome level (from all the reviewed studies). The biome level changes were aggregated to the continental scale. From both, dendrochronological and modelling studies, the certainty of these continental scale aggregated figures is not clear due to diversity in biomes, climatic conditions and species composition in Africa. In our analysis, we only included 19 tree-ring studies, and these studies did not include all the 5000 plus available species in Africa (Slik et al., 2015). Also, no tree-ring 
studies were available for the grassland and shrubland. This indicates a knowledge gap in understanding the growth rate of trees in these less studied biomes. Climatic conditions in Africa varies with space. This variation affect the growth rate of trees in different parts of the continent. We only analysed 6 modelling studies in this paper due to limited number of available studies covering African biomes. Availability of such studies would give much insight on our results. These sources of uncertainty thus, indicate a weakness in the aggregated results since not all tree species grow at the same rate. However, we were confident with the values reported by the researchers since they were all validated, especially NPP values that needed validation.

This review has highlighted the gap in knowledge in modelling and tree-ring studies in Africa. Thus, effects of climate change on forest productivity were not determined on all biomes, thereby limiting our understanding on how climate change will affect the productivity of some biomes. This study therefore, helps to prioritize future dendrochronological and modelling studies to better assess the response of species and biomes in Africa. However, the increased productivity of the Savanna biome determined by both dendrochronological and modelling studies indicates that the projected changes in climate will have effects on forests productivity in Africa though the extent of the effects on individual trees and biomes will not be uniform.

\subsection{Conclusions}

Both dendrochronological and modelling studies showed that rainfall has a direct effect on plants' growth and increased temperature has negative effects on plants' growth at species, and biome scales. The forests' productivity of the Savanna biome increased by the year 2000. However, the combined ring width of all studied trees reduced while NPP increased by the year 2000. The modelling studies showed that by the end of the $21^{\text {st }}$ century, combined NPP of all African biomes will decrease by $8 \%$ from 1950. Trees growing in low rainfall receiving areas respond more strongly to changes in rainfall than those growing in high rainfall receiving regions, and changes in temperature have more effects on tree's productivity in hotter regions than in colder areas. 
Chapter 4 


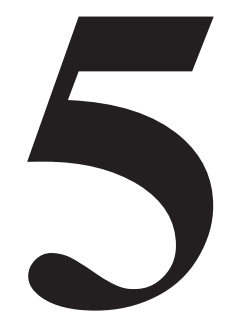

\section{THE DENDROCHRONOLOGICAL POTENTIAL OF BAIKIAEA PLURIJUGA IN ZAMBIA}

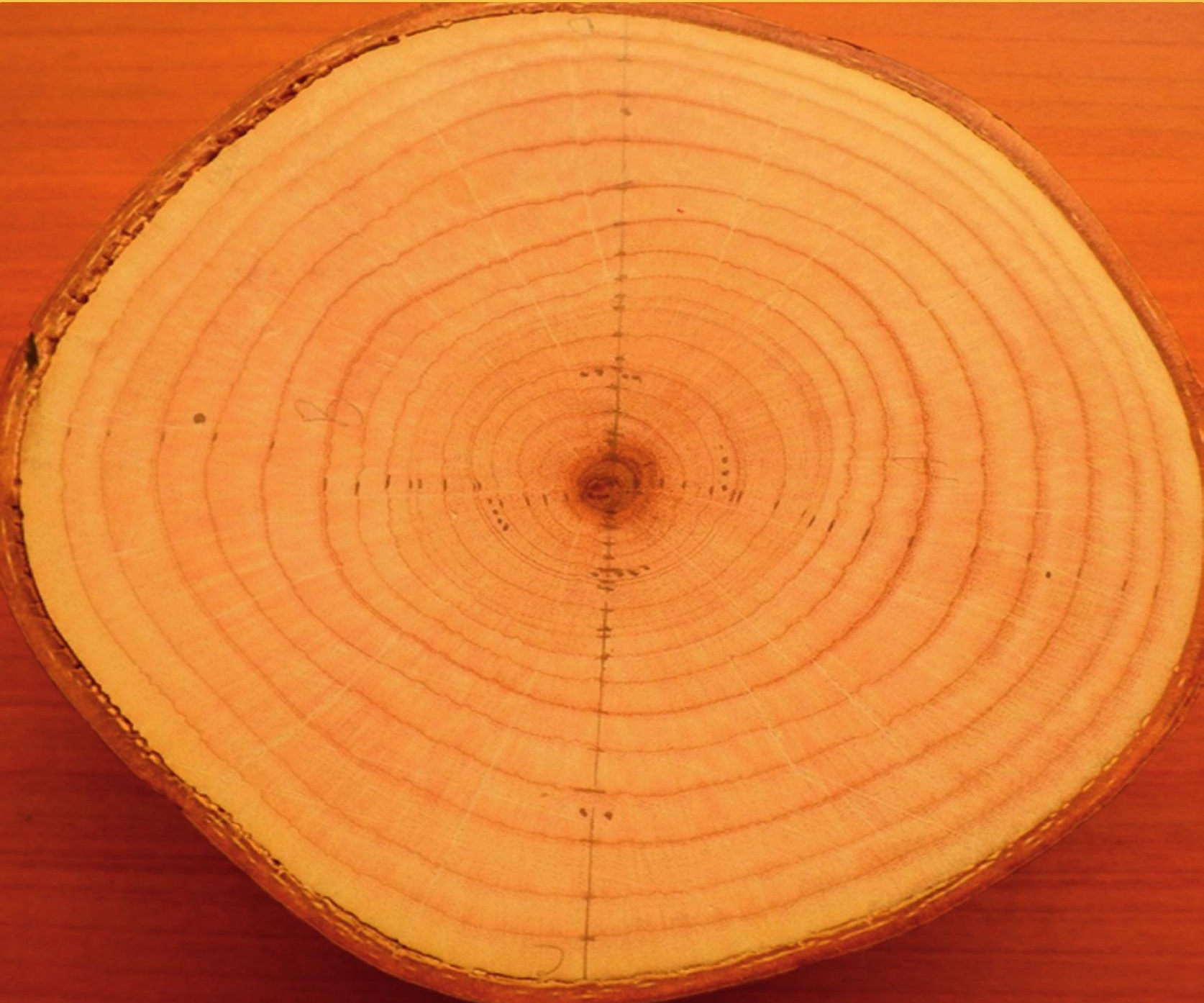




\section{Abstract}

Climate has been demonstrated to change at different scales for as far back as we have been able to reconstruct it. However, anthropogenic factors have accelerated and are predicted to cause significant changes in temperature and precipitation around the globe. As a consequence, vegetation is being affected. To understand the historical behaviour of individual tree species and have insight on the potential effects of climate change, tree-ring studies have been applied. In this study, we examined a genus new to dendrochronology, namely Baikiaea plurijuga (Spreng.) Harm that dominates the Zambezi teak forests in Zambia with the objective of determining whether B. plurijuga forms annual rings and if so, whether these rings are cross-datable. We further determined the relationship between ring-width of $B$. plurijuga and climatic variables with the aim of understanding the potential climate change effects on the growth of these species in Zambia. We collected tree-ring samples from three Zambezi Teak forest reserves: Zambezi, Ila and Masese located in Kabompo, Namwala and Sesheke study sites respectively. Our examination of wood anatomical structures reviewed that the wood of $B$. plurijuga is diffuse porous and forms annual rings which were confirmed with samples of known age. The analysis resulted in three strong tree-ring chronologies of $B$. plurijuga. These chronologies were correlated with climate data from local weather stations which correlated negatively with evaporation and temperature and positively with rainfall. Our regression analysis indicated that evaporation has the highest influence on tree growth at all the study sites compared to temperature and rainfall alone. Evaporation in November and March, for example, explained almost a third of the radii's variance at the Namwala and Sesheke sites. The likely future temperature increase and rainfall decrease that are projected by IPCC for Southern Africa, are likely to adversely affect B. plurijuga in Zambia.

Published as:

Ngoma J, Speer JH, Vinya R, Kruijt B, Moors E, Leemans R. 2017. The dendrochronological potential of Baikiaea plurijuga in Zambia. Dendrochronologia 41:65-77. 


\subsection{Introduction}

Climate has been demonstrated to change at different scales for as far back as we have been able to reconstruct it, but anthropogenic factors have accelerated and are predicted to cause significant changes in temperature and precipitation around the globe. In Africa, the temperature increased by $0.5^{\circ} \mathrm{C}$ during the last 50 to 100 years and minimum temperatures warmed more rapidly than maximum temperatures. Annual rainfall reduced over the past century over parts of the western, eastern Sahel region, eastern and southern Africa (Niang et al., 2014). In future, temperatures are projected to increase by $3^{\circ} \mathrm{C}$ to $6^{\circ} \mathrm{C}$ by the end of this $21^{\text {st }}$ century compared to $1986-2005$ in Africa. However, rainfall has been projected to vary in different parts of the continent (Niang et al., 2014). Following these changes, ecosystems have also been affected differently in various parts of Africa. For example, Net Primary Productivity (NPP) increased by 2.28 - 6.31Gt $\mathrm{Cyr}^{-1}$ in North, Central and Southern Africa following changes in temperature and rainfall over the period 1900s -1990s (Cao et al., 2001). NPP reduced by $6 \%$ following increased rainfall by $14.4 \mathrm{~mm}$ and temperature by $0.23^{\circ} \mathrm{C}$ (Gang et al., 2013) over the period from 1911 to 2000, though reduced rainfall by $0.33 \%$ resulted in reduced NPP by $25 \%$ (Fischer et al., 2014) in the whole of Africa. In the future, NPP is projected to increase by $252.82 \mathrm{~g} \mathrm{C} \mathrm{m}^{-2} \mathrm{yr}^{-1}$ over the period $1989-2000$ to 2080-2099 following increased rainfall by $0.3 \mathrm{~mm}$ per day and temperature by $3.4^{\circ} \mathrm{C}$ in East Africa (Doherty et al., 2010). However, in central Africa, rainfall reduction by $106 \mathrm{~mm}$ per year is projected to reduce NPP by $55 \mathrm{~g} \mathrm{C} \mathrm{m}^{-2} \mathrm{yr}^{-1}$ between the 1980s and 2080s (Delire et al., 2008). In southern Africa alone, NPP increased by $2.78 \mathrm{Gt} \mathrm{C} \mathrm{Yr}^{-1}$ due to changed temperature and rainfall over the period 1900s to 1990s (Cao et al., 2001). In Zambia, climate change affects ecosystems differently. So far variations in annual climatic conditions affects the Zambezi teak forests negatively. Thus, severe storms reduce flowering and fruiting potential, and irregular early season rainfall adversely affects germination and seedling survival of some trees in the forest (Calvet, 1986). High temperatures plus low humidity contribute to a high fire hazard that results in severe damage in the late dry season (Calvet, 1986). Low temperatures have been recorded causing frost damage to the vegetation (The Government of the Republic of Zambia, 1996). Though moderately sensitive to frost, Zambezi teak forests may get affected through damage to sprouts that are produced on the stumps. However, in our study sites, frost is not an issue. 
Of the many species in the Zambezi teak forests, the Baikiaea plurijuga (Spreng.) Harm (also called Mukusi, Zambezi Teak, or Rhodesian teak) have seedlings that are very sensitive to drought (Chisumpa, 1986). About 90\% of seedlings that die during the first year after germination are due to drought stress because of competition for moisture with the understory shrubs (Chisumpa, 1986). B. plurijuga is a very important species in Zambia as it is a source of hardwood timber that supplies local, national and international markets. It is also a very unique species as it is only found in southern Africa (Mubita, 1986). Thus, to understand the potential effects that climate change is likely to have on these species, it is important that a relationship is established between tree growth and climatic variables through tree-ring studies. Tree rings play a major role in determining the historical behaviour of individual tree species under natural micro-climatic conditions and, as such, may provide insight into the potential impacts of climate change on B. plurijuga. This study therefore aimed at understanding whether B. plurijuga forms annual rings and if so, whether these rings are cross-datable. We further, analysed the possible relationship between ring-width of $B$. plurijuga and the main climatic variables: rainfall, temperature and evaporation.

\subsection{Materials and Methods}

\subsubsection{Distribution of Baikiaea plurijuga}

Baikiaea plurijuga is found in the Zambezi teak forests. These forests are found on the Kalahari Sands of Angola, Botswana, Namibia, Zambia and Zimbabwe (Chisumpa, 1986; Piearce, 1986a; Piearce, 1986b; Selander, 1986). In Zambia, they are mainly found in the western, southern, and north-western provinces (Chisumpa, 1986; Mbughi, 1986). In the western province, they occur in the Sesheke, Senanga, Kalabo, Mongu and Kaoma districts, while in the southern province they occur in the Livingstone, Kalomo and Namwala districts. In the north-western province, Zambezi Teak forests are found in the Zambezi and Kabompo districts (Chisumpa, 1986; Mbughi, 1986).

\subsubsection{Description of Baikiaea plurijuga}

The genus B. plurijuga is of the tribe Detarieae and falls in the sub-family caesalpinioideae of the family leguminosae; commonly known as the legume (Brummitt, 1986). The deciduous broad-leaved B. plurijuga grows up to $20 \mathrm{~m}$ high and $120 \mathrm{~cm}$ in diameter and grows in dry sites on free-draining sandy soils. To reach soil depths which are moist during the dry season and to avoid competition with roots of the undergrowth (locally known as mutemwa), the taproot of the seedlings grows down very rapidly and becomes quite long, though few lateral roots 
develop. The first lateral roots appear at about $30 \mathrm{~cm}$ of soil depth. Seedlings of B. plurijuga are drought sensitive and their development is dependent on the amount of rainfall. However, the shoots of seedlings grow very slowly in the first three years. Lateral roots grow very wide in both seedlings and large trees (Högberg, 1984). The rooting depth is estimated at up to $6 \mathrm{~m}$ to $9 \mathrm{~m}$ (Högberg, 1984) though Childes (1988) reported a rooting depth of up to $10 \mathrm{~m}$. Fine roots of $B$. plurijuga develop below the roots of the undergrowth trees, which develop $5 \mathrm{~cm}$ to $30 \mathrm{~cm}$ of soil depth (Högberg, 1984). B. plurijuga is almost evergreen with leaf buds, mature and dead leaves present during most of the period of the year (Childes, 1988). In areas with little or no undergrowth, trees of $B$. plurijuga retain their leaves for a longer time during the dry season compared to trees growing with dense undergrowth (Högberg, 1984). The proportion of leaf buds reduces in the mid wet season when the tree is in full leaf. Leaf senescence and fall coincides with decreasing moisture levels in the soil and, following the rains, leaf flush starts in October (Childes, 1988) (The KMZ file 1 is available online: Zambezi teak forests). However, a new leaf flush is also supported by groundwater or water from soil levels close to the tree roots and variations in phenology occur due to differences in the groundwater table depth (Högberg, 1984). With the increase in size, B. plurijuga changes from evergreen to deciduous (Childes, 1988). Seedlings of up to $1.0 \mathrm{~m}$ height (when root to shoot ratio is very high) are less deciduous compared to larger trees (Calvet, 1986). For a full botanical description of B. plurijuga, the reader is referred to DFSC (2001).

\subsubsection{Composition of Baikiaea plurijuga in the Zambezi teak forest}

Reports (Mbughi, 1986; Mulolwa, 1986; Piearce, 1986a) indicate that B. plurijuga is a dominant species in the Zambezi Teak Forests and this was confirmed by our 2014 inventory in the Sesheke, Namwala and Kabompo sites (see Table 5.1). Thus, compared to other species in the natural forests, the undergrowth was found to be $0.3 \%$ in Kabompo and $1.9 \%$ in Namwala per $350 \mathrm{~m}^{2}$ assessed at each site, whereas in the Sesheke site, no undergrowth was recorded in the natural forests, indicating poor regeneration of B. plurijuga in this site. However, in the plantations of B. plurijuga in Sesheke, undergrowth of B. plurijuga was found to be $53.4 \%$ compared with other species. Due to poor management of the plantations, other tree species are also growing, a scenario which was not planned for.

\subsubsection{Topography and soil characteristics of the Zambezi teak forests}

Zambezi Teak forests are found in flat areas with seasonally high water tables. The area of the Zambezi teak forests is covered with a thick layer of so-called 'Kalahari sand' and the soil 
types are different ferralic, haplic, albic and gleyic arenosols (The Government of the

Republic of Zambia, 1996). The soils are deep, well drained, almost sterile, moderately acid, infertile, have low wilting coefficients, have $3-12 \%$ of silt and clay and $15-60 \%$ of fine sand (i.e. particles of between $0.02 \mathrm{~mm}$ and $0.2 \mathrm{~mm}$ in diameter) (The Government of the Republic of Zambia, 1969). Soil particles larger than $0.5 \mathrm{~mm}$ diameter are the major part of the total soil volume (Mbughi, 1986).

Table 5.1: Composition of Baikiaea plurijuga ( $\geq 5 \mathrm{~cm}$ diameter) in the Zambezi Teak forests of Zambia

\begin{tabular}{|l|l|c|l|l|c|}
\hline Study site & Forest type & $\begin{array}{l}\text { Inventoried } \\
\text { area coverage } \\
\text { (ha) }\end{array}$ & $\begin{array}{l}\text { Baikiaea } \\
\text { Plurijuga } \\
\text { coverage (\%) }\end{array}$ & $\begin{array}{l}\text { Abundance } \\
\text { (No. of trees } \\
\text { per plot }\end{array}$ & $\begin{array}{l}\text { Importance } \\
\text { Value Index } \\
\text { (IVI) }\end{array}$ \\
\hline Sesheke & $\begin{array}{l}\text { Plantations of } \\
\text { Baikiaea plurijuga }\end{array}$ & 2.20 & 75 & 118 & 171 \\
\hline Sesheke & Natural forests & 5.04 & 50 & 18 & 149 \\
\hline Namwala & Natural forests & 5.04 & 51 & 35 & 163 \\
\hline Kabompo & Natural forests & 5.04 & 12 & 11 & 48 \\
\hline
\end{tabular}

\subsubsection{Study sites and climatic conditions}

Zambia is divided into three agro-ecological zones defined by the amount of rainfall received annually (see I, II and III in Figure 5.1). Zone I receives less than $800 \mathrm{~mm}$ of annual rainfall; Zone II between $800 \mathrm{~mm}$ and $1000 \mathrm{~mm}$; and Zone III more than $1000 \mathrm{~mm}$ (The Government of the Republic of Zambia and UNDP, 2009) (see Figure 5.1) ${ }^{6}$. To understand the growth of $B$. plurijuga in different environments, three study sites were selected, located across the two different agro-ecological zones i.e. I and II along a precipitation gradient. Samples were taken from the Masese, Ila and Zambezi forest reserves. The Masese forest reserve is situated in the dry agro-ecological zone I (precipitation $<800 \mathrm{~mm}$ ), Ila is located at the border of agroecological zones I and II and the reserve stretches in the two zones. However, the Zambezi forest reserve is located in the wet agro-ecological zone II (precipitation between $800 \mathrm{~mm}$ and $1000 \mathrm{~mm}$ ) (see Figures 5.1 and 5.2). Masese is located near Sesheke town (17²1.278S, $24^{\circ} 22.560 \mathrm{E}$.), Ila is near Namwala town $\left(15^{\circ} 50.732 \mathrm{~S}, 026^{\circ} 28.927 \mathrm{E}\right)$ and Zambezi forest reserve is found near Kabompo town $\left(14^{\circ} 00.551 \mathrm{~S}, 023^{\circ} 35.106 \mathrm{E}\right)$. These sites were chosen based on their abundant Zambezi Teak forests dominated by B. plurijuga and accessibility by existing roads.

\footnotetext{
${ }^{6}$ Zone II is sub-divided into IIa and IIb. Zone IIa consists of a sub-region of the plateau including the main farming areas on the plateau of central, eastern and southern provinces, whereas zone IIb comprises the Kalahari (Barotse) sand plateau and the Zambezi flood plains. Both zones receive the same amount of rainfall (800 $1000 \mathrm{~mm} /$ year) (Wamunyima, 2014)
} 
Though the rainy season is generally taken to be from November to March in Zambia (Mbughi, 1986), in some parts of the country rains start in October and end in April.

Temperatures in Zambia vary from mean minima of $10-13^{\circ} \mathrm{C}$ in May - July, to $32-35^{\circ} \mathrm{C}$ mean maxima in August - October (Mubita, 1986). In the western province of Zambia, where the Zambezi Teak forests are concentrated, temperatures range from $31.1^{\circ} \mathrm{C}$ in cool months to $37.8^{\circ} \mathrm{C}$ in dry and hot months (Chingaipe and Jain, 1986) (see Figure 5.2).

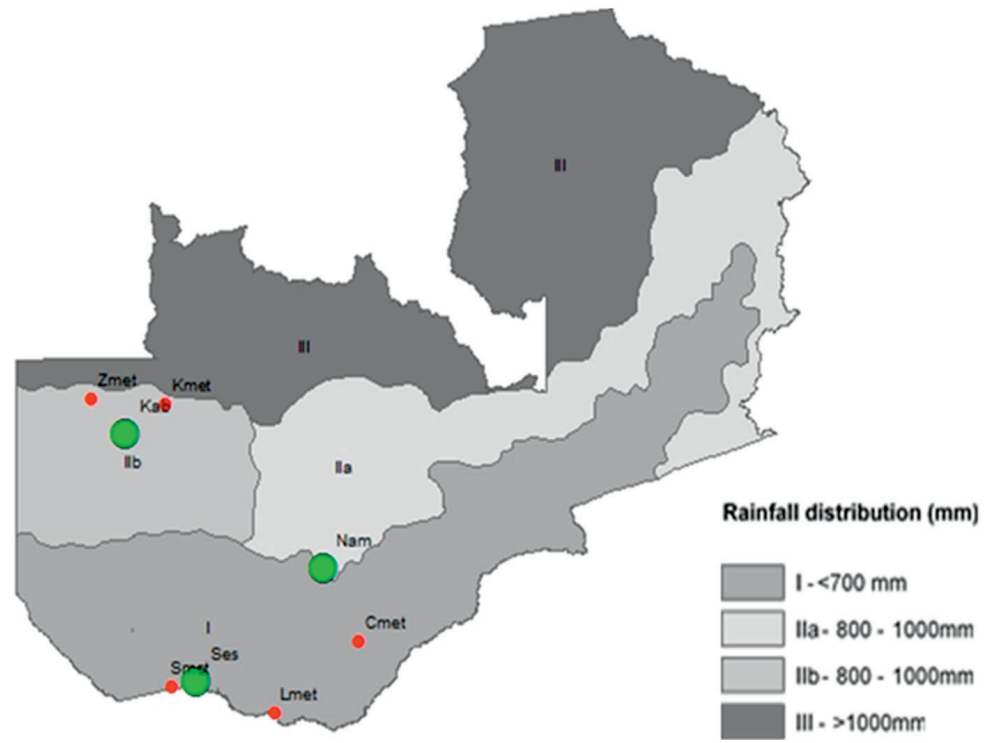

Figure 5.1 Agro-ecological zones (I, IIa, IIb and III) and distribution of study sites in Zambia. Green dots are study sites and Kab represents Zambezi forest reserve in Kabompo, Nam stands for Ila forest reserve in Namwala and Ses represents Masese forest reserve in Sesheke sites. Red dots are meteorological stations where climate data was drawn from. Zmet stands for Zambezi meteorological station, Kmet means Kabompo metorological station, Cmet represents Choma meteorological station, Lmet stands for Livingstone meteorological station and Smet means Sesheke meteorological station.

For this study, climate data was collected from the head meteorological office. This data was verified with observations from respective meteorological stations. We created regional climate series by averaging the data from multiple meteorological stations close to the field sites and in the same agro-ecological zone (maximum $200 \mathrm{~km}$ away from the field sites). This allowed us to fill data gaps from the individual site records. Historical data on total precipitation, maximum temperature, minimum temperature and evaporation were used for the period provided by the station records (usually back to 1950). To collect evaporation data, class 'A' evaporation pans (Hydrological services PTY LTD, 2003) are used in Zambia. 
Aggregate climate variables were also created for the growing season and from individual strongly responding months, such as averaged November and March evaporation values. For the Sesheke site, data were drawn from Sesheke and Livingstone meteorological stations, while for the Namwala site, data were drawn from the Choma meteorological station.

Climatic data for the Kabompo site were drawn from the Zambezi and Kabompo meteorological stations (Figure 5.1).

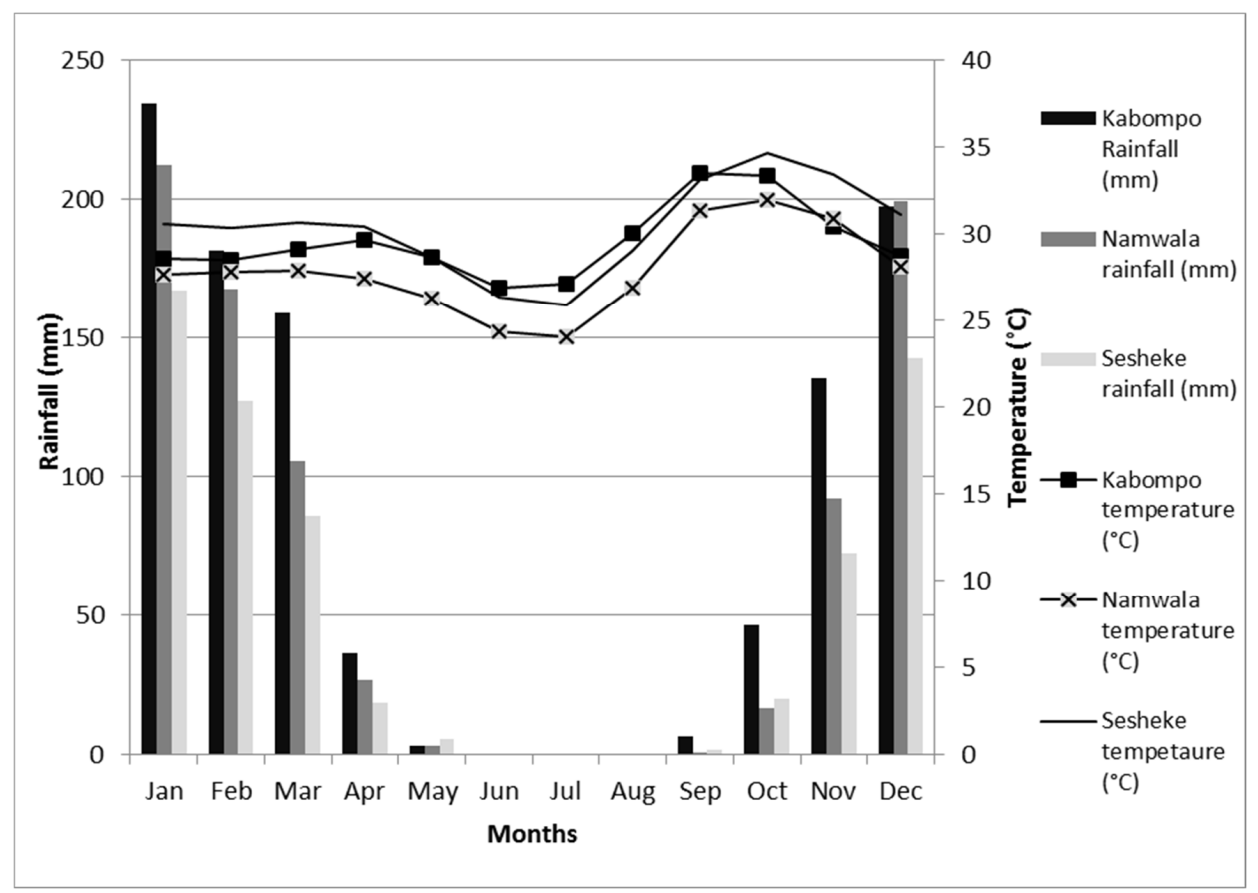

Figure 5.2 Annual rainfall (bars) and temperature (lines) distribution at Sesheke, Namwala and Kabompo study sites. Climatic data for Sesheke site was drawn from Sesheke and Livingstone meteorological stations (1975-2011), while for Namwala site, data was drawn from Choma meteorological station (1975-2011). For Kabompo site, climatic data was taken from Zambezi and Kabompo meteorological stations (1971-2007 for rainfall and 1957-1989 for temperature).

\subsubsection{Sampling strategy}

Young trees of $10 \mathrm{~cm}$ to $20 \mathrm{~cm}$ diameter were targeted because a preliminary analysis in all the three sites demonstrated that they had clearer ring boundaries compared to very old trees. Annual rings became less obvious in heartwood which increases as the tree ages. Also, we targeted trees of the same diameter range as those of known age for easy comparison. In addition to the diameter size, physical observations were made so as to get samples from trees 
that looked fresh and young (see Figure 5.3). The latter was done from observation in the forest and analysis in the lab. Trees with fresh and smooth bark proved to be younger than those with rough bark. Working on the species for the first time and to avoid errors associated with omitting rings during analysis, we choose to work with samples that had clear ring boundaries, such as from relatively young trees. We further worked with whole discs so as to increase dating accuracy

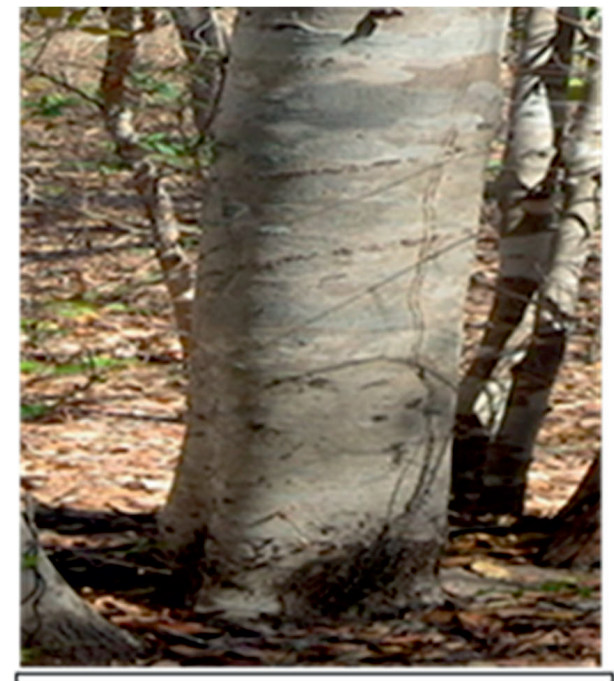

\section{B. plurijuga - Young and smooth}

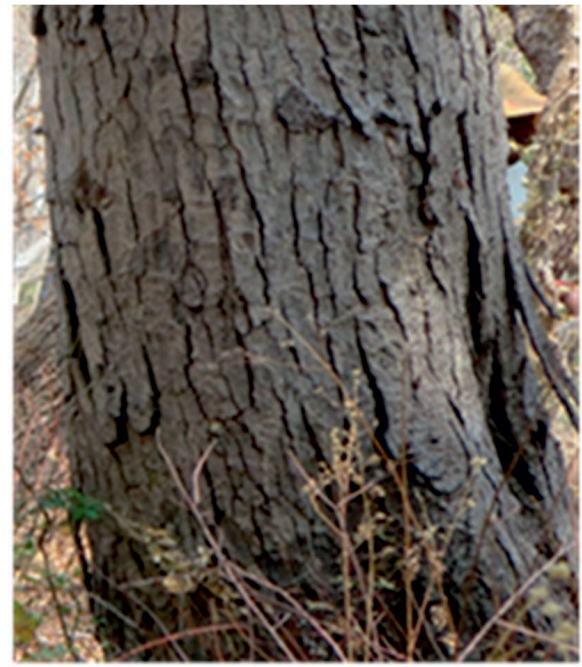

B. plurijuga-Old and rough

Figure 5.3 Physical appearance of young and old trees of B. plurijuga.

In the Namwala and Kabompo sites, fourteen $60 \mathrm{~m}$ by $60 \mathrm{~m}$ plots were randomly located in each site, while in Sesheke, twenty-one $60 \mathrm{~m}$ by $60 \mathrm{~m}$ plots were located in both natural forests and plantations. In each site, one to four trees were selected adjacent to all these plots and samples were taken from trees that had independent stems and were not leaning or did not show any defects. Samples were cut at stump height $(30 \mathrm{~cm})$, breast height $(1.3 \mathrm{~m})$ and at bole height (about $30 \mathrm{~cm}$ below the bole), which varied for each individual tree, but is defined as the height where the tree starts to branch. We analysed the stump height cross sections to determine the feasibility of dendrochronological dating of B. plurijuga and in total thirteen samples were analysed from Kabompo, twelve from Namwala and eight from Sesheke. Two of these eight Sesheke samples had known planting dates. One sample was collected from Kazungula near Katombora reformatory prison (about $160 \mathrm{~km}$ away from Sesheke) and in this study, this sample was considered part of the Sesheke samples. All samples were air-dried before sanding to prevent fungal growth. 


\subsubsection{Sample preparation, growth-ring measurements and statistical analysis}

The samples were first levelled with a Hitachi angle grinder (Hitachi Koki Co., 1994, 2011) and then sanded with progressively finer sand paper. A belt sander (Homer TLC Inc, 2013) was used for the coarser grits and an orbital sander (Homer TLC Inc, 2013) for the finer grits. Additional hand sanding was conducted in the laboratory using $3 \mathrm{M}^{\mathrm{TM}}$ micro finishing films when microscope observation indicated that this was needed. In the end, we created a polish on the cross sections where all of the rings were visible under the microscope and very few sanding striations were left on the surface. All individual cells were obviously visible under magnification.

Samples were then examined under 6-60 times magnification using Leica (Leica Microsystems (Switzerland) Ltd, 2012) and Nikon microscope (Nikon Instruments Europe B.V, 2016). One to four radii were skeleton plotted (Douglas, 1941; Speer, 2010) on each of the cross sections depending upon the eccentricity of the sample and the quality of the wood. More radii were plotted when they were available on the cross section. If the sample was eccentric (with the centre towards one side of the cross section), displayed poor circuit uniformity or had very tight rings around much of its circumference, only one radii was plotted were the rings were most evident. We followed the methods documented by Stahle (1999) when cross dating to test for annual ring formation in B. plurijuga and tested this with samples from known plantation sites and correlation to monthly and annual climate variables. The samples were then measured using a LinTab 6 measuring system (Rinn, 2013) with TSAP software (version 4.68e) from Rinntech (Rinn, 2013) to $0.01 \mathrm{~mm}$ precision. We checked the dating quality with the computer program COFECHA (Version 6.06P), (Holmes, 1983; Grissino-Mayer, 2001). The software ARSTAN (Version 44h3) (LDEO, 2016) was used to standardize the series with a 20 -year cubic smoothing spline (about half the length of our average chronology). This maintains $99 \%$ of the variance at nine years and should retain all potential ENSO signals.

\subsection{Results}

\subsubsection{Wood structure of Baikiaea plurijuga}

The basic structure of tree-rings is determined by genetic factors and the overall wood anatomical structure of tree species does not change. However, some variables of the wood structure can be modified by environmental factors (Wimmer, 2002). To define ring boundaries, it is important that growth zone analysis is done (Vetter and Botosso, 1989). This 
research followed the Wheeler et al. (1989) guide to provide both wood anatomical features and non-wood anatomical information of B. plurijuga (see Table 5.2). In all of the three study sites, growth-ring boundaries were distinct though samples taken from wetter Kabompo site had more distinct and wide rings followed by samples from Namwala and then the drier Sesheke site. The wood is diffuse porous with a reduced number of large vessels in the late wood compared with early wood.

Table 5.2: Wood anatomical features of B. plurijuga. The description follows Wheeler et al. (1989) guide and feature numbers (indicated in parentheses) are as described in the same guide. The reader is referred to this guide for a detailed explanation of the features.

\begin{tabular}{|c|c|}
\hline $\begin{array}{l}\text { Wood anatomical } \\
\text { Feature }\end{array}$ & Description \\
\hline Growth ring boundaries & $\begin{array}{l}\text { Kabompo - Growth rings were very distinct (1). } 92 \% \text { of sampled trees had } \\
\text { distinct growth ring boundaries. } \\
\text { Namwala - Some trees had very distinct growth rings (1) while other trees had } \\
\text { indistinct growth rings (2). } 83 \% \text { of samples taken had distinct growth ring } \\
\text { boundaries. } \\
\text { Sesheke - Some trees showed very distinct growth rings (1) while other trees had } \\
\text { indistinct growth rings (2). Of the samples taken, } 63 \% \text { had distinct growth ring } \\
\text { boundaries. } \\
\text { Summary - Growth rings are generally characterised by a distinct fibre zone with } \\
\text { no large (or very few) vessels in latewood and an abrupt boundary between early } \\
\text { wood and latewood. The number of trees with indistinct growth rings were high } \\
\text { in Sesheke followed by Namwala and then Kabompo. Figure } 5.4 \text { shows discs } \\
\text { with distinct and indistinct growth ring boundaries. }\end{array}$ \\
\hline $\begin{array}{l}\text { Wood porosity and } \\
\text { distribution of } \\
\text { parenchyma cells in } \\
\text { earlywood and latewood }\end{array}$ & $\begin{array}{l}\text { In all study sites, vessels (in white colour, Figure 5.5) had more or less the same } \\
\text { diameter in earlywood and latewood, but the number of bigger vessels reduced } \\
\text { (sometimes none) in latewood compared to earlywood. The frequency of } \\
\text { parenchyma bands (in black colour, Figure 5.5) within a growth ring decreased } \\
\text { towards the latewood. (Refer to Figure 5.5). }\end{array}$ \\
\hline Vessel arrangement & $\begin{array}{l}\text { Vessels (white colour) were in radial patterrn (7) in all study sites (refer to Figure } \\
5.7 \mathrm{C} \text { ) }\end{array}$ \\
\hline Vessel groupings & $\begin{array}{l}\text { Vessel grouping was mixed. Some vessels were partly solitary while others were } \\
\text { partly in radial multiples. In earlywood, vessels were often solitary } \\
\text { (approximately } 60 \% \text { or more), but with approximately equal numbers of solitary } \\
\text { vessels and vessel groups of two to four in latewood. }\end{array}$ \\
\hline $\begin{array}{l}\text { Paratracheal Axial } \\
\text { parenchyma }\end{array}$ & $\begin{array}{l}\text { Wood was characterised by axial parenchyma aliform (80) in all study sites (refer } \\
\text { to Figure } 5.7 \mathrm{C}) \text {. }\end{array}$ \\
\hline $\begin{array}{l}\text { Distribution of } \\
\text { paratracheal axial } \\
\text { parenchyma cells and } \\
\text { vessels in heartwood and } \\
\text { sapwood }\end{array}$ & $\begin{array}{l}\text { The frequency of Paratracheal Axial parenchyma bands reduced in the heartwood } \\
\text { compared with the sapwood. However, vessel distribution was similar in both } \\
\text { heartwood and sapwood. (Refer to Figure 5.6). }\end{array}$ \\
\hline \multicolumn{2}{|c|}{ Non-anatomical information applicable to $B$. plurijuga } \\
\hline \multicolumn{2}{|c|}{ Tropical mainland Africa and adjacent islands (Brazier and Franklin region 78) (178) } \\
\hline \multicolumn{2}{|l|}{ Tropical Africa (179) } \\
\hline \multicolumn{2}{|l|}{ Tree (189) } \\
\hline \multicolumn{2}{|c|}{ Wood of commercial importance (192) } \\
\hline \multicolumn{2}{|c|}{ Basic specific gravity $\geq 0.75(195)$} \\
\hline \multicolumn{2}{|c|}{ Heart wood colour darker than sapwood colour (Refer to Figure 5.4) (196) } \\
\hline \multicolumn{2}{|c|}{ Heart wood basically brown or shades of brown (Refer to Figure 5.4) (Figure 5.4) (197) } \\
\hline & L \\
\hline
\end{tabular}



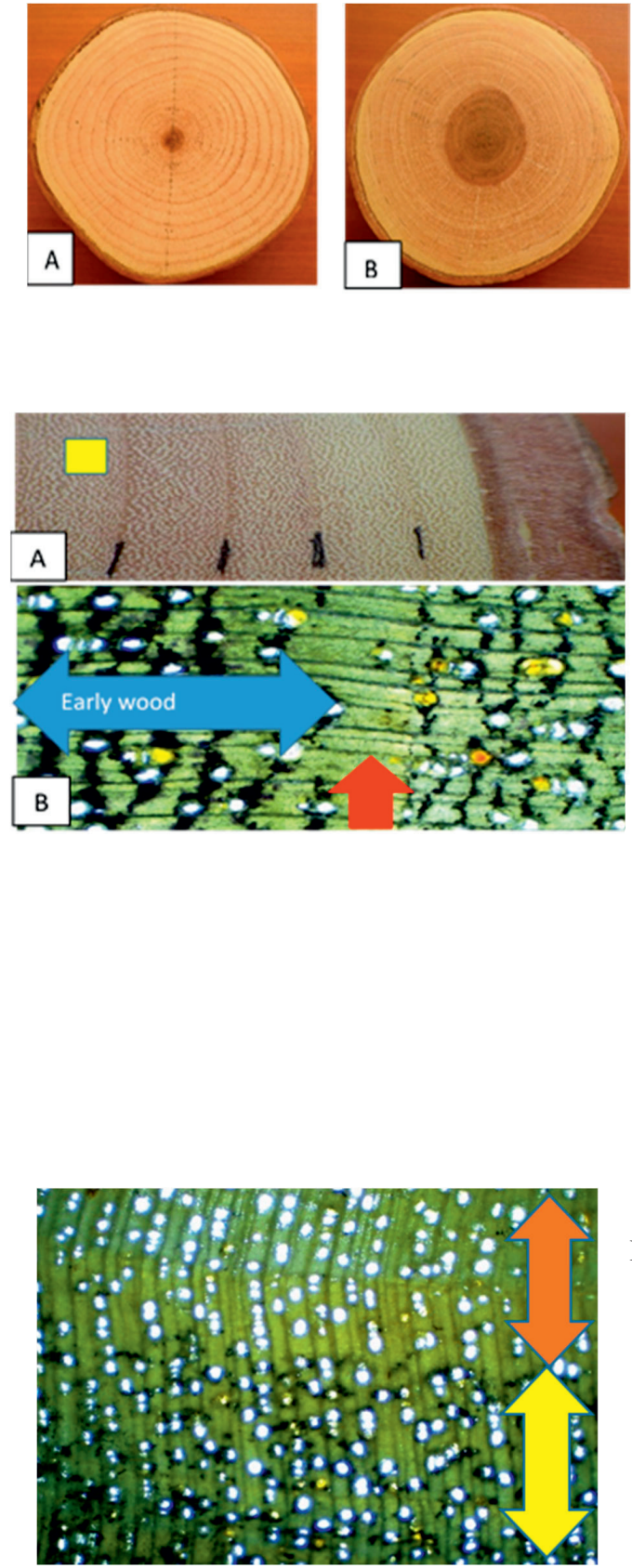

Figure 5.6 Distribution of axial parenchyma cells and vessels in heartwood and sapwood. Heart wood is shown by orange colour while sapwood by yellow colour. Lens: 004

\subsubsection{Growth ring formation in Baikiaea plurijuga}

Following the methods documented by Stahle (1999) to test for growth-ring formation, we confirmed ring formation in B. plurijuga based on ring porosity. The wood structure of $B$. 
plurijuga is diffuse porous (Figure 5.5) and at the end of the growing season is often (but not always) followed by dense fibre making up a latewood band that is fairly empty of pores.

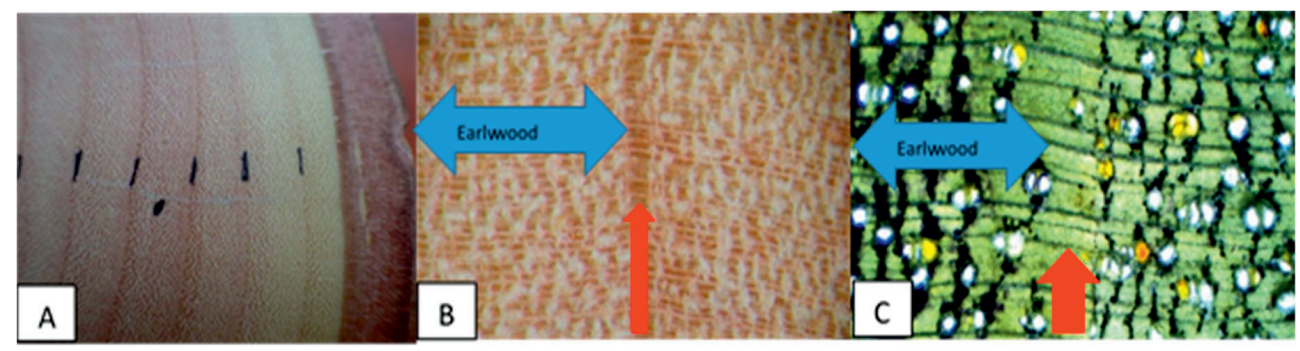

Figure 5.7 Growth rings (A), early and late wood (B) and microscopic features in early and late wood (C) of B. plurijuga. Late wood is shown by a red arrow (B) and microscopic features in the late wood are again shown by a red arrow (C).

We confirmed the annual nature of growth rings through cross dating. We successfully cross dated within trees and between trees at each site, but we were unable to cross date among the three sites. We further tested the annual formation of rings with samples of known age taken from Sesheke site and found that the age successfully correlated with the number of rings. The chronologies developed at each site were further correlated with monthly and annual climate variables to provide further evidence of the annual nature of growth rings. We found that the chronologies at each site successfully correlated with climatic variables (check details below) confirming that the rings formed in B. plurijuga are indeed annual. Following the diameter class (from $10 \mathrm{~cm}$ to $20 \mathrm{~cm}$ ) of the sampled trees, samples taken from Namwala were from 17-56 years old and those from Sesheke were 28 to 56 years old. However, samples from Kabompo site were from 32 to 44 years old.

The more distinct and wider Kabompo samples were easier to date than samples taken from the drier Sesheke site. We were able to date 92\% (12 samples) of the samples from Kabompo, 83\% (10 samples) from Namwala and 63\% (5 samples) from Sesheke sites. The mean sensitivity (i.e. change in ring width between subsequent years) increased and the series intercorrelation (i.e. correlation between trees within a single site) decreased as we moved from the wet Kabompo site to the dry Sesheke site. The Kabompo chronology (Figure 5.8A) was developed with 11 radii from nine trees and extends from 1973 to 2013 with a series intercorrelation of 0.603 and a mean sensitivity of 0.329 (Table 5.3). The chronology at the Namwala site (Figure 5.8B) was developed from 10 radii and eight trees and extends from 1958 to 2013 with a series inter-correlation of 0.604 and a mean sensitivity of 0.484 (Table 5.3). The Sesheke chronology (Figure 5.8C) was developed from eight radii representing five 
trees and extends from 1958 to 2013 with a series inter-correlation of 0.449 and a mean sensitivity of 0.527 (Table 5.3) (The KML file 2 is available on-line: B. plurijuga trees included in the chronologies). No segments in these three chronologies were flagged by the COFECHA software, indicating that all analysed segments have a high common signal strength in each of the studied sites.

Though we were able to cross-date the trees, problems occurred with locally wedging (or absent) rings and locally false rings. Where the number of rings between the radii of the same disc differed, all rings were followed around the whole disc to identify and settle the difference. Locally absent rings were easily detected and included in the analysis of the series by assigning them a zero width value. Locally false rings were subsumed into the total ring width. A total of six trees (one tree from Kabompo, two from Namwala and three trees from Sesheke) were removed from the analysis due to extreme problems of a lack of clear ring boundary.

Table 5.3: Descriptive statistics of the B. plurijuga chronologies for Kabompo, Namwala and Sesheke sites.

\begin{tabular}{|c|c|c|c|}
\hline \multirow[b]{2}{*}{ Descriptive statistics } & \multicolumn{3}{|l|}{ Study sites } \\
\hline & Site 1 (Kabompo) & Site 2 (Namwala) & Site 3 (Sesheke) \\
\hline $\begin{array}{l}\text { Annual rainfall (mm) (The } \\
\text { Government of the Republic } \\
\text { of Zambia and UNDP, 2009) }\end{array}$ & $800-1000$ & $\begin{array}{l}<700 \text { and } 800-1000 \\
\text { Located at the border of two } \\
\text { zones and thus experience } \\
\text { both climatic conditions }\end{array}$ & $<700$ \\
\hline Coordinates & $\begin{array}{l}14^{\circ} 00.551 \mathrm{~S}- \\
14^{\circ} 01.731 \mathrm{~S} \\
023^{\circ} 34.601 \mathrm{E}- \\
023^{\circ} 35.110 \mathrm{E}\end{array}$ & $\begin{array}{l}15^{\circ} 49.792 \mathrm{~S}-15^{\circ} 50.816 \mathrm{~S} \\
026^{\circ} 28.927 \mathrm{E}-026^{\circ} 31.875 \mathrm{E}\end{array}$ & $\begin{array}{l}16^{\circ} 50.979 \mathrm{~S}- \\
17^{\circ} 22.619 \mathrm{~S} \\
24^{\circ} 22.560 \mathrm{E}- \\
025^{\circ} 23.805 \mathrm{E}\end{array}$ \\
\hline Elevation (m) & 1059-1080 & 1040-1077 & $940-1005$ \\
\hline $\begin{array}{l}\text { Number of samples attempted } \\
\text { to analyse }\end{array}$ & 13 & 12 & $8^{\mathrm{a}}$ \\
\hline $\begin{array}{l}\text { Number of samples } \\
\text { successfully dated }\end{array}$ & 12 & 10 & $5^{\mathrm{a}}$ \\
\hline $\begin{array}{l}\text { Number of samples included } \\
\text { in the master chronology }\end{array}$ & 9 & 8 & $5^{\mathrm{a}}$ \\
\hline Number of radii & 11 & 10 & $8^{\mathrm{a}}$ \\
\hline Time span of the chronology & $1973-2013$ & $1958-2013$ & $1958-2013$ \\
\hline $\begin{array}{l}\text { Age of trees included in } \\
\text { chronology (years) }\end{array}$ & $32-44$ & $17-56$ & $28-56$ \\
\hline \begin{tabular}{|l} 
Series inter-correlation \\
(Correlation between trees)
\end{tabular} & 0.603 & 0.604 & 0.449 \\
\hline $\begin{array}{l}\text { Mean sensitivity (change in } \\
\text { ringwidth between two years) }\end{array}$ & 0.329 & 0.484 & 0.527 \\
\hline $\begin{array}{l}\text { Average ring width (mm) (raw } \\
\text { data before standardization) }\end{array}$ & 2.473 & 2.473 & 1.605 \\
\hline
\end{tabular}



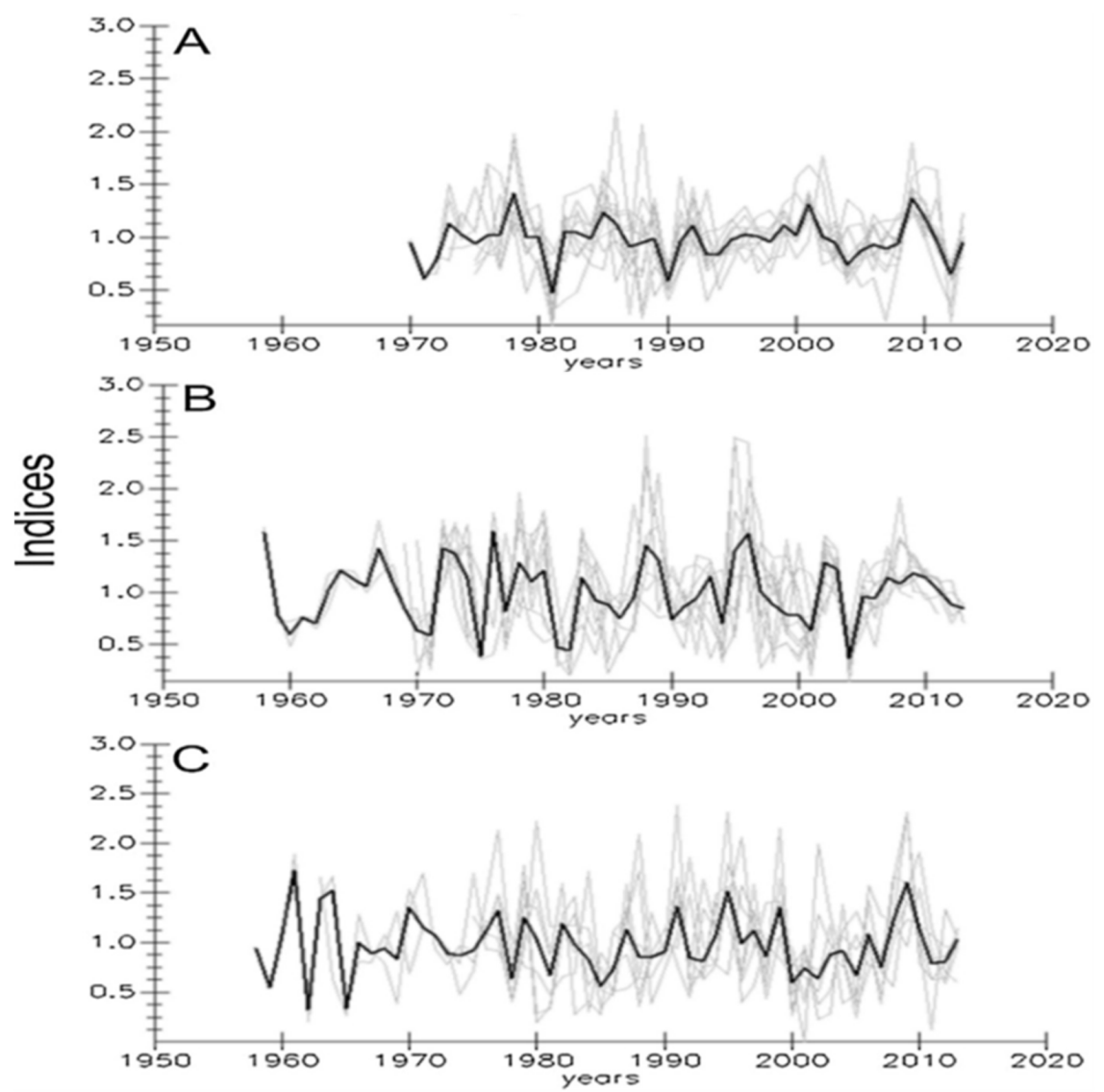

Figure 5.8 The tree-ring chronologies of B. plurijuga at Kabompo (A), Namwala (B) and Sesheke $(C)$ sites. The $\mathrm{Y}$-axis indicates the ring width after standardisation (indices). Greycurves are for individual samples and the black curves depict the mean for all the samples analysed at each site.

\subsubsection{Climate response analysis}

The chronologies of B. plurijuga were correlated $(\mathrm{p}<0.05)$ with rainfall, temperature and evaporation at Kabompo, Namwala and Sesheke sites (see Figure 5.9). At the Kabompo site the chronology significantly positively correlated only with total rainfall of February and March $(r=0.374)$ during the period 1975 - 2011, whereas for Namwala and Sesheke sites, no significant correlations were found between the chronologies and rainfall. Correlations between chronologies and temperature produced varying results with the highest correlation recorded in December at Kabompo site $(r=-0.540)$. At the Namwala site, the chronology positively correlated with October temperatures $(r=0.397)$, while other months recorded negative correlations during the period 1970 - 2011. Between 1958-2011, the tree-ring 
chronology at Sesheke site negatively correlated highest with January temperature $(r=-$ 0.378). At all the three sites, the chronologies were also correlated with evaporation. The strongest correlation $(\mathrm{r}=-0.557)$ was recorded at the Namwala site between the chronology and mean evaporation value of November plus March during the period 1973-2011. Whereas evaporation negatively correlated with the Sesheke chronology in March $(r=-0.436)$ only during the period 1972-1998, the chronology positively correlated highest $(r=-0.529)$ with March evaporation values during the period 1973-1999 at the Kabompo site. Comparing the three sites, the chronologies correlated the strongest with the mean evaporation of November plus March $(\mathrm{r}=-0.557)$ explaining $31 \%$ of the variance at the Namwala site and March value $(r=-0.436)$ explaining $19 \%$ of the variance at the Sesheke site. However, at the Kabompo site the chronology correlated highest with December temperature $(r=-0.540)$, explaining $29 \%$ of the variance.

The high evaporation influence on tree growth was also confirmed by a multiple regression analysis performed at the respective sites to determine the influence of total annual rainfall, mean annual temperature and mean annual evaporation. Results show that at all the three sites, evaporation has the highest influence (Table 5.4).

Table 5.4: Results of multiple regression performed at Kabompo, Namwala and Sesheke sites $(\mathrm{p}=95 \%)$

\begin{tabular}{|l|l|l|l|l|}
\hline \multirow{3}{*}{ Study site } & \multicolumn{2}{|l|}{$\mathbf{r}^{\mathbf{2}}(\mathbf{p}$-value) } & \multirow{2}{*}{} \\
\cline { 2 - 4 } & Temperature & Precipitation & Evaporation & Period covered \\
\hline Kabompo & $0.57(0.05)$ & $0.57(0.03)$ & $0.57(0.01)$ & $1973-1989$ \\
\hline Namwala & $0.31(0.81)$ & $0.31(0.15)$ & $0.31(0.01)$ & $1973-2011$ \\
\hline Sesheke & $0.22(0.96)$ & $0.22(0.52)$ & $0.22(0.02)$ & $1973-2000$ \\
\hline
\end{tabular}

\subsection{Discussion}

The specific objectives of this study were to determine whether B. plurijuga forms annual rings and if so, whether these rings are cross-datable. We further wanted to determine the relationship between ring width of $B$. plurijuga and climatic variables. We collected tree-ring samples from three Zambezi Teak forest reserves and were successful in developing tree-ring chronologies from each of the sites using B. plurijuga and finally correlated with temperature, rainfall and evaporation.

\subsubsection{Growth ring formation}

One factor controlling wood formation is tree phenology (Kozlowski, 1971) and with high seasonality in rainfall, trees are likely to form clear growth boundaries (Jacoby, 1989). In 
Zambia, there is only one distinct dry season. Rains start in late October and end in April (see Figure 5.2) and the phenology of B. plurijuga follows the same pattern. Leaf senescence and fall of $B$. plurijuga, coincides with decreasing moisture levels in the soil and leaf flush starts in October (following the rains) (Childes, 1988). This seasonality induces cambial dormancy of trees. A new leaf flush of $B$. plurijuga is also supported by groundwater or water at soil levels close to the tree. Thus, variations in phenology may also occur due to differences in the groundwater table (Högberg, 1984). However, during this study, data on ground water was not available.

An examination of the anatomical structure of B. plurijuga revealed that the wood is diffuse porous and forms growth rings. The absence of clear dormancy of the cambial layer (Sass et al., 1995) and lack of common features that clearly denote annual growth rings in some of the tropical trees (Gourlay, 1995a) might raise some questions on the dendrochronological potential of B. plurijuga. However, we confirmed further growth-ring formation and annual nature of the rings with samples of known age of trees from plantations that were included in the chronology at the Sesheke site. Also, identification of seasonal growth changes in the wood anatomy gave us more confidence in the results. In general, we found that the wood had clearer ring structure and rings were wider in wetter Kabompo $(2.473 \mathrm{~mm})$ than in drier Sesheke $(1.605 \mathrm{~mm})$ sites. This is probably because Kabompo receive more rain that the rings were larger and easier to differentiate. We further found that the wood became more eccentric in the drier Sesheke site. To increase dating accuracy, we worked with whole tree discs and we targeted younger trees (between $10 \mathrm{~cm}$ and $20 \mathrm{~cm}$ in diameter at breast height) because their ring structure was more clear compared to older trees that we checked during our pilot project. The unclear ring structure in the heartwood could be associated with the decreased frequency of parenchyma cells though vessel distribution is the same in both heartwood and sapwood (See Figure 5.6). We are aware that the sampling strategy we used of including young trees only $(10-20 \mathrm{~cm}$ diameter) would raise some questions on the potential nature of $B$. plurijuga for use in dendrochronological studies. However, being a species with complex anatomical structure and studying it for the first time, we wanted to work with samples that show clear growth-ring boundaries so that we would have higher confidence in the results. We also wanted to use samples of a similar diameter class with those of known age for easy comparison. This biased sample selection reduced the chances of errors resulting from omitting some rings, though the length of the chronologies was relatively short: 1973-2013 at Kabompo, 1958-2013 at Namwala and 1958-2013 at Sesheke sites. To get a clear view of the 
relationship between age and tree-ring formation, a more detailed study across ecological zones needs to be conducted on trees of different age classes.

Despite being successful in developing individual chronologies at each site, we could not develop a regional master chronology as samples from different sites could not be crossdated. Sites were located between $350 \mathrm{~km}$ and $610 \mathrm{~km}$ apart and these long distances, which indicate different environmental conditions, limited the cross dating. Series inter-correlation (i.e. the average correlation of each series with a master chronology) reduced with decreasing rainfall. Series inter-correlation measures the strength of the common signal in trees which is likely due to a climate signal. Thus, the trend in series inter-correlation from a high rainfall receiving area $(r=0.60)$ to a low rainfall receiving area $(r=0.45)$ shows that trees in all study sites depend on rainfall though the dependence reduces with reduced amount of rainfall received. Series inter-correlation also indicate a measure of chronology reliability of which higher values indicate more reliable chronologies compared to chronologies with low series inter-correlation. In this research, though the chronology developed in Sesheke (low rainfall receiving area) has a lower value of series inter-correlation $(r=0.45)$ compared with that developed at Kabompo site, it is still a very reliable chronology in that some trees (2 out of 5 trees) included in the chronology were of known age and we were able to correlate the number of tree rings with the ages of the trees. Lower series inter-correlation reported in Sesheke could also be attributed to the distribution of sampled trees. Trees that were sampled in Sesheke were more spread out than those sampled in Kabompo and Namwala. This indicate that trees within Sesheke site might experience different environmental conditions, thereby reducing the series inter-correlation (See KML file 2 online). A comparison with other studies in southern Africa (see Table 5.5) showed that series inter-correlation of B. plurijuga in all the three study site is higher than in some other species indicating a high common signal and more reliable chronologies (see Table 5.5).

Higher mean sensitivity values (change in ring-width from one year to the next) indicate the ease of dating the trees at a study site, but up-to a certain limit. Complacent trees (mean sensitivity around 0.1 ) are difficult to date because of the low degree of their annual variation. More sensitive trees (mean sensitivity of more than 0.4) are also hard to date due to frequent micro rings next to very wide rings (Speer, 2010) that result from high year-to-year variability of limiting growth factors (e.g. rainfall and temperature). This behaviour was observed during this research where the drier Sesheke site with higher mean sensitivity (0.527) was quiet difficult to date compared to the wet Kabompo site which has lower mean sensitivity value (0.329) ( see Tables 5.3). Thus, the high mean sensitivity in Sesheke indicate high annual 
variations of environmental growth factors. Table 5.5 gives mean sensitivity values of other species in southern Africa.

\subsubsection{Climate correlations}

The locations of the study sites clearly indicate a moisture-availability trend from the wetter Kabompo site area to the drier Sesheke site. The Namwala site is located at the border of the two agro-ecological zones and the Ila forest reserve stretches in both zones.

Evaporation correlates negatively at all the study sites with higher correlations recorded during the rainy season. In Zambia, the rainfall period (Figure 5.2) is usually associated with high temperatures which is one of the important factors affecting evaporation. Thus, available water in combination with high temperatures results in more water being lost in the form of evaporation, which leaves less water remaining in the soil for root uptake and thereby affecting tree growth negatively (see Figure 5.9).

Just like evaporation, temperature correlates negatively with tree-ring chronologies at all the study sites except for October correlations at Namwala site. The negative relationship between temperature and tree-ring chronologies at our sites are similar to the results reported for other trees in southern Africa (see Table 5.6). The negative correlation could be as a result of reduced photosynthesis (reduced carbon assimilation) due to increased temperature (Clark, 2004; Galbraith et al., 2010). The positive relationship recorded in October (i.e. the beginning of the rain season, see Figure 5.2) could be as a result of rapid tree growth immediately after bud burst. This seems to be a common behaviour for trees in Zambia as similar results $\left(\mathrm{r}^{2}=\right.$ 0.24 ) were reported by other researchers (Trouet, 2004) who carried out research on Brachystegia spiciformis at Mpika site (see Table 5.6).

In general, the relationship between growth and rainfall was positive during the rainy season (Figure 5.9), indicating that growth is limited by the amount of rainfall. Other studies (Fichtler et al., 2004; Schöngart et al., 2006; Therrell et al., 2006; Therrell et al., 2007; Couralet et al., 2010; Trouet et al., 2010) (also See Table 5.7) conducted on tropical trees reported similar results under wetter conditions. For B. plurijuga, significant correlations were only recorded at the wetter Kabompo site with the total sum of February and March rainfall. 


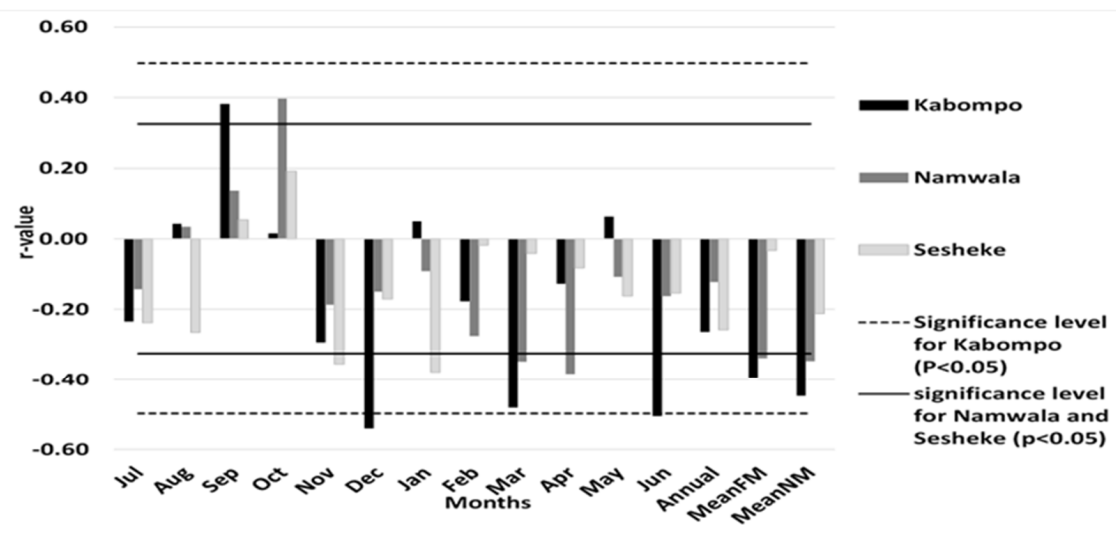

(A) Correlation between temperature and indexed chronologies of Baikiaea plurijuga at Kabompo (1973 - 1989), Namwala(1970 - 2011) and Sesheke (1958 - 2011) study sites

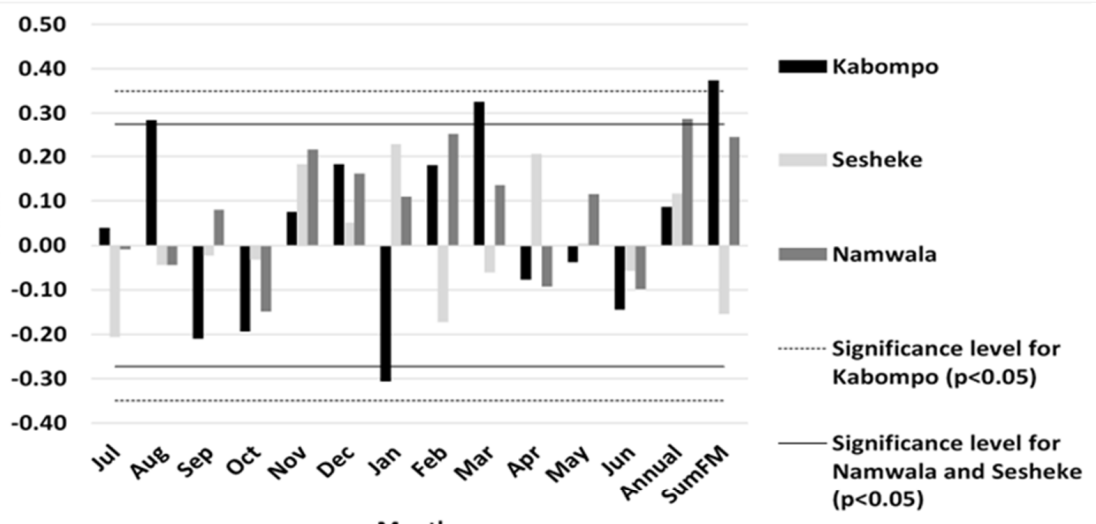

Months

(B) Correlation between rainfall and indexed chronologies of Baikiaea plurijuga at Kabompo (1975 2011), Namwala(1970 - 2011) and Sesheke (1958 - 2011) study sites

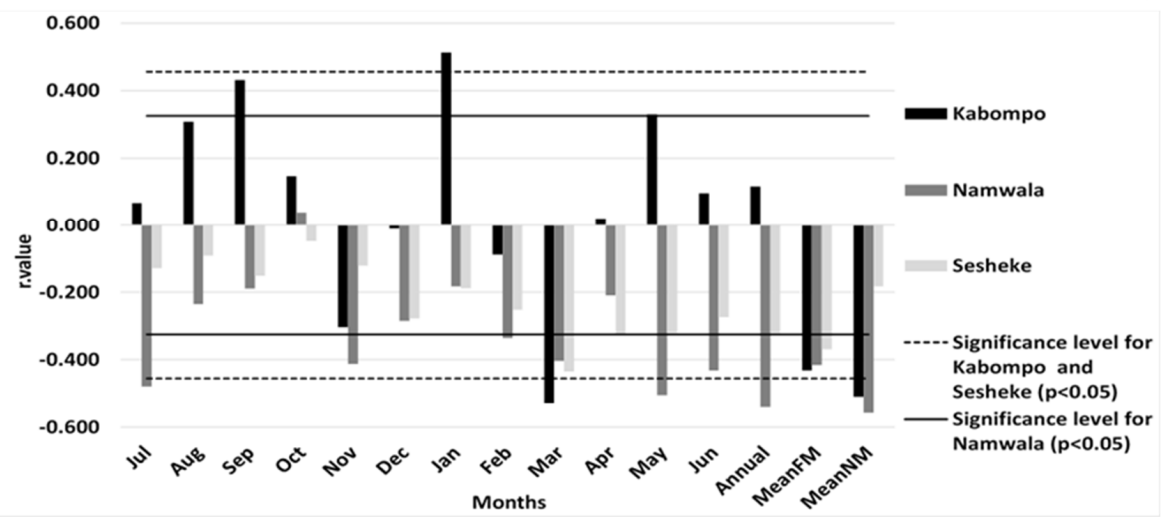

(C) Correlation between Evaporation and indexed chronologies of Baikiaea plurijuga at Kabompo (1975 - 2011), Namwala(1970 - 2011) and Sesheke (1972 - 1998) study sites

Figure 5.9 Correlation values between tree-ring chronologies and temperature (A), rainfall (B) and evaporation (C) in Kabompo, Namwala and Sesheke sites. 
Table 5.5: Series inter-correlation and mean sensitivity of different species in southern Africa.

\begin{tabular}{|c|c|c|c|c|c|}
\hline $\begin{array}{l}\text { Country of } \\
\text { study }\end{array}$ & Study site & Species & $\begin{array}{l}\text { Series inter- } \\
\text { correlation }\end{array}$ & $\begin{array}{l}\text { Mean } \\
\text { sensitivity }\end{array}$ & Reference \\
\hline Zambia & Kabompo & Baikiaea plurijuga & 0.60 & 0.33 & This study \\
\hline Zambia & Namwala & Baikiaea plurijuga & 0.60 & 0.48 & This study \\
\hline Zambia & Sesheke & Baikiaea plurijuga & 0.45 & 0.53 & This study \\
\hline Zambia & Mongu (site 1) & Brachystegia spiciformis & 0.24 & 0.41 & (Trouet et al., 2006) \\
\hline Zambia & Mongu (site 2) & Brachystegia spiciformis & 0.29 & 0.39 & (Trouet et al., 2006) \\
\hline Zambia & Mongu (site 3) & Brachystegia spiciformis & 0.26 & 0.49 & (Trouet et al., 2006) \\
\hline Zambia & Livingstone & Brachystegia spiciformis & 0.17 & 0.48 & (Trouet, 2004) \\
\hline Zambia & Choma & Brachystegia spiciformis & 0.16 & 0.43 & (Trouet, 2004) \\
\hline Zambia & Mumbwa & Brachystegia spiciformis & 0.13 & 0.52 & (Trouet, 2004) \\
\hline Zambia & Mpika & Brachystegia spiciformis & 0.13 & 0.50 & (Trouet, 2004) \\
\hline Zambia & Mongu & Brachystegia bakariana & 0.30 & 0.42 & (Trouet, 2004) \\
\hline Zambia & Solwezi & Brachystegia boehemii & 0.18 & 0.42 & (Trouet, 2004) \\
\hline Zambia & Ndola & Brachystegia boehemii & 0.15 & 0.38 & (Trouet, 2004) \\
\hline Zambia & Ndola & Erythophleum africanum & 0.22 & 0.32 & (Trouet, 2004) \\
\hline Namibia & Ondangwa & Burkea africana & 0.21 & 0.57 & (Trouet, 2004) \\
\hline Namibia & Ondangwa & Pterocarpus angolensis & 0.24 & 0.47 & (Trouet, 2004) \\
\hline Namibia & Katima Mulilo & Pterocarpus angolensis & 0.40 & 0.53 & (Trouet, 2004) \\
\hline Namibia & Katima Mulilo & Burkea africana & 0.25 & 0.56 & (Trouet, 2004) \\
\hline Zimbabwe & $\begin{array}{l}\text { Matabeleland, } \\
\text { Sikumi and } \\
\text { Mzola }\end{array}$ & Pterocarpus angolensis & 0.63 & - & $\begin{array}{l}\text { (Therrell et al., } \\
\text { 2006) }\end{array}$ \\
\hline Zimbabwe & Sikumi & Pterocarpus angolensis & 0.56 & - & (Stahle et al., 1999) \\
\hline Zimbabwe & Mzola & Pterocarpus angolensis & 0.49 & - & (Stahle et al., 1999) \\
\hline Mozambique & Sofala province & Millettia stuhlmannii & $0.39-0.75$ & 0.806 & $\begin{array}{l}\text { (Remane and } \\
\text { Therrell, 2015) }\end{array}$ \\
\hline
\end{tabular}

This shows that for these species, the monthly response of tree growth to rainfall is very minimal when there is a little water in the soil until the end of the rainy season when there is accumulated tree growth and an increased amount of water in the soil. Thus, after a time-lapse of 3-4 months following the start of the rainy season, there is enough water in the soil to support significant tree growth supporting the concept that B. plurijuga is a slow growing tree. 


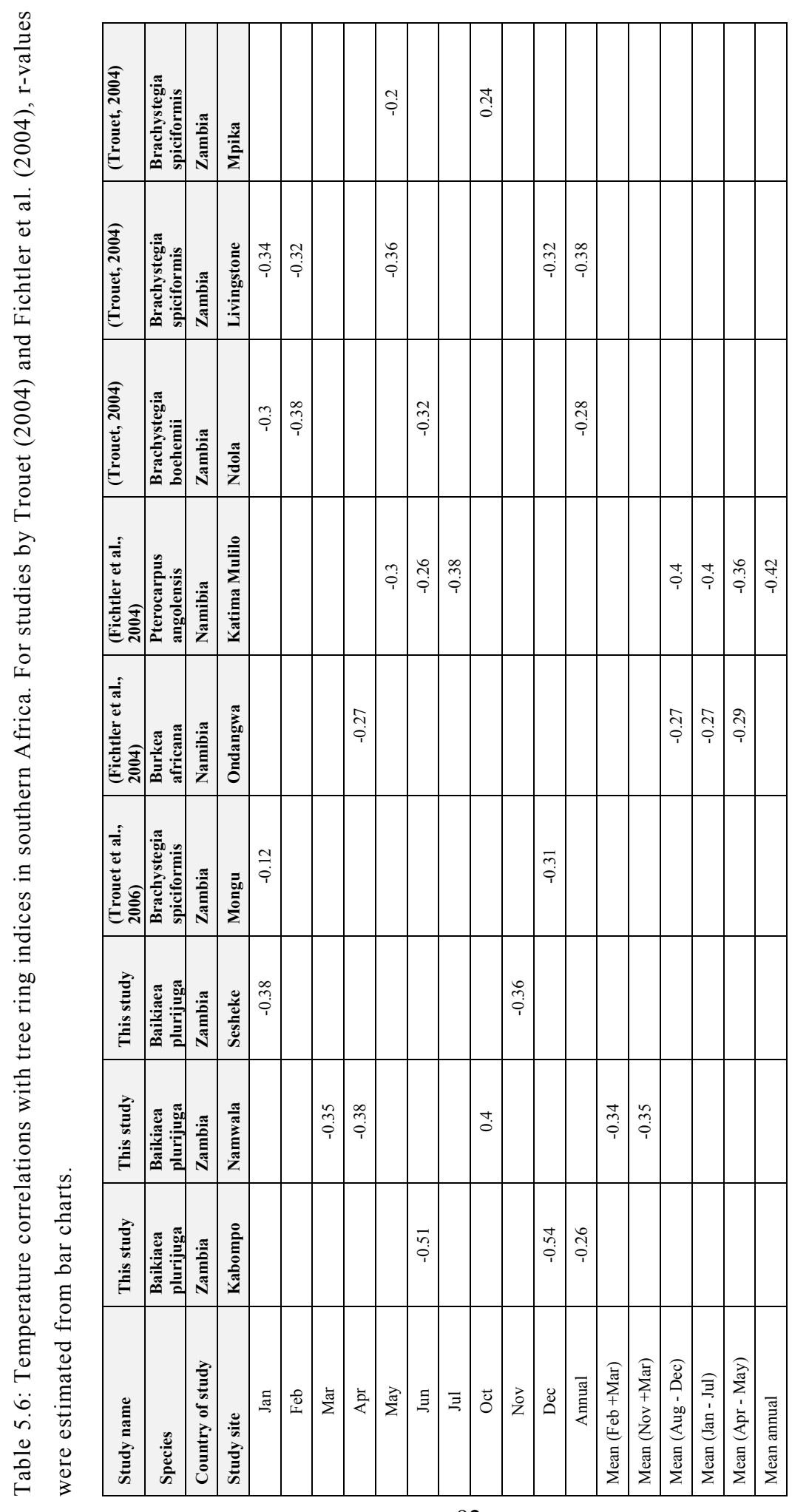




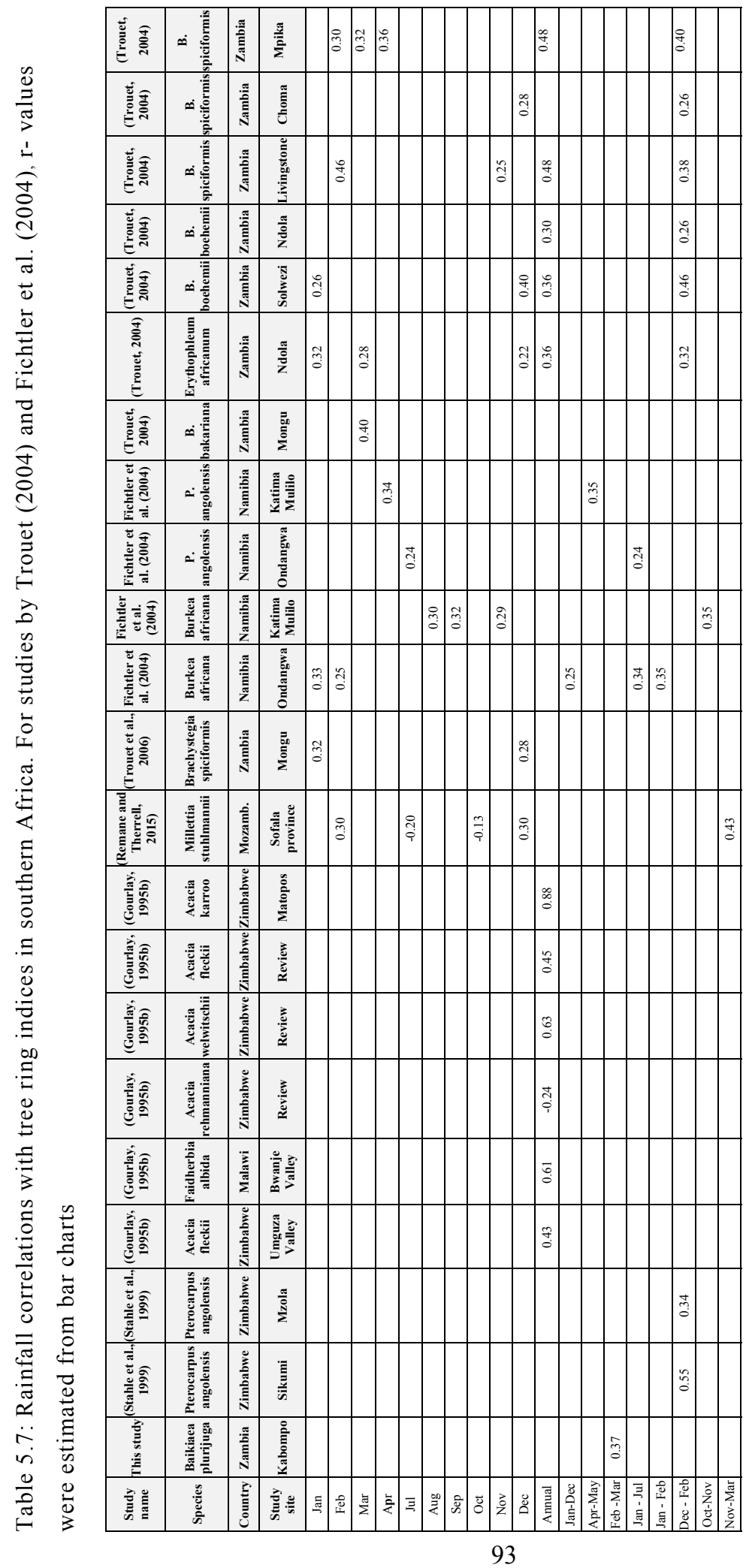


The correlations at the Namwala site were difficult to understand since this site is located at the border of two agro-ecological zones and the forest reserve stretches across these zones. Climate data was drawn from the Choma meteorological station, which only represents one zone (see Figure 5.2). Tree growth could thus be affected by more diverse climatic conditions. This could explain the lower correlations (see Figure 5.9) between tree-ring chronologies and the three climatic variables studied.

Following the report by Niang et al. (2014), the temperature is projected to increase and rainfall reduce in southern Africa. Results of this study show an indirect relationship between tree growth and temperature and a direct relationship with rainfall. This means that with projected changes in climate, B. plurijuga will be affected negatively. This situation will apply to most trees in southern Africa as the relationships are similar though the strengths differ (see Tables 5.6 and 5.7).

Tree growth is strongly influenced by rooting characteristics in combination with water availability. In general, shallow rooting trees are more sensitive to current rainfall compared to deep-rooted trees that are able to reach a more permanent groundwater table (Gourlay, 1995a). The tap root of $B$. plurijuga grows very deep and the rooting depth is estimated at down to $6 \mathrm{~m}$ to $9 \mathrm{~m}$ as reported by Högberg (1984) though Childes (1988) reported a rooting depth of down to $10 \mathrm{~m}$. During this research, maximum rooting depth of down to $5.8 \mathrm{~m}$ was observed when three trees of diameter size $25 \mathrm{~cm}, 35 \mathrm{~cm}$ and $44 \mathrm{~cm}$ (diameter at breast height, $\mathrm{dbh}$ ) where excavated at the Sesheke site. The rooting depths were recorded at the point when roots reached $5 \mathrm{~mm}$ in diameter. Although no trees were uprooted in the Namwala and Kabompo sites during our research, it is assumed that in these two study sites, roots of $B$. plurijuga grow very deep since the soil has large fractions of sand as well. To have a better understanding of the rooting depth of B. plurijuga in the different ecological zones, further studies need to be conducted to compare rooting characteristics in combination with water availability.

To understand if other factors might influence the growth of $B$. plurijuga in different sites, soil parameters and vegetation composition were considered. An analysis of soil texture in the field revealed that the soils are mainly sand in all the three sites. This was confirmed with existing literature (The Government of the Republic of Zambia, 1969; Chisumpa, 1986; Mbughi, 1986). An inventory we carried out in 2014 showed that the vegetation composition is the same in all the study sites. In all the study sites, samples were collected in areas with almost no disturbance by local people to avoid anthropogenic influence on tree growth. This leaves climate to be the main parameter that is different in the three sites studied which is thus 
likely to be the main cause of differences in tree ring formation of $B$. plurijuga in the three study sites.

\subsection{Conclusions}

This research focused on the potential of B. plurijuga to use in dendrochronological studies and further understand the potential climate change effects on the growth of the species through the use of relatively young trees. Our analysis clearly shows that relatively young trees of B. plurijuga form annual rings and that these rings are cross-datable within a site. As for older trees, further studies need to be conducted to determine growth ring formation with age in different ecological zones. Tree growth is affected positively by rainfall, but temperature and evaporation have a negative influence. In the wetter areas studied, effects of rainfall, temperature and evaporation are higher compared with the effects in the drier sites. This is because in drier areas there is less rainfall available to satisfy the evapotranspiration demand. Our analysis indicates that future temperature increase, which increases evaporation and reduced rainfall as projected by Niang et al. (2014), will adversely affect southern African young B. plurijuga. 
Chapter 5 


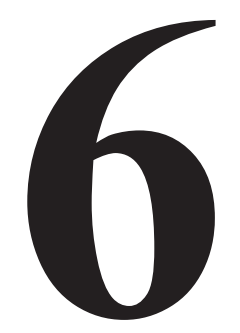

\section{MODELLING THE RESPONSE OF NET PRIMARY PRODUCTIVITY OF ZAMBEZI TEAK FORESTS TO CLIMATE CHANGE ALONG A RAINFALL GRADIENT IN ZAMBIA}

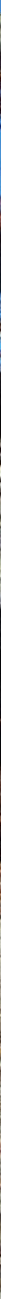




\section{Abstract}

Understanding climate change effects on forests is important considering the role forests play in mitigating climate change. We studied the effects of changes in temperature, rainfall, atmospheric carbon dioxide $\left(\mathrm{CO}_{2}\right)$ concentration, solar radiation and number of wet days (as a measure of rainfall intensity) on net primary productivity (NPP) of the Zambian Zambezi teak forests along a rainfall gradient. Using 1960-1989 as base-line, we projected changes in NPP for the end of the $21^{\text {st }}$ century (2070-2099). We adapted the parameters of the dynamic vegetation model, LPJ-GUESS, to simulate the growth of Zambian forests at three sites along a moisture gradient receiving annual rainfall of between $700 \mathrm{~mm}$ to more than $1000 \mathrm{~mm}$. The thus adjusted plant functional type was tested against measured data. We forced the model with contemporary climate data (1960-2005) and with climatic forecasts of an ensemble of five General Circulation Models (GCMs) following RCP4.5 and RCP8.5. We used local soil parameter values to characterize texture and measured local tree parameter values for maximum crown area, wood density, leaf longevity and allometry. The results simulated with the LPJ-GUESS model improved when we used these newly generated local parameters indicating that using local parameter values is essential to obtaining reliable simulations at site level. The adapted model setup provided a baseline for assessing the potential effects of climate change on NPP in the Zambezi teak forests. While increased $\mathrm{CO}_{2}$ concentration enhances NPP at the wetter Kabompo and the intermediate Namwala sites, NPP decreases at the drier Sesheke site under both RCPs by the end of the $21^{\text {st }}$ century. The projected decreased NPP under RCP8.5 at the Sesheke site results from the reduced rainfall coupled with increasing temperatures. We thus demonstrated that differences in rainfall pattern influence the way in which climate change will affect forest resources. The projected increase in $\mathrm{CO}_{2}$ concentration would thus, have more effects on NPP in high rainfall receiving areas, while in arid regions, NPP would be affected more by the changes in rainfall and temperature.

\footnotetext{
Submitted to Biogeosciences as:
}

Ngoma J, Braakhekke MC, Kruijt B, Moors E, Supit I, Speer JH, Vinya R, Leemans R. 2019. Modelling the response of Net Primary Productivity of Zambezi teak forests to climate change along a rainfall gradient in Zambia. Biogeosciences. "Under review", 1-23

The initial submission of this paper received positive comments from the handling editor and the two reviewers. The paper has been re-submitted after incorporating the received comments. We are currently waiting for final decision from the journal. 


\subsection{Introduction}

The tropical Zambezi teak forests represent important forest types of southern Africa. They are found in Angola, Botswana, Namibia, Zambia, and Zimbabwe. These forests are a source of valuable commercial timber produced from Baikiaea plurijuga Harm and provide employment through wood based industries (Piearce, 1986a; Piearce, 1986c). Additionally, the Zambezi teak forests play a substantial role in mitigating climate change as carbon sinks (Sarmiento and Gruber, 2002).

The Zambezi teak forests cover 9\% of Zambia's total forest area (Matakala et al., 2015) and store between $15 \mathrm{t} \mathrm{C} \mathrm{ha}^{-1}$ to $36 \mathrm{t} \mathrm{Cha}^{-1}$ (Ngoma et al., 2018a) across a south-north climatic gradient with annual rainfall ranging from $700 \mathrm{~mm}$ to $1100 \mathrm{~mm}$. They are found on the flat areas covered with a thick layer of Kalahari sands (The Government of the Republic of Zambia, 1996). These Zambezi teak forests are threatened by deforestation, and between 1975 to 2005 the forests halved in area (Musgrave, 2016) due to logging and agricultural activities, driven by economic and population growth (Theilade et al., 2001; Matakala et al., 2015).

Climate change is another threat to the Zambezi teak forests.

In southern Africa, rainfall has declined (Hoerling et al., 2006; Niang et al., 2014) and dry spells have increased (New et al., 2006) over the last few decades. Model projections indicate that this trend will continue in the future. During the past half century, mean annual temperatures increased by $0.5^{\circ} \mathrm{C}$ in some parts of Africa (Niang et al., 2014). By the end of the $21^{\text {st }}$ century, southern African mean temperatures are projected to increase by between $3.4^{\circ} \mathrm{C}$ and $4.2^{\circ} \mathrm{C}$ above the $1981-2000$ baseline under the $\mathrm{A} 2$ scenario (Niang et al., 2014). In southern Zambia, maximum temperatures increased by $1^{\circ} \mathrm{C}$ between 1976 and 2016 (Dube and Nhamo, 2018), and over the past 30 years, the Zambian mean temperatures increased by $0.6^{\circ} \mathrm{C}$ (Bwalya, 2010). A 31 years of temperature records showed a substantial increase in average seasonal temperatures (October-April) (Mulenga et al., 2017). By the year 2070, Zambia's temperatures are projected to increase by $2.9^{\circ} \mathrm{C}$ with reference to 1880 (The Government of the Republic of Zambia et al., 2007). Rainfall reduced by $47 \mathrm{~mm}$ between 1976 and 2016 in Southern Zambia (Dube and Nhamo, 2018). Magadza (2011) reported a declining trend in rainfall beginning in the early 1980's though other researchers did not find significant changes in Zambia's rainfall (Kampata et al., 2008; Stern and Cooper, 2011; Mulenga et al., 2017). Drought and seasonal floods have increased in Zambia and the worst drought was experienced in 1991/1992 (The Government of the Republic of Zambia et al., 2007). The latest drought was recorded in 2007/2008 rainy season (Bwalya, 2010). During the 
1978/1979 season, Zambia experienced the wettest conditions ever (Bwalya, 2010).

Projections show that by the year 2070, Zambia's rainfall will increase with reference to 2010 (The Government of the Republic of Zambia et al., 2007).

The effects of these climatic changes will vary with location, ecosystem types, and climate zones (Wu et al., 2011). While increased temperature stimulates plant productivity to its optimal temperature in some plants (Wu et al., 2011) it also exponentially stimulates autotrophic plant respiration (Burton et al., 2008; Wu et al., 2011). Such increasing temperature effects can either be enhanced or moderated, depending on whether water availability decreases or increases (Chen et al., 2013). Reduced rainfall, generally supresses the productivity of the plants (Wu et al., 2011).

In Zambia, the potential effects of climate change on the forests remain uncertain and the response of net primary productivity (NPP) to climate change could be diverse due to strong heterogeneity and variability in regional contemporary climatic conditions and the differences in projected future climatic conditions. Understanding how terrestrial NPP responds to climate change is important as it subsequently affects forests' biomass. Biomass loss also implies a potential risk of losing the various ecosystem services provided by the forests (Piearce, 1986a; Piearce, 1986c; Sarmiento and Gruber, 2002). In this study, we applied the LPJ-GUESS model (Smith et al., 2001; Ahlström et al., 2012) to quantify the projected future effects of changes in temperature, rainfall, $\mathrm{CO}_{2}$ concentration, solar radiation and number of wet days on NPP under RCP4.5 and RCP8.5. We projected changes in NPP for the end of the $21^{\text {st }}$ century (2070-2099) with reference to $1960-1989$ period as baseline. Our overall objective was to assess the future response of the NPP to climate change in the Zambezi teak forests along a rainfall gradient in Zambia.

\subsection{Materials and methods}

\subsubsection{Study sites}

We carried out the study for the Zambian Zambezi teak forests at the Kabompo $\left(14^{\circ} 00.551 \mathrm{~S}\right.$, $\left.023^{\circ} 35.106 \mathrm{E}\right)$, Namwala $\left(15^{\circ} 50.732 \mathrm{~S}, 026^{\circ} 28.927 \mathrm{E}\right)$ and Sesheke $\left(17^{\circ} 21.278 \mathrm{~S}, 24^{\circ}\right.$ 22.560E) sites. At the Sesheke site, the Masese forest reserve was assessed while at the Namwala site, we assessed the Ila forest reserve. At the Kabompo site, we studied the Kabompo and Zambezi forest reserves. While the Masese forest reserve is found in the drier agro-ecological zone I, the Kabompo and Zambezi forest reserves are located in the wetter 
ecological zone II. The Ila forest reserve at the Namwala site stretches along ecological zones I and II (Figure 6.1 and Table 6.1).

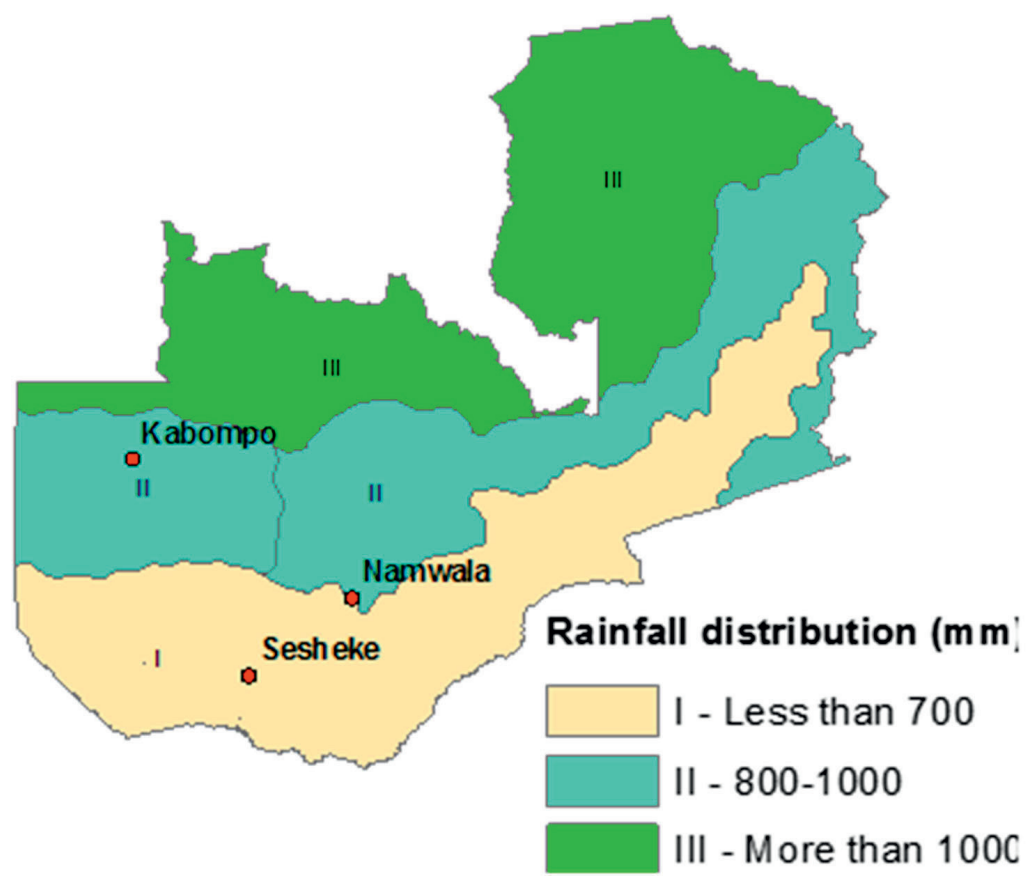

Figure 6.1 Rainfall pattern and distribution of study sites following the ecological zones I, II and III (Wamunyima, 2014).

Table 6.1: Climate and soil characteristics at Kabompo, Namwala and Sesheke. For rainfall and temperature, the period covered for average values presented are given in brackets.

\begin{tabular}{|l|l|l|l|}
\hline Parameter & Kabompo & Namwala & Sesheke \\
\hline Coordinates & $14^{\circ} 00.551 \mathrm{~S}$, & $15^{\circ} 50.732 \mathrm{~S}$, & $17^{\circ} 21.278 \mathrm{~S}$, \\
& $023^{\circ} 35.106 \mathrm{E}$ & $026^{\circ} 28.927 \mathrm{E}$ & $24^{\circ} 22.560 \mathrm{E}$ \\
\hline Ecological zone & II & I and II & I \\
\hline Total annual rainfall (mm) & $983.46(1944-2011)$ & $905.20(1944-2011)$ & $643(1947-2011)$ \\
\hline Mean annual temperature $\left({ }^{\circ} \mathbf{C}\right)$ & $21.35(1959-2003)$ & $21.61(1959-2011)$ & $21.46(1950-2011)$ \\
\hline Nitrogen $(\%)$ & 0.0404 & 0.0301 & 0.0300 \\
\hline Clay $(\%)$ & 0.53 & 0.56 & 0.31 \\
\hline Silt $\mathbf{( \% )}$ & 0.54 & 0.55 & 0.43 \\
\hline Fine sand $(\%)$ & 35.51 & 63.22 & 24.89 \\
\hline Course sand $(\%)$ & 63.42 & 35.70 & 74.31 \\
\hline pH-H2O & 5.55 & 5.74 & 5.86 \\
\hline Organic carbon $(\%)$ & 0.77 & 0.73 & 0.90 \\
\hline Soil bulky density $\left(\mathbf{g} / \mathbf{m}^{3}\right)$ & 1.54 & 1.53 & 1.87 \\
\hline
\end{tabular}




\subsubsection{The LPJ-GUESS model description}

LPJ-GUESS (Smith et al., 2001; Ahlström et al., 2012) is a dynamic vegetation model (DVM) optimised for local, regional and global applications. The model uses temperature, precipitation, solar radiation, number of wet days, $\mathrm{CO}_{2}$ concentrations and soil texture as input variables to simulate the exchange of water and carbon between soils, plants and the atmosphere. The ecosystem composition and structure is then determined for each simulated scale. One grid cell has a number of patches of approximately 0.1 ha in size (Smith et al., 2001). Each patch has a mixture of PFTs (Sitch et al., 2003; Ahlström et al., 2012), distinguished by their bioclimatic niche (distribution in climate space), growth form (tree or herb), leaf phenology (evergreen, summer green, or rain green), photosynthetic pathway (C3 or C4) and life history type (shade-tolerant or shade-intolerant). In a patch, each woody plant belongs to one PFT and has a unique set of parameters that control establishment, phenology, carbon allocation, allometry, survival response to low light conditions, scaling of photosynthesis and respiration rates, and the limits in climate space the PFT can occupy. In the model, leaf longevity has a direct relationship with carbon storage and in LPJ-GUESS the relationship is implemented by relating the specific leaf area (SLA; $\mathrm{m}^{2} \mathrm{~kg} \mathrm{C}^{-1}$ ) to leaf longevity (See Equation 6.1) according to the 'leaf economics spectrum' (Reich et al., 1997): SLA $=0.2 \times e^{(6.15-0.46 \times \ln (12 \alpha))}$ (Equation 6.1) where $\alpha$ is leaf longevity (in years).

Photosynthesis, stomatal conductance, plant water uptake and evapotranspiration are modelled concurrently on a daily time step by a coupled photosynthesis and water module, which was adapted from the BIOME3 model (Haxeltine and Prentice, 1996). Soils have an upper $(0.0 \mathrm{~m}$ to $0.5 \mathrm{~m})$ and a lower $(0.5 \mathrm{~m}$ to $1.5 \mathrm{~m})$ layer, identical in texture. Water enters the upper soil layer through precipitation. Transpiration and evapotranspiration deplete the water content of the soil. Additional depletion of soil water may occur through percolation beyond the lower soil layer and out of reach by plant roots. Uptake by plants is partitioned according to the PFT specific fraction of roots situated in each layer (Smith et al., 2001).

NPP is determined from Gross Primary Productivity (GPP) after accounting for maintenance and growth respiration. The accrued NPP is allocated on an annual basis to leaves, sapwood and fine roots, enabling tree growth (Sitch et al., 2003). This allocation is adjusted such that the following four allometric equations, or 'constraints', controlling the structural development of the average individual, remain satisfied: Leaf area to sapwood cross-sectional area relationship (McDowell et al., 2002) (See Equation 6.2), the functional balance constraint 
(See Equation 6.3), the stem mechanics equation (Huang et al., 1992) (See Equation 6.4) and the crowding constraint (See Equation 6.5) (Reineke, 1933). In LPJ-GUESS, crown area ( $\mathrm{m}^{2}$ per individual) is determined from stem diameter (See Equation 6.6) and tree diameter is derived from the sapwood, heartwood and wood density (See Equation 6.7).

Changes in PFT populations occur through the establishment and mortality of individuals. Bioclimatic limits (average climate of the last 30 years) determine which PFTs are able to establish under current climatic conditions and establishment is implemented at the end of each simulation year for each PFT. Individual plants die due to stress, senescence, disturbance and fire. Fire depends on litter load, flammability and the available water content. Available water content is determined from the uppermost soil layer as a surrogate for the litter moisture content, which is not modelled explicitly (Thonicke et al., 2001). Biomass-destroying disturbances are simulated as a stochastic (random) process, affecting individual patches. The generic disturbances with a 100 year expected interval were prescribed. These kill all individuals on an affected patch, converting their biomass to litter (Smith et al., 2001). We used LPJ-GUESS version 3.0 and implemented a 'cohort mode' for our study (Smith et al., 2001; Braakhekke et al., 2017). Though this model version accounts for nitrogen dynamics in soil and vegetation, we did not switch nitrogen on during our simulations.

$$
\begin{array}{ll}
L A I=K_{\text {lasa }} \times S A & \text { (Equation 6.2) } \\
C_{\text {leaf }}=K_{l r} \times \omega \times C_{\text {root }} & \text { (Equation 6.3) } \\
\mathrm{H}=\mathrm{K}_{\text {allom } 2} \times \mathrm{D}^{\mathrm{K}_{\text {allom3 }}} & \text { (Equation 6.4) } \\
N \approx D^{-k_{r p}} & \text { (Equation 6.5) } \\
C A=K_{\text {allom } 1} \times D^{K_{r p}} & \text { (Equation 6.6) } \\
\mathrm{D}=\left[\frac{4 \times\left(C_{\text {sapwood }}+C_{\text {heartwood }}\right)}{W D \times \pi \times K_{\text {allom } 2}}\right]^{1 /\left(2+K_{\text {allom } 3}\right.} & \text { (Equation 6.7) }
\end{array}
$$

Where $\mathrm{K}_{\text {lasa, }} \mathrm{K}_{\mathrm{lr}}, \mathrm{K}_{\mathrm{rp}}$, $\mathrm{K}_{\mathrm{allom} 1}, \mathrm{~K}_{\mathrm{allom}}$ and $\mathrm{K}_{\text {allom3 }}$ are all constants, LAI is the leaf area index, SA is the sapwood cross section area $\left(\mathrm{m}^{2}\right)$, Cleaf is leaf carbon $\left(\mathrm{kg} \mathrm{C} \mathrm{m}^{2}\right), \mathrm{C}_{\text {root }}$ is root carbon $\left(\mathrm{kg} \mathrm{C} \mathrm{m}{ }^{2}\right), \omega$ is the mean annual value of a drought-stress factor which varies between 0 and 1 and higher values represent greater water availability. In our study we used a value of 0.35 , which is the water stress threshold for leaf abscission (i.e. the point at which the leaves start shading). H stands for total tree height (m), D is tree diameter (m), N stands for population density (individuals per $\left.\mathrm{m}^{2}\right), \mathrm{CA}$ is crown area $\left(\mathrm{m}^{2}\right)$, WD stands for wood density $\left(\mathrm{kg} \mathrm{C} \mathrm{m}^{-3}\right)$,

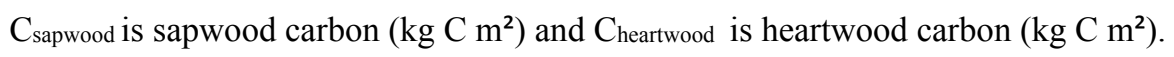




\subsubsection{Data sources}

We collected data on soil and vegetation parameters from the field survey (Ngoma et al., 2018a; Ngoma et al., 2018b) while climate data was collected from local weather stations and the dataset of the Coupled Model Inter-comparison Project phase 5 (CMIP5). Forcing data on observed temperature, rainfall and cloud cover were collected from local weather stations within the respective ecological zones. We collected climate data from 15, 13 and 28 weather stations for Sesheke, Kabompo and Namwala sites respectively. The surveyed Ila forest reserve at the Namwala site stretches in zones I and II, thus climate data were averaged from all local weather stations in both zones. Contemporary number of wet days were downloaded from Climatic Research Unit (CRU) website (University of East Anglia Climatic Research Unit et al., 2015), while contemporary and projected temperature, rainfall, solar radiation and number of wet days were taken from CMIP5: CNRM-CM5.1 (Voldoire et al., 2013), ECEarth (Hazeleger et al., 2011), HADGEM2-ES (Collins et al., 2011), IPSL-CM5A-LR (Dufresne et al., 2013) and MPI-ESM-LR (Jungclaus et al., 2013; Giorgetta et al., 2016) (See Supplementary Information Table S6.2 for full names and details on resolutions of these models). We analysed soil parameters down to $1.5 \mathrm{~m}$ depth from the plots where we conducted vegetation survey (Ngoma et al., 2018a). We determined soil texture and bulk density following the method by Sarkar and Haldar (2005) and organic carbon by Walkley and Black (1934) (See Supplementary Information Table S6.1 for details). Data on $\mathrm{CO}_{2}$ concentration was taken from Representative Concentration Pathway (RCP) database: RCP4.5 (Smith and Wigley, 2006; Clarke et al., 2007; Wise et al., 2009) and RCP8.5 (Riahi et al., 2007).

We collected data on crown area, tree diameter and total tree height from the field survey in our previous studies (Ngoma et al., 2018a; Ngoma et al., 2018b), while data on leaf longevity was determined from Specific Leaf Area (SLA) (Reich et al., 1997) to parameterize the LPJGUESS model. We determined SLA from tree leaves we collected from the trees that we felled to develop allometric equations (Ngoma et al., 2018a; Ngoma et al., 2018b). Data on vegetation carbon and tree ring indices for the LPJ-GUESS model validation was taken from the biomass (Ngoma et al., 2018a; Ngoma et al., 2018b) and dendrochronological (Ngoma et al., 2017) studies respectively.

\subsubsection{Description of the modelled climate data}

We used the Representative Concentration Pathways 4.5 and 8.5 (RCP 4.5 and RCP 8.5) with an ensemble of five Global Circulation Models (GCMs): CNRM-CM5, EC-EARTH, HADGEM2-ES, IPSL-CM5A-LR and MPI-ESM-LR (See Supplementary information Table 
S6.2 for full names) following the available GCMs for the project CMIP5 that we used as the source of our modelled climate data. Using more than one scenario and the use of ensemble means reduces the uncertainty in projected climate data compared to a single model. The climate data was re-gridded from the original spatial resolution of the climate model to a resolution of $0.5^{\circ} \times 0.5^{\circ}$. We applied the method by Piani et al. (2010) to bias-correct daily rainfall and temperature (minimum and maximum) values from the five GCMs against the WATCH Forcing Data (Weedon et al., 2011). The solar radiation data was bias-corrected following the method by Haddeland et al. (2012) using WATCH forcing data series (19712000) as a reference.

\subsubsection{Climate change}

In this study, we defined climate as the average weather pattern over a period of 30 years. Climate change was thus, defined as the difference between the climates of two periods. We used 1960-1989 as the baseline to determine the relative climate change for the end of the $21^{\text {st }}$ century (2070-2099).

\subsubsection{Description of the Zambezi teak forests.}

Following the defined PFTs (Sitch et al., 2003; Ahlström et al., 2012), we used the "deciduous tropical broadleaved rain green" PFT in our study. Deciduous tropical trees shed their leaves during the dry season (See Appendix A in Ngoma et al. (2017) for the Zambezi teak forests in different seasons of the year). Trees of the Zambezi teak forests tolerate shade. For example, seedlings of Baikiaea plurijuga need some shade to survive (PROTA4U, 2017). Shade tolerant species are able to dominate a closed-forest and seeds are able to germinate in a closed forest. For Baikiaea plurijuga, regeneration is mainly from seeds, though seedlings are usually destroyed by wild animals within the forests (Piearce, 1986a).

The Zambezi Teak forests are two storeyed forests with either a closed or open canopy (Mulolwa, 1986). They are composed of 80 species (Ngoma et al., 2018a; Ngoma et al., 2018b) but Baikiaea plurijuga Harms is most common (i.e. 50\%) (Ngoma et al., 2017; Ngoma et al., 2018a; Ngoma et al., 2018b). Trees of the Zambezi teak forests grow up to 20m high and $120 \mathrm{~cm}$ in diameter (Piearce, 1986b). The forests have a deciduous shrub layer which is locally known as mutemwa and grows up to $3 \mathrm{~m}$ to $6 \mathrm{~m}$ high. During the rainy season the forests have a ground layer of herbs and grasses (Mulolwa, 1986). These herbs and grasses have shallow root systems that develop during the rainy season and die or become dormant during the dry season. 


\subsubsection{Model set-up}

We initiated the model with a 1000 year spin-up at each site to allow the model time to reach equilibrium in all carbon pools. We spun-up the model with observed climate data from local weather stations and contemporary modelled climate data during the respective model runs. Observed climate data are temperature, rainfall and cloud cover data observed from local weather stations in the respective study sites, while contemporary data on $\mathrm{CO}_{2}$ concentration were downloaded from the RCP database (RCP Database, 2018). Data on the number of wet days per month were downloaded from Centre for Environmental Data Analysis (University of East Anglia Climatic Research Unit et al., 2015). Contemporary modelled climate data are temperature, rainfall, number of wet days per month and solar radiation averaged from the five GCMs described under Section 6.2.4 and $\mathrm{CO}_{2}$ concentration data downloaded from RCP data base (RCP Database, 2018).

Using observed local climate data, we forced LPJ-GUESS during the spin-up with repeated cycle of 30-year climate data for 1959-1988 and a constant $\mathrm{CO}_{2}$ concentration of 316ppm, corresponding to the observed value for 1959. After the 1000-year spin-up period, the model was forced with a 53-year observed climate and $\mathrm{CO}_{2}$ values, corresponding to the 1959-2011 period at Namwala and Sesheke sites. We forced the model with a 45-year observed climate and $\mathrm{CO}_{2}$, corresponding to the 1959-2003 period at Kabompo site. $\mathrm{CO}_{2}$ had reached $375 \mathrm{ppm}$ and 390ppm by 2003 and 2011 respectively.

Before forcing the model with projected climate data, we first spun-up the model with 30 years modelled climate data from 1960-1989 and a constant $\mathrm{CO}_{2}$ of 317ppm, corresponding to 1960 . We then forced the model with 46-year contemporary modelled climate data for the period 1960-2005. We used $\mathrm{CO}_{2}$ data for the same period of 1960-2005 and by $2005, \mathrm{CO}_{2}$ had reached $379 \mathrm{ppm}$.

After the spin-up period, and using observed local climate data at the respective sites as forcing, we performed a factorial experiment to determine the effects of various tree parameters (Table 6.2) and soil textures (Table 6.1 and Supplementary Information Table S6.1) on different model output. We first ran the model with default tree parameters that were provided together with the model code (These are tree parameters from literature, but provided together with the model code (See Table 6.2). After identifying some limitations (Section 6.3.2), we tested the effects of local tree parameter values listed in Table 6.2 that coincided with the locations of our measurement plots (Ngoma et al., 2018a). We assessed effects of changing each parameter separately and of changing all parameters combined at 
each site (Table 6.2). We further assessed the effects of soil by running the model with default soil parameters (provided with the model code on a $0.5 \times 0.5$ global grid) and with local soil parameters derived from samples at the respective sites (Supplementary Information Table S6.1). Results at each site were averaged for 45 years (1959-2003) at Kabompo and for 53 years (1959-2011) at the Namwala and Sesheke sites. Forcing the model with observed climate data and using local tree and soil parameters, we compared the LPJ-GUESS simulated carbon stocks and NPP with measured carbon stock (Ngoma et al., 2018a; Ngoma et al., 2018b) and tree-ring indices (Ngoma et al., 2017) respectively.

Table 6.2: Local and default tree parameter values used in LPJ-GUESS. $\mathrm{K}_{\mathrm{rp}}, \mathrm{K}_{\mathrm{allom} 1}, \mathrm{~K}_{\mathrm{allom} 2}$ and $\mathrm{K}_{\text {allom3 }}$ are constants in allometric equations (See Section 6.2.2 and Smith et al. (2001). Default parameters were provided together with the model code (Smith et al. (2001)).

\begin{tabular}{|l|l|l|l|l|l|l|l|}
\hline Site & $\mathbf{K}_{\text {allom1 }}$ & $\mathbf{K}_{\text {allom2 }}$ & $\mathbf{K}_{\text {allom3 }}$ & $\mathbf{K}_{\mathbf{r p}}$ & $\begin{array}{l}\text { Maximum } \\
\mathbf{c r o w n} \text { area } \\
\mathbf{~ m}^{\mathbf{2}}\end{array}$ & $\begin{array}{l}\text { Wood density } \\
\left(\mathbf{k g ~ m}^{-\mathbf{3}}\right)\end{array}$ & $\begin{array}{l}\text { Leaf longevity } \\
(\text { Years })\end{array}$ \\
\hline Default & 250 & 60 & 0.67 & 1.60 & 50 & 200 & 0.50 \\
\hline Kabompo & 279 & 21 & 0.48 & 1.11 & 336 & 790 & 0.95 \\
\hline Namwala & 424 & 20 & 0.56 & 1.39 & 269 & 790 & 0.94 \\
\hline Sesheke & 480 & 31 & 0.58 & 1.19 & 452 & 790 & 0.94 \\
\hline
\end{tabular}

We performed a factorial experiment for projected effects of temperature, rainfall, $\mathrm{CO}_{2}$ concentration, incoming solar radiation and number of wet days per month for the end of the $21^{\text {st }}$ century (2070-2099) following RCP4.5 and RCP8.5. To isolate the contemporary effects of each of these climatic variables, the model was forced with the 1960-2005 values of the input climate variable of interest while keeping the 1960 values constant for the other input climatic variables. When assessing the projected effects, we forced the model with projected climate values for the period 2006-2099 of the input climate variable of interest, while keeping the 2006 value constant for the other input climatic variables.

\subsection{Results}

\subsubsection{Projected climate conditions: RCP4.5 and RCP8.5}

Temperature (Figure 6.2b) and incoming solar radiation (Figure 6.2c) are projected to increase by the end of the $21^{\text {st }}$ century (2070-2099) at all sites under both scenarios relative to 1960-1989. Temperature increases by $3^{\circ} \mathrm{C}$ at all sites by the end of the $21^{\text {st }}$ century under $\mathrm{RCP} 4.5$ while, under RCP8.5, temperature is projected to increase by $5^{\circ} \mathrm{C}$ at the Kabompo and Namwala sites, and by $6^{\circ} \mathrm{C}$ at the Sesheke site. 
Rainfall is projected to decrease by $33 \mathrm{~mm}$ and $23 \mathrm{~mm}$ at Kabompo and Sesheke respectively, and to increase by $28 \mathrm{~mm}$ at Namwala under RCP8.5 by 2099. Under RCP4.5, rainfall will increase by $32 \mathrm{~mm}$ and $3 \mathrm{~mm}$ at Namwala and Sesheke respectively while at Kabompo, rainfall will decrease by $10 \mathrm{~mm}$ by the end of the $21^{\text {st }}$ century (Figure 6.2a). The number of wet days will decrease at all sites under both scenarios by the end of the $21^{\text {st }}$ century (Figure 6.2d). Carbon dioxide concentration is projected to almost double under RCP8.5 by 2099 (Figure $6.2 \mathrm{e})$.

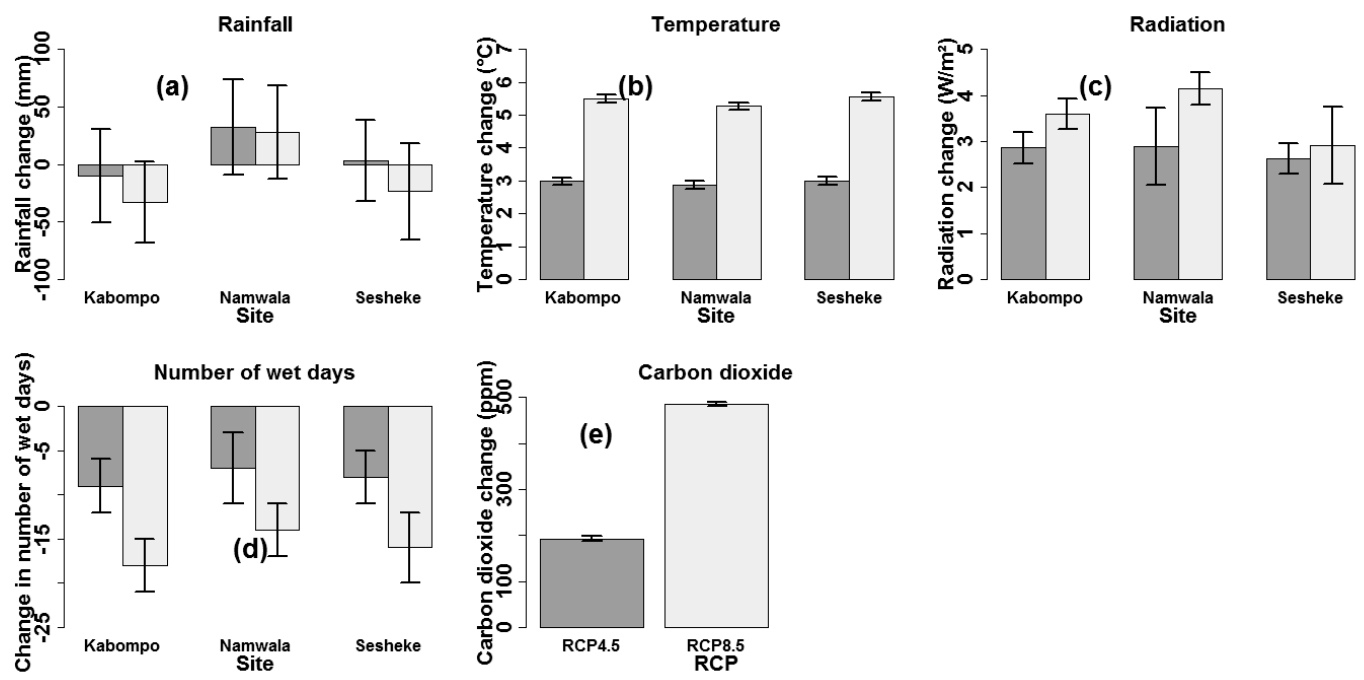

Figure 6.2 Projected changes in rainfall (a), mean temperature (b), incoming solar radiation (c), number of wet days (d) and $\mathrm{CO}_{2}$ concentration (e) under RCP4.5 and RCP 8.5 by the end of the $21^{\text {st }}$ century. End of the 21 st century is the period 2070-2099. Values were determined as means of the five GCMs and changes were determined with reference to 1960-1989 period as baseline. For sources of data, refer to Section 6.2.3.

\subsubsection{The LPJ-GUESS model validation}

We forced the LPJ-GUESS model with observed local climate data and used local tree (Table 6.2) and soil parameter values (Supplementary Information Table S6.1) to validate the model. We validated the model by comparing standardised tree-ring indices to LPJ-GUESS simulated annual NPP, i.e. for the period 1970-2003 at the Kabompo site and 1959-2011 at the Namwala and Sesheke sites. The relationships were not significant at all the three sites. 
We also validated the model by comparing measured vegetation carbon with simulated vegetation carbon at the respective study sites. We forced the model with local climate data and ran it with default soil and tree parameters to assess its performance and the model overestimated vegetation carbon stock at all sites by between $44 \%$ and $145 \%$. However, replacing default with local soil parameters (Supplementary Information Table S6.1), maximum crown area, wood density, leaf longevity and allometry (Table 6.2), the error reduced to $5 \%, 47 \%$ and $17 \%$ at the Kabompo, Namwala and Sesheke sites compared to measured vegetation carbon (Figure 6.3).

We further assessed the LPJ-GUESS model performance by comparing measured and simulated tree heights and crown area. Using Equation 6.4, tree heights estimated using default tree parameter values (Table 6.2) of $K_{\text {allom } 2}$ and $K_{\text {allom } 3}$ were taller than those estimated using local tree parameters of these same constants for the measured tree diameter at breast height (DBH) at all sites (Figure 6.4). Applying the Mean Absolute Percentage Error (Sileshi, 2014) to indicate allometric model performance, tree heights were over-estimated by $111 \%$ at the Kabompo, $156 \%$ at the Namwala and $56 \%$ at the Sesheke sites when we used default tree parameter values of $K_{\text {allom } 2}$ and $K_{\text {allom } 3}$ in the allometric equation compared to measured tree heights. Using local tree parameter values (Table 6.2), tree heights were overestimated by $2 \%$ and $1 \%$ at Kabompo and Namwala and under-estimated by $8 \%$ at Sesheke respectively. Thus, both default and local tree parameters over-estimated tree heights at Kabompo and Namwala compared to measured heights, though the over-estimation was largest with default parameters (Figure 6.4).

The crown area, estimated with Equation 6.6, was under-estimated by $61 \%$ at Kabompo and Namwala and by $76 \%$ at Sesheke when we used default tree parameters. However, with local tree parameters, the model under-estimated crown area by $15 \%, 11 \%$, and $23 \%$ at Kabompo, Namwala and Sesheke, respectively compared to measured crown area (Figure 6.5 and Table $6.2)$. 
(a)

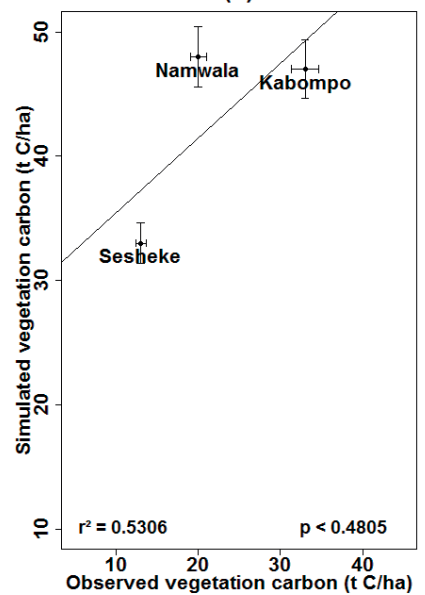

(b)

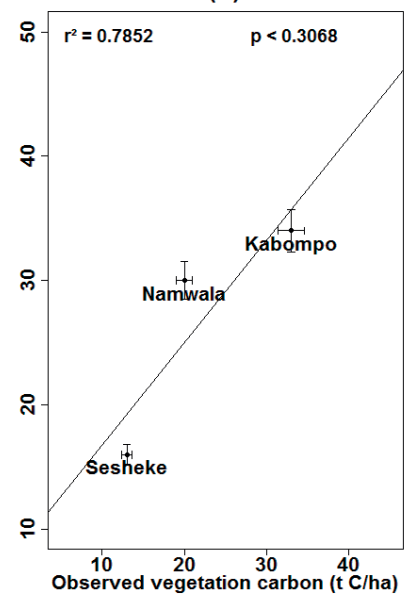

(c)

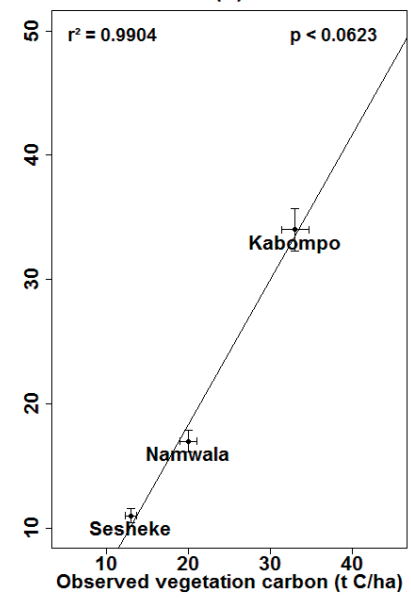

Figure 6.3 Measured versus LPJ-GUESS simulated vegetation carbon stock simulated with default soil parameters, default tree parameters and observed local climate (a), local soil, local tree parameters and observed local climate (b), and with local soil, local tree parameters and modelled contemporaneously climate (c).
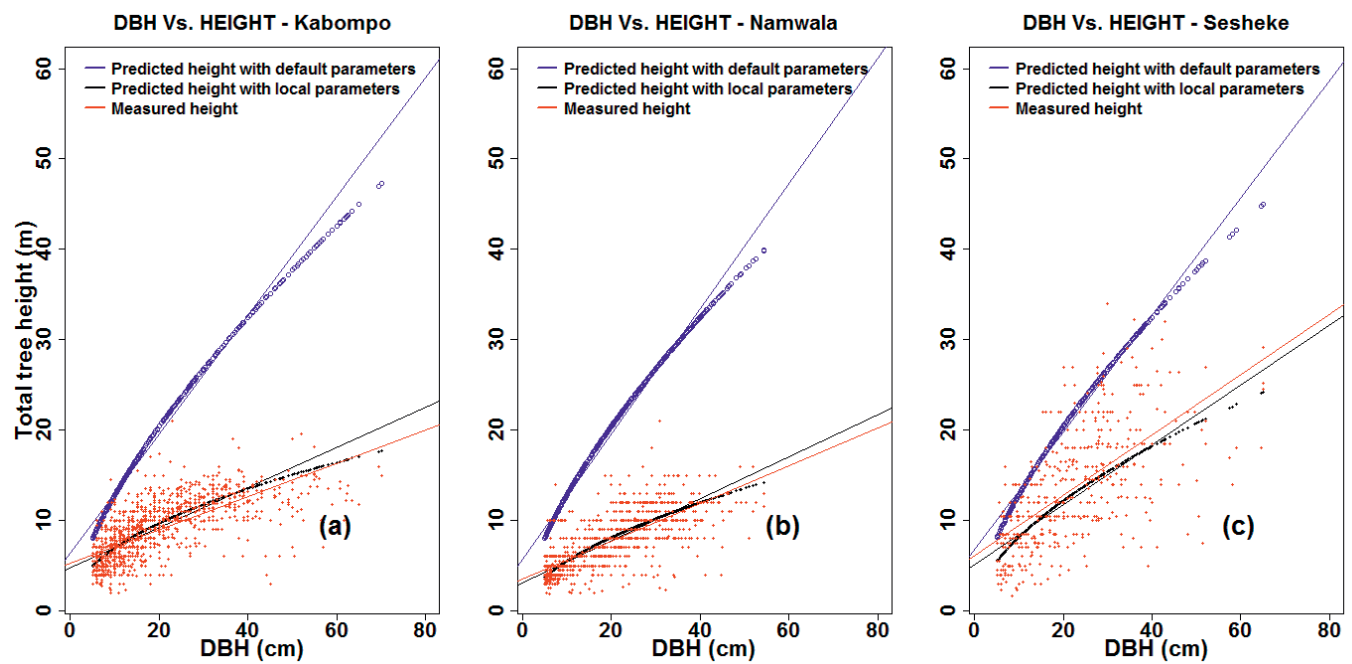

Figure 6.4 Measured and predicted total tree height, plotted against DBH at Kabompo (a), Namwala (b) and Sesheke (c). 

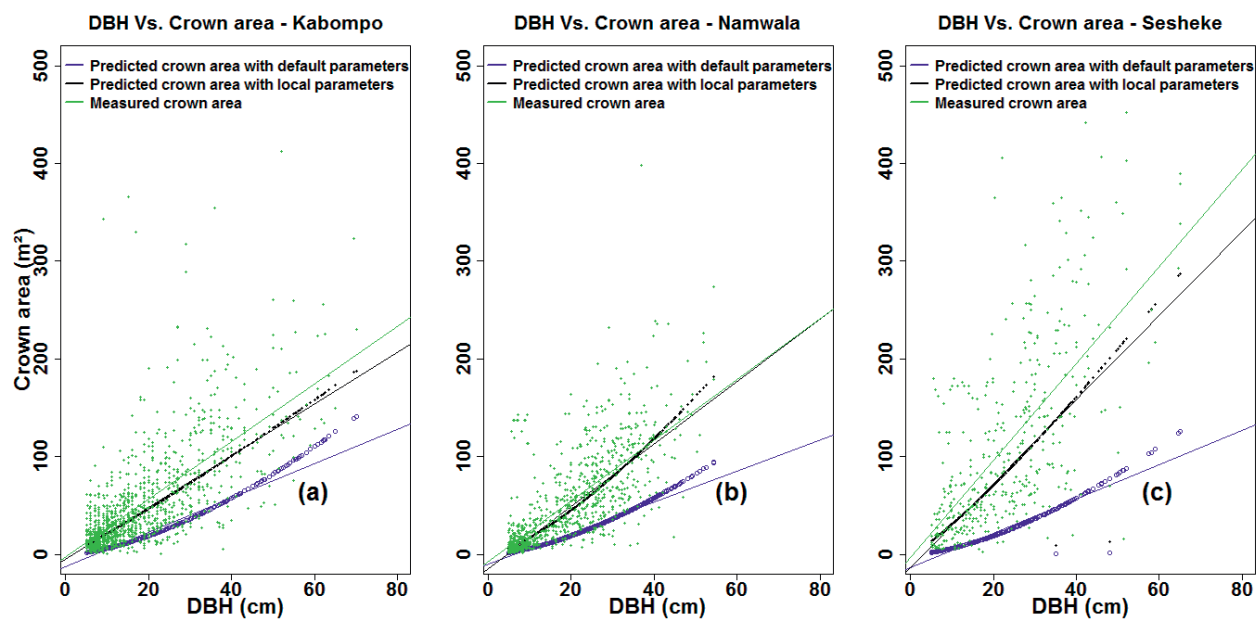

Figure 6.5 Measured and predicted crown area plotted against DBH at Kabompo (a), Namwala (b) and Sesheke (c).

\subsubsection{Carbon stocks, LAI and NPP}

Running the LPJ-GUESS model with local soil and tree parameters, and forcing it with local observed climate data for the period 1960-2003, vegetation carbon stocks and Leaf Area Index (LAI) were highest at Kabompo, and Sesheke had the lowest values. The aggregated three carbon pools (vegetation, litter and soil carbon) were highest at Kabompo and lowest at Namwala. Vegetation carbon was lower when we forced the LPJ-GUESS model with contemporary modelled climate data for the period 1960-2003 at all sites compared to the values simulated with observed local climate data (Figure 6.6 and Supplementary Information Figure S6.6). Vegetation carbon stocks, LAI and NPP simulated with both local soil and local tree parameters, and forcing the model with local climate data were lower at all sites compared to values generated by default tree and soil parameters (Figure 6.6 and Supplementary Information Figure S6.6). 

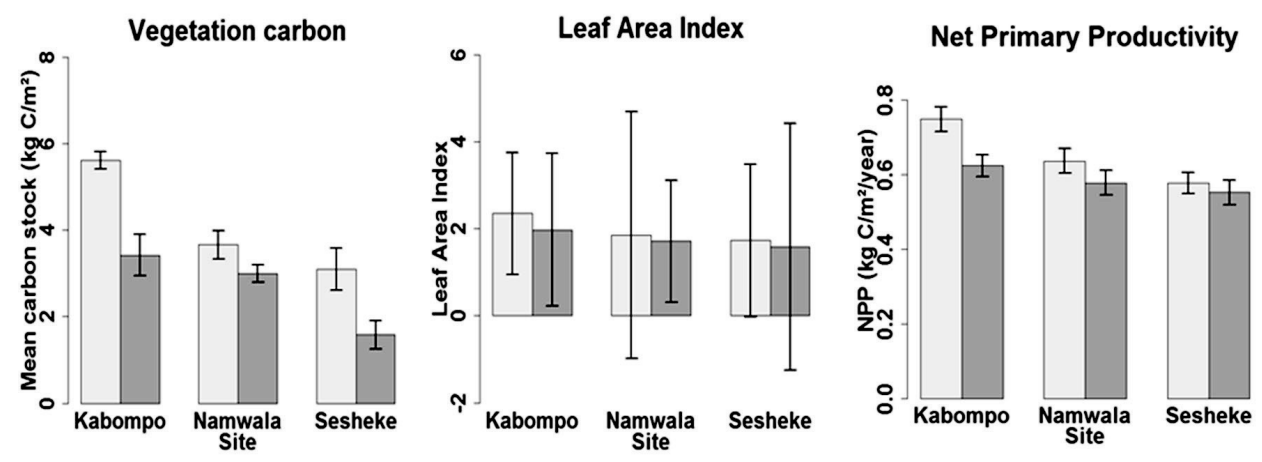

\section{Simulated with default tree, default soil, and modelled climate}

- Simulated with local tree, local soil, and local climate

Figure 6.6 Mean annual vegetation carbon stocks, LAI and NPP simulated with local and default soil and tree parameter values, and forcing the model with local and modelled climate data. Simulations were done for the period 1959-2003. This figure only shows values simulated with a combination of default tree, default soil and modelled climate data, and also a combination of local tree, local soil and local climate data. The reader is referred to supplementary information (Figure S6.6) for the results of the effects of each of these default tree parameters, default soil parameters, local tree, local soil parameters, local climate and modelled climate data.

\subsubsection{Climate change effects on NPP}

By the end of the $21^{\text {st }}$ century, combined changes of all climatic variables is projected to increase NPP at all sites under both scenarios except at the Sesheke site where NPP reduces. NPP is projected to increase most at the Kabompo site under RCP8.5 (Figure 6.7). Increased $\mathrm{CO}_{2}$ concentration is projected to positively have most effects on NPP at Kabompo and Namwala under both scenarios, while under RCP8.5 decreased precipitation coupled with increasing temperature negatively affects NPP at Sesheke. 

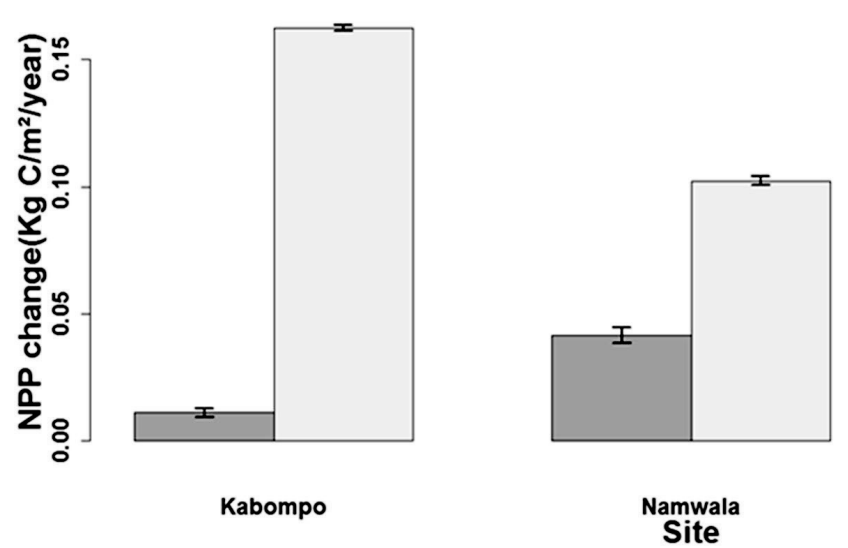

- RCP4.5

RCP8.5

Figure 6.7 Projected changes in NPP at Kabompo, Namwala and Sesheke resulting from combined changes in temperature, rainfall, $\mathrm{CO}_{2}$ concentration, solar radiation and number of wet days by the end of the $21^{\text {st }}$ century (2070-2099) with reference to $1960-1989$ as the baseline.

\subsection{Discussion}

\subsubsection{The LPJ-GUESS model performance}

We generated new soil texture and tree parameter values for maximum crown area, wood density, leaf longevity and allometry, and the results simulated with the LPJ-GUESS model improved when we used these local soil and tree parameter values compared to using the default parameters. The over-estimation of vegetation carbon that resulted from using default soil parameter values indicates the differences in clay, silt and sand proportions between default and local soils of the Zambezi teak forests. Our field measurements (Ngoma et al., 2018a; Ngoma et al., 2018b) showed that trees were between $2 \mathrm{~m}$ and $21 \mathrm{~m}$ tall. The high default tree heights of between $8 \mathrm{~m}$ and $47 \mathrm{~m}$ led to over-estimating vegetation carbon by between $33 \%$ and $92 \%$.

We found no correlation between LPJ-GUESS-simulated NPP and tree-ring indices at all sites. This lack of correlation is probably due to differences in the number of tree species incorporated in the two methods. We used one species only in the tree-ring analysis, while in modelling studies, which were conducted at ecosystem level, all available tree species in the forests were incorporated to determine the net NPP. The forests' survey that we conducted in 2014 (Ngoma et al., 2018a; Ngoma et al., 2018b) showed that the Zambezi teak forests have eighty tree species. Thus, the net growth rate of these eighty species incorporated in the 
modelling studies is probably not the same as the growth rate of one dominant species used in tree-ring analysis.

The significant positive relationship between tree ring indices and rainfall of previous two years at Sesheke (Supplementary Information Figure S6.2 (i)) indicates a carry-over effects of rainfall on trees' productivity. Though rainfall of the previous years is probably captured by trees through soil moisture in the model, this aspect is not clearly addressed in LPJ-GUESS model. Babst et al. (2013) reported the lack of representation of carry-over effects of rainfall in Dynamic Global Vegetation Models (DGVM's). The clear representation of carry-over effects in LPJ-GUESS model would improve model results. Also, increasing the number of tree species in tree-ring analysis would improve the relationship between LPJ-GUESS simulated NPP and tree-ring indices. Thus, further tree-ring studies would need to be conducted with similar number of species as those included in modelling studies to validate the LPJ-GUESS model.

\subsubsection{NPP's distribution}

NPP was highest in the high rainfall receiving Kabompo site compared to the low rainfall receiving Sesheke site (Figure 6.6 and Supplementary Information Figure S6.6). The upward trend in NPP from the drier site to the wetter site was similar to the trend in LAI and vegetation carbon (Figure 6.6 and Supplementary Information Figure S6.6). The trend in NPP was also similar to the trend reported in literature where the forests growing in high rainfall receiving areas were more productive than the forests growing in arid regions (Cao et al., 2001; Delire et al., 2008; Williams et al., 2008; Ngoma et al., 2019b).

\subsubsection{NPP's climate response}

We projected an NPP increase at Kabompo and Namwala caused by increasing $\mathrm{CO}_{2}$ concentration and temperature. The positive temperature and $\mathrm{CO}_{2}$ effects were clearly observed from the high positive correlations between NPP and temperature (Supplementary Information Figure S6.5) and NPP and $\mathrm{CO}_{2}$ (Supplementary Information Figure S6.4). However, the positive temperature effects could just be up to an optimal temperature level. For tropical trees, carbon uptake reduces with leaf temperature of above $31^{\circ} \mathrm{C}$ (Doughty and Goulden, 2008). Higher temperatures of above $31^{\circ} \mathrm{C}$ also reduce activities of photosynthetic enzymes (Farquhar et al., 1980), resulting in reduced NPP.

The projected NPP increase at Kabompo and Namwala is in the same direction as the results reported by other researchers (Alo and Wang, 2008; Pan et al., 2015; Mohammed et al., 2018) 
for some parts of Africa (Table 6.3). Some modelling studies on tropical forests (Melillo et al., 1993; Midgley et al., 2005; Thuiller et al., 2006; Ciais et al., 2009; Doherty et al., 2010; Pan et al., 2015; Braakhekke et al., 2017) also reported large positive effects of increased $\mathrm{CO}_{2}$ concentration on forests' productivity. This positive effect could probably be due to increased Water-Use-Efficiency (WUE, which is a measure of a plant's water-use during photosynthesis in relation to the amount of water withdrawn (Grain Research and Development Cooperation, 2009)) by the plants. The stomata partially close to maintain a near constant concentration of $\mathrm{CO}_{2}$ inside the leaf even under continually increasing atmospheric $\mathrm{CO}_{2}$ levels. Such stomatal closure decreases evapotranspiration (Keenan et al., 2013) and thus increases WUE. The positive effects of increased $\mathrm{CO}_{2}$ on NPP could also be due to increased Nitrogen-UseEfficiency (NUE, i.e., the amount of carbon converted into sugars during the photosynthetic process per unit of leaf nitrogen) (Davey et al., 1999). When $\mathrm{CO}_{2}$ concentration increases, the amount of rubisco enzymes are reduced. As a consequence, foliar nitrogen is mobilized out of leaves and into other areas of the plant. This decreases the amount of nitrogen in the leaves. However, despite a reduction in leaf nitrogen, photosynthesis is still higher at elevated $\mathrm{CO}_{2}$ concentrations. This result in increased carbon uptake at lower nutrient supplies. The higher photosynthesis activities and lower leaf nitrogen content increase the photosynthetic NUE (Davey et al., 1999). However some other studies indicate that herbaceous plants and deciduous trees acclimate quickly to increased $\mathrm{CO}_{2}$ concentrations by reducing photosynthetic capacity and stomatal conductance (Ellsworth, 1999; Mooney et al., 1999). As a result, the required water and nitrogen needed to fix a given amount of carbon is reduced (Chapin et al., 2007). However, such acclimation has sometimes no effect on the photosynthetic rate and stomatal conductance (Curtis and Wang, 1998). To what extent our modelling results are realistic is therefore not fully clear.

Currently, the responses of tropical trees and forests to increased $\mathrm{CO}_{2}$ are still poorly understood (Thomas et al., 2008) since $\mathrm{CO}_{2}$ enrichment experiments are lacking in the tropics. Such experiments should be done because they could explain whether the enhanced NPP that result from increased $\mathrm{CO}_{2}$ is due to increased WUE, NUE or $\mathrm{CO}_{2}$ fertilization. In our study, the correlations between tree ring indices and $\mathrm{CO}_{2}$ concentration were not significant at all sites (Supplementary Information Figure S6.3), contrary to modelling results, indicating the need for further research more especially the $\mathrm{CO}_{2}$ enrichment experiments to ascertain modelling results. 
The projected decreased NPP under RCP8.5 at the Sesheke site results from high negative effects of the projected reduced rainfall coupled with increasing temperatures. NPP of the drier areas is mainly influenced by water by enhancing the WUE of vegetation (Yu and Chen, 2016). Reduced rainfall decreases soil water availability needed by the plants. High temperature enhances evapotranspiration resulting in reduced soil moisture (Miyashita et al., 2005). When soil water decreases, the stomata close to restrict water loss. The closure of stomata prevents the movement of carbon into the plant, resulting in reduced NPP (McGuire and Joyce, 2005). Decreased soil water also limits nutrient absorption (e.g. Nitrogen) by the roots and transportation to the plants. Increased temperature enhances plant respiration, reducing photosynthetic activities (Burton et al., 2008; Wu et al., 2011). The projected reduced number of wet days likely have more effects on NPP at Sesheke under RCP4.5 by the year 2099. The projected NPP decrease at Sesheke is in the same direction as the findings of Delire et al. (2008) who reported an NPP reduction of $12 \%$ for the savanna forests by 2080 . Similar results were also reported by Ngoma et al. (2019b) who projected an NPP decrease of $8 \%$ by the end of the $21^{\text {st }}$ century for the whole of Africa. Furthermore, Alo and Wang (2008) projected NPP decrease in west and southern Africa.

The differences in NPP's response to climate change at each of the study sites is especially caused by variability in rainfall and nutrient distribution (Figure 6.1 and Table 6.1). Though the photosynthesis process is dependent on $\mathrm{CO}_{2}$ concentration, plant's response to increasing $\mathrm{CO}_{2}$ is limited by the availability of soil water and nutrients. Thus, plants growing in poor nutrient condition respond less to rising $\mathrm{CO}_{2}$ concentration (Lloyd and Farquhar, 1996). This could be the case with the reduced NPP response at Sesheke where nitrogen content is lower than at Kabompo and Namwala (Table 6.1) despite the increasing projected $\mathrm{CO}_{2}$ concentration. However, deciduous trees sometimes acclimate to increased $\mathrm{CO}_{2}$ concentration by reducing photosynthetic capacity and stomatal conductance (Ellsworth, 1999; Mooney et al., 1999). As a result, the required nitrogen and water needed to fix a given amount of carbon is reduced (Chapin et al., 2007), resulting in decreased NPP. 
Table 6.3: Projected changes in NPP: Current study compared to literature. A negative sign (-) under 'Change in NPP (\%)', means a reduction in NPP.

\begin{tabular}{|c|c|c|c|c|c|c|}
\hline $\begin{array}{l}\text { Change in } \\
\text { NPP }(\%)\end{array}$ & Forest biome & Study site & $\begin{array}{l}\text { Period } \\
\text { covered }\end{array}$ & $\begin{array}{l}\text { Applied } \\
\text { model }\end{array}$ & Reference & Comments \\
\hline-16.98 & $\begin{array}{l}\text { Tropical evergreen } \\
\text { forest/woodland }\end{array}$ & \multirow[t]{6}{*}{$\begin{array}{l}\text { Central and } \\
\text { West Africa }\end{array}$} & \multirow[t]{6}{*}{$\begin{array}{l}1950-2000 \text { to } \\
2070-2099\end{array}$} & \multirow[t]{6}{*}{ IBIS } & \multirow[t]{6}{*}{$\begin{array}{l}\text { (Delire et al., } \\
\text { 2008) }\end{array}$} & \multirow{6}{*}{$\begin{array}{l}\text { Used CRU } \\
\text { data for } \\
\text { control results }\end{array}$} \\
\hline-24.18 & $\begin{array}{l}\text { Tropical deciduous } \\
\text { forest/woodland }\end{array}$ & & & & & \\
\hline-6.06 & Savanna & & & & & \\
\hline 10.00 & Grassland/steppe & & & & & \\
\hline 0.00 & Open shrubland & & & & & \\
\hline-50.00 & Desert & & & & & \\
\hline-18.47 & $\begin{array}{l}\text { Tropical evergreen } \\
\text { forest/woodland }\end{array}$ & \multirow[t]{6}{*}{$\begin{array}{l}\text { Central and } \\
\text { West Africa }\end{array}$} & \multirow[t]{6}{*}{$\begin{array}{l}1961-1990 \text { to } \\
2070-2099\end{array}$} & \multirow[t]{6}{*}{ IBIS } & \multirow[t]{6}{*}{$\begin{array}{l}\text { (Delire et al., } \\
2008)\end{array}$} & \multirow{6}{*}{$\begin{array}{l}\text { Used climate } \\
\text { data from } \\
\text { Mark et al. } \\
\text { (1999) for } \\
\text { control results } \\
\text { - Both rainfall } \\
\text { and } \\
\text { temperature } \\
\text { changed }\end{array}$} \\
\hline-26.03 & $\begin{array}{l}\text { Tropical deciduous } \\
\text { forest/woodland }\end{array}$ & & & & & \\
\hline-15.12 & Savanna & & & & & \\
\hline 12.99 & Grassland/steppe & & & & & \\
\hline-6.78 & Open shrubland & & & & & \\
\hline-16.67 & Desert & & & & & \\
\hline 28.11 & All biomes & East Africa & $\begin{array}{l}1981-2000 \\
\text { and } 2080- \\
2099\end{array}$ & LPJ DGVM & $\begin{array}{l}\text { (Doherty et } \\
\text { al., 2010) }\end{array}$ & $\begin{array}{l}\text { Difference } \\
\text { sources of } \\
\text { climate data } \\
\text { (Refer to the } \\
\text { article) }\end{array}$ \\
\hline-8 & All biomes & Whole Africa & $1950-2099$ & $\begin{array}{l}\text { Various } \\
\text { models }\end{array}$ & $\begin{array}{l}\text { (Ngoma et al., } \\
\text { 2019b) }\end{array}$ & $\begin{array}{l}\text { Difference } \\
\text { sources of } \\
\text { climate data }\end{array}$ \\
\hline 1.50 & Deciduous forests & $\begin{array}{l}\text { Kabompo - } \\
\text { Zambia - } \\
\text { Southern } \\
\text { Africa }\end{array}$ & $\begin{array}{l}1960-1989 \\
\text { and } 2070- \\
2099\end{array}$ & LPJ GUESS & $\begin{array}{l}\text { Current } \\
\text { study }\end{array}$ & RCP4.5 \\
\hline 6.70 & Deciduous forests & $\begin{array}{l}\text { Namwala - } \\
\text { Zambia - } \\
\text { Southern } \\
\text { Africa }\end{array}$ & $\begin{array}{l}1960-1989 \\
\text { and } 2070- \\
2099\end{array}$ & LPJ GUESS & $\begin{array}{l}\text { Current } \\
\text { study }\end{array}$ & RCP4.5 \\
\hline-0.90 & Deciduous forests & $\begin{array}{l}\text { Sesheke - } \\
\text { Zambia - } \\
\text { Southern } \\
\text { Africa }\end{array}$ & $\begin{array}{l}1960-1989 \\
\text { and } 2070- \\
2099\end{array}$ & LPJ GUESS & $\begin{array}{l}\text { Current } \\
\text { study }\end{array}$ & RCP4.5 \\
\hline 21.70 & Deciduous forests & $\begin{array}{l}\text { Kabompo - } \\
\text { Zambia - } \\
\text { Southern } \\
\text { Africa } \\
\end{array}$ & $\begin{array}{l}1960-1989 \\
\text { and } 2070- \\
2099\end{array}$ & LPJ GUESS & $\begin{array}{l}\text { Current } \\
\text { study }\end{array}$ & RCP8.5 \\
\hline 16.40 & Deciduous forests & $\begin{array}{l}\text { Namwala - } \\
\text { Zambia - } \\
\text { Southern } \\
\text { Africa }\end{array}$ & $\begin{array}{l}1960-1989 \\
\text { and } 2070- \\
2099\end{array}$ & LPJ GUESS & $\begin{array}{l}\text { Current } \\
\text { study }\end{array}$ & RCP8.5 \\
\hline-0.30 & Deciduous forests & $\begin{array}{l}\text { Sesheke - } \\
\text { Zambia - } \\
\text { Southern } \\
\text { Africa }\end{array}$ & $\begin{array}{l}1960-1989 \\
\text { and } 2070- \\
2099\end{array}$ & LPJ GUESS & $\begin{array}{l}\text { Current } \\
\text { study }\end{array}$ & RCP8.5 \\
\hline Symbol & \multicolumn{6}{|l|}{ Meaning of symbol } \\
\hline $\begin{array}{l}\text { LPJ- } \\
\text { DGVM }\end{array}$ & \multicolumn{6}{|c|}{ Lund-Potsdam-Jena Dynamic Global Vegetation Model } \\
\hline IBIS & \multicolumn{6}{|c|}{ Integrated Biosphere Simulator } \\
\hline $\begin{array}{l}\text { LPJ- } \\
\text { GUESS }\end{array}$ & \multicolumn{6}{|c|}{ Lund-Potsdam-Jena General Ecosystem Simulator } \\
\hline
\end{tabular}


The different NPP responses to climate change at the three sites could also be attributed to differences in species composition and the variable responses of these distinct tree species to the environment caused by variation in their physiological properties. While $9 \%$ of the total tree species are common in all the three sites, $25 \%$ of the total surveyed species are found at Kabompo, 38\% at Namwala and 16\% at Sesheke only (Ngoma et al., 2018b).

Although we projected different NPP patterns at the three study sites, these projections depend on the accuracy of climate data. In our study, we used climate data from five GCMs considering the different climatic values generated by each GCM. The use of ensembles improves the modelling of climate data compared to a single model, thereby reducing the uncertainty that might be caused by sources of climate data.

We carried out our study in the three study sites of the Zambezi teak forests in Zambia applying the LPJ-GUESS model. These sites experience some disturbances resulting from illegal activities (e.g. charcoal burning). The artificial disturbances are not captured by the model since the model does not provide for such kind of disturbances in the forests. Thus, an incorporation of such forest disturbances in the model would improve model results. The fires, which are also other forms of disturbances, are common in the Zambezi teak forests. These fires are usually caused by humans during the dry season. Though the LPJ-GUESS model provides for natural fires, it does not provide for artificial fires. Thus, the incorporation of these artificial fires would improve the model results further though more studies would need to be conducted to determine the frequency and intensity of these fires in the forests before incorporating them in the model. This would reduce the uncertainties of the model results.

Generally, there are some similarities in the results we generated in our study with literature (Tables 6.3) for similar forest types. The differences in actual values hint at the differences in models applied and the extent of area coverage. For example, while we conducted our study at local level, other researchers conducted similar studies at regional level (Doherty et al., 2010). Studies conducted at regional level constitute average results of different biomes while our study covered one biome only at all the three sites. Other factors such as species composition and soils also differ between our study sites and study sites of other researchers. We compared our results to few studies due to limited literature on modelling studies reported for African biomes. Also, studies using the same model as our study (LPJ- GUESS) are limited in Africa. We could not find any studies applying LPJ- GUESS model at local level in Africa as most studies are conducted at global level (Cao and Woodward, 1998a; Schaphoff et al., 2006). Availability of such studies would give much insight on our results. This therefore 
presents an opportunity to focus modelling research in Africa so as to determine the potential response of the different biomes to climate change. However, our study highlighted the need to use local or regional specific parameter values in models in order to obtain reliable estimates unlike using default parameter values.

\subsection{Conclusions}

We generated new soil texture and tree parameter values for maximum crown area, wood density, leaf longevity, and allometry. Using these newly generated local parameters, we adapted and evaluated the dynamic vegetation model LPJ-GUESS for the historical climate conditions. The results simulated with the LPJ-GUESS model improved when we used these newly generated local parameters. This indicates that using local parameter values is essential to obtaining reliable simulations at site-level. The adapted model setup provided a baseline for assessing the potential effects of climate change on NPP in the Zambezi teak forests in Zambia. NPP was thus projected to increase at the wetter Kabompo and intermediate Namwala sites under both RCPs especially caused by the increased $\mathrm{CO}_{2}$ concentration by the end of the $21^{\text {st }}$ century, while at the drier Sesheke site, NPP would decrease by the end of the $21^{\text {st }}$ century under both RCPs. The projected decreased NPP under RCP8.5 at the Sesheke site results from the reduced rainfall coupled with increasing temperature. We thus demonstrated that differences in rainfall pattern influence the way in which climate change will affect forests resources. The projected increase in carbon dioxide concentration would thus, have more effects on NPP in high rainfall receiving areas, while in arid regions, NPP would be affected more by the changes in rainfall and temperature. 
Chapter 6 


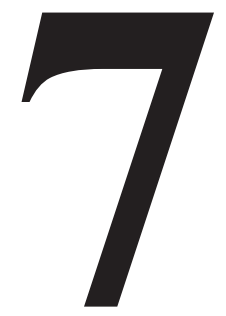

\section{SYNTHESIS}

4. 2 1)

(1) 1210

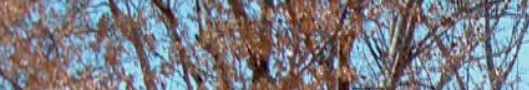
- 1010 (1) 1010

$-1 \times 1 / 21$

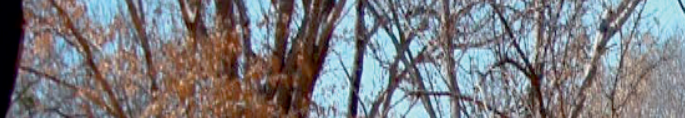
(x) 12 W

$\left.\frac{-1}{10}\right)^{2}$
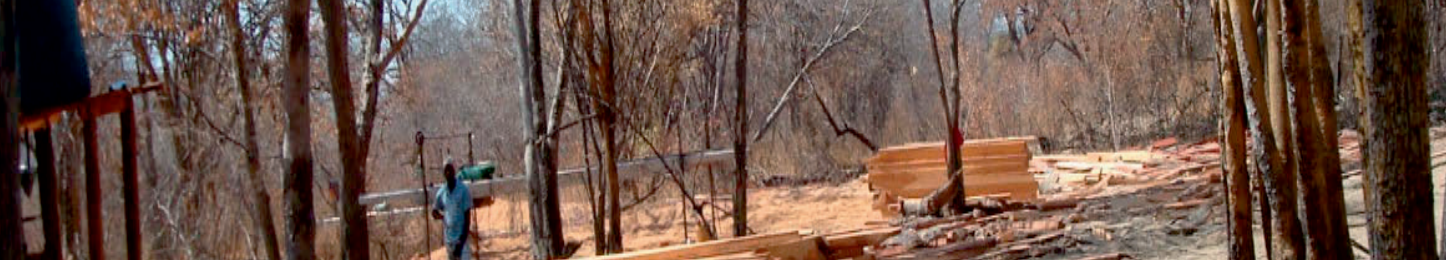

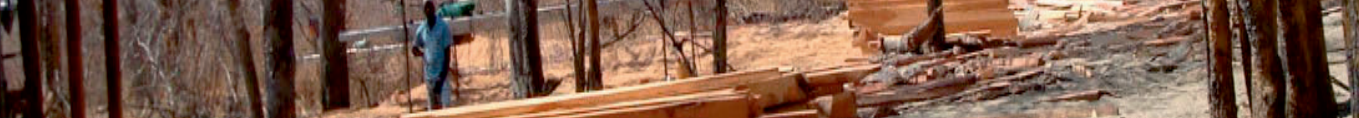

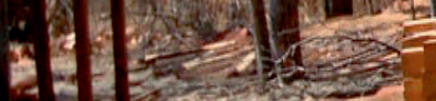

1112

- 1 if s. 14 I

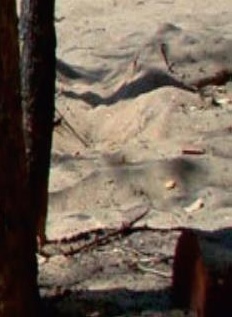
eles. 49 


\subsection{General discussion}

I studied the effects of climate change on the productivity of the Zambezi Teak forests in Zambia across a south-north climatic gradient with annual rainfall ranging from $700 \mathrm{~mm}$ in the south to $1100 \mathrm{~mm}$ in the north by integrating information from biomass measurements, treering analysis and dynamic vegetation modelling. The study was conducted at the drier Sesheke, intermediate Namwala and wetter Kabompo sites. In Chapter 1, I gave an overview of climate variability and change, and its effects on forest's productivity in Africa. I also discussed the importance of and threaths to the forests in Zambia, a country where more than half of the population depend on forests resources for their livelihoods. Chapter 2 presented data on DBH, total tree height, tree biomass, carbon fraction and carbon stocks of each surveyed tree and tree species in the respective study sites. This data was used in Chapter 3 to develope above and below-ground biomass models and to estimate carbon stocks for each site. I reviewed literature on tree-ring and modelling studies in Chapter $\mathbf{4}$ to obtain an in depth understanding of forest's productivity's response to climate change in Africa.

From the data presented in Chapter 2, I identified B. plurijuga Harms as the most dominant tree species. I then determined the relationships between annual growth rings of this dominant species and climatic variables (Chapter 5). The carbon stocks and tree-ring indices determined in respectively Chapters 3 and 5 were used to validate the LPJ-GUESS vegetation model in Chapter 6. This model was applied to project the response of NPP to climate change.

Six research questions (RQs) guided me through the integration process of these research activities. The answers to these questions are presented and discussed below. Section 7.2 outlines the scientific contribution of my research while Section 7.3 presents the general conclusions. Policy and management implications are presented in Section 7.4 whereas Section 7.5 identifies future research possibilities.

\subsection{RQ1 Are biomass models available for the Zambezi teak forests and if so, what kind of data are needed to develop these models?}

Henry et al. (2011) present the available biomass and volume allometric equations in Africa. They indicate that one volume allometric equation exist for the Zambezi teak forests and its dominant $B$. plurijuga species. However, no biomass allometric equations were developed using direct tree measurements from these forests. Stump models for the Zambezi teak forests 
are also lacking. Most available biomass allometric equations are developed using species from the vast Zambian Miombo woodlands (Chidumayo, 1990; Chidumayo, 2014; Kapinga et al., 2018). Against this background, I developed three above-ground biomass models, one below-ground biomass model and one stump model (Chapter 3) using data that were presented in Chapter 2. The two above-ground biomass models estimated biomass of large $(\geq 5 \mathrm{~cm} \mathrm{DBH})$ and small trees (between $1.1 \mathrm{~cm}$ and $4.9 \mathrm{~cm} \mathrm{DBH})$. The third above-ground biomass model estimated biomass of trees that have been harvested from the forests, while the below-ground biomass model evaluated below-ground biomass of all trees in the forests. The stump model quantified biomass in stumps.

A multiple regression that ran between the dependent variable (biomass) and independent variables (i.e. DBH, total tree height, and wood density), showed that only DBH ( $p<0.0001)$ significantly affected tree biomass and the power model fitted well (Chapter 3). This strong relationship between DBH and tree biomass reduces the need to measure other variables, such as total tree heights, in forest inventories. This relationship is consistent with other studies on tropical trees (Brown et al., 1989; Chidumayo, 1990; Deans et al., 1996; Brown, 1997; Chamshama et al., 2004; Chave et al., 2005; Basuki et al., 2009; Lima et al., 2012). However, comparing the general performance of my newly developed models to models reported in literature (Henry et al., 2011) was challenging because different indicators were used to measure the model's performances. Scientists have not agreed on any standard indicator to use to measure the performance of biomass allometric models. They still use many different indicators to measure model performances (Chave et al., 2005; Henry et al., 2011; Sileshi, 2014; Jibrin and Abdulkadir, 2015).

Though most studies reported the coefficient of determination $\left(r^{2}\right)$ values for non-linear models (Henry et al., 2011), this indicator can be used to measure the performance of linear models, but is less appropriate for non-linear models since the total sum of squares (TSS) does not equal the sum of the regression-sum-of-squares (REGSS) and the residual sum-ofsquares (RSS) (Spiess and Neumeyer, 2010). I therefore did not report $r^{2}$-values for the nonlinear power models in my study. Moreover, $r^{2}$ - values increase not only when polynomial terms are added (Sileshi, 2014), but also when sample size is reduced. Therefore, $r^{2}$ is probably only a very weak indicator for the model selection criterion.

The root-to-shoot ratio of 0.38:0.62 that I determined in my study (Chapter 3), was similar to the ratios reported by other researchers for tropical dry forests (Castellanos et al., 1991; 
Malimbwi et al., 1994; Deans et al., 1996; Kraenzel et al., 2003; Ryan et al., 2011; Mugasha et al., 2013). The variation in its actual values is likely due to differences in the species studied, the sample size, the size of the sampled trees, sampling methods and the minimum diameter of the roots that were included in the ratio calculations. My determined root-to-shoot ratios decreased with increasing $\mathrm{DBH}(\mathrm{r}=-0.26)$. This indicates that, even though the ratio can be applied to smaller trees, this ratio will be biased for the small trees.

The 12 out of the 80 recorded tree species that I sampled to develop above-ground biomass models, included data from the most common and dominant tree species in an effort to reduce sample bias. Bias was further reduced by generating these data from all the three study sites to capture trees growing in different environments (i.e. dry, intermediate and wetter environments). I developed separate models for the large and small trees since my combined data was skewed even after a log transformation. The Shapiro-Wilk Normality Test $(p=95 \%)$ further showed that the combined data of large and small trees were not normally distributed $(\mathrm{p}<0.0001)$.

I included the most common and dominant tree species to the seven trees that I sampled, to reduce bias since data were generated from the three species of these deep rooted trees (Högberg, 1984; Childes, 1988) and in the drier Sesheke site only due to limited resources that did not allow for sampling more trees following the high cost and laborious nature of the activities. I used a chain saw with a narrow kerf size and corrected for width of the cut to reduce the errors resulting from the loss of wood and root material when cutting following my destructive sampling methods (Chapter 2). This below-ground sampling provided unique below-ground data on below-ground biomass of tropical tree species and helped to estimate the parameters of the first African below-ground biomass model for these forests.

\subsection{RQ2 How are forests' carbon stocks distributed in the wetter, intermediate and drier sites of the Zambezi teak forests?}

The forests' carbon stock was highest at the wetter Kabompo site (36ton $\mathrm{C} \mathrm{ha}^{-1}$ ), followed by the intermediate Namwala site $\left(25\right.$ ton $\left.\mathrm{C} \mathrm{ha}^{-1}\right)$ and the lowest carbon stock value was recorded at the drier Sesheke site (16ton $\mathrm{C} \mathrm{ha}^{-1}$ ) (Chapter 3). These carbon stocks were determined from biomass stocks that were estimated using my better allometric biomass models and average site-specific carbon fractions of respectively $44.0 \%, 40.5 \%$ and $41.3 \%$ at the Kabompo, Namwala and Sesheke sites. Following the rainfall pattern, the carbon fraction 
increased with increasing rainfall (Chapters 2 and 3). This was most evident for Baikiaea plurijuga and Baphia massaiensis, which were both found in all the three sites. The carbon fraction in B. plurijuga was $4 \%$ higher at the wetter Kabompo site than at the drier Sesheke site (Chapter 2).

The highest carbon stock increase at the wetter Kabompo site resulted from the high biomass stocks and average carbon fractions. Tree density was also highest at the Kabompo site, which probably resulted from higher regeneration after logging activities. This regeneration was further stimulated by higher rainfall and nutrient (especially nitrogen) contents (Chapter 6). Though the carbon fraction was lowest at the Namwala site, its carbon stock was higher than at the Sesheke site. This high Namwala carbon stock is explained by its high biomass stock, which likely results from increased tree density more than high basal area. Carbon stock of different forest categories (i.e. live trees, dead wood, stumps and seedlings) were captured and they increased the accuracy in carbon stock values at all sites. However, I only determined carbon fraction from 12 species out of the 80 recorded species. This small species number included the most common and dominant tree species, B. plurijuga, which represented a quarter of all the surveyed trees. The total available carbon stock at each site was determined after accounting for the biomass stock that had been removed from the forests through different illegal activities such as logging and charcoal burning. The highest loss was recorded at Namwala where 7 ton $\mathrm{C} \mathrm{ha}^{-1}$ was removed from the forests. Individual species carbon stocks showed that B. plurijuga had the highest carbon stock (Chapter 2).

I found a clear trend of carbon fraction and carbon stock values following a rainfall gradient. Thus, both carbon fraction and carbon stock increased with increasing rainfall. This trend indicates that a rainfall decrease for southern Africa, as projected by Niang et al. (2014) for future climate change could negatively affect carbon stock of the Zambezi teak forests through its effects on forest productivity. These negative effect, coupled with forest degradation and deforestation (Musgrave, 2016), which were also observed in my sites, likely reduced the carbon stocks. These reduced carbon stock will negatively affect the carbon storage potential of the studied Zambezi teak forests resulting in decreased mitigating role in climate change. 


\subsection{RQ3 What is the relationship between forest productivity and climatic} variables in the wetter, intermediate and drier sites of the Zambezi teak forests?

In this study, forest productivity was measured as the width of annual growth rings determined using tree-ring analysis (Chapters 5 and 6) and Net Primary Productivity (NPP) determined by a vegetation growth model (LPJ-GUESS) (Chapter 6). Chapters $\mathbf{2}$ and $\mathbf{5}$ indicate that B. plurijuga is the most common and dominant species in the Zambezi teak forests. I therefore, analysed the tree-rings of this species and correlated $(\mathrm{p}<0.05)$ them with climatic variables (temperature and rainfall) and evaporation at the wetter Kabompo, the intermediate Namwala and the drier Sesheke sites.

Chapters 5 and 6 show that tree-ring indices positively correlate with current year's rainfall at the wetter Kabompo site, while at the drier Sesheke site, rainfall of the previous two years had positive relationship with tree-ring indices (Chapter 6). This indicates a carry-over effect of rainfall from the previous years. The positive relationship between tree-ring indices and rainfall was in the same direction as earlier tropical tree studies (Fichtler et al., 2004; Schöngart et al., 2006; Therrell et al., 2006; Therrell et al., 2007; Couralet et al., 2010; Trouet et al., 2010). No significant correlations were recorded between tree-ring indices and rainfall at the intermediate Namwala site (Chapters 5 and 6). The trends in correlations presented in Chapters 5 and 6 are opposite to the trends reported in Chapter 4 where relationships between rainfall and productivity are higher in low rainfall receiving regions than in high rainfall receiving areas. These contrasting trends are probably due to different responses of individual tree species to climatic conditions. No significant relationships between LPJGUESS simulated NPP and rainfall of current year, previous year and previous two years were observed at all sites (Chapter 6).

LPJ-GUESS simulates annual NPP, which is positively related to mean annual temperatures of current year, previous year and previous two years at all sites (Chapter 6). However, no significant relationships were observed between the tree-ring indices and mean annual temperatures of current year, previous year and previous two years at all sites apart from at the Namwala site, where the negative relationship between tree-ring indices and mean annual temperature of the previous two years was significant. This indicates a carry-over effect of temperature between several years in the Namwala site (Chapter 6) meaning that current temperatures affect future NPP. 
Monthly correlations showed that tree-ring indices correlated the strongest with the mean evaporation value of November and March $(\mathrm{r}=-0.557)$, which explained $31 \%$ of the variance at the Namwala site. The March value $(r=-0.436)$ explained $19 \%$ of the variance at the Sesheke site. However, at the Kabompo site the chronology correlated best with the December temperature $(r=-0.540)$. This explained 29\% of the variance (Chapter 5).

The annual correlations produced by the LPJ-GUESS modelling and tree-ring analysis are contradictory. This hints at the methodological differences. Only one species (B. plurijuga) was used to analyse tree-rings. However, the modelling study, which was conducted at ecosystem level, incorprated all the available tree species in the forests. During our 2014 forest survey, we recorded eighty tree species (Ngoma et al., 2018a; Ngoma et al., 2018b) and the simulated NPP incorporated all the eighty species. The response of these eighty different species to climate varies and this results in a net response to climate, which differs from the specific response of $B$. plurijuga alone. Rainfall and temperature representation in LPJGUESS model probably has some effects on NPP. While rainfall and temperature of the previous years have effects on the current year's tree-rings, the climatic variables of the previous years are not clearly represented in LPJ-GUESS model, and likely do not affect current year's NPP generated by the model. The limited representation of carry-over effects of rainfall on trees' productivity in dynamic vegetation models was also reported by other studies (e.g. Babst et al. (2013)). This limits NPP growth in the LPJ-GUESS model and a clear representation of previous climatic variables in the model would improve model results. The contradictory results produced by tree-ring analysis and modelling studies were also observed in Chapter 4 where the mean tree-ring indices reduced by 0.011 over the period from 1569 to 2014 while mean annual NPP increased by 4.8\% from 1900 to 2011 in Africa.

However, though the annual correlations produced by the LPJ-GUESS modelling and treering analysis are different, my results showed clearly that the relationships between tree's productivity and climatic variables are higher in the wetter areas than in the drier areas. This indicates that following the temperature increase and rainfall decrease in southern Africa as projected by Niang et al. (2014), trees growing in wetter areas will be affected more than the trees growing in drier areas. 


\subsection{RQ4 How do contemporary and future climate affect the productivity of the forests in Africa?}

Chapter 4 presents positive relationships between trees' productivity and high rainfall $(\mathrm{r}=$ between 0.50 and 0.94 ) (Cao et al., 2001; Pan et al., 2015; Mohammed et al., 2018). Trees growing in low rainfall areas respond more strongly to changes in rainfall than those growing in high rainfall regions. Rainfall correlated highly (i.e. correlation coefficient ranges $0.54-$ 0.79 ) with tree-ring chronologies in areas receiving between $400 \mathrm{~mm}$ and $700 \mathrm{~mm}$ rain $\mathrm{yr}^{-1}$ (Stahle et al., 1999; Gebrekirstos et al., 2008; Nicolini et al., 2010) while low correlations (i.e.

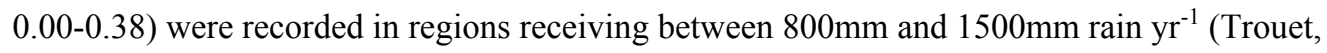
2004; Trouet et al., 2006; Couralet et al., 2010; Ridder et al., 2013). A similar trend was also reported by Zhu and Southworth (2013). They found that NPP-to-rainfall relationship was high and significant when mean annual rainfall was less than $850 \mathrm{~mm}$ while, with rainfall of more than $850 \mathrm{~mm}$, the relationship between NPP and rainfall was not significant. The low correlations between high rainfall and trees' productivity is because plants use water up-to a certain limit and in high rainfall receiving areas, not all the water received through rainfall is used by plants, instead, most of it is lost through run-off (Zhang et al., 2004; MurrayTortarolo et al., 2017). The positive high effects of rainfall on forest productivity in low rainfall receiving regions could be due to the high effect of soil moisture that controls tree's growth (Knapp and Smith, 2001). High temperatures negatively influence tree growth for most species (Trouet, 2004; Trouet et al., 2006; Nicolini et al., 2010; Ilmen et al., 2016) though some species respond positively to increasing temperature (Trouet, 2004; Ciais et al., 2009; Pan et al., 2015; Mohammed et al., 2018). Thus, plants' response to temperature change increases with the rise in temperature (Chapter 4).

Following the above correlations, the mean tree-ring indices of all studied biomes reduced by 0.011 over the period from 1569 to 2014 while from 1900 to 2011, mean annual NPP increased by $4.8 \%$ in Africa (Chapter 4). This contrasting response could be due to methodological differences. Tree-ring analysis was conducted on selected species while modelling studies were conducted on all tree species in distinct biomes. Thus, the combined response of the selected trees studied in tree-ring analysis and that of the biome differs because of the different trees' composition and the number of tree species included in the analysis. From the year 1950, the combined NPP of all African biomes is projected to reduce 
by $8 \%$ by the end of the $21^{\text {st }}$ century (Chapter 4 ), following the changes in climate as projected by Niang et al. (2014).

My review results likely indicate that accurate determination of climate change effects on forest's productivity is dependent on the applied method. However, both methods have clearly shown that trees growing in low rainfall receiving areas respond more strongly to changes in rainfall than the trees growing in high rainfall receiving regions and that changes in temperature have more effects on tree's productivity in hotter areas than in colder areas.

\section{$4.15 R Q 5$ Can the forests' carbon stock realistically be reproduced for current climate conditions at the wetter, intermediate and drier sites?}

Chapter 6 presents the forest carbon values that are simulated with the LPJ-GUESS model using contemporary climate as a baseline for the projected climate change effects assessment. I compared the LPJ-GUESS simulated forest carbon (Chapter 6) to the forest carbon stock that I measured from a combined area of $15 \mathrm{ha}$ at the wetter Kabompo, the intermediate Namwala and the drier Sesheke sites along a south-north rainfall gradient (Chapter 3). Using local soil parameter values to characterize texture and measured local tree parameter values for maximum crown area, wood density, leaf longevity and allometry, LPJ-GUESS simulated forest carbon values were closest to the measured forest carbon stock values at the wetter Kabompo site, followed by the drier Sesheke site and then the intermediate Namwala site. These results coincided with the rainfall pattern with Kabompo receiving the highest amount of rainfall $(983 \mathrm{~mm})$ followed by Namwala $(905 \mathrm{~mm})$ and then the Sesheke $(643 \mathrm{~mm})$ sites (Chapter 6). The minimal too high estimate of forest carbon by the LPJ-GUESS model is probably because trees in the model are simulated to be taller compared to measured heights (Chapters 2 and 6).

I further assessed the performance of the LPJ-GUESS model by comparing the model's simulated NPP (Chapter 6) with tree-ring indices that I determined in Chapter 5. The relationships were not significant at all the three sites (Chapter 6) probably due to different species composition incorporated in the two methods. Tree ring analysis used one species only in the study (Chapter 5), while modelling studies incorporated all the available species in the forests since the studies were conducted at ecosystem level. The forest survey we conducted in our previous studies show that the Zambezi teak forests have eighty species (Ngoma et al., 2018a; Ngoma et al., 2018b) and the net NPP simulated by the LPJ-GUESS 
model incorporated all these available eighty tree species (Chapter 6). Thus, the net growth rate of these eighty species used in the model is probably not the same as the growth rate of one dominant species used in tree-ring analysis.

The LPJ-GUESS model is a flexible model that can be applied at different scales ranging from local to global. However, using its default parameter values, the model did not reproduce realistic vegetation carbon values at all sites. I reproduced vegetation carbon values under contemporary climate that reasonably compared with measured values after replacing the default with locally obtained parameter values (Chapter 6). The trends in vegetation carbon values then showed that the LPJ-GUESS model simulates vegetation carbon better in areas that receive high amounts of rainfall compared to the drier sites. My results therefore showed that using local parameter values is essential to obtaining reasonably reliable simulations.

\subsection{RQ6 How will climate change affect the productivity of the Zambezi teak forests in the wetter, intermediate and drier sites, and what are the main drivers of change?}

Using the validated LPJ-GUESS model described in Chapter 6, I projected changes in NPP following the changes in rainfall, temperature, incoming solar radiation, number of wet days and $\mathrm{CO}_{2}$ concentration under the RCP4.5 and RCP8.5 climate-change pathways as projected for the end of this $21^{\text {st }}$ century. I combined changes in all these climatic variables to assess changes in NPP for the different sites. NPP will increase at all sites under both RCP4.5 and RCP8.5 except at the Sesheke site where NPP is reduced. Increased $\mathrm{CO}_{2}$ concentrations are projected to enhance NPP at the Kabompo and Namwala sites under both RCPs. In RCP8.5 precipitation decreases and temperature increases and this combination reduces NPP at the Sesheke site.

The projected NPP increases at the Kabompo and Namwala sites is in the same direction as the results reported by other studies (Alo and Wang, 2008; Pan et al., 2015; Mohammed et al., 2018) that were carried out for other parts of Africa. Most modelling studies on tropical forests (Melillo et al., 1993; Midgley et al., 2005; Thuiller et al., 2006; Ciais et al., 2009; Doherty et al., 2010; Pan et al., 2015; Braakhekke et al., 2017) also reported large positive effects of increased $\mathrm{CO}_{2}$ concentrations on forests' productivity. This positive effect could probably be due to increased Water-Use-Efficiency (WUE, which is a measure of a plant's water-use during photosynthesis in relation to the amount of water withdrawn (Grain 
Research and Development Cooperation, 2009)) by the plants. The stomata partially close to maintain a near constant concentration of $\mathrm{CO}_{2}$ inside the leaf even under continually increasing atmospheric $\mathrm{CO}_{2}$ levels. Such stomatal closure decreases evapotranspiration (Keenan et al., 2013) and thus increases WUE. The positive effects of increased $\mathrm{CO}_{2}$ on NPP could also be due to increased Nitrogen-Use-Efficiency (NUE, i.e., the amount of carbon converted into sugars during the photosynthetic process per unit of leaf nitrogen) (Davey et al., 1999). When $\mathrm{CO}_{2}$ concentration increases, the amount of rubisco enzymes are reduced. As a consequence, foliar nitrogen is mobilized out of leaves and into other areas of the plant. This decreases the amount of nitrogen in the leaves. However, despite a reduction in leaf nitrogen, photosynthesis is still higher at elevated $\mathrm{CO}_{2}$ concentrations. This results in increased carbon uptake at lower nutrient supplies. The higher photosynthesis activities and lower leaf nitrogen content increase the photosynthetic NUE (Davey et al., 1999). However some other studies indicate that herbaceous plants and deciduous trees acclimate quickly to increased $\mathrm{CO}_{2}$ concentrations by reducing photosynthetic capacity and stomatal conductance (Ellsworth, 1999; Mooney et al., 1999). As a result, the required water and nitrogen needed to fix a given amount of carbon is reduced (Chapin et al., 2007). However, such acclimation has sometimes no effect on the photosynthetic rate and stomatal conductance (Curtis and Wang, 1998). To what extent our modelling results are realistic is therefore not fully clear. Currently, the responses of tropical trees and forests to increased $\mathrm{CO}_{2}$ are still poorly understood (Thomas et al., 2008) since $\mathrm{CO}_{2}$ enrichment experiments are lacking in the tropics. Such experiments should be done because they could explain whether the enhanced NPP that result from increased $\mathrm{CO}_{2}$ is due to increased WUE, NUE or $\mathrm{CO}_{2}$ fertilization.

The projected NPP decrease at the Sesheke site is similar to the 12\% NPP reduction for the savanna forests by 2080 (Delire et al., 2008). Alo and Wang (2008) also projected NPP decrease in west and southern Africa. Yu and Chen (2016) show that NPP of the drier areas is mainly influenced by changes in water availability and by enhancing the forest's WUE. Thus, reduced rainfall decreases soil water availability that is needed by the plants. High temperature enhances evapotranspiration and this reduces soil moisture (Miyashita et al., 2005). When soil moisture decreases, the stomata close to restrict water loss and this minimises carbon dioxide uptake into plants, consequently resulting in reduced NPP (McGuire and Joyce, 2005). Decreased soil water also limits nutrient absorption by the roots and further transportation into the plants. Increased temperature enhances plant respiration and this results in reduced NPP (Burton et al., 2008; Wu et al., 2011). 
NPP's response to climate change differed at the wetter Kabompo, intermediate Namwala and drier Sesheke. This trend is probably amplified by the variation in rainfall and nutrient distribution that affect other factors that sebsequently affect NPP (Chapter 6). Differences in species composition among sites also determine in which way species respond to climate change. While $9 \%$ of the total tree species are common in all the three sites, $25 \%$ of the total surveyed species are only found at the Kabompo site, $38 \%$ at the Namwala site and $16 \%$ at the Sesheke site (Chapter 2). However, despite these inter-site NPP's response to climate change, some similarities emerge from my results (Chapter 6) and the literature (Chapter 4) for similar forest types. The differences in actual values are likely caused by the differences in models applied, extent of area coverage, species composition and soil types. I also compared my results to the available other studies for African biomes. Only a few studies on African forests use the LPJ-GUESS model. However, I could not find any studies that, like mine, applied the LPJ-GUESS model to local sites. Most model-based studies were conducted for the whole world or for the whole continent (Cao and Woodward, 1998a; Schaphoff et al., 2006). Availability of more local studies would provide better insight on the validity of my results and their general applicability. Focussing more forest modelling on African sites will certainly help to better understand the potential response of the African forest biomes to climate change. In my study, I already demonstrated that differences in rainfall patterns strongly influence how climate change will affect NPP and thus forests resources.

\subsection{Scientific contributions of my research}

My study aimed to determine the projected effects of climate change on NPP of the Zambezi teak forests along a rainfall gradient in Zambia. I addressed this aim by dividing my research into two sections: (1) determining available vegetation carbon stock and (2) establishing forests' responses to climate change.

\section{1) Determining available vegetation carbon stock}

The Zambezi teak forests provide important resources such as timber, biodiversity and carbon sequestration. However, quantifying their biomass requires the use of allometric models. These models were lacking. Thus, developing ecosystem-specific biomass models for these forests is crucial to reduce uncertainties and achieve a more accurate carbon accounting in dry tropical forests. The carbon fraction for the Zambezi teak forests is also not available. I therefore made three scientific contributions in this area. First I developed the urgently needed allometric biomass models. Second, I determined the carbon fractions for different species 
and sites. Finally, I estimated the carbon stocks of these Zambezi teak forests in the wetter, intermediate and drier sites by applying the newly developed biomass allometric models. The results from these sites can probably be extrapolated towards other regions covered by the Zambezi teak forests on the basis of available soil and climate data.

\section{2) Establishing forests' response to climate change}

Climate change is one of the most challenging problems of this century and its effects on forests' resources varies in space and time (Niang et al., 2014). Understanding these effects requires the application of various methods including tree-ring analysis and modelling. In the Zambezi teak forests, a few limited studies have been conducted to understand their contemporary and future responses to climate change. I made three additional scientific contributions in this area. First, I established the relationships between tree productivity and some climatic variables (i.e. temperature and rainfall) and evaporation. Second, I generated local soil and tree parameter values to apply LPJ-GUESS model to the Zambezi teak forests. The model simulations were validated with data from the wetter, intermediate and drier sites. These new parameterisations can probably also be applied for similar tropical deciduous dry forests. Finally, I used future climate change scenarios to assess their effects on the productivity of the Zambezi teak forests in these three sites. This is probably the first detailed assessment of climate change impacts on the Zambezi teak forests.

\subsection{General conclusions}

I developed three above-ground biomass models, one below-ground biomass model and one stump model. Applying these newly developed models, I found the highest vegetation carbon stock at the wetter Kabompo site (36ton $\mathrm{C} \mathrm{ha}^{-1}$ ), followed by the intermediate Namwala site (25ton $\mathrm{C} \mathrm{ha}^{-1}$ ) and the lowest carbon stock value was recorded at the drier Sesheke site (16ton $\mathrm{C} \mathrm{ha}^{-1}$ ). The tree-ring indices of the most common and dominant B. plurijuga species correlated positively with current year's annual rainfall at the wetter Kabompo site, while at the drier Sesheke site, the indices related positively with annual rainfall of the previous two years. At the intermediate Namwala site, tree-ring indices correlated negatively with mean annual temperatures of the previous two years. I recorded the highest negative correlations between tree ring indices and evaporation of the current year and the regression analysis indicated that evaporation had the highest influence on tree growth at all the three study sites compared to temperature and rainfall alone. LPJ-GUESS simulated annual NPP related positively with mean annual temperatures of current year, previous year and previous two 
years at all sites. I generated local soil parameter values to characterize texture and measured local tree parameter values for maximum crown area, wood density, leaf longevity and allometry, and the model results improved when I replaced default with local parameter values. Using the improved LPJ-GUESS model, NPP was projected to increase at the wetter Kabompo and the intermediate Namwala sites caused by increased $\mathrm{CO}_{2}$ concentration under RCP4.5 and RCP8.5, while at the drier Sesheke site NPP would decrease by the end of $21^{\text {st }}$ century under RCP8.5 caused by a combination of increased temperature and reduced rainfall. This distinct response at the wetter Kabompo, intermediate Namwala and drier Sesheke sites indicates that differences in rainfall and temperature patterns influence the way in which the projected changes in climate and $\mathrm{CO}_{2}$ will affect forests resources.

\subsection{Policy and management implications}

The results at my three study sites (Kabompo, Namwala and Sesheke) vary. This indicates divergent responses of the same forest type to climate change. This diverse response calls for distinct local specific adaptation and mitigation measures to be implemented at each of the sites. Thus, various stakeholders including the Government of the Republic of Zambia, should come up with these distinct measures in line with my varying results. For example, measures at Kabompo and Namwala should focus on enhancing growth of the species that are currently growing at the respective sites, while measures at Sesheke should promote planting other tree species that are better adapted to high temperatures and low rainfall, and the future's more arid conditions.

Chapter 1 stated that about $65 \%$ of people in Zambia depend on forestry resources for their livelihood (The Government of the Republic of Zambia, 2011b). However, climate change and its effects on the forestry resources in Zambia is mainly discussed at high management levels and sometimes up to district levels. The formal structure in the forestry department do not exist at village level, and in Zambia, most people who depend on forestry resources for livelihoods are found in villages. This lack of formal structure at village level limits the local people from receiving the information on climate change and its effects on the forestry resources. Moreover, most of the rural people have limited personal facilities to inform them. Unfortunately, most of the rural communities have limited formal education to enable them read about climate change information. The Government of the Republic of Zambia should therefore ensure that formal structures in the Forestry Department reach down to village level for easy communication of climate change information to people in rural areas. The government should also initiate a deliberate program to disseminate this important 
information to these forest dependent communities using local languages in the respective regions of the country. The received information will help rural people to prepare and plan for alternative sources of livelihoods when the negative climate-change scenarios become reality. Effects of climate change on forestry resources can mainly be understood after carrying out various studies on these resources including monitoring programs. Currently, not much research is carried out in the forestry sector in Zambia. Forestry monitoring programs are almost non-existent. This is due to lack of funding and low staffing levels to facilitate implementation of such important activities. The goverment of the Republic of Zambia should therefore allocate enough funds and employ qualified and adequate number of staff to enable implementation of research activities and monitoring programs.

\subsection{Future research}

I conducted research in the Zambezi teak forests, which is one of the forest type covering a small area in Zambia. Other researchers focussed their work on climate change effects on the forestry resources in the vast Miombo woodlands (Chidumayo, 2005; Trouet et al., 2010). However, Zambia has different forests types (Storrs et al., 1979). Research should therefore be conduct in all forestry types so as to have a complete understanding of the fate of the entire forestry resources in the country. This would help the government prepare in the case of negative effects of these resources by climate change.

One of the research types conducted on forest resources is to develop biomass allometric models (Henry et al., 2011). Researchers working on these models use different indicators to measure the performance of the newly developed models, such as Mean Absolutely Percentage Error, $\mathrm{r}^{2}$-values, Mean Square Error and Root Mean Square Error. This variation in measurement indicators makes it challenging to compare the performance of different models. A uniform standard should therefore be developed by researchers in this field of science against which all newly developed models should be measured before they are accepted by the scientific community. This measurement standard will also help users of the models to choose the best performing model from a variety of available models.

The significant positive relationship between tree-ring indices and rainfall and temperature of previous two years indicate carry-over effects of these climatic variables on trees' productivity. This aspect is not clearly addressed in the LPJ-GUESS model. Lack of clear representation of carry-over effects in the model limits the proper simulation of NPP and its responses to changes in climate. This should be addressed in LPJ-GUESS model so as to improve the models' performances in biodiverse tropical forests. 

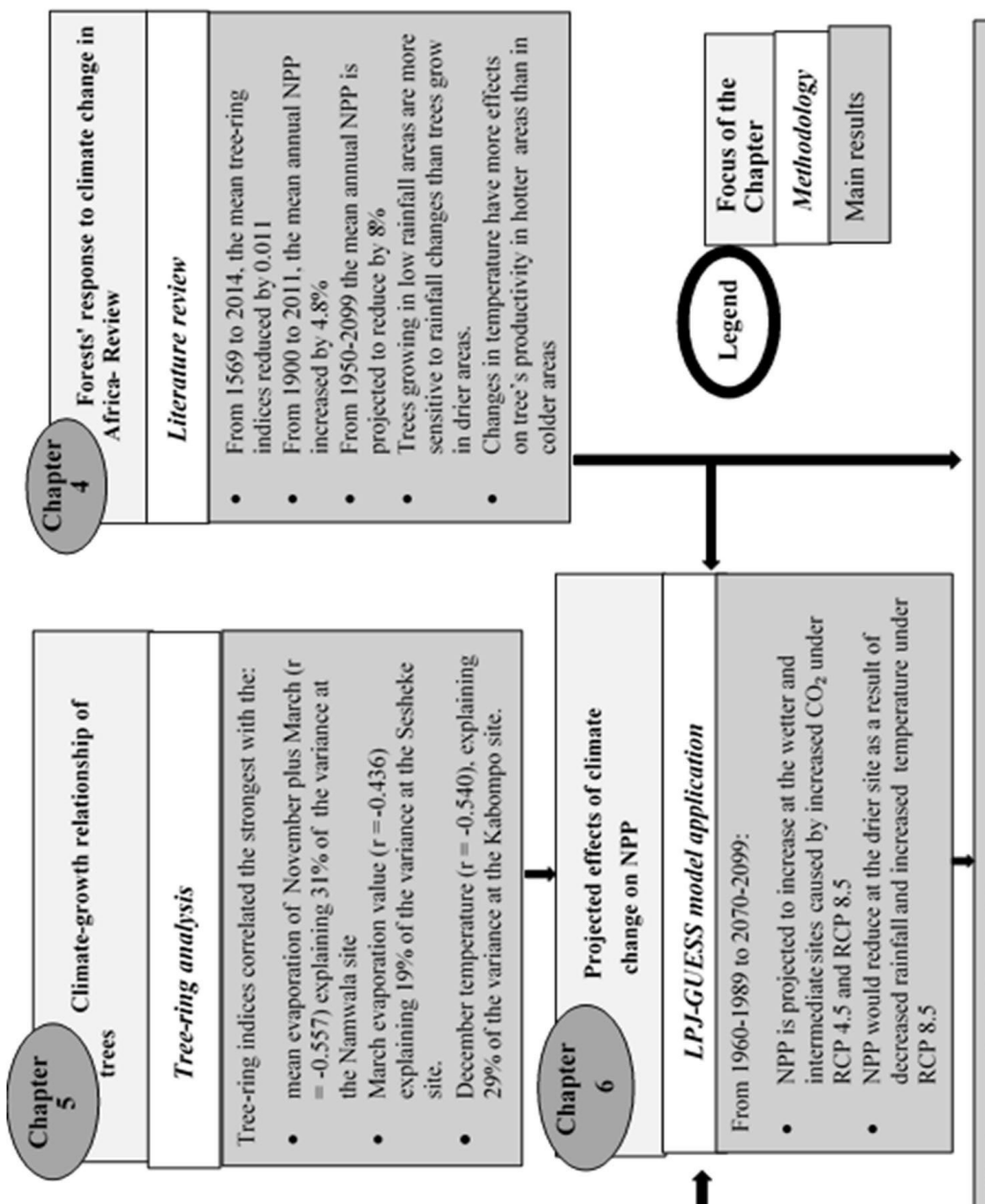

总 言

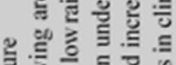

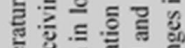

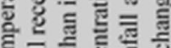

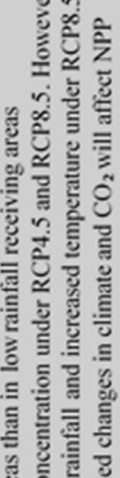

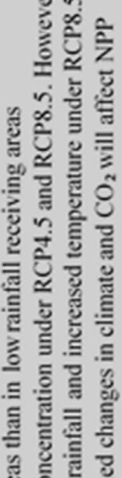

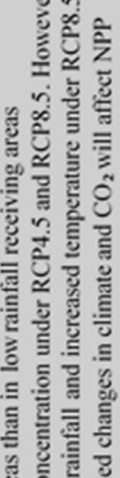

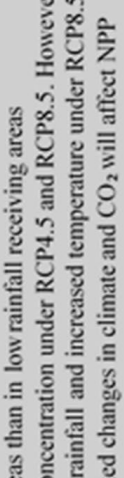

$\hat{\bar{z}}$ है हैं 3 of 0 这 웅호 흘 흔

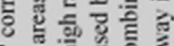

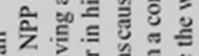

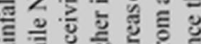

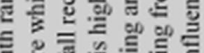

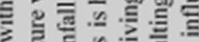

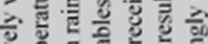

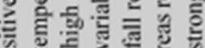

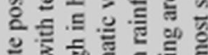
해를

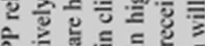
总的言

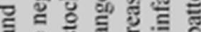
嵒 인

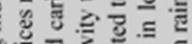

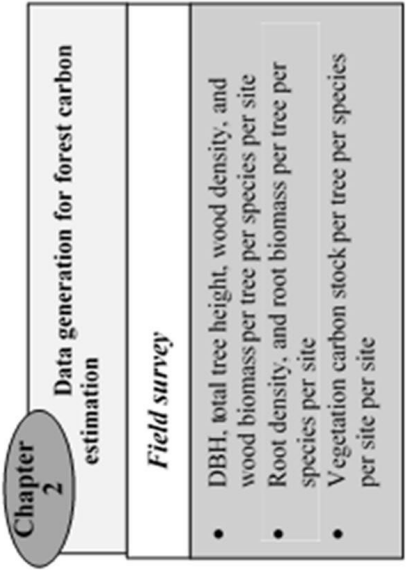

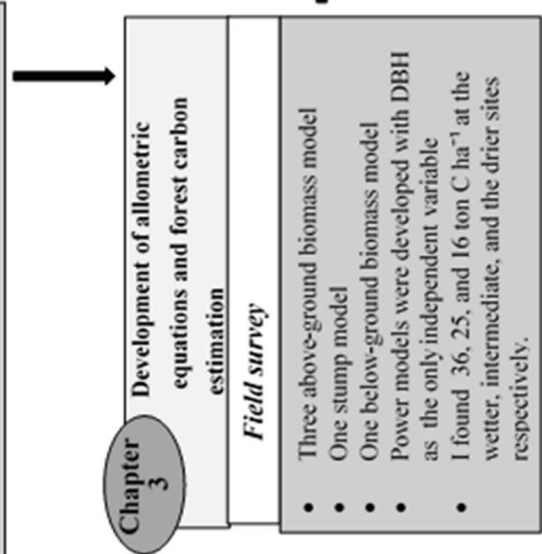
00 근 है

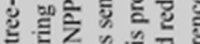
言起产商产言产 蒙总高

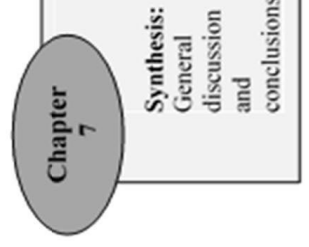


Ahlström, A., Schurgers, G., Arneth, A. \& Smith, B. 2012. Robustness and uncertainty in terrestrial ecosystem carbon response to CMIP5 climate change projections.

Environmental Research Letters, 7, 044008 (pp9).

Aho, K., Derryberry, D. \& Peterson, T. 2014. Model selection for ecologists: the worldviews of AIC and BIC. Ecology, 95, 631-636.

Alo, C. A. \& Wang, G. 2008. Potential future changes of the terrestrial ecosystem based on climate projections by eight general circulation models. Journal of Geophysical Research, 113, G01004.

Arias, D., Calvo-Alvarado, J., Richter, D. d. B. \& Dohrenbusch, A. 2011. Productivity, aboveground biomass, nutrient uptake and carbon content in fast-growing tree plantations of native and introduced species in the Southern Region of Costa Rica. Biomass and Bioenergy, 35, 1779-1788.

ASTM. 2007. D2395-07. Standard Test Methods for Specific Gravity of Wood and WoodBased Materials ASTM International, West Conshohocken, PA, 2007, www.astm.org.

Babst, F., Poulter, B., Trouet, V., Tan, K., Neuwirth, B., Wilson, R., Carrer, M., Grabner, M., Tegel, W., Levanic, T., Panayotov, M., Urbinati, C., Bouriaud, O., Ciais, P. \& Frank, D. 2013. Site- and species-specific responses of forest growth to climate across the European continent. Global Ecology and Biogeography, 22, 706-717.

Baccini, A., Laporte, N., Goetz, S. J., Sun, M. \& Dong, H. 2008. A first map of tropical Africa's above-ground biomass derived from satellite imagery. Environmental Research Letters, 3, 045011 (9pp).

Barker, P. 2001. A Technical Manual for Vegetation Monitoring. Resource Management and Conservation, Department of Primary Industries, Water and Environment., Hobart.

Basuki, T. M., van Laake, P. E., Skidmore, A. K. \& Hussin, Y. A. 2009. Allometric equations for estimating the above-ground biomass in tropical lowland Dipterocarp forests. Forest Ecology and Management, 257, 1684-1694.

Battipaglia, G., Zalloni, E., Castaldi, S., Marzaioli, F., Cazzolla- Gatti, R., Lasserre, B., Tognetti, R., Marchetti, M. \& Valentini, R. 2015. Long Tree-Ring Chronologies Provide Evidence of Recent Tree Growth Decrease in a Central African Tropical Forest. PLoS ONE, 10, e0120962.

Baty, F., Christian, R., Sandrine, C., Martin, B., Jean-Pierre, F. \& Marie-Laure, D.-M. 2015. A Toolbox for Nonlinear Regression in R: The Package nlstools. Journal of Statistical Software 66, 1-21.

Beaty, T. W., Olsen, L. M., Brown, S. \& Gaston, G. 2001. Tropical Africa: Land Use, biomass, and Carbon Estimates for 1980. Carbon Dioxide Information Analysis Center, USA.

Becker, G. S., Braun, D., Gliniars, R. \& Dalitz, H. 2012. Relations between wood variables and how they relate to tree size variables of tropical African tree species. Trees, 26, 1101-1112.

Berger, A. L., Guiot, J., Mathieu, L. \& Munaut, A. V. 1979. Tree-Rings and Climate in Morocco. Tree-Ring Bulletin, 39, 61-75.

Bert, D. \& Danjon, F. 2006. Carbon concentration variations in the roots, stem and crown of mature Pinus pinaster (Ait.). Forest Ecology and Management, 222, 279-295.

Best, M. J., Pryor, M., Clark, D. B., Rooney, G. G., Essery, R. L. H., Ménard, C. B., Edwards, J. M., Hendry, M. A., Porson, A., Gedney, N., Mercado, L. M., Sitch, S., Blyth, E., 
Boucher, O., Cox, P. M., Grimmond, C. S. B. \& Harding, R. J. 2011. The Joint UK Land Environment Simulator (JULES), model description - Part 1: Energy and water fluxes. Geoscience Model Development, 4, 677-699.

Bombelli, A., Henry, M., Castaldi, S., Adu-Bredu, S., Arneth, A., De Grandcourt, A., Grieco, E., Kutsch, W. L., Lehsten, V., Rasile, A., Reichstein, M., Tansey, K., Weber, U. \& Valentini, R. 2009. An outlook on the Sub-Saharan Africa carbon balance. Biogeosciences, 6, 2193-2205.

Braakhekke, M. C., Rebel, K. T., Dekker, S. C., Smith, B., Beusen, A. H. W. \& Wassen, M. J. 2017. Nitrogen leaching from natural ecosystems under global change: a modelling study. Earth System Dynamics, 8, 1121-1139.

Branthomme, A. 2006. Integrated land use assessment, Zambia . Field Manual Food and Agricultural Organisation (FAO), 1-98.

Brown, S. 1997. Estimating Biomass and Biomass Change of Tropical Forests: a Primer. FAO Forestry Paper - 134. Food and Agricultural Organisation (FAO) Rome

Brown, S., D. Shoch, T. Pearson \& Delaney., M. 2004. Methods for Measuring and Monitoring Forestry Carbon Projects in California. Winrock International, for the California Energy Commission, PIER Energy-Related Environmental Research. 50004-072F.

Brown, S., Gillespie, A. J. R. \& Lugo, A. E. 1989. Biomass Estimation Methods for Tropical Forests with Applications to Forest Inventory Data. Forest Science, 35, 881-902.

Brown, S., Gillespie, A. J. R. \& Lugo, A. E. 1991. Biomass of tropical forests of south and southeast Asia. Canadian Journal of Forest Research, 21, 111-117.

Brown, S. \& Lugo, A. E. 1984. Biomass of tropical forests: a new estimate based on forest volumes. Science, 223, 1290-1293.

Brummitt, R. K. 1986. A taxonomic perspective of the Genus Baikiaea. In: Piearce, G. D. (ed.) The Zambezi teak forests : proceedings of the first international conference on the teak forests of Southern Africa, Livingstone, Zambia, 18 - 24th March 1984. Forest Department [etc.], Ndola.

Burton, A. J., Melillo, J. M. \& Frey, S. D. 2008. Adjustment of Forest Ecosystem Root Respiration as Temperature Warms. Journal of Integrative Plant Biology, 50, 14671483.

Bwalya, S., M 2010. Climate Change in Zambia: Opportunities for Adaptation and Mitigation through Africa Bio-Carbon Initiative. Center for International Forest Research. Southern Africa Regional Office, Lusaka, Zambia.

Calvet, G. M. 1986. The ecology and management of the Kalahari Sand Forest vegetation of South-Western Zimbabwe. In: Piearce, G. D. (ed.) The Zambezi teak forests : proceedings of the first international conference on the teak forests of Southern Africa, Livingstone, Zambia, 18 - 24th March 1984. Forest Department [etc.], Ndola.

Cao, M. \& Woodward, F. I. 1998a. Dynamic responses of terrestrial ecosystem carbon cycling to global climate change. Nature, 393, 249-252.

Cao, M. \& Woodward, F. I. 1998b. Net primary and ecosystem production and carbon stocks of terrestrial ecosystems and their responses to climate change. Global Change Biology, 4, 185-198.

Cao, M., Zhang, Q. \& Shugart, H. H. 2001. Dynamic responses of African ecosystem carbon cycling to climate change. Climate Research, 17 183-193.

Castellanos, J., Maass, M. \& Kummerow, J. 1991. Root biomass of a dry deciduous tropical forest in Mexico. Plant and Soil, 131, 225-228.

Chambers, J. Q., Schimel, J. P. \& Nobre, A. D. 2001. Respiration from coarse wood litter in Central Amazon Forests. Biogeochemistry, 52, 115-131. 
Chamshama, S. A. O., Mugasha, A. G., and \& Zahabu, E. 2004. Stand biomass and volume estimation for Miombo woodlands at Kitulangalo, Morogoro, Tanzania. Southern African Forestry Journal, 59-70.

Chapin, F. S., Eviner, V. T., Holland, H. D. \& Turekian, K. K. 2007. 8.06 - Biogeochemistry of Terrestrial Net Primary Production. In: Schlesinger, W. H. (ed.) Treatise on Geochemistry. Pergamon, Oxford.

Chave, J., Andalo, C., Brown, S., Cairns, M. A., Chambers, J. Q., Eamus, D., Fölster, H., Fromard, F., Higuchi, N., Kira, T., Lescure, J. P., Nelson, B. W., Ogawa, H., Puig, H., Riéra, B. \& Yamakura, T. 2005. Tree allometry and improved estimation of carbon stocks and balance in tropical forests. Oecologia, 145, 87-99.

Chave, J., Condit, R., Lao, S., Caspersen, J. P., Foster, R. B. \& Hubbell, S. P. 2003. Spatial and temporal variation of biomass in a tropical forest: results from a large census plot in Panama. Journal of Ecology, 91, 240-252.

Chen, T., Werf, G. R., Jeu, R. A. M., Wang, G. \& Dolman, A. J. 2013. A global analysis of the impact of drought on net primary productivity. Hydrology and Earth System Sciences, 17, 1467-1483.

Chidumayo, E., Okali, D., Kowero, G. \& Larwanou, M., (eds.). 2011. Climate change and African forest and wildlife resources African Forest Forum, Nairobi, Kenya.

Chidumayo, E. N. 1990. Above-ground woody biomass structure and productivity in a Zambezian woodland. Forest Ecology and Management, 36, 33-46.

Chidumayo, E. N. 1993. Zambian charcoal production. Energy Policy, 21, 586-597.

Chidumayo, E. N. 1997. Miombo ecology and management: An introduction Intermediate Technology Publishers, London.

Chidumayo, E. N. 2005. Effects of climate on the growth of exotic and indigenous trees in central Zambia. Journal of Biogeography, 32, 111-120.

Chidumayo, E. N. 2014. Estimating tree biomass and changes in root biomass following clear-cutting of Brachystegia-Julbernardia (miombo) woodland in central Zambia. Environmental Conservation, 41, 54-63.

Chidumayo, E. N. \& Gumbo, D. J. 2010. The dry forests and woodlands of Africa : managing for products and services. Earthscan, London [etc.].

Childes, S. L. 1988. Phenology of Nine Common Woody Species in Semi-Arid, Deciduous Kalahari Sand Vegetation. Vegetatio, 79, 151-163.

Chingaipe, T. M. \& Jain, M. K. 1986. Propagation, management and protection of Zambezi teak in Zambia. In: Piearce, G. D. (ed.) The Zambezi teak forests : proceedings of the first international conference on the teak forests of southern Africa, Livingstone, Zambia, 18 - 24th March 1984. Forest Department [etc.], Ndola.

Chisumpa, S. M. 1986. Mukusi Ecological Associations and Environmental Effects. In: Piearce, G. D. (ed.) The Zambezi teak forests : proceedings of the first international conference on the teak forests of Southern Africa, Livingstone, Zambia, 18 - 24th March 1984. Forest Department [etc.], Ndola.

Christensen, J. H., B. Hewitson, A. Busuioc, A. Chen, X. Gao, I. Held, R. Jones, R.K. Kolli, W.-T. Kwon, R. Laprise, V. Magaña Rueda, L. Mearns, C.G. Menéndez, J. Räisänen, A. Rinke, A. Sarr and P. Whetton. 2007. Regional Climate Projections. Climate Change 2007: The Physical Science Basis. Contribution of Working Group I to the Fourth Assessment Report of the Intergovernmental Panel on Climate Change [Solomon, S., D. Qin, M. Manning, Z. Chen, M. Marquis, K.B. Averyt, M. Tignor and H.L. Miller (eds.)]. Cambridge University Press, Cambridge, United Kingdom and New York, NY, USA.

Ciais, P., Piao, S. L., Cadule, P., Friedlingstein, P. \& Chédin, A. 2009. Variability and recent trends in the African terrestrial carbon balance. Biogeosciences, 6, 1935-1948. 
Ciais, P., Tans, P. P., Trolier, M., White, J. W. C. \& Francey, R. J. 1995. A Large Northern Hemisphere Terrestrial CO2 Sink Indicated by the 13C/12C Ratio of Atmospheric CO2. Science, 269, 1098-1102.

Clark, D. A. 2004. Sources or Sinks? The Responses of Tropical Forests to Current and Future Climate and Atmospheric Composition. Philosophical Transactions: Biological Sciences, 359, 477-491.

Clark, D. B., Mercado, L. M., Sitch, S., Jones, C. D., Gedney, N., Best, M. J., Pryor, M., Rooney, G. G., Essery, R. L. H., Blyth, E., Boucher, O., Harding, R. J., Huntingford, C. \& Cox, P. M. 2011. The Joint UK Land Environment Simulator (JULES), model description - Part 2: Carbon fluxes and vegetation dynamics. Geoscientific Model Development, 4, 701-722.

Clarke, L., J. Edmonds, H. Jacoby, H., Pitcher, J. Reilly \& R. Richels. 2007. Scenarios of Greenhouse Gas Emissions and Atmospheric Concentrations. Sub-report 2.1A of Synthesis and Assessment Product 2.1 by the U.S. Climate Change Science Program and the Subcommittee on Global Change Research In: Department of Energy (ed.). Office of Biological \& Environmental Research, Washington, USA.

Collins, W. J., Bellouin, N., Doutriaux-Bouche, M., Gedney, N., Halloran, P., Hinton, T., Hughes, J., Jones, C. D., Joshi, M., Liddicoat, S., Martin, G., O’Connor, F., Rae, J., Senior, C., Sitch, S., Totterdell, I., Wiltshire, A. \& Woodward, S. 2011. Development and evaluation of an Earth-System model - HadGEM2. Geoscientific Model Development 4, 1051-1075.

Cottam, G. \& Curtis, J. T. 1956. The Use of Distance Measures in Phytosociological Sampling. Ecology, 37, 451-460.

Couralet, C., Sass-Klaassen, U., Sterck, F., Bekele, T. \& Zuidema, P. A. 2005. Combining dendrochronology and matrix modelling in demographic studies: An evaluation for Juniperus procera in Ethiopia. Forest Ecology and Management, 216, 317-330.

Couralet, C., Sterck, F. J., Sass-Klaassen, U., Van Acker, J. \& Beeckman, H. 2010. SpeciesSpecific Growth Responses to Climate Variations in Understory Trees of a Central African Rain Forest. Biotropica, 42, 503-511.

Crowther, T. W., Glick, H. B., Covey, K. R., Bettigole, C., Maynard, D. S., Thomas, S. M., Smith, J. R., Hintler, G., Duguid, M. C., Amatulli, G., Tuanmu, M. N., Jetz, W., Salas, C., Stam, C., Piotto, D., Tavani, R., Green, S., Bruce, G., Williams, S. J., Wiser, S. K., Huber, M. O., Hengeveld, G. M., Nabuurs, G. J., Tikhonova, E., Borchardt, P., Li, C. F., Powrie, L. W., Fischer, M., Hemp, A., Homeier, J., Cho, P., Vibrans, A. C., Umunay, P. M., Piao, S. L., Rowe, C. W., Ashton, M. S., Crane, P. R. \& Bradford, M. A. 2015. Mapping tree density at a global scale. Nature, 525, 201-205.

Curtis, P. S. \& Wang, X. 1998. A meta-analysis of elevated CO2 effects on woody plant mass, form, and physiology. Oecologia, 113, 299-313.

Davey, P., Parsons, A., Atkinson, L., Wadge, K. \& Long, S. 1999. Does photosynthetic acclimation to elevated $\mathrm{CO} 2$ increase photosynthetic nitrogen-use efficiency? A study of three native UK grassland species in open-top chambers. Functional Ecology, 13, 21-28.

Davison, A. C. \& Hinkley, D. V. 1997. Bootstrap Methods and Their Applications Cambridge University Press Cambridge.

de Ridder, M., Trouet, V., van den Bulcke, J., Hubau, W., van Acker, J. \& Beeckman, H. 2013. A tree-ring based comparison of Terminalia superba climate-growth relationships in West and Central Africa. Trees - Structure and Function, 27, 12251238. 
Deans, J. D., Moran, J., and \& Grace, J. 1996. Biomass relationships for tree species in regenerating semi-deciduous tropical moist forest in Cameroon. Forest Ecology and Management, 88, 215-225.

Delire, C., Ngomanda, A. \& Jolly, D. 2008. Possible impacts of 21st century climate on vegetation in Central and West Africa. Global and Planetary Change, 64, 3-15.

DFSC. 2001. Conservation plan for genetic resources of Zambezi teak (Baikiaea plurijuga) in Zambia. DFSC Series of Case Studies. CS No.2. Danida Forest Seed Centre, Humlebaek, Denmark.

Doherty, R. M., Sitch, S., Smith, B., Lewis, S. L. \& Thornton, P. K. 2010. Implications of future climate and atmospheric $\mathrm{CO} 2$ content for regional biogeochemistry, biogeography and ecosystem services across East Africa. Global Change Biology, 16, 617-640.

Doughty, C. E. \& Goulden, M. L. 2008. Are tropical forests near a high temperature threshold? Journal of Geophysical Research: Biogeosciences, 113.

Douglas, A. E. 1941. Crossdating in Dendrochronology. Journal of Forestry.

Dube, K. \& Nhamo, G. 2018. Climate variability, change and potential impacts on tourism: Evidence from the Zambian side of the Victoria Falls. Environmental Science \& Policy, 84, 113-123.

Dufresne, J.-L., Foujols, M.-A., Denvil, S., Caubel, A., Marti, O., Aumont, O., Balkanski, Y., Bekki, S., Bellenger, H., Benshila, R., Bony, S., Bopp, L., Braconnot, P., Brockmann, P., Cadule, P., Cheruy, F., Codron, F., Cozic, A., Cugnet, D., de Noblet, N., Duvel, J.P., Ethé, C., Fairhead, L., Fichefet, T., Flavoni, S., Friedlingstein, P., Grandpeix, J.-Y., Guez, L., Guilyardi, E., Hauglustaine, D., Hourdin, F., Idelkadi, A., Ghattas, J., Joussaume, S., Kageyama, M., Krinner, G., Labetoulle, S., Lahellec, A., Lefebvre, M.P., Lefevre, F., Levy, C., Li, Z. X., Lloyd, J., Lott, F., Madec, G., Mancip, M., Marchand, M., Masson, S., Meurdesoif, Y., Mignot, J., Musat, I., Parouty, S., Polcher, J., Rio, C., Schulz, M., Swingedouw, D., Szopa, S., Talandier, C., Terray, P., Viovy, N. \& Vuichard, N. 2013. Climate change projections using the IPSL-CM5 Earth System Model: from CMIP3 to CMIP5. Climate Dynamics, 40, 2123-2165.

Dunwiddie, P. W. \& LaMarche, V. C. 1980. A climatically responsive tree-ring record from Widdringtonia cedarbergensis, Cape Province, South Africa. Nature, 286, 796-797.

Dutilleul, P. \& Till, C. 1992. Evidence of periodicities related to climate and planetary behaviors in ring-width chronologies of Atlas cedar (Cedrusatlantica) in Morocco. Canadian Journal of Forest Research, 22, 1469-1482.

Elias, M. \& Potvin, C. 2003. Assessing inter- and intra-specific variation in trunk carbon concentration for 32 neotropical tree species. Canadian Journal of Forest Research, 33, 1039-1045.

Ellsworth, D. S. 1999. CO2 enrichment in a maturing pine forest: are CO2 exchange and water status in the canopy affected? Plant, Cell \& Environment, 22, 461-472.

Eshete, G. \& Ståhl, G. O. 1999. Tree rings as indicators of growth periodicity of acacias in the Rift Valley of Ethiopia. Forest Ecology and Management, 116, 107-117.

FAO. 2000. FRA 2000. On Definintions of Forest and Forest Change. Forest Resources Assessment WP 33. http://www.fao.org/docrep/006/ad665e/ad665e00.htm\#TopOfPage.

FAO. 2001a. FRA 2000. Global ecological zoning for the global forest resources assessment 2000. Final report. Forestry Department. Food and Agriculture Organization of the United Nations.

FAO. 2001b. Global Forest Resources Assessment 2000. Main report. FAO forestry paper 140. 
FAO. 2007. Management practices for the protection of forest reserves: the Case of Kalahari Sand teak forest reserves in western Zimbabwe. Based on the work by John Mudekwe. Forest Management Working Paper. FAO, Italy, Rome.

Farquhar, G. D., von Caemmerer, S. \& Berry, J. A. 1980. A biochemical model of photosynthetic CO2 assimilation in leaves of C3 species. Planta, 149, 78-90.

Fayolle, A., Engelbrecht, B., Freycon, V., Mortier, F., Swaine, M., Réjou-Méchain, M., Doucet, J.-L., Fauvet, N., Cornu, G. \& Gourlet-Fleury, S. 2012. Geological Substrates Shape Tree Species and Trait Distributions in African Moist Forests. PLoS ONE, 7.

Felzer, B. S., Kicklighter, D. W., Melillo, J. M., Wang, C., Zhuang, Q. \& Prinn, R. G. 2004. Effects of ozone on net primary production and carbon sequestration in the conterminous United States using a biogeochemistry model. Tellus B 56, 230-248.

Fichtler, E., Trouet, V., Beeckman, H., Coppin, P. \& Worbes, M. 2004. Climatic signals in tree rings of Burkea africana and Pterocarpus angolensis from semiarid forests in Namibia. Trees, 18, 442-451.

Fischer, R., Armstrong, A., Shugart, H. H. \& Huth, A. 2014. Simulating the impacts of reduced rainfall on carbon stocks and net ecosystem exchange in a tropical forest. Environmental Modelling \& Software, 52, 200-206.

Foley, J. A., Prentice, I. C., Ramankutty, N., Levis, S., Pollard, D., Sitch, S. \& Haxeltine, A. 1996. An integrated biosphere model of land surface processes, terrestrial carbon balance, and vegetation dynamics. Global Biogeochemical Cycles, 10, 603-628.

Fritts, H. C. 1976. Tree Rings and Climate. Academic Press London, New York San Francisco

Galbraith, D., Levy, P. E., Sitch, S., Huntingford, C., Cox, P., Williams, M. \& Meir, P. 2010. Multiple mechanisms of Amazonian forest biomass losses in three dynamic global vegetation models under climate change. New Phytologist, 187, 647-665.

Gang, C., Zhou, W., Li, J., Chen, Y., Mu, S., Ren, J., Chen, J. \& Groisman, P. Y. 2013. Assessing the Spatiotemporal Variation in Distribution, Extent and NPP of Terrestrial Ecosystems in Response to Climate Change from 1911 to 2000. PLoS ONE, 8, 80394.

Gareth, J., Daniela, W., Trevor, H. \& Robert, T. 2013. An Introduction to Statistical Learning with Applications in R. .

Gautam, S. \& Pietsch, S. A. 2012. Carbon pools of an intact forest in Gabon. African Journal of Ecology, 50, 414-427.

Gebrekirstos, A., Mitlöhner, R., Teketay, D. \& Worbes, M. 2008. Climate-growth relationships of the dominant tree species from semi-arid savanna woodland in Ethiopia. Trees, 22, 631-641.

Giorgetta, M. A., Jungclaus, J., Reick, C. H., Legutke, S., Bader, J., Böttinger, M., Brovkin, V., Crueger, T., Esch, M., Fieg, K., Glushak, K., Gayler, V., Haak, H., Hollweg, H. D., Ilyina, T., Kinne, S., Kornblueh, L., Matei, D., Mauritsen, T., Mikolajewicz, U., Mueller, W., Notz, D., Pithan, F., Raddatz, T., Rast, S., Redler, R., Roeckner, E., Schmidt, H., Schnur, R., Segschneider, J., Six, K. D., Stockhause, M., Timmreck, C., Wegner, J., Widmann, H., Wieners, K. H., Claussen, M., Marotzke, J. \& Stevens, B. 2016. Climate and carbon cycle changes from 1850 to 2100 in MPI-ESM simulations for the Coupled Model Intercomparison Project phase 5. Journal of Advances in Modeling Earth Systems, 5, 572-597.

Gourlay, I. D. 1995a. The definition of seasonal growth zones in Some African Acacia species - a review. IAWA Journal 16, 353-359.

Gourlay, I. D. 1995b. Growth Ring Characteristics of Some African Acacia Species. Journal of Tropical Ecology, 11, 121-140.

Grain Research and Development Cooperation. 2009. Water Use Efficiency. Fact sheet. Southern and western region. 
Grissino-Mayer, H. D. 2001. Evaluating Crossdating Accuracy: A Manual and Tutorial for the Computer Program COFECHA. Tree-Ring Research, 57, 205-221.

Haddeland, I., Heinke, J., Voß, F., Eisner, S., Chen, C., Hagemann, S. \& Ludwig, F. 2012. Effects of climate model radiation, humidity and wind estimates on hydrological simulations. Hydrology and Earth System Sciences, 16, 305-318.

Hansen, M., R. DeFries, J.R.G. Townshend \& Sohlberg, R. 1998. UMD Global Land Cover Classification, 1 Kilometer, 1.0, 1981-1994. University of Maryland, USA

Harmon, M. E. \& Sexton, J. 1996. Guidelines for Measurements of Woody Detritus in Forest Ecosystems University of Washington, USA.

Haxeltine, A. \& Prentice, I. C. 1996. BIOME3: An equilibrium terrestrial biosphere model based on ecophysiological constraints, resource availability, and competition among plant functional types. Global Biogeochemical Cycles, 10, 693-709.

Hazeleger, W., Wang, X., Severijns, C., tefa nescu, S. S., Bintanja, R., Sterl, A., Wyser, K., Semmler, T., Yang, S., Van den Hurk, B., Van Noije, T., Van der Linden, E. \& Van der Wiel, K. 2011. EC-Earth V2.2: description and validation of a new seamless earth system prediction model. Climate Dynamics.

Henry, M., Picard, N., Trotta, C., Manlay, R., Valentini, R., Bernoux, M. \& Saint-André, L. 2011. Estimating tree biomass of sub-Saharan African forests: a review of available allometric equations. Silva Fennica, 45.

Henry, M., Valentini, R. \& Bernoux, M. 2009. Soil carbon stocks in ecoregions of Africa. Biogeosciences Discussions, 1-14.

Hertel, D., Moser, G., Culmsee, H., Erasmi, S., Horna, V., Schuldt, B. \& Leuschner, C. 2009. Below- and above-ground biomass and net primary production in a paleotropical natural forest (Sulawesi, Indonesia) as compared to neotropical forests. Forest Ecology and Management, 258, 1904-1912.

Hitachi Koki Co., L. 1994, 2011. Hitachi Power Tools Canada. Hitachi Power Tools Canada. Hitachi Koki Co., Ltd, Canada.

Hoerling, M., J. Hurrell, J. Eischeid \& Phillips, A. 2006. Detection and Attribution of Twentieth-Century Northern and Southern African Rainfall Change. Journal of Climate, 19, 3989-4008.

Högberg, P. 1984. Rooting habit and mycorrhizas of Baikiaea plurijuga. In: Piearce, G. D. (ed.) The Zambezi teak forests: proceedings of the first international conference on the teak forests of Southern Africa, Livingstone, Zambia, 18 - 24th March 1984. Forest Department [etc.], Ndola.

Holmes, R. L. 1983. Computer-Assisted Quality Control in Tree-Ring Dating and Measurement. Tree-Ring Bulletin, 1983, 51-67.

Homer TLC Inc. 2013. Products and services. http://www.homedepot.com/b/ToolsHardware-Power-Tools-Sanders-Belt-Sanders/N-5yc1vZc286.

Huang, S., Titus, S. J. \& Wiens, D. P. 1992. Comparison of nonlinear height-diameter functions for major Alberta tree species. Canadian Journal of Forest Research, 22, 1297-1304.

Hughes, R. F., Kauffman, J. B. \& Jaramillo, V. J. 2000. Ecosystem-Scale Impacts of Deforestation and Land Use in a Humid Tropical Region of Mexico. Ecological Applications, 10, 515-527.

Hui, D., Luo, Y. \& Katul, G. 2003. Partitioning interannual variability in net ecosystem exchange between climatic variability and functional change. Tree Physiology, 23, 433-442.

Hulme, M., Doherty, R., Ngara, T., New, M. \& Lister, D. 2001. African climate change: 1900-2100. Climate Research, 17, 145-168. 
Huth, A. \& Ditzer, T. 2000. Simulation of the growth of a lowland Dipterocarp rain forest with FORMIX3. Ecological Modelling, 134, 1-25.

Huth, A., Thomas, D. \& Hartmut, B. 1997. Rain Forest Growth Model. FORMIX3: A Tool for Forest Management Planning Towards Sustainability. Model Development and Case Study for Deramakot Forest Reserve in Sabah, Malaysia., Eschborn.

Hydrological services PTY LTD. 2003. Instruction manual evaporation pan class A. Quality system IS0 90012000 certified. Australia.

Ilmen, R., Benjelloun, H. \& Ouahmane, L. 2016. Tree ring growth of Atlas Cedar, facing climate changes in inter-annual and seasonal scales in Western Rif (Morocco). Bulletin de l'Institut Scientifique, Rabat, Section Sciences de la Vie, 2015, $n^{\circ}$ 37, 0000, .

IPCC. 1996. Revised 1996 IPCC Guidelines for National Greenhouse Gas Inventories. Greenhouse Gas Inventory Reference Manual. Volume 3. JT Houghton, LG Meira Filho, B Lim, K Treanton, I Mamaty, Y Bonduki, DJ Griggs and BA Callender (Eds).

IPCC. 2006. 2006 IPCC Guidelines for National Greenhouse Gas Inventories, Prepared by the National Greenhouse Gas Inventories Programme, Eggleston H.S., Buendia L., Miwa K., Ngara T. and Tanabe K. (eds). IGES, Japan.

IPCC. 2014 Climate Change 2014: Synthesis Report. Contribution of Working Groups I, II and III to the Fifth Assessment Report of the Intergovernmental Panel on Climate Change [Core Writing Team, R.K. Pachauri and L.A. Meyer (eds.)]. IPCC, Geneva, Switzerland, $151 \mathrm{pp}$.

Jacoby, G. 1989. Over view of tree-ring analysis in tropical regions. In: In: Sass, Ute., Killmann, Wulf., and Eckstein, Dieter (1995). Wood formation in two species of dipterocarpaceae in peninsular Malaysia IAWA Journal, 16, 37 1-384.

Jibrin, A. \& Abdulkadir, A. 2015. Allometric Models for Biomass Estimation in Savanna Woodland Area, Niger State, Nigeria. International Journal of Environmental, Chemical, Ecological, Geological and Geophysical Engineering, 9.

Jungclaus, J. H., Fischer, N., Haak, H., Lohmann, K., Marotzke, J., Matei, D., Mikolajewicz, U., Notz, D. \& Storch, J. S. 2013. Characteristics of the ocean simulations in the Max Planck Institute Ocean Model (MPIOM) the ocean component of the MPI-Earth system model. Journal of Advances in Modeling Earth Systems, 5, 422-446.

Kamelarczyk, K. B. F. 2009. Carbon Stock Assessment and Modelling in Zambia. Country study. A UN-REDD programme study. Food and Agriculture Organization of the United Nations, United Nations Development Programme, and United Nations Environment Programme. MRV Working Paper 4.

Kampata, J. M., Parida, B. P. \& Moalafhi, D. B. 2008. Trend analysis of rainfall in the headstreams of the Zambezi River Basin in Zambia. Physics and Chemistry of the Earth, Parts $A / B / C, 33,621-625$.

Kapinga, K., Syampungani, S., Kasubika, R., Yambayamba, A. M. \& Shamaoma, H. 2018. Species-specific allometric models for estimation of the above-ground carbon stock in miombo woodlands of Copperbelt Province of Zambia. Forest Ecology and Management, 417, 184-196.

Keenan, T. F., Hollinger, D. Y., Bohrer, G., Dragoni, D., Munger, J. W., Schmid, H. P. \& Richardson, A. D. 2013. Increase in forest water-use efficiency as atmospheric carbon dioxide concentrations rise. Nature, 499, 324.

Kershaw, J. A., Ducey, M. J., Beers, T. W. \& Husch, B. 2016. Determination of tree volume, weight, and biomass. Forest Mensuration. John Wiley \& Sons, Ltd.

Knapp, A. K. \& Smith, M. D. 2001. Variation Among Biomes in Temporal Dynamics of Aboveground Primary Production. Science, 291, 481-484. 
Koss, P. A., Martin, D. \& Oehmichen, W. 2007. Factors Associated with Carbon Sequestration. University of Wisconsin.

Kozlowski, T. T. 1971. Growth and development of trees. Vol. II. Academic Press. New York, Lond on. In: Sass Ute., Killmann Wulf., and Eckstein Dieter. Wood formation in two species of dipterocarpaceae in peninsular Malaysia IAWA Journal, 16, 37 1384.

Kraenzel, M., Castillo, A., Moore, T. \& Potvin, C. 2003. Carbon storage of harvest-age teak (Tectona grandis) plantations, Panama. Forest Ecology and Management, 173, 213225.

Krinner, G., Viovy, N., de Noblet-Ducoudré, N., Ogée, J., Polcher, J., Friedlingstein, P., Ciais, P., Sitch, S. \& Prentice, I. C. 2005. A dynamic global vegetation model for studies of the coupled atmosphere-biosphere system. Global Biogeochemical Cycles, 19, GB1015.

Kwashirai, V. C. 2007. Indigenous management of teak woodland in Zimbabwe, 1850-1900. Journal of Historical Geography, 33, 816-832.

LDEO. 2016. Lamont Doherty-Earth Observatory, Columbia University, Earth Institute, ARSTAN program.

Leica Microsystems (Switzerland) Ltd. 2012. Leica M50. CH-9435 Heerbrugg. .

Lima, A. J. N., Suwa, R., de Mello Ribeiro, G. H. P., Kajimoto, T., dos Santos, J., da Silva, R. P., de Souza, C. A. S., de Barros, P. C., Noguchi, H., Ishizuka, M. \& Higuchi, N. 2012. Allometric models for estimating above- and below-ground biomass in Amazonian forests at São Gabriel da Cachoeira in the upper Rio Negro, Brazil. Forest Ecology and Management, 277, 163-172.

Lloyd, J. \& Farquhar, G. D. 1996. The carbon dioxide dependence of photosynthesis, plant growth responses to elevated atmospheric carbon dioxide concentrations and their interaction with soil nutrient status. I. General Principles and Forest Ecosystems. Functional Ecology, 10, 4-32.

Magadza, C. 2011. Indications of the effects of climate change on the pelagic fishery of Lake Kariba, Zambia-Zimbabwe. Lakes \& Reservoirs: Research \& Management, 16, 1522.

Malimbwi, R. E., Solberg, B. \& Luoga, E. 1994. Estimate of biomass and volume in miombo woodland at Kitulangalo Forest Reserve, Tanzania. Journal of Tropical Forest Science, 230-242.

Mark, N., Mike, H. \& Phil, J. 1999. Representing Twentieth-Century Space-Time Climate Variability. Part I: Development of a 1961-90 Mean Monthly Terrestrial Climatology. Journal of Climate, 12, 829-856.

Martin, A. R. \& Thomas, S. C. 2011. A Reassessment of Carbon Content in Tropical Trees. PLoS ONE, 6, e23533.

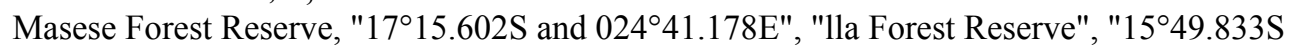
and $026^{\circ} 28.669 \mathrm{E}^{\circ}$, "Kabompo and Zambezi Forest Reserves " \& "1401.038S and $023^{\circ} 37.170 E^{\prime \prime} .2017$. Forests reserves. Google earth. December 1984 and December 2017. Down loaded date: 3rd December, 2017.

Matakala, P. W., Misael, K. \& Jochen, S. 2015. Zambia National Strategy to Reduce Emissions from Deforestation and Forest Degradation (REDD+). In: Forestry Department, Ministry of Lands Natural Resources and Environmental Protection, FAO, UNDP \& UNEP (eds.). Government of the Republic of Zambia, Zambia.

Mbughi, R. J. 1986. The Habitat and Regeneration of Zambezi teak in Zambia. In: Piearce, G. D. (ed.) The Zambezi teak forests : Proceedings of the first international conference on the teak forests of Southern Africa, Livingstone, Zambia, 18 - 24th March 1984. Forest Department [etc.], Ndola. 
McDowell, N., Barnard, H., Bond, B., Hinckley, T., Hubbard, R., Ishii, H., Köstner, B., Magnani, F., Marshall, J. \& Meinzer, F. 2002. The relationship between tree height and leaf area: sapwood area ratio. Oecologia, 132, 12-20.

McGuire, A. D. \& Joyce, L. A. 2005. Responses of Net Primary Production to Changes in $\mathrm{CO} 2$ and Climate Productivity of America's forests to climate change. US Department of Agriculture (USDA), USA.

Melillo, J. M., A. David McGuire, David W. Kicklighter, Berrien Moore III, Charles J. Vorosmarty, a. \& Schloss., A. L. 1993. Global climate change and terrestrial net primary production. Nature, 363, 234-240.

Midgley, G., Greg, H., Wilfried, T., Gill, D. \& Wendy, F. 2005. Assessment of potential climate change impacts on Namibia's floristic diversity, ecosystem structure and function Namibian National Biodiversity Programme. Directorate of Environmental Affairs. Climate Change Research Group. South African National Biodiversity Institute Kirstenbosch Botanical Garden, Rhodes Drive Cape Town, Windhoek. Namibia.

Miyashita, K., Tanakamaru, S., Maitani, T. \& Kimura, K. 2005. Recovery responses of photosynthesis, transpiration, and stomatal conductance in kidney bean following drought stress. Environmental and Experimental Botany, 53, 205-214.

Mohammed, S., Jun, Z. \& Shi, F. 2018. Impacts of climate change on net primary productivity in Africa continent from 2001 to 2010. International Journal of Science, Environment and Technology, Vol. 7, No 2365 - 381.

Mooney, H. A., Canadell, J., Chapin, F. S., 111, Ehleringer, J. R., Kijrner, C., McMurtrie, R. E., Parton, W. J., Piteka, L. F. \& Schulze, E.-D. 1999. Ecosystem physiology responses to global change. In: Walker, B., Steffen, W. L., Canadell, J. \& Ingram, J. (eds.) The Terrestrial Biosphere and Global Change: Implications for Natural and Managed Ecosystems Cambridge University Press, Cambridge.

Moss, R. H., Edmonds, J. A., Hibbard, K. A., Manning, M. R., Rose, S. K., van Vuuren, D. P., Carter, T. R., Emori, S., Kainuma, M., Kram, T., Meehl, G. A., Mitchell, J. F., Nakicenovic, N., Riahi, K., Smith, S. J., Stouffer, R. J., Thomson, A. M., Weyant, J. P. \& Wilbanks, T. J. 2010. The next generation of scenarios for climate change research and assessment. Nature, 463, 747-56.

Mubita, A. C. 1986. Prospects for genetic improvement of Zambian teak forests timber trees. In: Piearce, G. D. (ed.) The Zambezi teak forests : proceedings of the first international conference on the teak forests of Southern Africa, Livingstone, Zambia, 18 - 24th March 1984. Forest Department [etc.], Ndola.

Mugasha, W. A., Eid, T., Bollandsås, O. M., Malimbwi, R. E., Chamshama, S. A. O., Zahabu, E. \& Katani, J. Z. 2013. Allometric models for prediction of above-and belowground biomass of trees in the miombo woodlands of Tanzania. Forest Ecology and Management, 310, 87-101.

Mulenga, B. P., Wineman, A. \& Sitko, N. J. 2017. Climate trends and farmers' perceptions of climate change in Zambia. Environmental management, 59, 291-306.

Mulolwa, J. M. 1986. Forestry in Zambia's Western province. In: Piearce, G. D. (ed.) The Zambezi teak forests: Proceedings of the first international conference on the teak forests of Southern Africa, Livingstone, Zambia, 18 - 24th March 1984. Forest Department [etc.], Ndola.

Murray-Tortarolo, G., Jaramillo, V. J., Maass, M., Friedlingstein, P. \& Sitch, S. 2017. The decreasing range between dry- and wet- season precipitation over land and its effect on vegetation primary productivity. PLOS ONE, 12. 
Musgrave, M. K. 2016. Carbon and the commons in the Zambezi teak (Baikiaea plurijuga, Harms) forests of western Zambia : sustainable forest management for commodity and community. PhD Thesis. The University of St Andrews. .

Musokotwane, I. E. O., and Kufakwandi, S.F. 1986. The importance of the Teak forets in the Zambian Economy. In: Piearce, G. D. (ed.) The Zambezi teak forests : Proceedings of the first international conference on the teak forests of Southern Africa, Livingstone, Zambia, 18 - 24th March 1984. Forest Department [etc.], Ndola.

Negi, J. D. S., Manhas, R.K. and Chauhan P.S. . 2003. Carbon allocation in different components of some tree species of India: A new approach for carbon estimation. Current Science 85, 1528-1531.

New, M., Hewitson, B., Stephenson, D. B., Tsiga, A., Kruger, A., Manhique, A., Gomez, B., Coelho, C. A. S., Masisi, D. N., Kululanga, E., Mbambalala, E., Adesina, F., Saleh, H., Kanyanga, J., Adosi, J., Bulane, L., Fortunata, L., Mdoka, M. L. \& Lajoie, R. 2006. Evidence of trends in daily climate extremes over southern and west Africa. Journal of Geophysical Research, 111, D14102.

Ng'andwe, P., Simbangala, L. \& Kabibwa, N. 2012. Biennial compendium of forestry statistics of Zambia.

Ng'andwe, P., Donald, C., Obote, S. \& Lauri, V. 2017. Abundance and distribution of top five most valuable hardwood timber species in Zambia and their implications on sustainable supply. 6th International Scientific Conference on Hardwood Processing. Natural Resources Institute Finland, Helsinki 2017.

Ng'andwe, P., Jacob, M., Ambayeba, M.-K., Nkandu, K. \& Litia, S. 2015. Contribution of the Forestry Sector to the National Economy. Forest Policy, Economics, and Markets in Zambia. Academic Press.

Ngoma, J., Braakhekke, M. C., Kruijt, B., Moors, E., Supit, I., Speer, J. H., Vinya, R. \& Leemans, R. 2019a. Modelling the response of Net Primary Productivity of Zambezi teak forests to climate change along a rainfall gradient in Zambia. Biogeosciences. "Under review", 1-23.

Ngoma, J., Moors, E., Kruijt, B., Speer, J. H., Vinya, R., Chidumayo, E. N. \& Leemans, R. 2018a. Below and above-ground carbon distribution along a rainfall gradient. A case of the Zambezi teak forests, Zambia Acta Oecologica 87, 45-57.

Ngoma, J., Moors, E., Kruijt, B., Speer, J. H., Vinya, R., Chidumayo, E. N. \& Leemans, R. 2018b. Data for developing allometric models and evaluating carbon stocks of the Zambezi Teak Forests in Zambia. Data in Brief 17, 1361-1373.

Ngoma, J., Moors, E., Speer, J. H., Kruijt, B., Vinya, R. \& Leemans, R. 2019b. Forest response to climate change - A review of net primary productivity in Africa. "Unpublished".

Ngoma, J., Speer, J. H., Vinya, R., Kruijt, B., Moors, E. \& Leemans, R. 2017. The dendrochronological potential of Baikiaea plurijuga in Zambia. Dendrochronologia, 41, 65-77.

Niang, I., Ruppel, O. C., Abdrabo, M. A., Essel, A., Lennard, C., Padgham, J. \& Urquhart, P. 2014. Africa. Climate Change 2014: Impacts, Adaptation, and Vulnerability. Part B: Regional Aspects. Contribution of Working Group II to the Fifth Assessment Report of the Intergovernmental Panel on Climate Change [Barros, V.R., C.B. Field, D.J. Dokken, M.D. Mastrandrea, K.J. Mach, T.E. Bilir, M. Chatterjee, K.L. Ebi, Y.O. Estrada, R.C. Genova, B. Girma, E.S. Kissel, A.N. Levy, S. MacCracken, P.R. Mastrandrea, and L.L. White (eds.)] Cambridge University Press, Cambridge, United Kingdom and New York, NY, USA 
Nicolini, G., Tarchiani, V., Saurer, M. \& Cherubini, P. 2010. Wood-growth zones in Acacia seyal Delile in the Keita Valley, Niger: Is there any climatic signal? Journal of Arid Environments, 74, 355-359.

Niklas, K. J. 1995. Size-dependent Allometry of Tree Height, Diameter and Trunk-taper. Annals of Botany, 75, 217-227.

Niklas, K. J. \& Spatz, H.-C. 2004. Growth and hydraulic (not mechanical) constraints govern the scaling of tree height and mass. Proceedings of the National Academy of Sciences of the United States of America, 101, 15661-15663.

Nikon Instruments Europe B.V. 2016. SMZ645 (discontinued). https://www.nikoninstruments.com/Products/Stereomicroscopes-andMacroscopes/Stereomicroscopes/SMZ660.

Norby, R. J., Warren, J. M., Iversen, C. M., Medlyn, B. E. \& McMurtrie, R. E. 2010. $\mathrm{CO}_{2}$ enhancement of forest productivity constrained by limited nitrogen availability. Proceedings of the National Academy of Sciences, 107, 19368-19373.

Pan, S., Dangal, S. R. S., Tao, B., Yang, J. \& Tian, H. 2015. Recent patterns of terrestrial net primary production in Africa influenced by multiple environmental changes. Ecosystem Health and Sustainability, 1, 18.

Pan, Y., Birdsey, R. A., Phillips, O. L. \& Jackson, R. B. 2013. The structure, distribution, and biomass of the world's forests Annual Review of Ecology, Evolution, and Systematics 44, 593-622.

Peele, E. N. 1986. Marketing of teak forests timber products. In: Piearce, G. D. (ed.) The Zambezi teak forests : proceedings of the first international conference on the teak forests of Southern Africa, Livingstone, Zambia, 18 - 24th March 1984. Forest Department [etc.], Ndola.

Piani, C., Weedon, G. P., Best, M., Gomes, S. M., Viterbo, P., Hagemann, S. \& Haerter, J. O. 2010. Statistical bias correction of global simulated daily precipitation and temperature for the application of hydrological models. Journal of Hydrology, 395, 199-215.

Piearce, G. D. 1986a. How to save the Zambezi teak forests. . FAO (1986). Unasylva - No. 152 - Genetics and the forests of the future. An international journal of the forestry and food industries. FAO - Food and Agriculture Organization of the United Nations. SPECIAL FAO's Forestry Action Plan, 38pp.

Piearce, G. D. 1986b. Properties and end-uses of Zambezi teak. In: Piearce, G. D. (ed.) The Zambezi teak forests : proceedings of the first international conference on the teak forests of Southern Africa, Livingstone, Zambia, 18 - 24th March 1984. Forest Department [etc.], Ndola.

Piearce, G. D. 1986c. The Zambezi teak forests : proceedings of the first international conference on the teak forests of Southern Africa, Livingstone, Zambia, 18 - 24th March 1984. Forest Department [etc.], Ndola.

Ping, Z., Bruce, A., Mathew, B., Bin, T. \& B., M. R. 2004. Climate-related vegetation characteristics derived from Moderate Resolution Imaging Spectroradiometer (MODIS) leaf area index and normalized difference vegetation index. Journal of Geophysical Research: Atmospheres, 109.

PROTA4U. 2017. Baikiaea plurijuga Harms. https://www.prota4u.org/database/protav8.asp?g=pe\&p=Baikiaea+plurijuga+Harms. Accessed date: 15 th December.

R Core Team. 2017. R: A language and environment for statistical computing. R Foundation for Statistical Computing, Vienna, Austria

Rana, R., Langenfeld-Heyser, R., Finkeldey, R. \& Polle, A. 2010. FTIR spectroscopy, chemical and histochemical characterisation of wood and lignin of five tropical timber 
wood species of the family of Dipterocarpaceae. Wood Science and Technology, 44, 225-242.

RCP Database. 2018. RCP Database (Version 2.0.5).

https://tntcat.iiasa.ac.at/RcpDb/dsd?Action=htmlpage\&page=compare. Accessed date: 11th April, 2018.

Reich, P. B., Walters, M. B. \& Ellsworth, D. S. 1997. From tropics to tundra: Global convergence in plant functioning. Proceedings of the National Academy of Sciences, 94, 13730-13734.

Reineke, L. H. 1933. Perfecting a stand-density index for even-aged forests. Journal of Agricultural Research 46, 627-638.

Remane, I. A. D. \& Therrell, M. D. 2015. Dendrochronological potential of Millettia stuhlmannii in Mozambique. Trees - Structure and Function, 29, 729-736.

Riahi, K., Gruebler, A. \& N, N. 2007. Scenarios of long-term socio-economic and environmental development under climate stabilization. Technological Forecasting and Social Change 74, 7, 887-935.

Riahi, K., Rao, S., Krey, V., Cho, C., Chirkov, V., Fischer, G., Kindermann, G., Nakicenovic, N. \& Rafaj, P. 2011. RCP 8.5-A scenario of comparatively high greenhouse gas emissions. Climatic Change, 109, 33-57.

Ridder, M., Trouet, V., Bulcke, J., Hubau, W., Acker, J. \& Beeckman, H. 2013. A tree-ring based comparison of Terminalia superba climate-growth relationships in West and Central Africa. Trees, 1-14.

Rinn, F., Heidelberg. 2013. TSAP-Win User Reference. Time Series Analysis and Presentation for Dendrochronology and Related Applications. Version 4.6x for Microsoft windows. Heidelberg - Germany. .

Ryan, C. M., Williams, M. \& Grace, J. 2011. Above- and Belowground Carbon Stocks in a Miombo Woodland Landscape of Mozambique. Biotropica, 43, 423-432.

Sakamoto, Y., Ishiguro, M. \& Kitagawa, G. 1986. Akaike Information Criterion Statistics. D. Reidel Publishing Company.

Sanogo, K., Gebrekirstos, A., Bayala, J., Villamor, G. B., Kalinganire, A. \& Dodiomon, S. 2016. Potential of dendrochronology in assessing carbon sequestration rates of Vitellaria paradoxa in southern Mali, West Africa. Dendrochronologia, 40, 26-35.

Sarkar, D. \& Haldar, A. 2005. Physical and chemical methods in soil analysis. Fundamental concepts of analysical chemistry and intrumental techniques. New Age International (P) Limited, Publishers, New Delhi.

Sarmiento, J. L. \& Gruber, N. 2002. Sinks for Anthropogenic carbon. American Institute of Physics, 1-7.

Sass-Klaassen, U., Couralet, C., Sahle, Y. \& Sterck, F. J. 2008. Juniper from Ethiopia Contains a Large-Scale Precipitation Signal. International Journal of Plant Sciences, 169, 1057-1065.

Sass, U., Killmann, W. \& Eckstein, D. 1995. Wood formation in two species of Dipterocarpaceae in peninsular Malaysia. IAWA 16, 371-384.

Schaphoff, S., Lucht, W., Gerten, D., Sitch, S., Cramer, W. \& Prentice, I. C. 2006. Terrestrial biosphere carbon storage under alternative climate projections. Climatic Change, 74, 97-122.

Schöngart, J., Orthmann, B., Hennenberg, K. J., Porembski, S. \& Worbes, M. 2006. Climategrowth relationships of tropical tree species in West Africa and their potential for climate reconstruction. Global Change Biology, 12, 1139-1150.

Schreuder, H. T., Gregoire, T. G. \& Wood, G. B. 1993. Sampling Methods for Multiresource Forest Inventory. Wiley. 
Selander, J., and Malaya, F.M. 1986. Protection of Young Zambezi Teak plantations against weeds and Game Damage. In: Piearce, G. D. (ed.) The Zambezi teak forests : Proceedings of the first international conference on the teak forests of Southern Africa, Livingstone, Zambia, 18 - 24th March 1984. Forest Department [etc.], Ndola.

Sellers, P. J., Mintz, Y., Sud, Y. C. \& Dalcher, A. 1986. A Simple Biosphere Model (SIB) for Use within General Circulation Models. Journal of the Atmospheric Sciences, 43, 505531.

Shirima, D. D., Munishi, P. K. T., Lewis, S. L., Burgess, N. D., Marshall, A. R., Balmford, A., Swetnam, R. D. \& Zahabu, E. M. 2011. Carbon storage, structure and composition of miombo woodlands in Tanzania's Eastern Arc Mountains. African Journal of Ecology, 49, 332-342.

Sileshi, G. W. 2014. A critical review of forest biomass estimation models, common mistakes and corrective measures. Forest Ecology and Management, 329, 237-254.

Sitch, S., Smith, B., Prentice, I. C., Arneth, A., Bondeau, A., Cramer, W., Kaplan, J. O., Levis, S., Lucht, W., Sykes, M. T., Thonicke, K. \& Venevsky, S. 2003. Evaluation of ecosystem dynamics, plant geography and terrestrial carbon cycling in the LPJ dynamic global vegetation model. Global Change Biology, 9, 161-185.

Slik, J. W. F., Arroyo-Rodríguez, V., Aiba, S.-I., Alvarez-Loayza, P., Alves, L. F., Ashton, P., Balvanera, P., Bastian, M. L., Bellingham, P. J., van den Berg, E., Bernacci, L., da Conceição Bispo, P., Blanc, L., Böhning-Gaese, K., Boeckx, P., Bongers, F., Boyle, B., Bradford, M., Brearley, F. Q., Breuer-Ndoundou Hockemba, M., Bunyavejchewin, S., Calderado Leal Matos, D., Castillo-Santiago, M., Catharino, E. L. M., Chai, S.-L., Chen, Y., Colwell, R. K., Chazdon, R. L., Clark, C., Clark, D. B., Clark, D. A., Culmsee, H., Damas, K., Dattaraja, H. S., Dauby, G., Davidar, P., DeWalt, S. J., Doucet, J.-L., Duque, A., Durigan, G., Eichhorn, K. A. O., Eisenlohr, P. V., Eler, E., Ewango, C., Farwig, N., Feeley, K. J., Ferreira, L., Field, R., de Oliveira Filho, A. T., Fletcher, C., Forshed, O., Franco, G., Fredriksson, G., Gillespie, T., Gillet, J.-F., Amarnath, G., Griffith, D. M., Grogan, J., Gunatilleke, N., Harris, D., Harrison, R., Hector, A., Homeier, J., Imai, N., Itoh, A., Jansen, P. A., Joly, C. A., de Jong, B. H. J., Kartawinata, K., Kearsley, E., Kelly, D. L., Kenfack, D., Kessler, M., Kitayama, K., Kooyman, R., Larney, E., Laumonier, Y., Laurance, S., Laurance, W. F., Lawes, M. J., Amaral, I. L. d., Letcher, S. G., Lindsell, J., Lu, X., Mansor, A., Marjokorpi, A., Martin, E. H., Meilby, H., Melo, F. P. L., Metcalfe, D. J., Medjibe, V. P., Metzger, J. P., Millet, J., Mohandass, D., Montero, J. C., de Morisson Valeriano, M., Mugerwa, B., Nagamasu, H., Nilus, R., Ochoa-Gaona, S., et al. 2015. An estimate of the number of tropical tree species. Proceedings of the National Academy of Sciences, 112, 74727477.

Smith, B., Prentice, I. C. \& Sykes, M. T. 2001. Representation of vegetation dynamics in the modelling of terrestrial ecosystems: comparing two contrasting approaches within European climate space. Global Ecology and Biogeography, 10, 621-637.

Smith, S. J. \& Wigley, T. M. L. 2006. Multi-Gas Forcing Stabilization with the MiniCAM. Energy Journal, 27, 373-391.

Speer, J. H. 2010. Fundamentals of tree-ring research University of Arizona Press. Tucson

Spiess, A.-N. \& Neumeyer, N. 2010. An evaluation of R(2 )as an inadequate measure for nonlinear models in pharmacological and biochemical research: a Monte Carlo approach. BMC Pharmacology, 10, 6-6.

Stahle, D. W. 1999. Useful strategies for the development of tropical tree-ring chronologies. Journal of International Association of Wood Anatomists (IAWA), 20, 249-253. 
Stahle, D. W., Mushove, P. T., Cleaveland, M. K., Roig, F. \& Haynes, G. A. 1999. Management implications of annual growth rings in Pterocarpus angolensis from Zimbabwe. Forest Ecology and Management, 124, 217-229.

Stern, R. \& Cooper, P. 2011. Assessing climate risk and climate change using rainfall data-a case study from Zambia. Experimental Agriculture, 47, 241-266.

Storrs, A. E. G., Storrs, J. H. \& Zambia Forest Department. 1979. Know Your Trees: Some of the Common Trees Found in Zambia. Forest Department.

Symonds, M. R. E. \& Moussalli, A. 2011. A brief guide to model selection, multimodel inference and model averaging in behavioural ecology using Akaike's information criterion. Behavioral Ecology and Sociobiology, 65, 13-21.

The Government of the Republic of Zambia. 1969. The vegetation of Zambia. . In: D.B. Fanshawe. B.A. (OXON) (ed.). Ministry of Rural Development. Division of forest Research, Kitwe, Zambia.

The Government of the Republic of Zambia. 1996. The Forest Resources Management Study for Zambia Teak Forests in South-western Zambia: Final Report. Volume 1. (summary section). In: Ministry of Environment and Natural Resources. Japan International Cooperation Agency.

The Government of the Republic of Zambia. 2008. Intergrated Land Use Assesment (ILUA). Zambia. Zambia Forest Department. Ministry of Tourism, Environenment and Natural Resources. Food and Agricultural Organisation of the United Nations.

The Government of the Republic of Zambia. 2011a. 2010 Census of population and housing. Preliminary Population Figures. In: Central stastistics Office (ed.). Zambia.

The Government of the Republic of Zambia. 2011b. Forests and Climate Change. Integrating Climate Change Issues into National Forest Programmes and Policy Frameworks. Background paper for the national workshop, Zambia In: Forestry Department (ed.). Lusaka, Zambia.

The Government of the Republic of Zambia. 2016. Zambia in figures. In: Central Statistical Office (ed.). Lusaka, Zambia.

The Government of the Republic of Zambia \& UNDP. 2009. Adaptation to the effects of drought and climate change in Agro-ecological Regions I and II in Zambia. Project document. Ministry of Agriculture and Cooperatives. Accepted by: Ministry of finance and National Planning, and UNDP.

The Government of the Republic of Zambia, United National Development Programme \& Global Environment Facility. 2007. Formulation of the National Adaptation Programme of Action on Climate Change. In: Ministry of Tourism Environment and Natural Resources (ed.). Lusaka, Zambia.

Theilade, I., Sekeli, P. M., Hald, S. \& Graudal, L. O. V. 2001. Conservation plan for genetic resources of Zambezi teak (Baikiaea plurijuga) in Zambia. Danida Forest Seed Centre. DFSC Case Study No. 2.

Therrell, M. D., Stahle, D. W., Mukelabai, M. M. \& Shugart, H. H. 2007. Age, and radial growth dynamics of Pterocarpus angolensis in southern Africa. Forest Ecology and Management, 244, 24-31.

Therrell, M. D., Stahle, D. W., Ries, L. P. \& Shugart, H. H. 2006. Tree-ring reconstructed rainfall variability in Zimbabwe. Climate Dynamics, 26, 677-685.

Thomas, H., Benjamin, S., Colin, P. I., Kristina, M., Paul, M., Almut, A. \& T., S. M. 2008. $\mathrm{CO} 2$ fertilization in temperate FACE experiments not representative of boreal and tropical forests. Global Change Biology, 14, 1531-1542.

Thomas, S. C. \& Baltzer, J. L. 2002. Tropical Forests. http:/homepages.wmich.edu/ kohlers/bios105/files/tropical\%20forests.pdf. 
Thomas, S. C. \& Martin, A. R. 2012. Carbon Content of Tree Tissues: A Synthesis. Forests, 3,332 .

Thonicke, K., Venevsky, S., Sitch, S. \& Cramer, W. 2001. The role of fire disturbance for global vegetation dynamics: coupling fire into a Dynamic Global Vegetation Model. Global Ecology and Biogeography, 10, 661-677.

Thuiller, W., Midgley, G. F., Hughes, G. O., Bomhard, B., Drew, G., Rutherford, M. C. \& Woodward, F. I. 2006. Endemic species and ecosystem sensitivity to climate change in Namibia. Global Change Biology, 12, 759-776.

Tian, H., Chen, G., Liu, M., Zhang, C., Sun, G., Lu, C., Xu, X., Ren, W., Pan, S. \& Chappelka, A. 2010. Model estimates of net primary productivity, evapotranspiration, and water use efficiency in the terrestrial ecosystems of the southern United States during 1895-2007. Forest Ecology and Management, 259, 1311-1327.

Timberlake, J., Chidumayo, E. \& Sawadogo, L. 2010. Distribution and characteristics of African dry forest and woodlands. pp.11-42 In: Chidumayo E. N and Gumbo, D. J. (ed.) The Dry Forests and Woodlands of Africa. Managing for Products and Services. Eatrhscan, London.

Trouet, V. 2004. The El Niño Southern Oscillation effect on Zambezian miombo vegetation: proxies from tree ring series and satellite-derived data. Faculteit Bioingenieurswetenschappen. Katholieke Universiteit Leuven.

Trouet, V., Coppin, P. \& Beeckman, H. 2006. Annual Growth Ring Patterns in Brachystegia spiciformis Reveal Influence of Precipitation on Tree Growth. Biotropica, 38, 375382.

Trouet, V., Esper, J. \& Beeckman, H. 2010. Climate/growth relationships of Brachystegia spiciformis from the miombo woodland in south central Africa. Dendrochronologia, 28, 161-171.

Ullah, M. R. \& Al-Amin, M. 2012. Above- and below-ground carbon stock estimation in a natural forest of Bangladesh. Journal of Forest Science, 58, 372-379.

UNEP/FAO. 1984. Final report. World and Africa GIS Data Base; December 1984." Prepared by ESRI -Environmental Systems Research Institute. (one full volume including appendices). http://geodata.grid.unep.ch/.

University of East Anglia Climatic Research Unit, Harris, I. C. \& Jones, P. D. 2015. CRU TS3.23: Climatic Research Unit (CRU) Time-Series (TS) Version 3.23 of High Resolution Gridded Data of Month-by-month Variation in Climate (Jan. 1901- Dec. 2014) Centre for Environmental Data Analysis, 09 November 2015. doi:10.5285/4c7fdfa6-f176-4c58-acee-683d5e9d2ed5., .

Venables, W. N. \& Ripley, B. D. 2002. Modern Applied Statistics with S. Fourth Edition Springer, New York

Vetter, R. \& Botosso, P. 1989. Remarks on age and growth rate determination of Amazonian trees. Wood anatomical features in tree-rings as indicators of environmental change. IAWA Bull.

Voldoire, A., Sanchez-Gomez, E., Salas y Mélia, D., Decharme, B., Cassou, C., Sénési, S., Valcke, S., Beau, I., Alias, A., Chevallier, M., Déqué, M., Deshayes, J., Douville, H., Fernandez, E., Madec, G., Maisonnave, E., Moine, M.-P., Planton, S., Saint-Martin, D., Szopa, S., Tyteca, S., Alkama, R., Belamari, S., Braun, A., Coquart, L. \& Chauvin, F. 2013. The CNRM-CM5.1 global climate model: description and basic evaluation. Climate Dynamics, 40, 2091-2121.

Vuuren, D. P., Edmonds, J., Kainuma, M., Riahi, K., Thomson, A., Hibbard, K., Hurtt, G. C., Kram, T., Krey, V., Lamarque, J.-F., Masui, T., Meinshausen, M., Nakicenovic, N., Smith, S. J. \& Rose, S. K. 2011. The representative concentration pathways: an overview. Climatic Change, 109, 5-31. 
Walkley, A. \& Black, I. A. 1934. An examination of the Degtjareff method for determining soil organic matter, and a proposed modification of the chromic acid titration method. Soil science, 37, 29-38.

Wamunyima, S. 2014. Ecological zones of Zambia. Personal communication. In: Ngoma, J. (ed.). Lusaka, Zambia.

Weber, U., Jung, M., Reichstein, M., Beer, C., Braakhekke, M. C., Lehsten, V., Ghent, D., Kaduk, J., Viovy, N., Ciais, P., Gobron, N. \& Rödenbeck, C. 2009. The interannual variability of Africa's ecosystem productivity: A multi-model analysis. In: Bombelli A, Henry M, Castaldi S, Adu-Bredu S, Arneth A, De Grandcourt A, Grieco E, Kutsch WL, Lehsten V, Rasile A, Reichstein M, Tansey K, Weber U, Valentini R. ( 2009). An outlook on the Sub-Saharan Africa carbon balance. Biogeosciences, 6, 285-295.

Weedon, G. P., Balsamo, G., Bellouin, N., Gomes, S., Best, M. J., \& \& Viterbo, P. 2014. The WFDEI meteorological forcing data set: WATCH Forcing Data methodology applied to ERA-Interim reanalysis data Water Resources Research 50, 7505-7514.

Weedon, G. P., Gomes, S., Viterbo, P., Shuttleworth, W. J., Blyth, E., Österle, H., Adam, J. C., Bellouin, N., Boucher, O. \& Best, M. 2011. Creation of the WATCH Forcing Data and Its Use to Assess Global and Regional Reference Crop Evaporation over Land during the Twentieth Century. Journal of Hydrometeorology, 12, 823-848.

West, G. B., Brown, J. H. \& Enquist, B. J. 1999. The Fourth Dimension of Life: Fractal Geometry and Allometric Scaling of Organisms. Science, 284, 1677-1679.

Wheeler, E. A., Baas, P. a. \& Gasson, P. E. 1989. IAWA List of Microscopic Features for Hardwood Identification with an appendix on non-anatomical information. IAWA Bulletin n.s, 10, 219-332.

White, F. 1983. The vegetation of Africa: A descriptive memoir to accompany the UNESCO/AETFAT/UNSO vegetation map of Africa. Natural resources research.

Williams, A. P., Funk, C., Michaelsen, J., Rauscher, S. A., Robertson, I., Wils, T. H., Koprowski, M., Eshetu, Z. \& Loader, N. J. 2012. Recent summer precipitation trends in the Greater Horn of Africa and the emerging role of Indian Ocean sea surface temperature. Climate Dynamics, 39, 2307-2328.

Williams, C. A., Hanan, N. P., Baker, I., Collatz, G. J., Berry, J. \& Denning, A. S. 2008. Interannual variability of photosynthesis across Africa and its attribution. Journal of Geophysical Research: Biogeosciences, 113, G04015.

Williams, C. A., Hanan, N. P., Neff, J. C., Scholes, R. J., Berry, J. A., Denning, A. S. \& Baker, D. F. 2007. Africa and the global carbon cycle. Carbon Balance and Management, 2, 1-13.

Wimmer, R. 2002. Wood anatomical features in tree-rings as indicators of environmental change. Dendrochronologia, 20, 21-36.

Wise, M., KV Calvin, AM Thomson, LE Clarke, B Bond-Lamberty, RD Sands, SJ Smith, AC Janetos \& Edmonds, J. 2009. Implications of Limiting CO2 Concentrations for Land Use and Energy. Science, 324, 1183-1186.

Wu, Z., Dijkstra, P., Koch, G. W., PeÑUelas, J. \& Hungate, B. A. 2011. Responses of terrestrial ecosystems to temperature and precipitation change: a meta-analysis of experimental manipulation. Global Change Biology, 17, 927-942.

Yu, B. \& Chen, F. 2016. The global impact factors of net primary production in different land cover types from 2005 to 2011. SpringerPlus, 5, 1235.

Zhang, P., Anderson, B., Barlow, M., Tan, B. \& Myneni, R. B. 2004. Climate-related vegetation characteristics derived from Moderate Resolution Imaging Spectroradiometer (MODIS) leaf area index and normalized difference vegetation index. Journal of Geophysical Research: Atmospheres, 109, D20105. 
Zhu, L. \& Southworth, J. 2013. Disentangling the Relationships between Net Primary Production and Precipitation in Southern Africa Savannas Using Satellite Observations from 1982 to 2010. Remote Sensing, 5, 3803-3825. 
Supplementary information of tables and figures contain additional information to the following chapters of my $\mathrm{PhD}$ thesis:

Chapter 2 (Published in 'Data in Brief': Ngoma et al 2018)

Chapter 4 (Unpublished article)

Chapter 6 (Under review in 'Biogeosciences': Ngoma et al 2019)

The text, figures and tables of the supplementary information from published article (Chapter 2) have been adjusted to the $\mathrm{PhD}$ thesis format (e.g. numbering). The $\mathrm{PhD}$ thesis version of the supplementary material is available on request (justinangoma@yahoo.com). The versions of the supplementary materials for the published article (Chapter 2) are available on-line, though the PhD version can also be requested. The supplementary information to the unpublished article (Chapter 4) and the manuscript under review (Chapter 6) is included in this $\mathrm{PhD}$ thesis.

The KMZ files are available online with the published articles (Chapters 3 and 5)

Table S2.1: Parameters of all surveyed small trees $(<5 \mathrm{~cm} \mathrm{DBH})$ (Available on-line: https://doi.org/10.1016/j.dib.2018.02.057)

Table S2.2: Parameters of all surveyed large trees $(\geq 5 \mathrm{~cm}$ DBH) (Available on-line: https://doi.org/10.1016/j.dib.2018.02.057) 


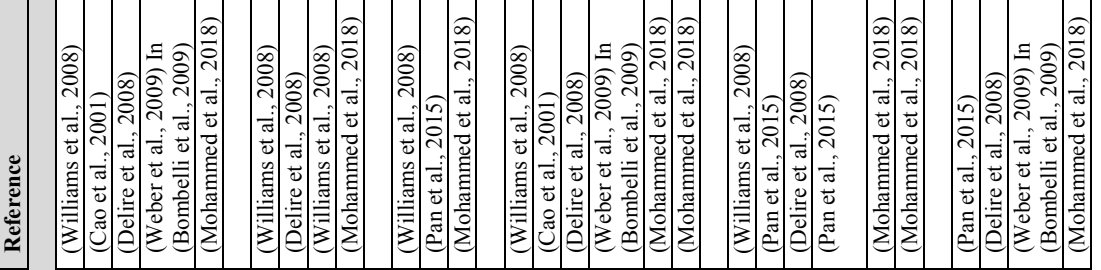

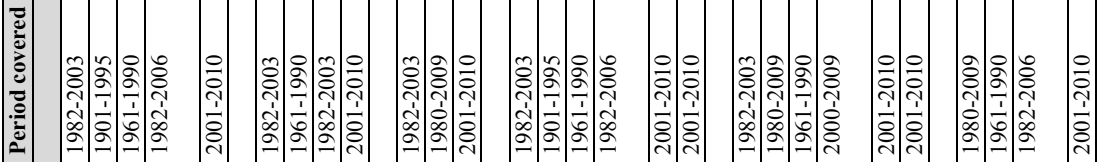

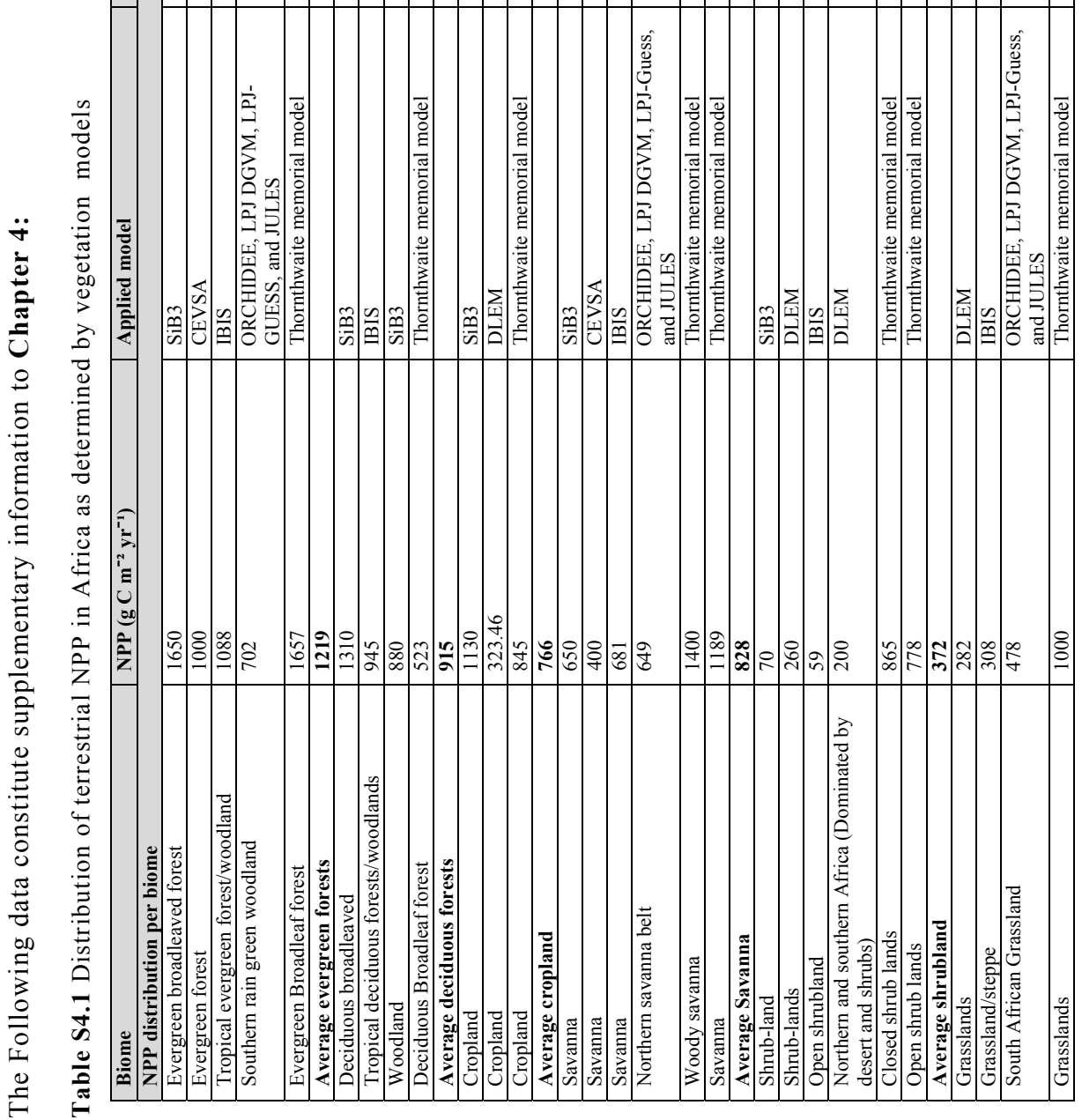




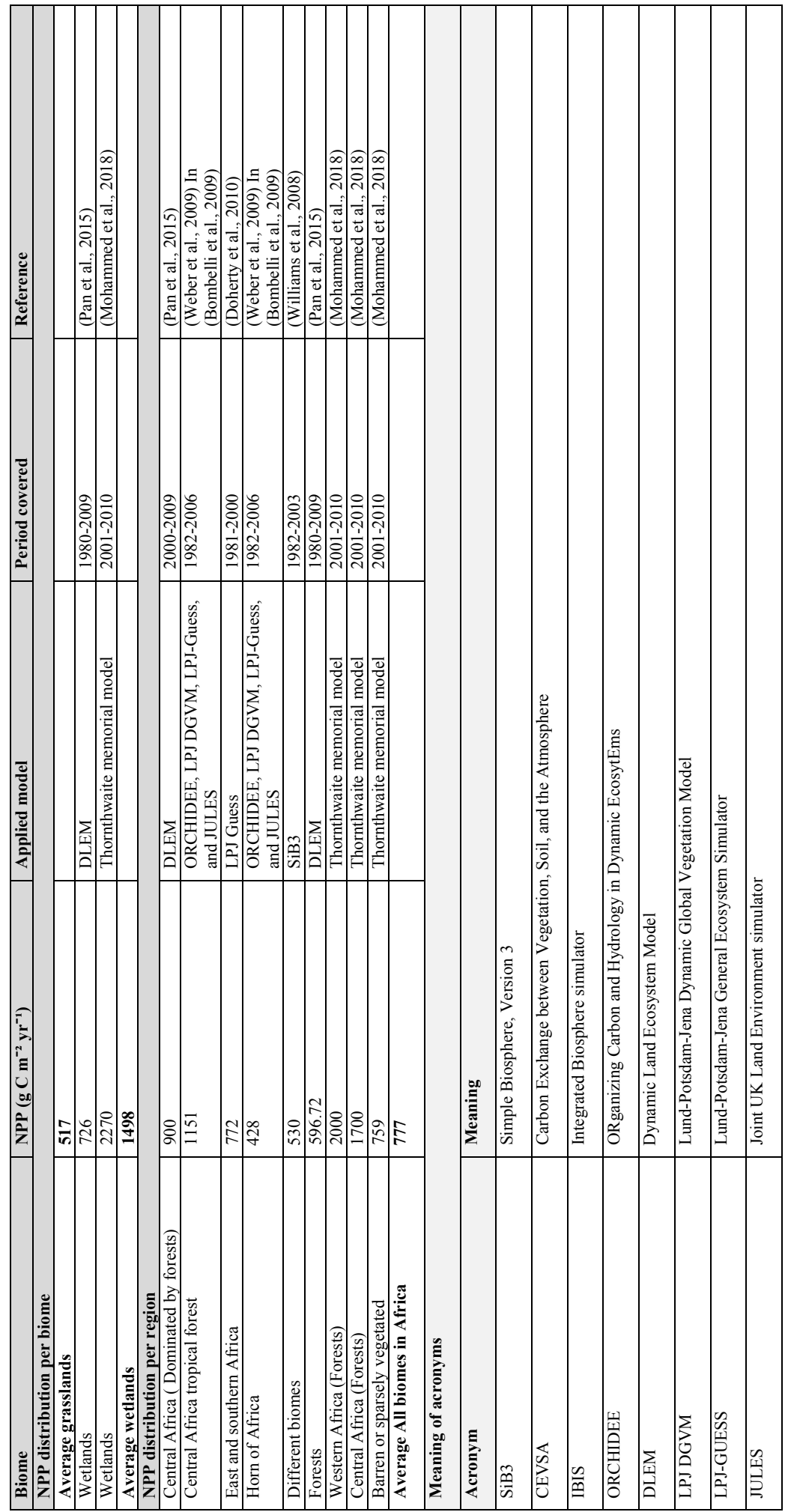


केके

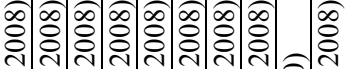

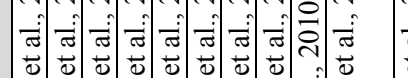

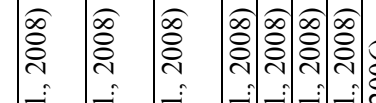

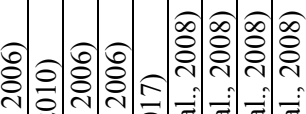

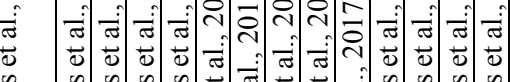

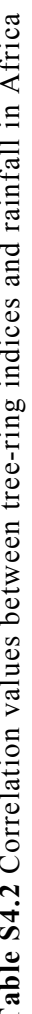

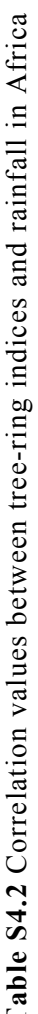

嘌

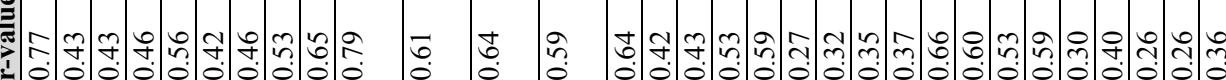

تี

a

$\stackrel{\circlearrowright}{\Xi}$

.

$\stackrel{1}{3}$

$\pm$

$\sum_{0}^{0}$

.

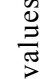

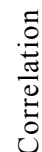

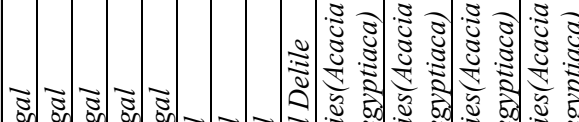

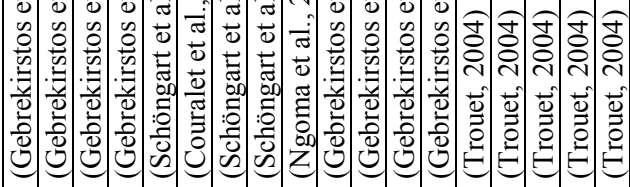

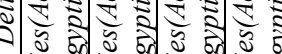

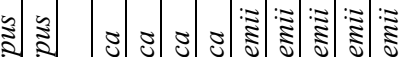
(3)

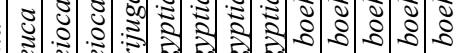

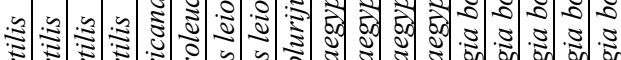

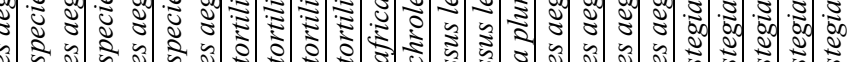

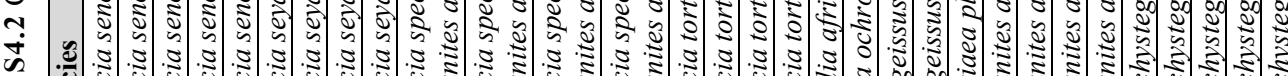

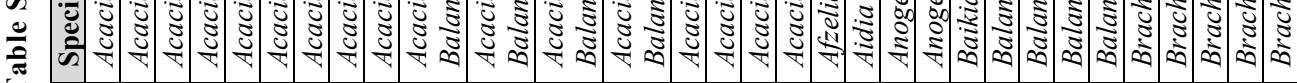




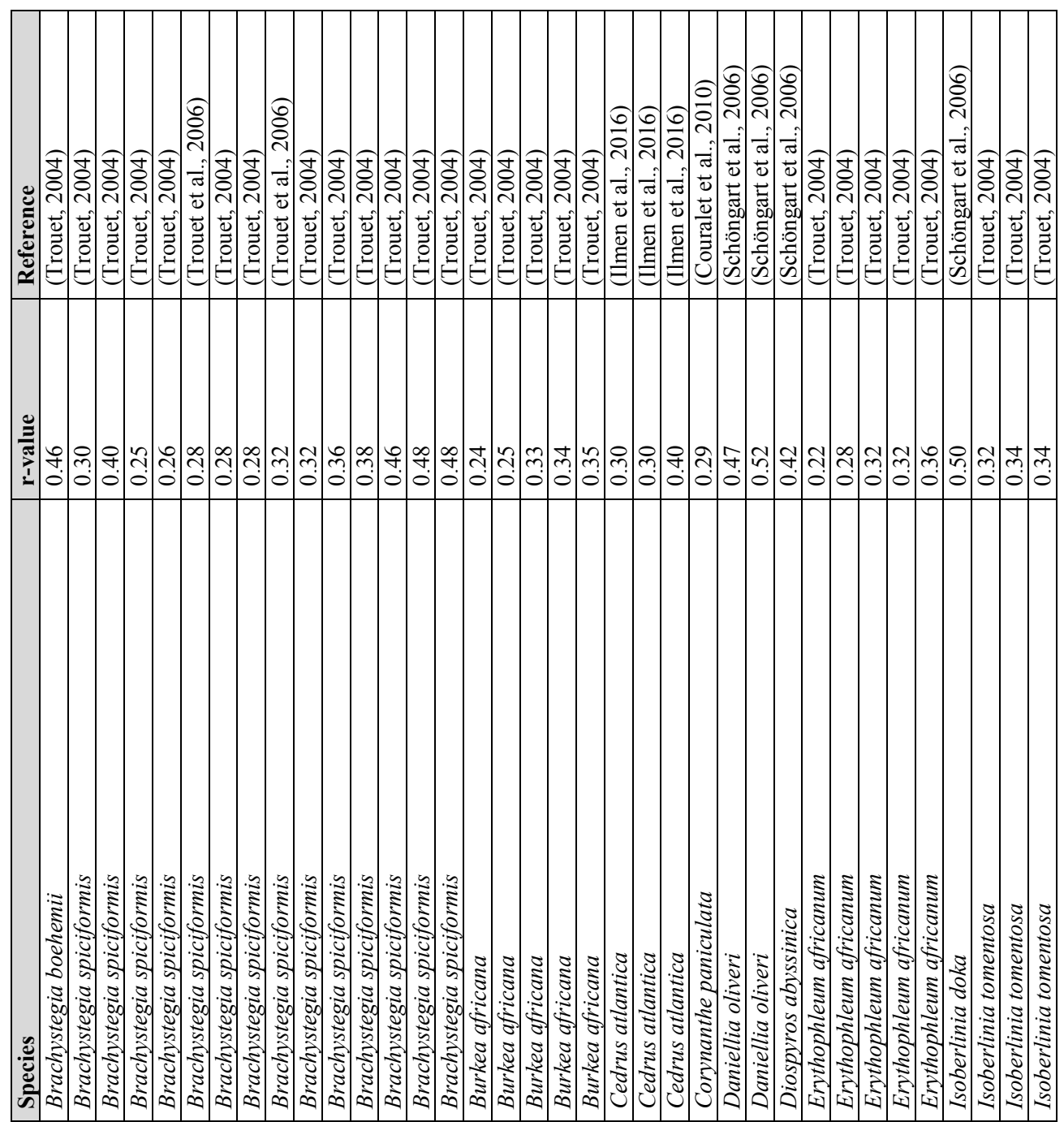



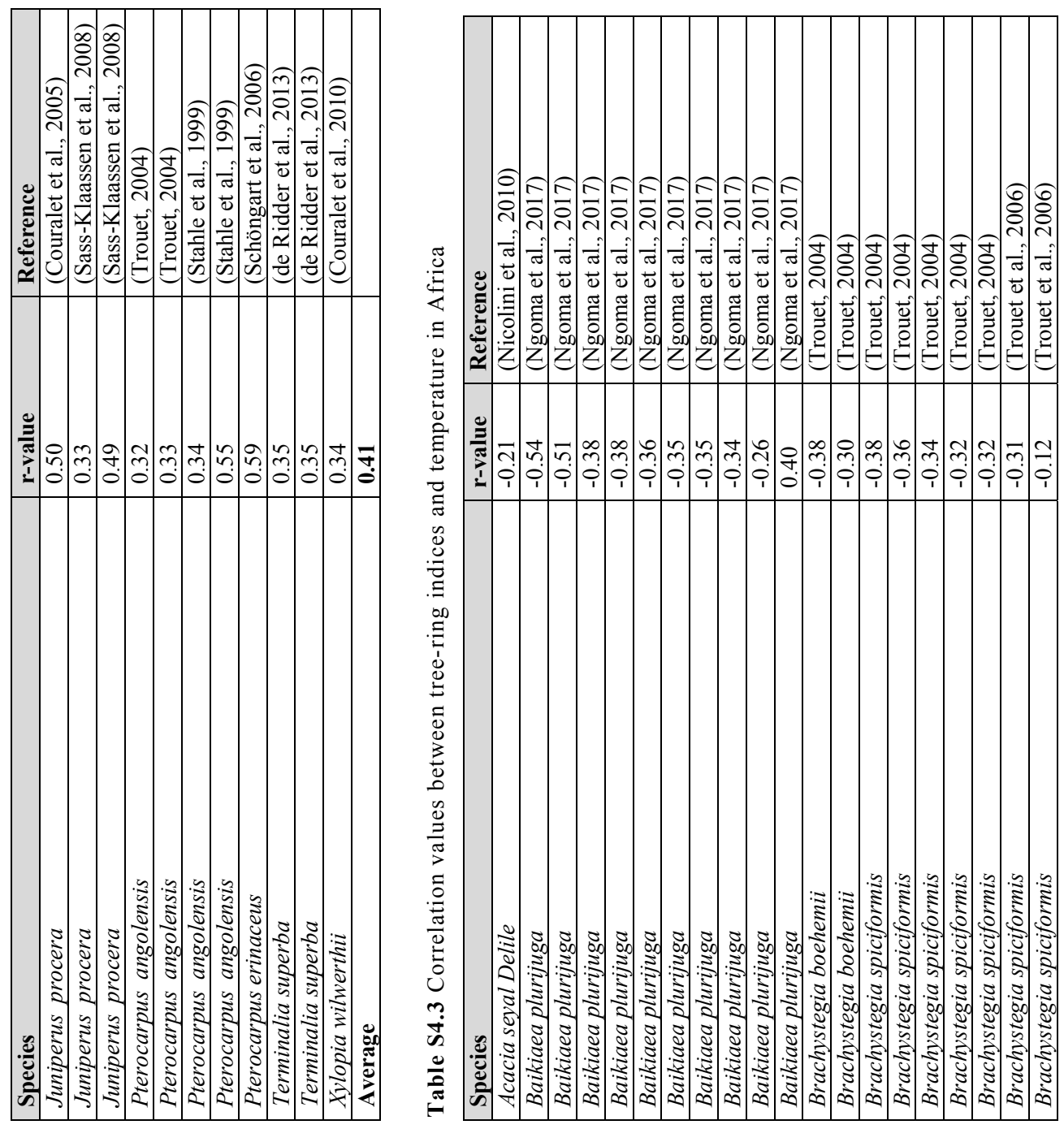


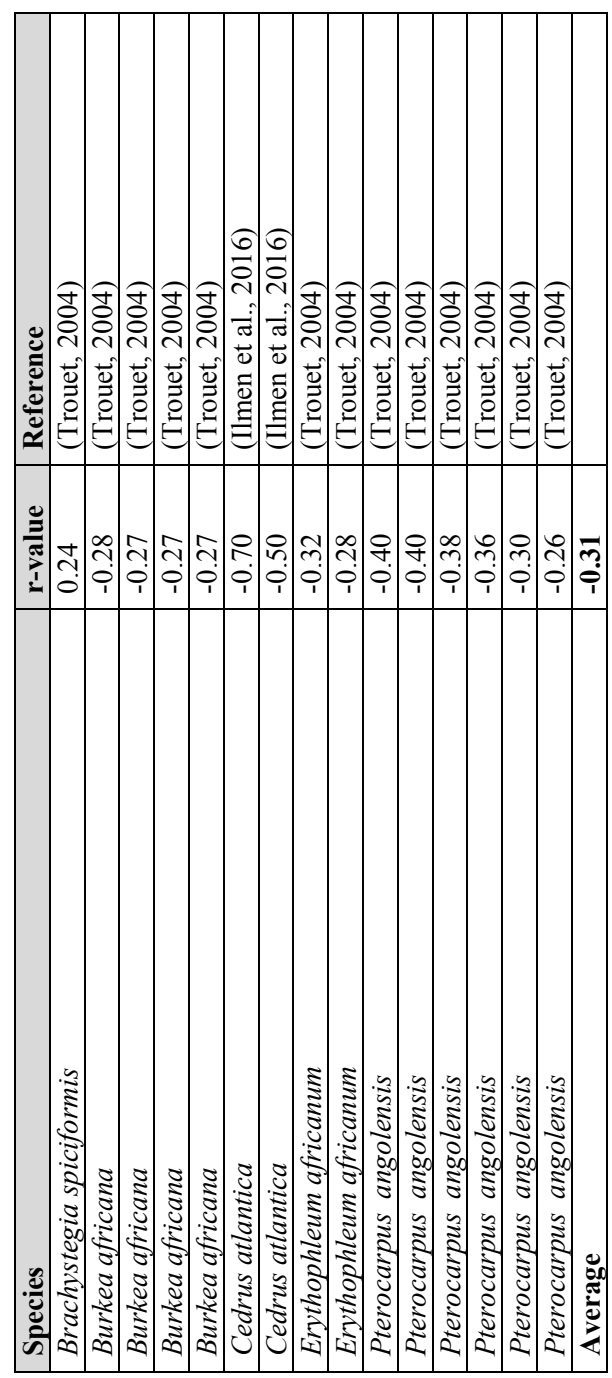




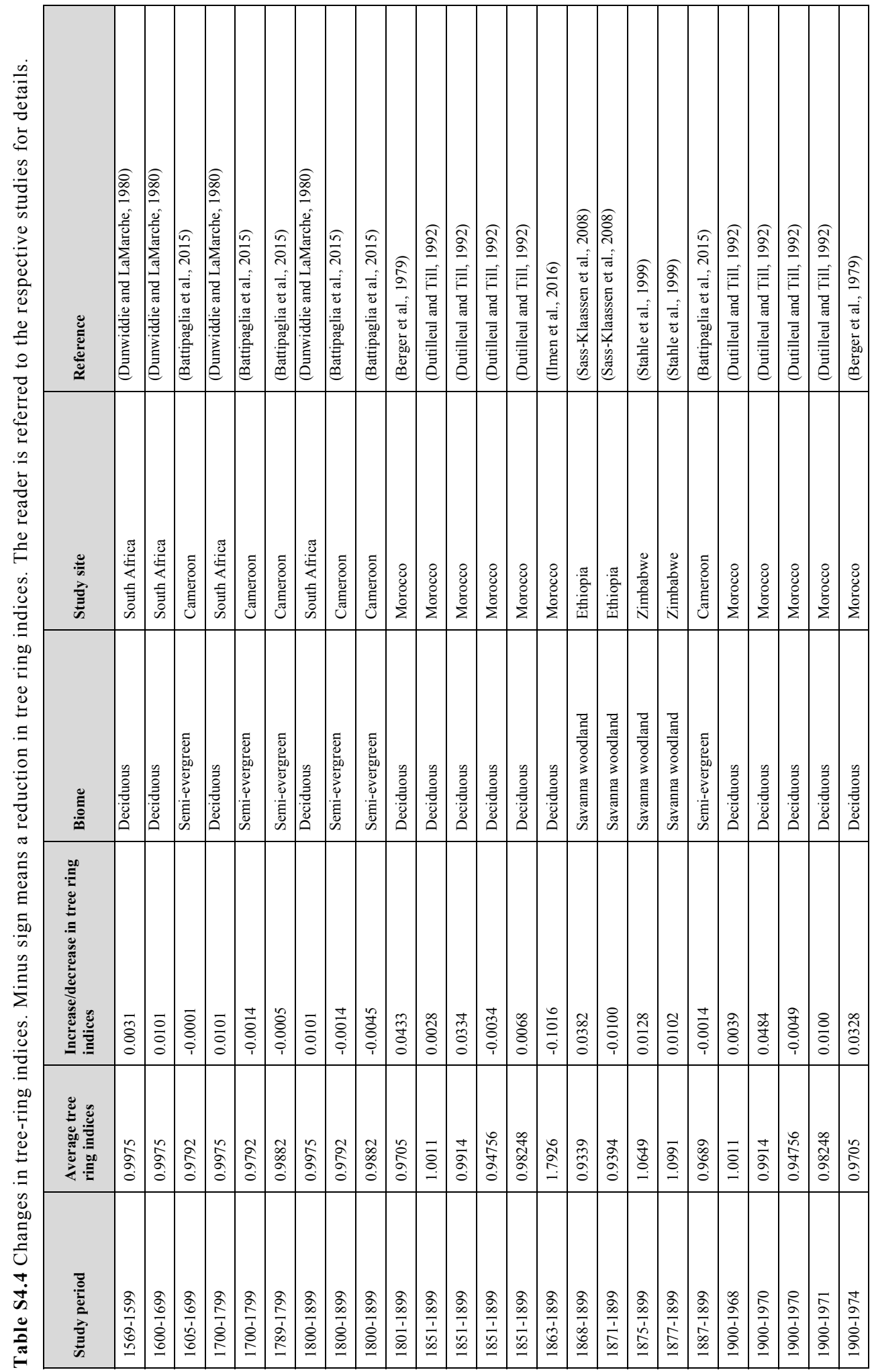




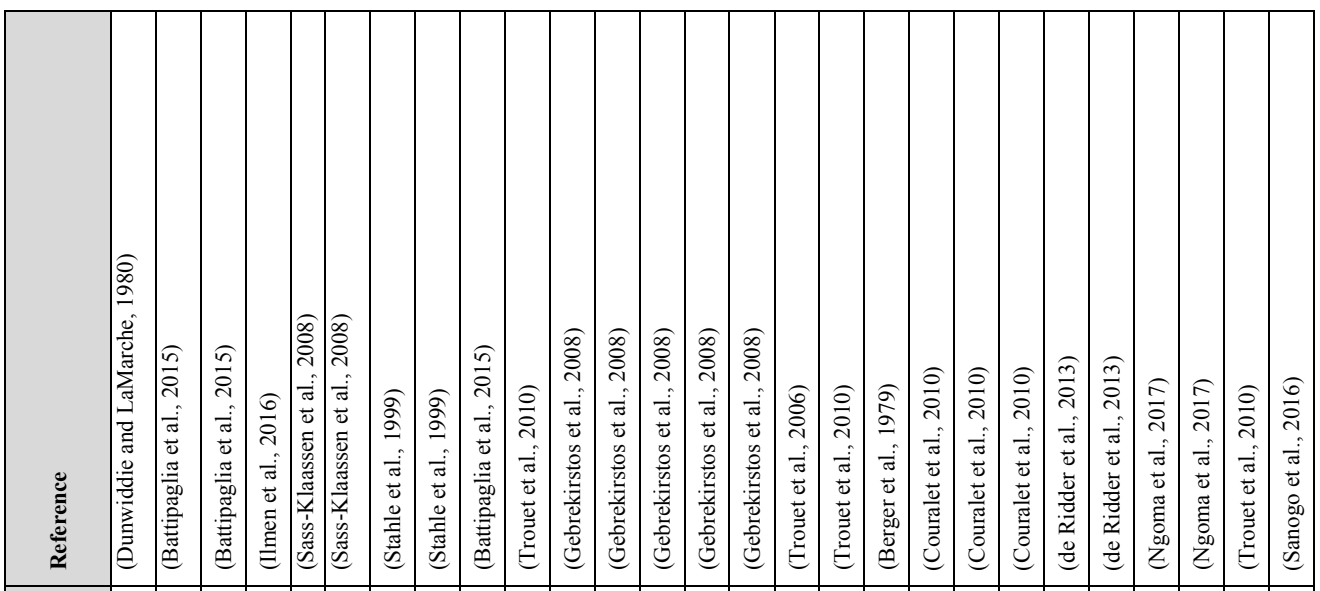

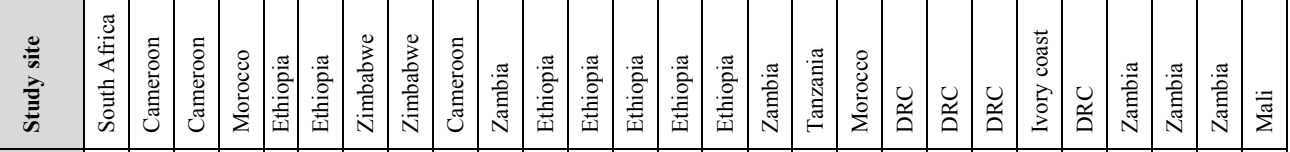

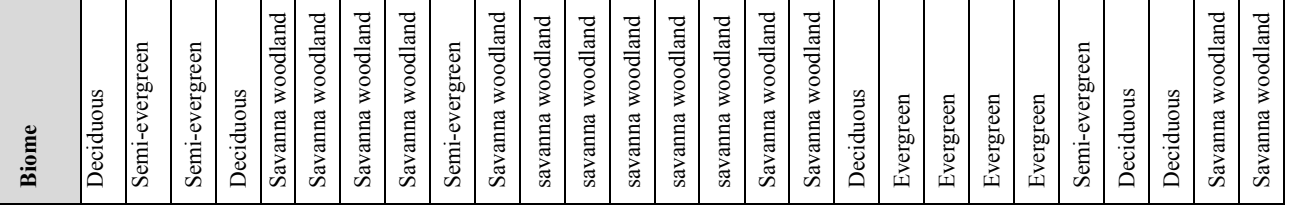

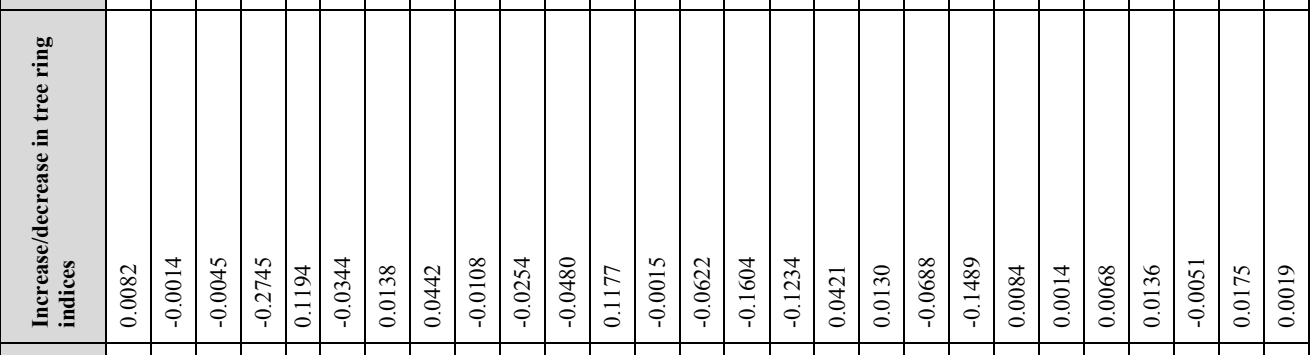

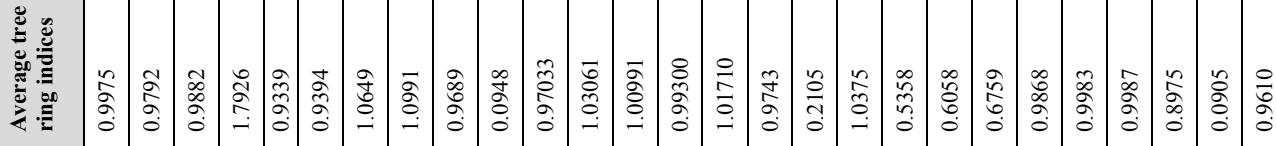

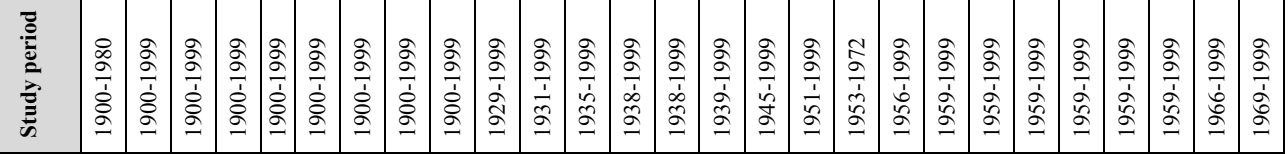




\begin{tabular}{|c|c|c|c|c|c|c|c|c|c|c|c|c|c|c|c|c|c|c|c|c|c|c|c|c|c|c|}
\hline 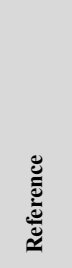 & 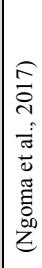 & 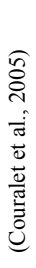 & 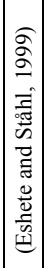 & 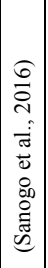 & 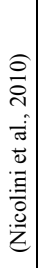 & 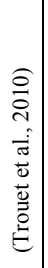 & 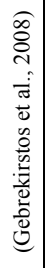 & 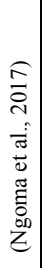 & 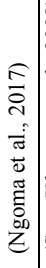 & 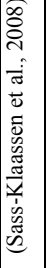 & 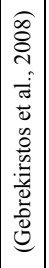 & 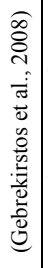 & 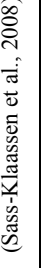 & 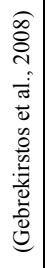 & 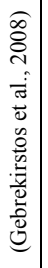 & 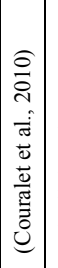 & 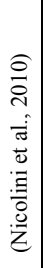 & 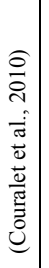 & 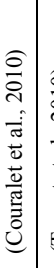 & 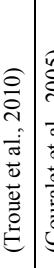 & 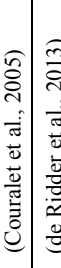 & 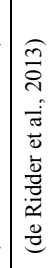 & 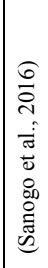 & 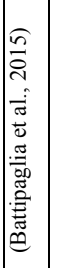 & 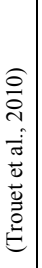 & 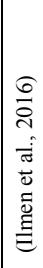 \\
\hline 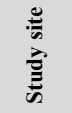 & 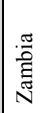 & 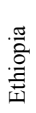 & 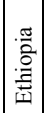 & $\frac{\bar{z}}{\overline{2}}$ & $\begin{array}{l}\overrightarrow{\mathrm{s}} \\
\overline{\mathrm{o}} \\
\overline{\mathrm{z}}\end{array}$ & 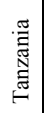 & 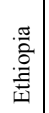 & 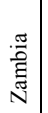 & 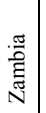 & 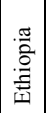 & 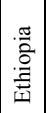 & 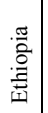 & 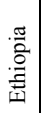 & 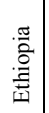 & 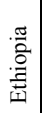 & Oี & 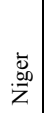 & $\begin{array}{l}\ddot{\Delta} \\
\stackrel{0}{*}\end{array}$ & 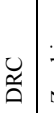 & 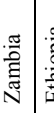 & 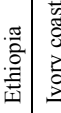 & 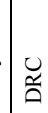 & $\frac{\bar{J}}{\bar{m}}$ & 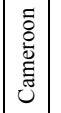 & 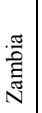 & 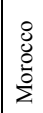 \\
\hline 芯 & 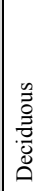 & 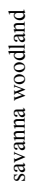 & 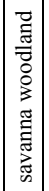 & 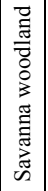 & 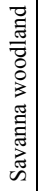 & 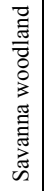 & 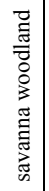 & 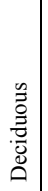 & 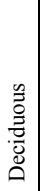 & 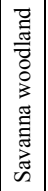 & 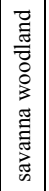 & 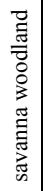 & 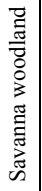 & 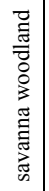 & 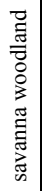 & 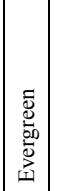 & 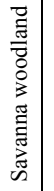 & 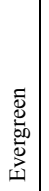 & 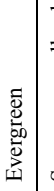 & 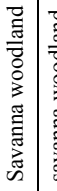 & 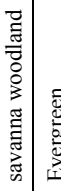 & 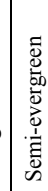 & 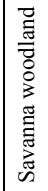 & 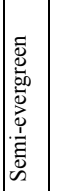 & 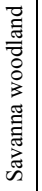 & 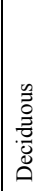 \\
\hline 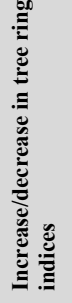 & 离 & $\begin{array}{l}\stackrel{8}{0} \\
\vdots \\
\end{array}$ & 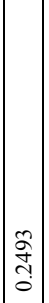 & $\begin{array}{l}\tilde{Z} \\
\stackrel{0}{0} \\
\dot{0}\end{array}$ & $\begin{array}{l}\qquad \\
0 \\
0 \\
0\end{array}$ & $\begin{array}{l}\tilde{3} \\
\dot{0} \\
\dot{0}\end{array}$ & \begin{tabular}{|l|}
$\overrightarrow{8}$ \\
0 \\
$\dot{i}$ \\
1
\end{tabular} & $\begin{array}{l}m \\
0 \\
0 \\
0\end{array}$ & 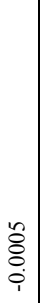 & $\mid \begin{array}{l}\vec{a} \\
\dot{0} \\
\dot{i}\end{array}$ & 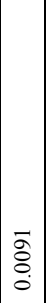 & $\begin{array}{l}\vec{m} \\
\overrightarrow{0} \\
\dot{i}\end{array}$ & $\begin{array}{l}1 \\
\tilde{O} \\
0 \\
0\end{array}$ & $\begin{array}{l}\text { cat } \\
0 \\
\dot{1} \\
i\end{array}$ & $\begin{array}{l}0 \\
0 \\
\vdots \\
\vdots \\
1\end{array}$ & $\begin{array}{l}\infty \\
\vec{\delta} \\
\stackrel{0}{0} \\
\end{array}$ & 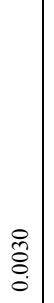 & $\begin{array}{l}\text { oे } \\
\text { o. } \\
\stackrel{i}{i}\end{array}$ & $\begin{array}{l}\frac{\pi}{8} \\
\stackrel{0}{0}\end{array}$ & $\begin{array}{l}0 \\
\stackrel{0}{0} \\
\stackrel{0}{0}\end{array}$ & 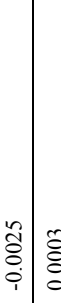 & 旾 & 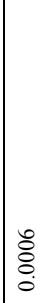 & 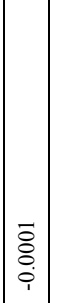 & $\begin{array}{l}0 \\
\tilde{2} \\
0 \\
0 \\
i\end{array}$ & $\begin{array}{l}0 \\
0 \\
\tilde{\delta} \\
0 \\
0 \\
i\end{array}$ \\
\hline 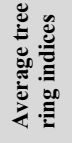 & 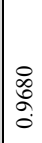 & 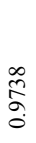 & 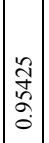 & $\begin{array}{l}\tilde{O} \\
0 \\
0 \\
o \\
0\end{array}$ & $\hat{\tilde{o}}$ & 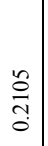 & $\mid \begin{array}{c}\bar{\alpha} \\
\dot{\sigma} \\
\stackrel{-}{-}\end{array}$ & 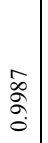 & 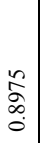 & $\begin{array}{l} \pm \\
\tilde{\sigma} \\
o \\
0\end{array}$ & 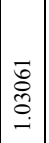 & 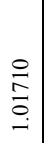 & ڤેे & $\mid \begin{array}{l}\hat{2} \\
\hat{尺} \\
\vdots \\
0 \\
0\end{array}$ & $\begin{array}{l}\stackrel{\delta}{\circ} \\
\stackrel{2}{\circ} \\
\dot{0}\end{array}$ & \begin{tabular}{|l}
$\infty$ \\
0 \\
0 \\
0 \\
0 \\
0
\end{tabular} & $\begin{array}{l}\tilde{\hat{o}} \\
\stackrel{-}{-}\end{array}$ & $\begin{array}{l}\text { ڤn } \\
\hat{n} \\
\vdots\end{array}$ & $\begin{array}{l}\text { हे } \\
\text { to } \\
\text {. }\end{array}$ & $\begin{array}{l}n \\
\vdots \\
0 \\
0 \\
0\end{array}$ & 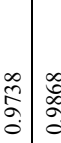 & $\begin{array}{l}\infty \\
\alpha \\
\alpha \\
\sigma\end{array}$ & $\begin{array}{l}0 \\
\stackrel{0}{0} \\
8 \\
0 \\
0\end{array}$ & $\begin{array}{l}\hat{\alpha} \\
\hat{\alpha} \\
\hat{\sigma}\end{array}$ & $\begin{array}{l}\infty \\
\vdots \\
0 \\
0 \\
0\end{array}$ & 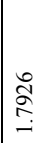 \\
\hline 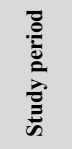 & $\begin{array}{l}2 \\
2 \\
\frac{2}{1} \\
2 \\
2\end{array}$ & $\begin{array}{l}\frac{a}{\partial} \\
\frac{1}{\hat{N}}\end{array}$ & 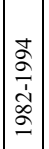 & 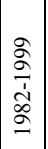 & $\begin{array}{l}\frac{\sigma}{1} \\
\frac{1}{\infty} \\
\stackrel{2}{-}\end{array}$ & 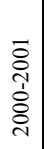 & 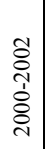 & 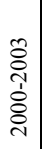 & 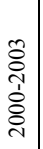 & 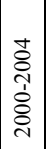 & 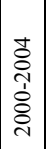 & 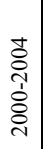 & 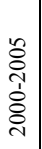 & $\mid$ & 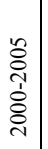 & 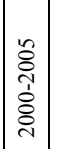 & 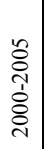 & 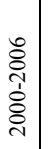 & $\begin{array}{l}\text { ¿ें } \\
\text { ஸे } \\
\text { के }\end{array}$ & 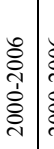 & 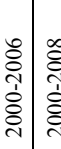 & 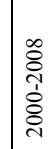 & 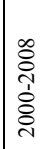 & 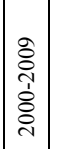 & 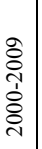 & 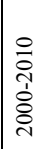 \\
\hline
\end{tabular}




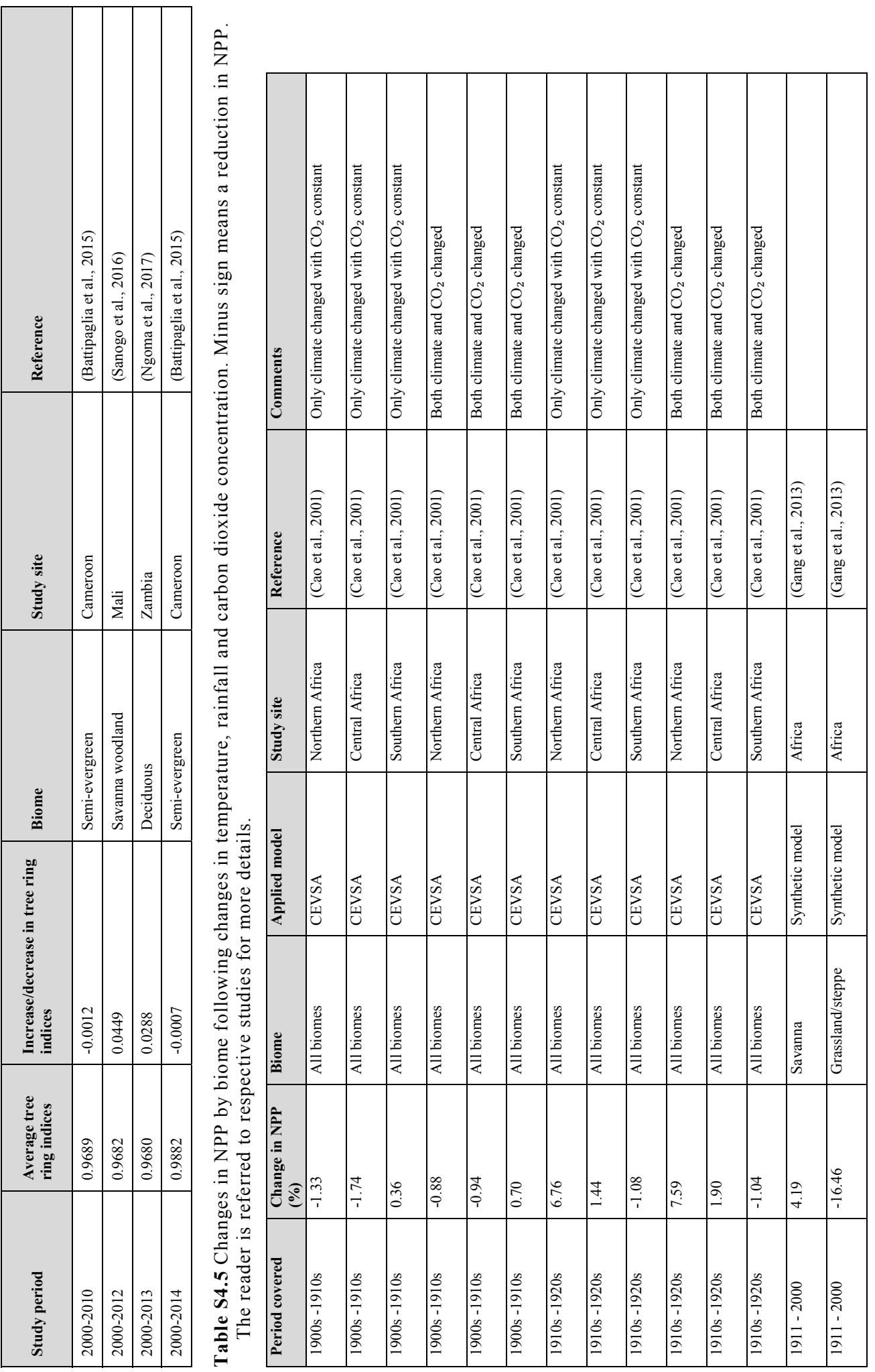




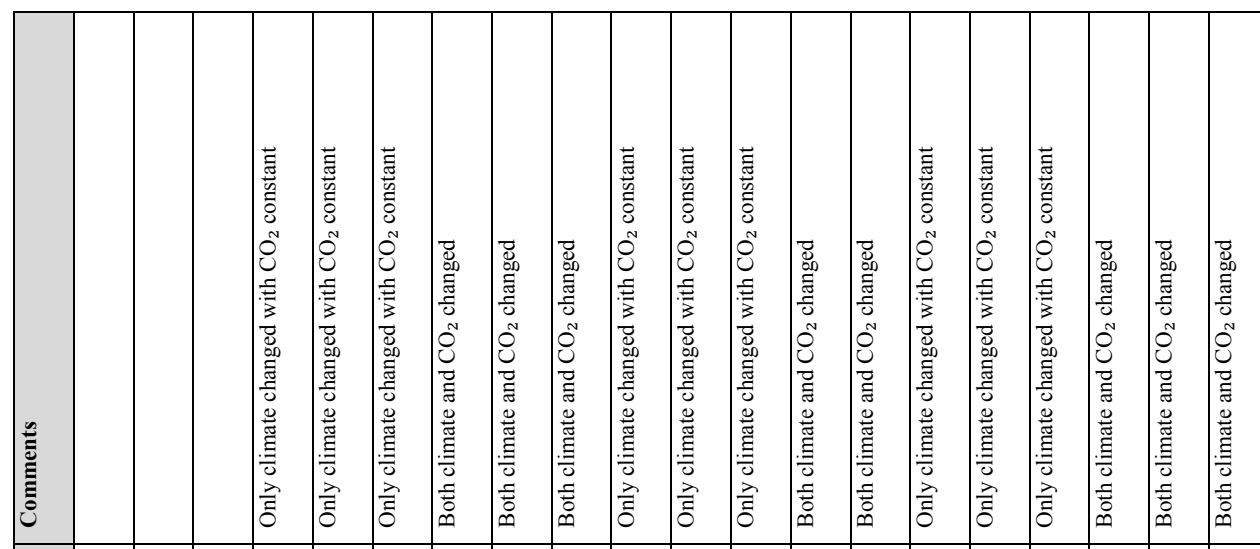

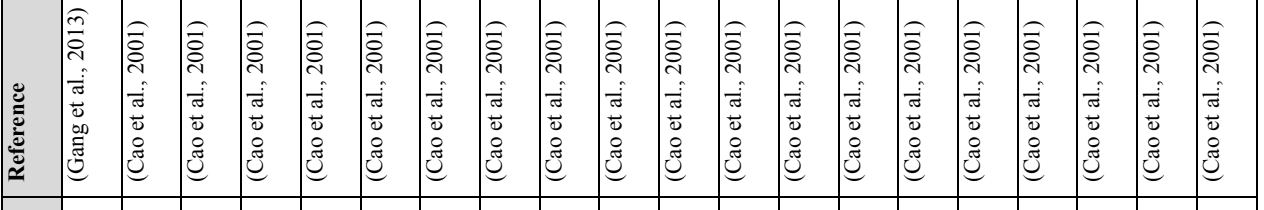

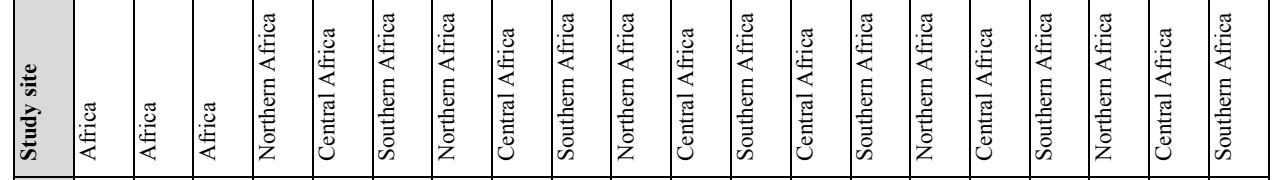
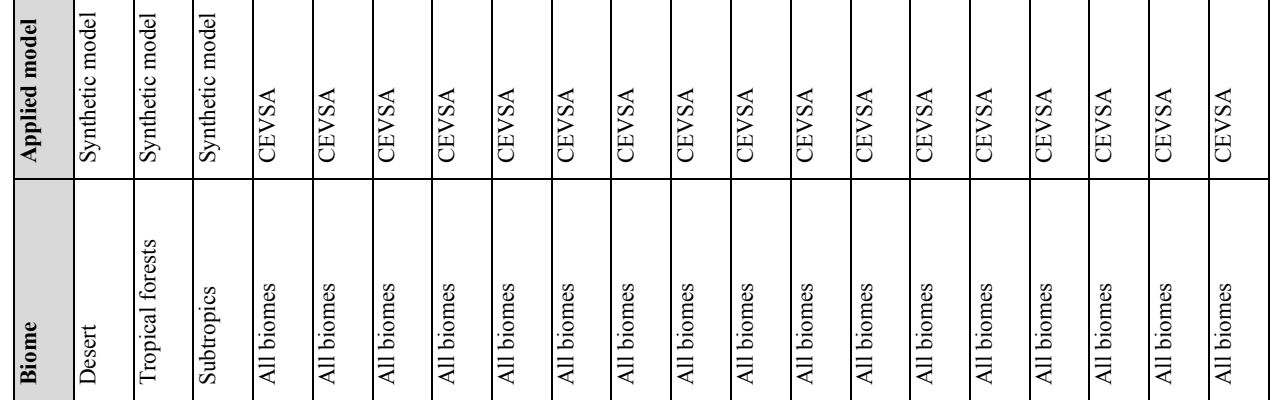

言

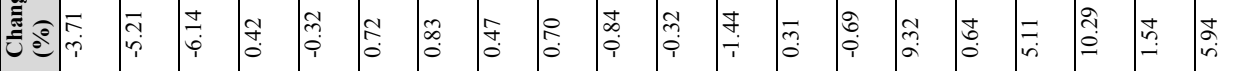

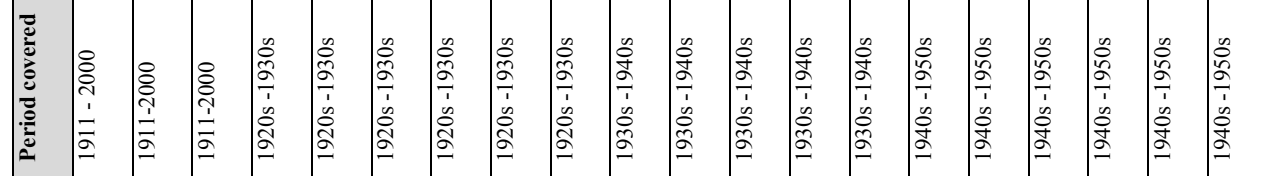




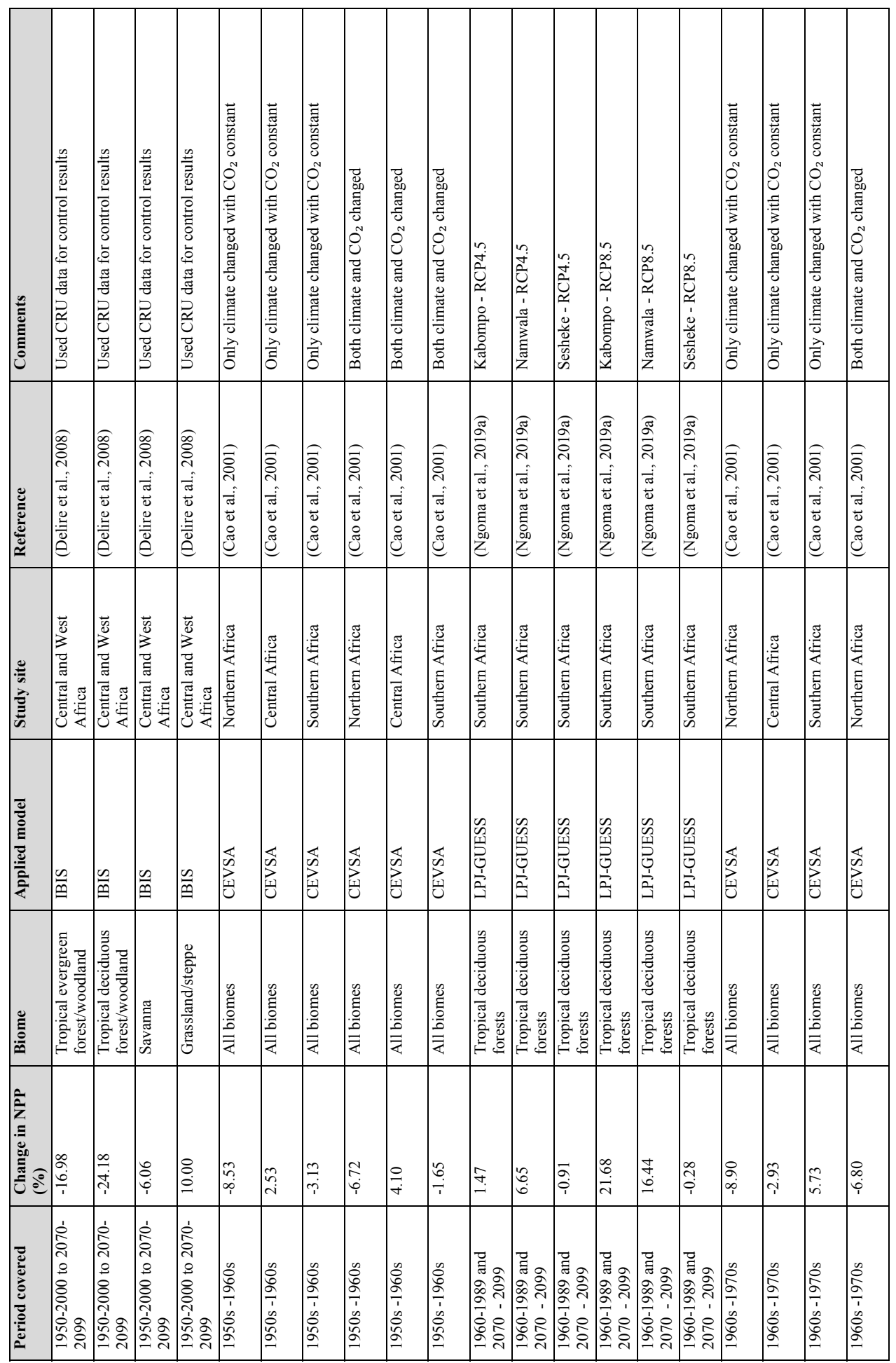




\begin{tabular}{|c|c|c|c|c|c|c|c|c|c|c|c|c|c|c|c|c|c|c|}
\hline 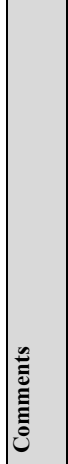 & 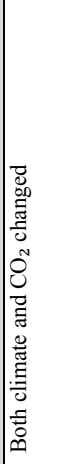 & 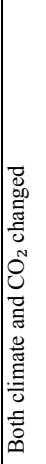 & 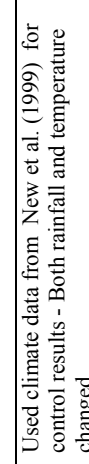 & 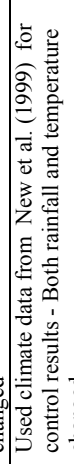 & 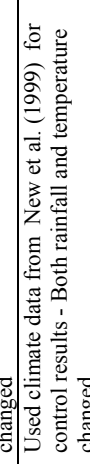 & 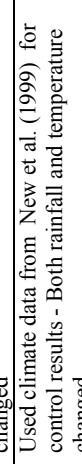 & 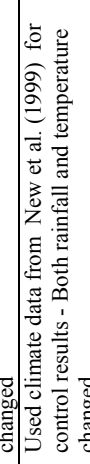 & 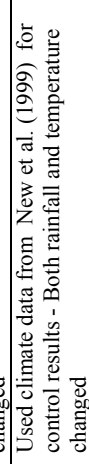 & 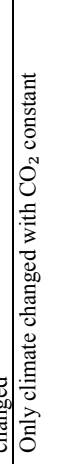 & 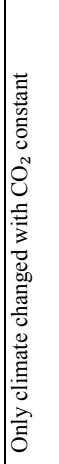 & 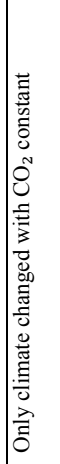 & 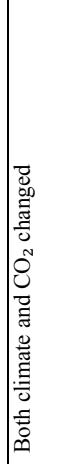 & 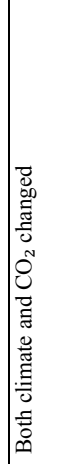 & 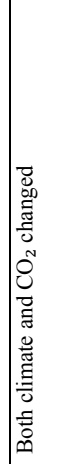 & & & & 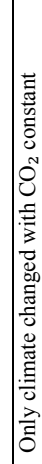 \\
\hline 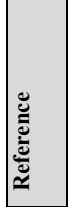 & 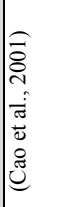 & 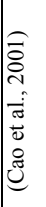 & 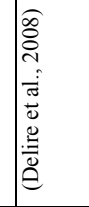 & 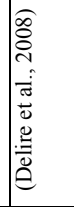 & 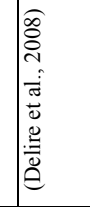 & 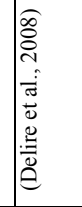 & 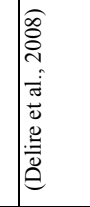 & 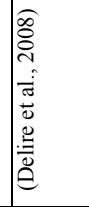 & 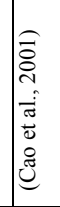 & 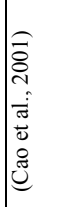 & 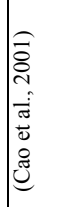 & 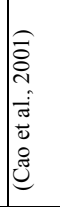 & 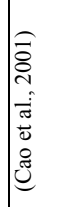 & 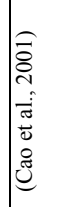 & 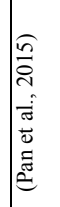 & 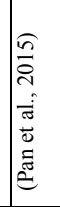 & 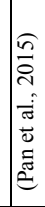 & 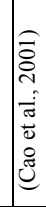 \\
\hline 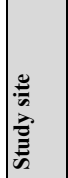 & 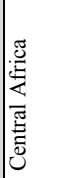 & 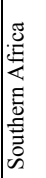 & 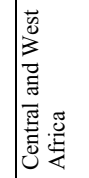 & 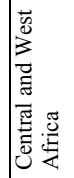 & 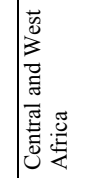 & 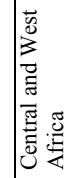 & 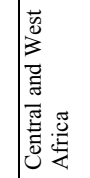 & 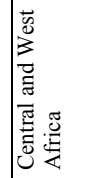 & 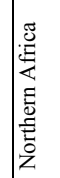 & 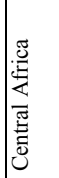 & 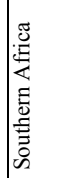 & 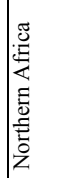 & 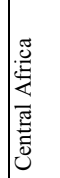 & 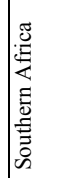 & 莺 & 菭 & 迎 & 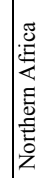 \\
\hline 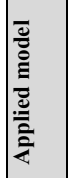 & 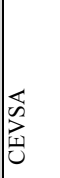 & 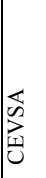 & $\stackrel{\tilde{\mu}}{\underline{\Theta}}$ & $\underline{\mathscr{n}}$ & $\stackrel{\tilde{\nu}}{\underline{\underline{n}}}$ & $\stackrel{\mathscr{N}}{\mathscr{M}}$ & $\stackrel{\mathscr{\varkappa}}{\cong}$ & $\frac{\mathscr{n}}{\underline{M}}$ & 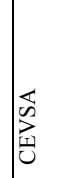 & 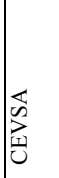 & 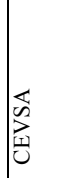 & 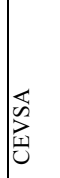 & 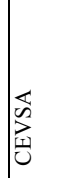 & $\begin{array}{l}\text { 岕 } \\
\text { 恶 }\end{array}$ & $\begin{array}{l}\sum_{i=1} \\
\vec{\Delta}\end{array}$ & $\begin{array}{l}\sum_{i=1} \\
\vec{\theta}\end{array}$ & 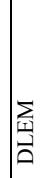 & 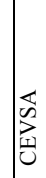 \\
\hline 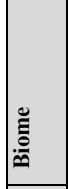 & 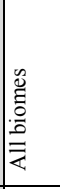 & 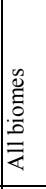 & 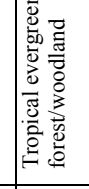 & 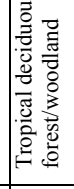 & 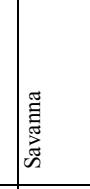 & 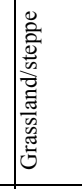 & 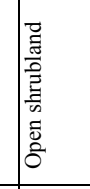 & 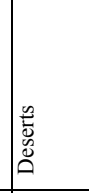 & 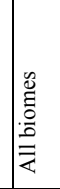 & 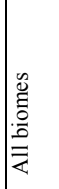 & 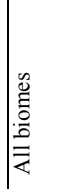 & 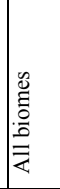 & 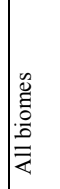 & 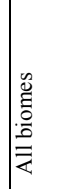 & 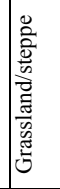 & 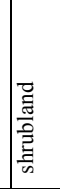 & 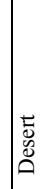 & 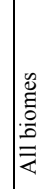 \\
\hline 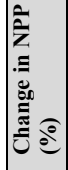 & $T$ & $\underset{\infty}{\stackrel{N}{\infty}}$ & $\mid \begin{array}{l}F \\
\infty \\
\infty\end{array}$ & 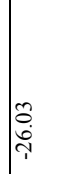 & $\stackrel{\vec{n}}{\vec{n}}$ & 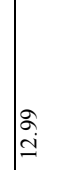 & 文 & $\begin{array}{l}\tilde{b} \\
\stackrel{0}{1}\end{array}$ & 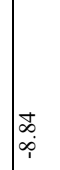 & & $\frac{m}{a}$ & 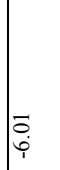 & in & $\overrightarrow{\bar{i}}$ & $\stackrel{R}{=}$ & $\begin{array}{l}\text { 导 } \\
\dot{I}\end{array}$ & 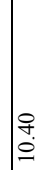 & $\stackrel{\Re}{=}$ \\
\hline 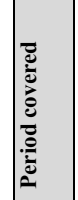 & 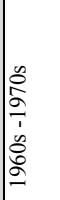 & 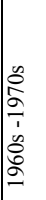 & 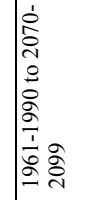 & 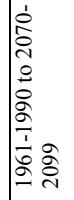 & 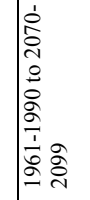 & 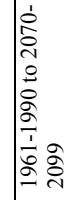 & 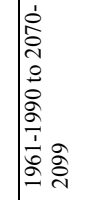 & 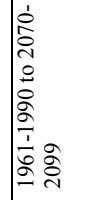 & 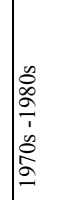 & 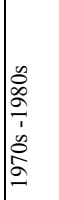 & 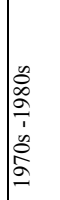 & 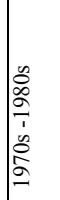 & 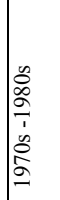 & 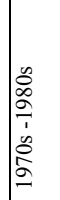 & 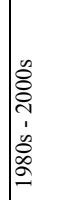 & 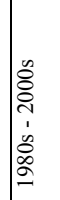 & 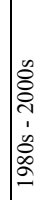 & 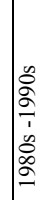 \\
\hline
\end{tabular}




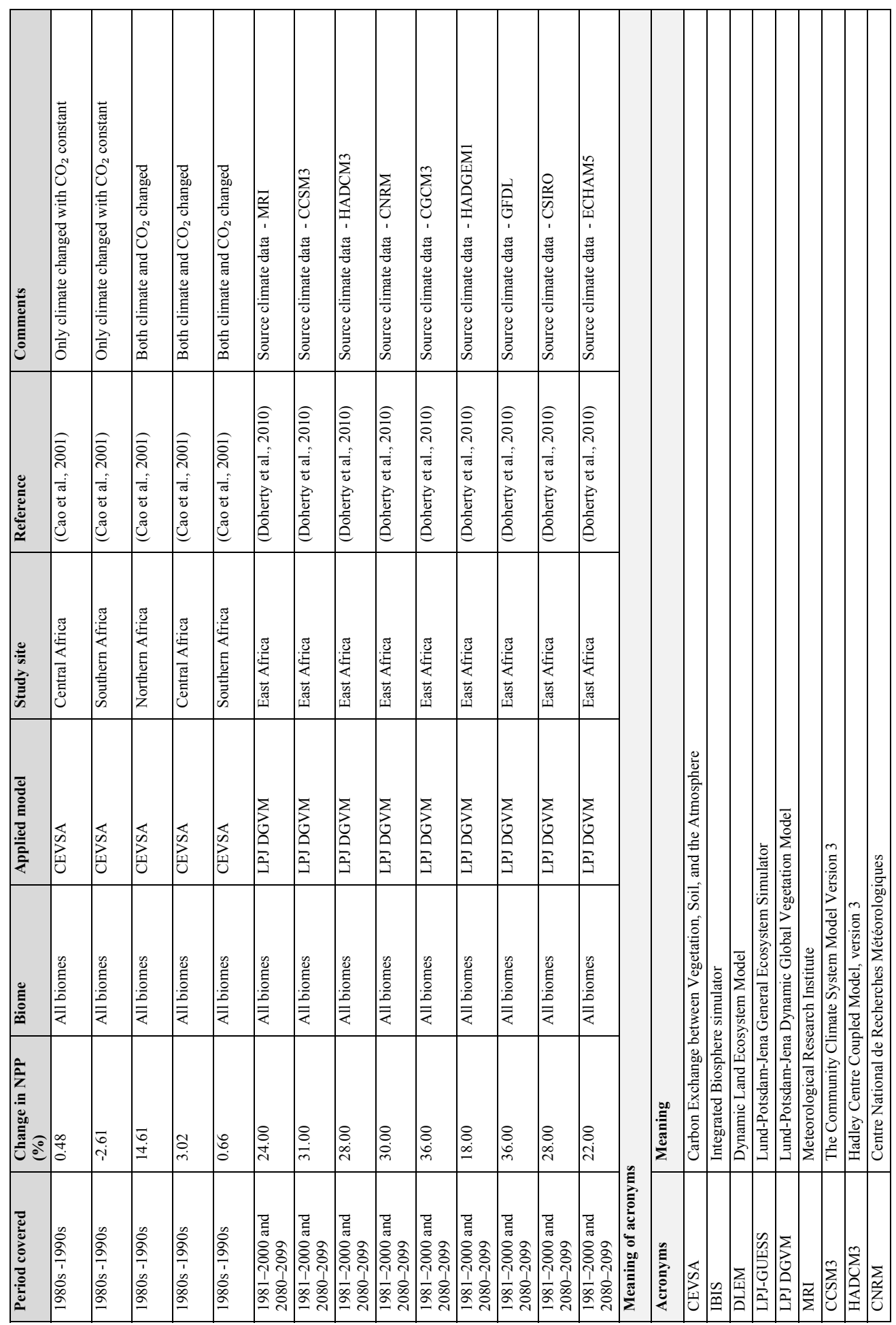




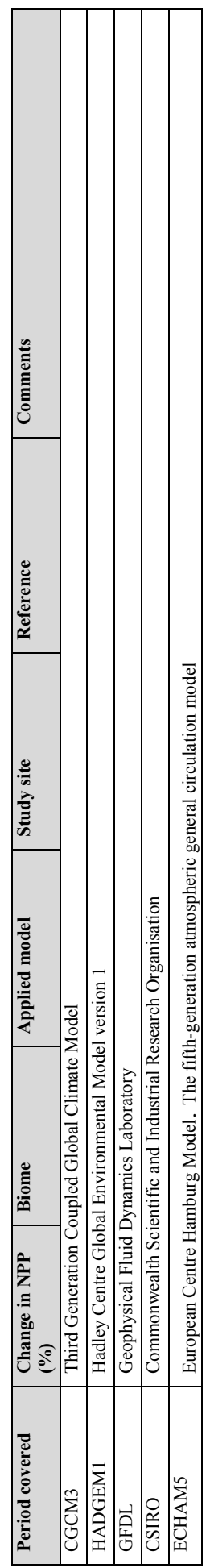




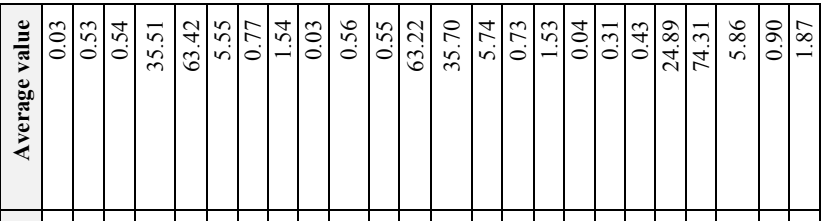

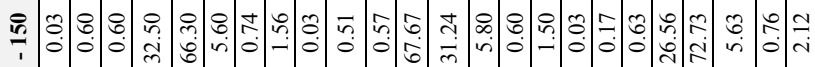
ป

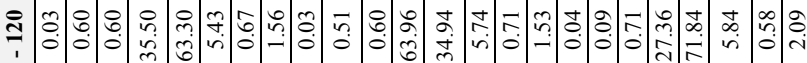
๖ิ

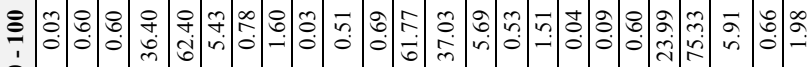
in

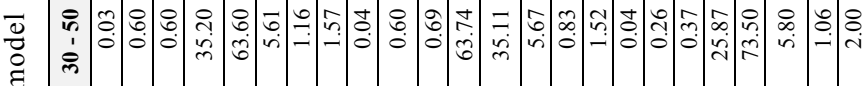

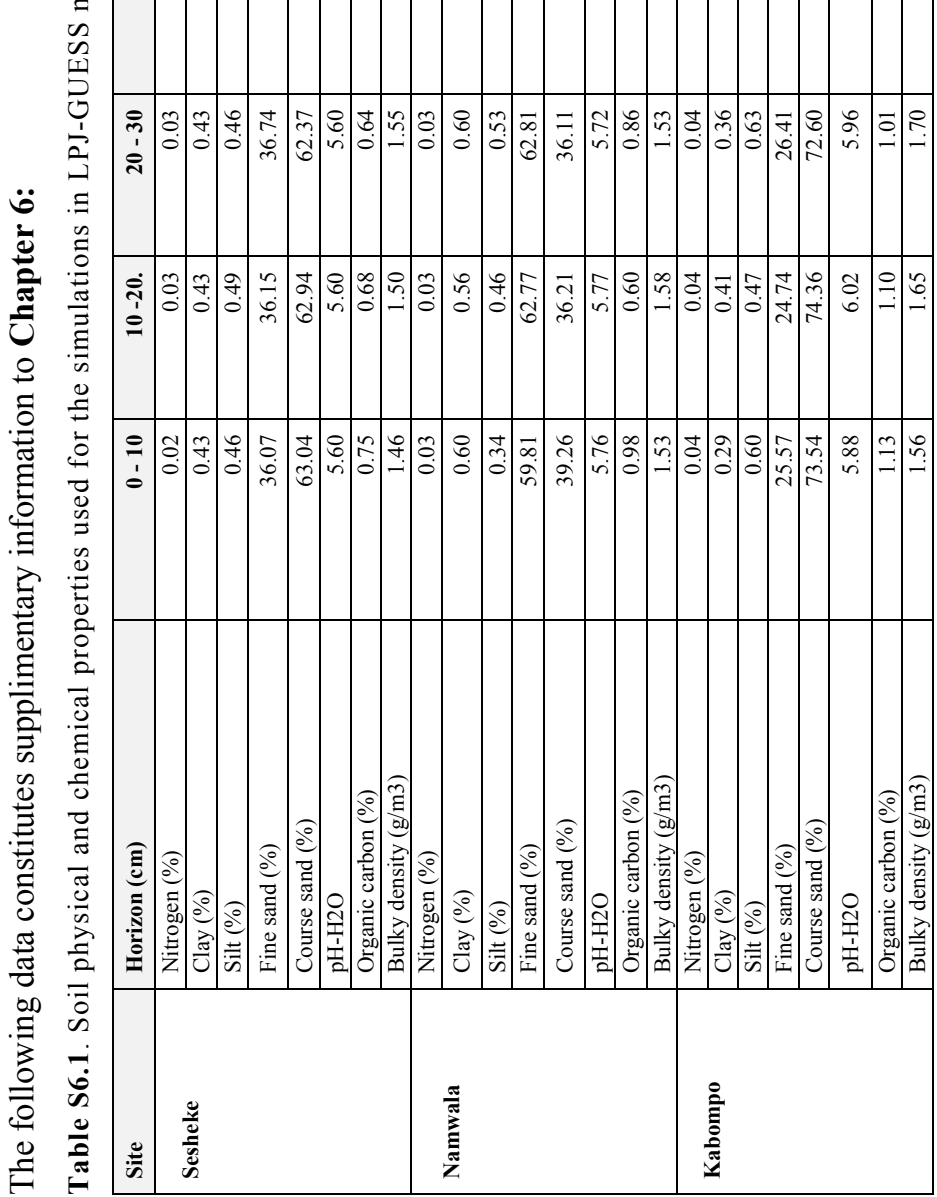




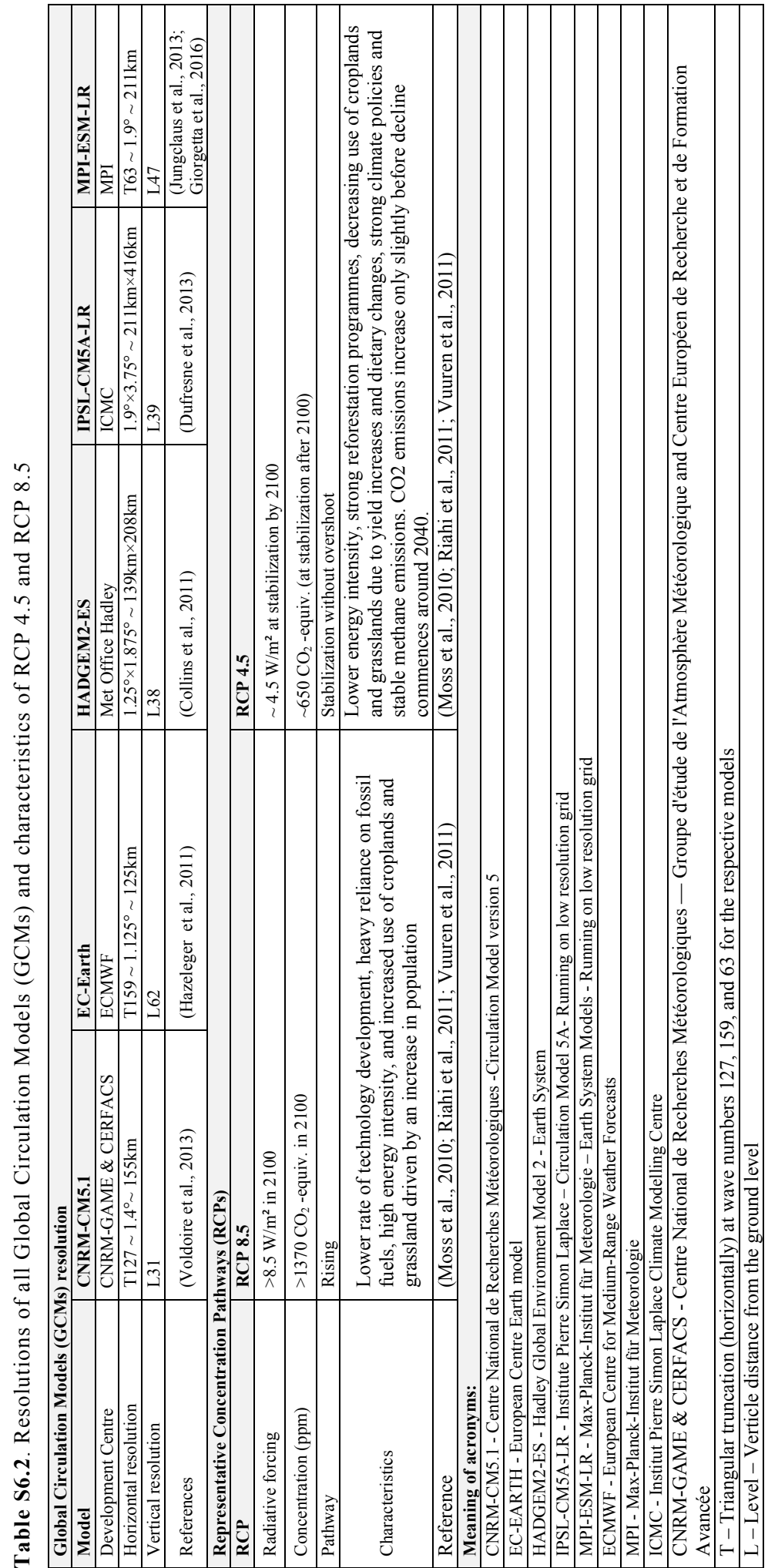



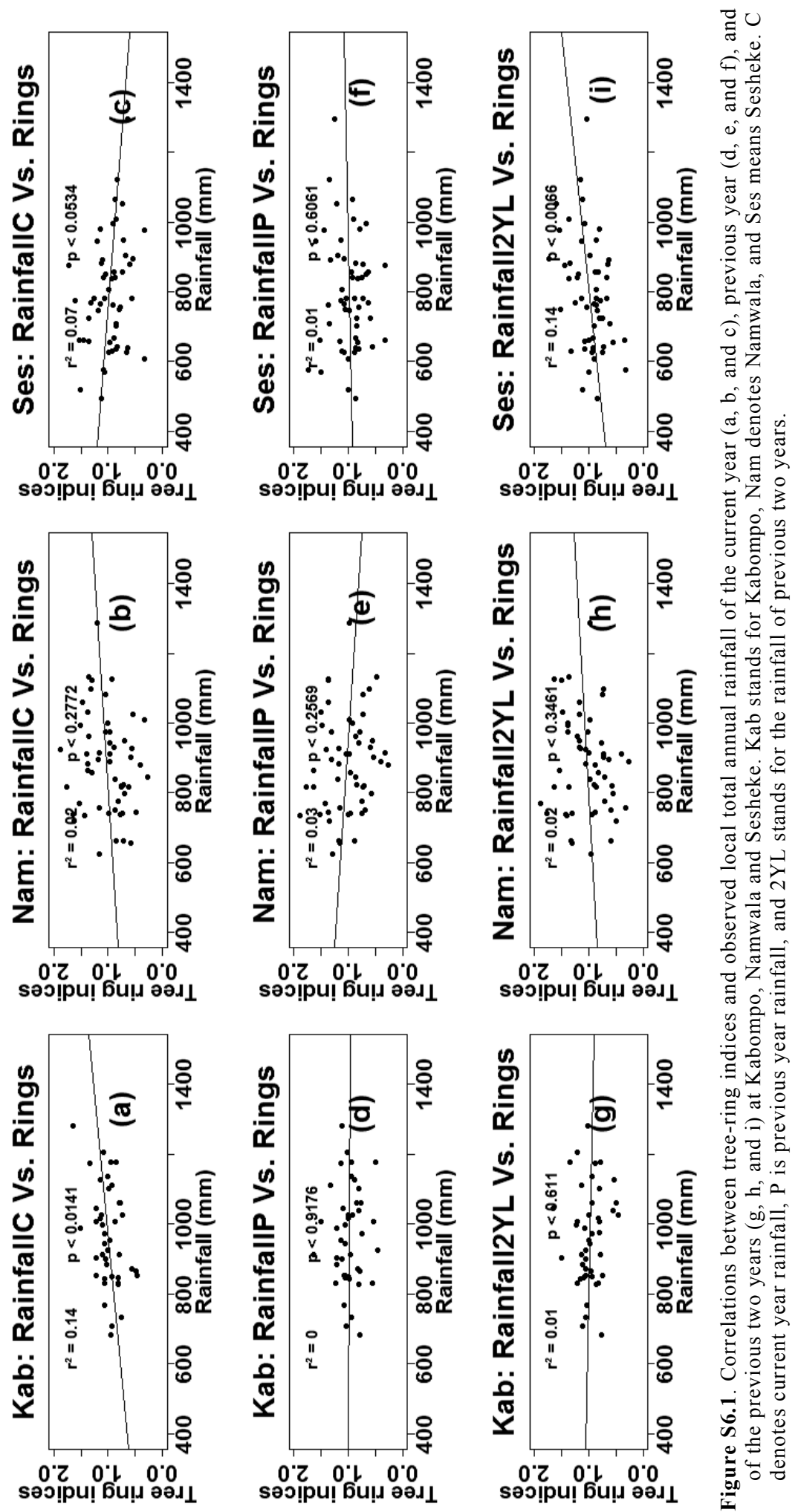

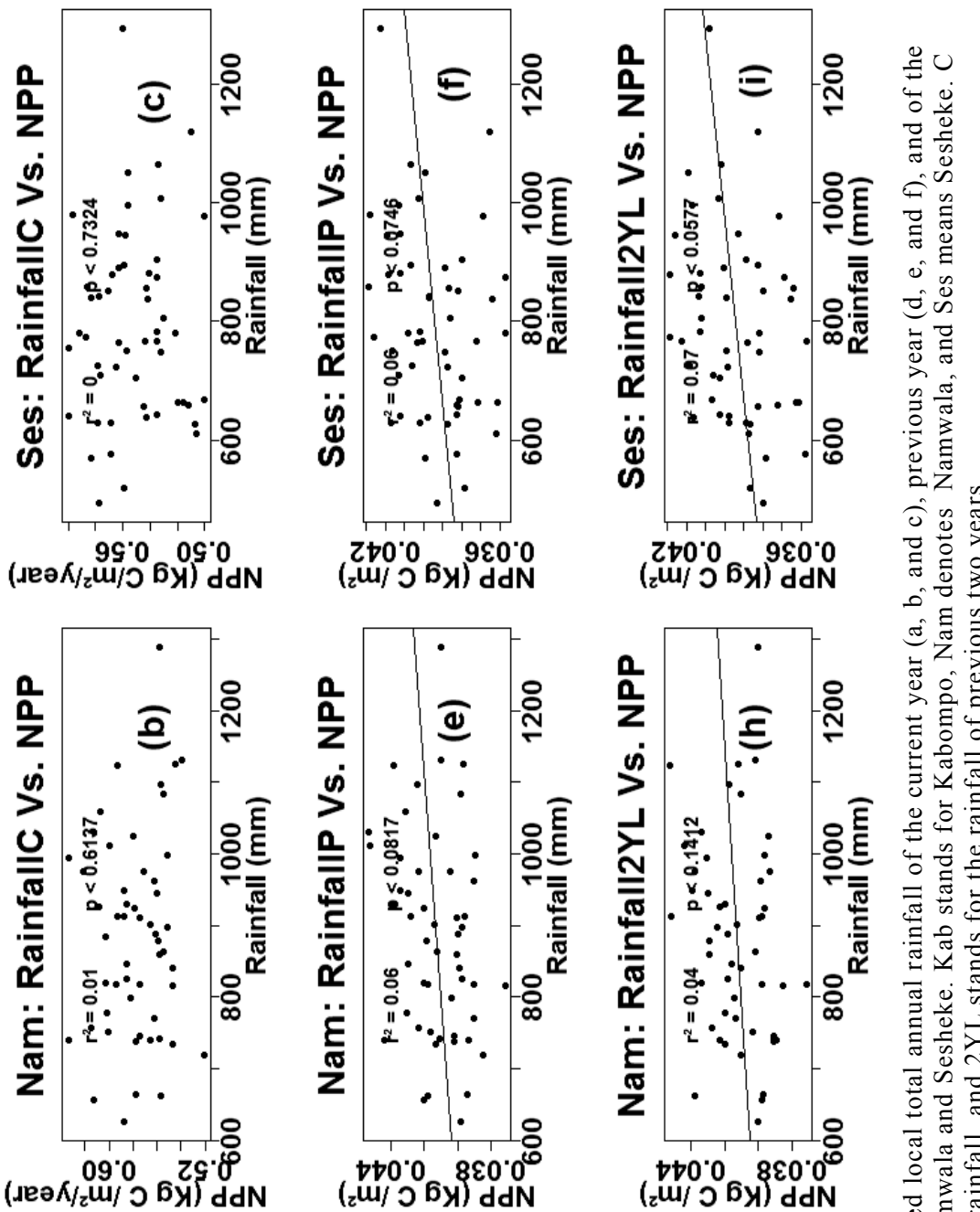

ฮิ
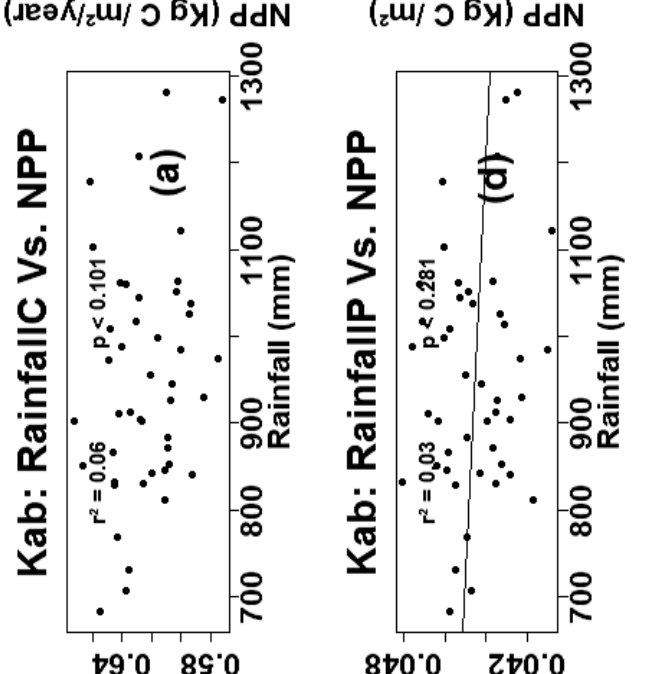

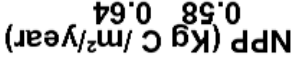

$870^{\circ} 02700^{\circ} 0$

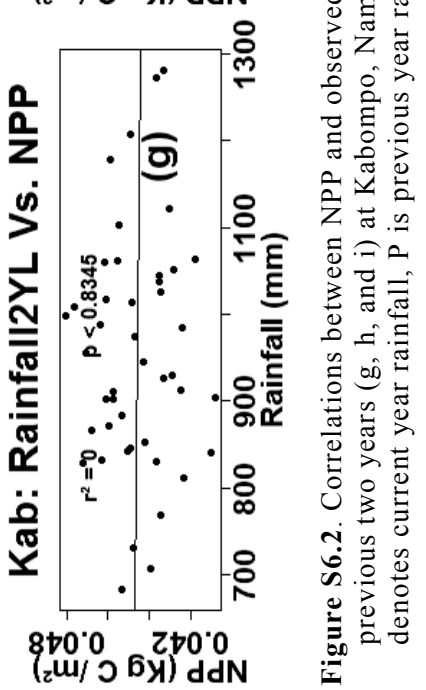




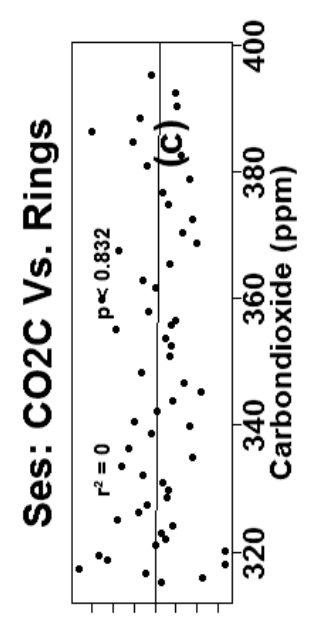

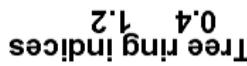
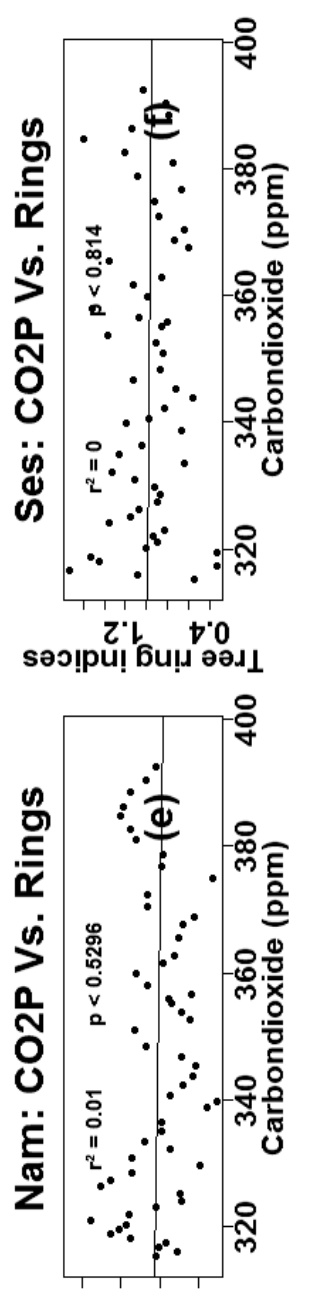

s'l G'0 sәэ!pu! 6u!̣ วәג

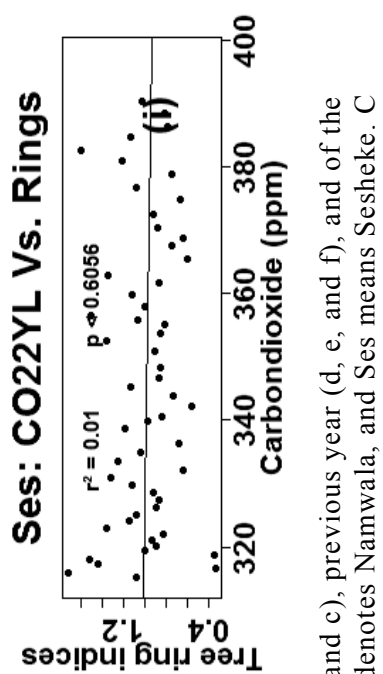

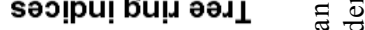

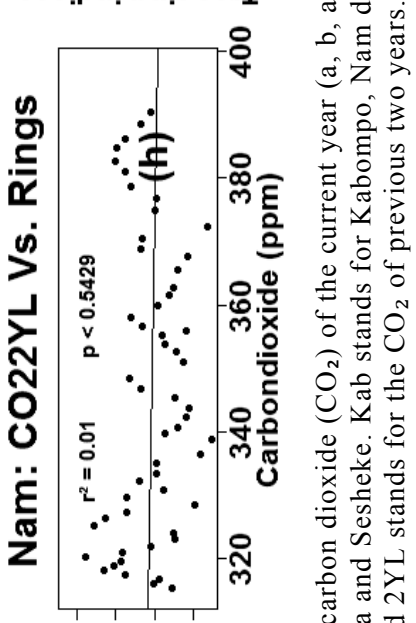

c'l s.0 $^{\prime} 0$ sәэ!pu! 6u!̣ әәд।

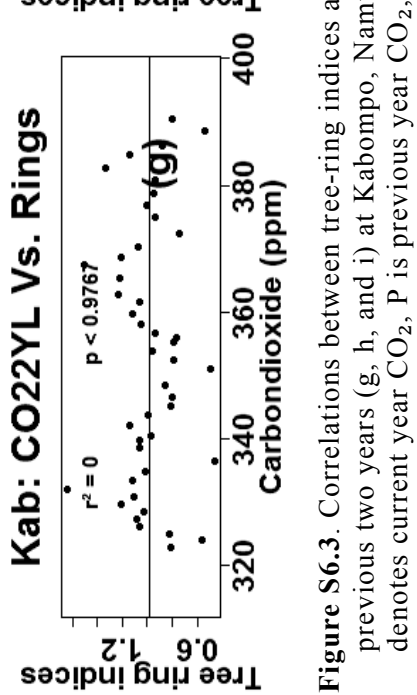

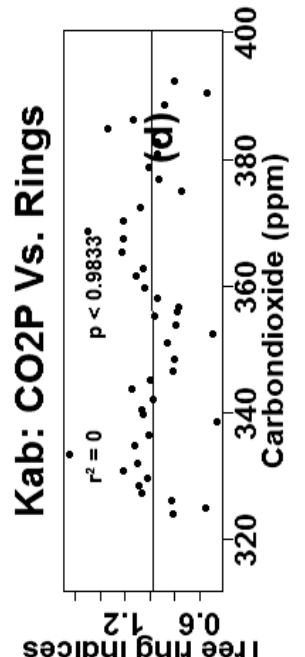



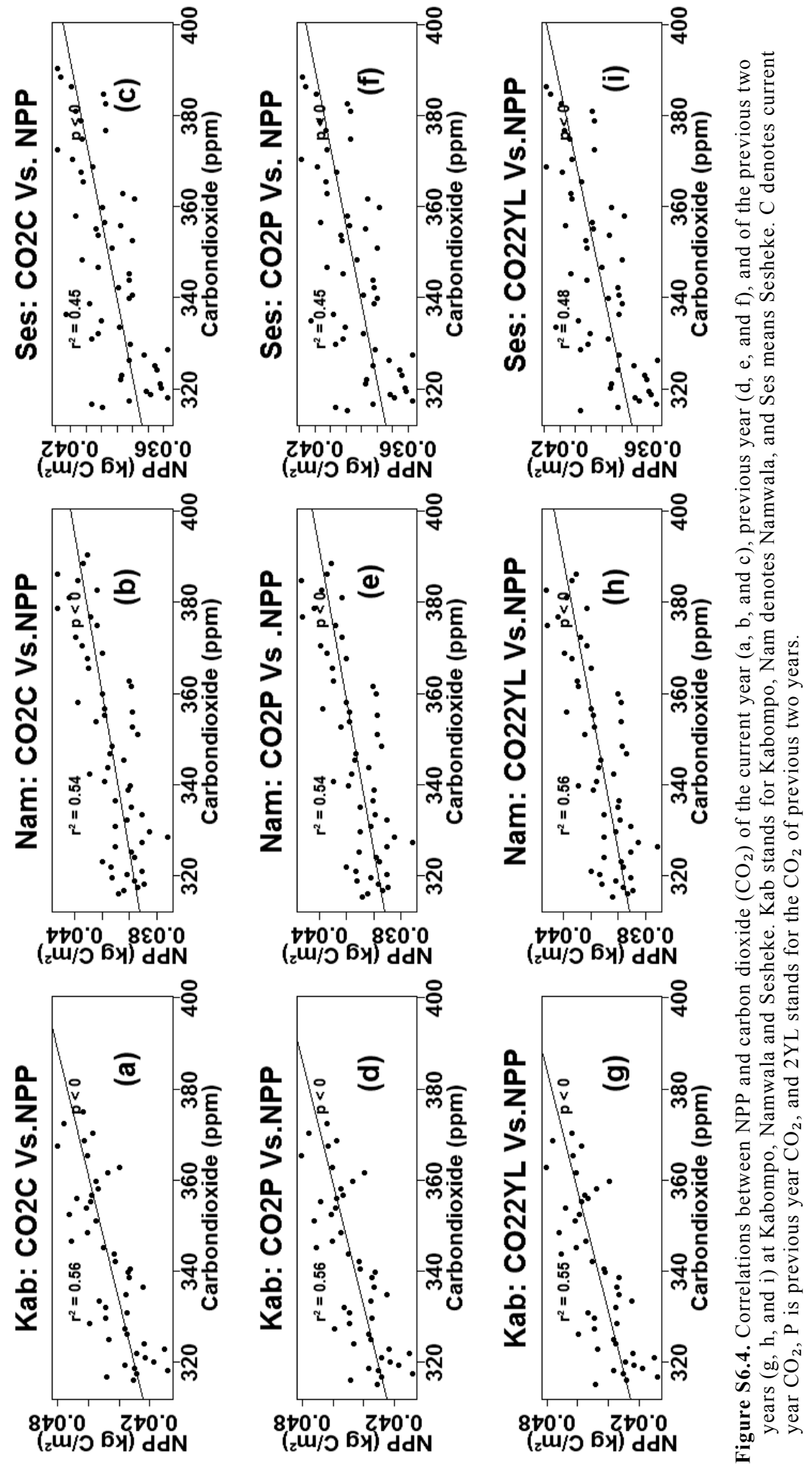

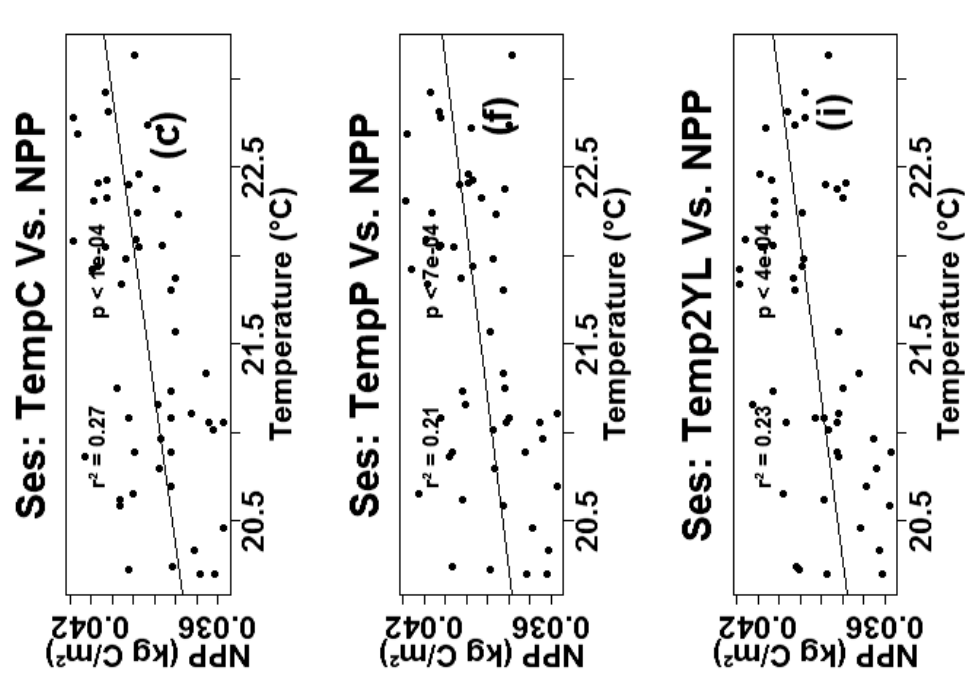

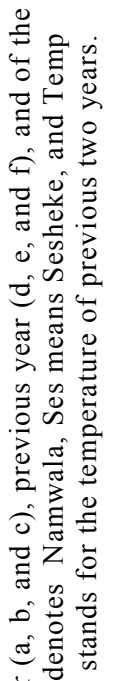
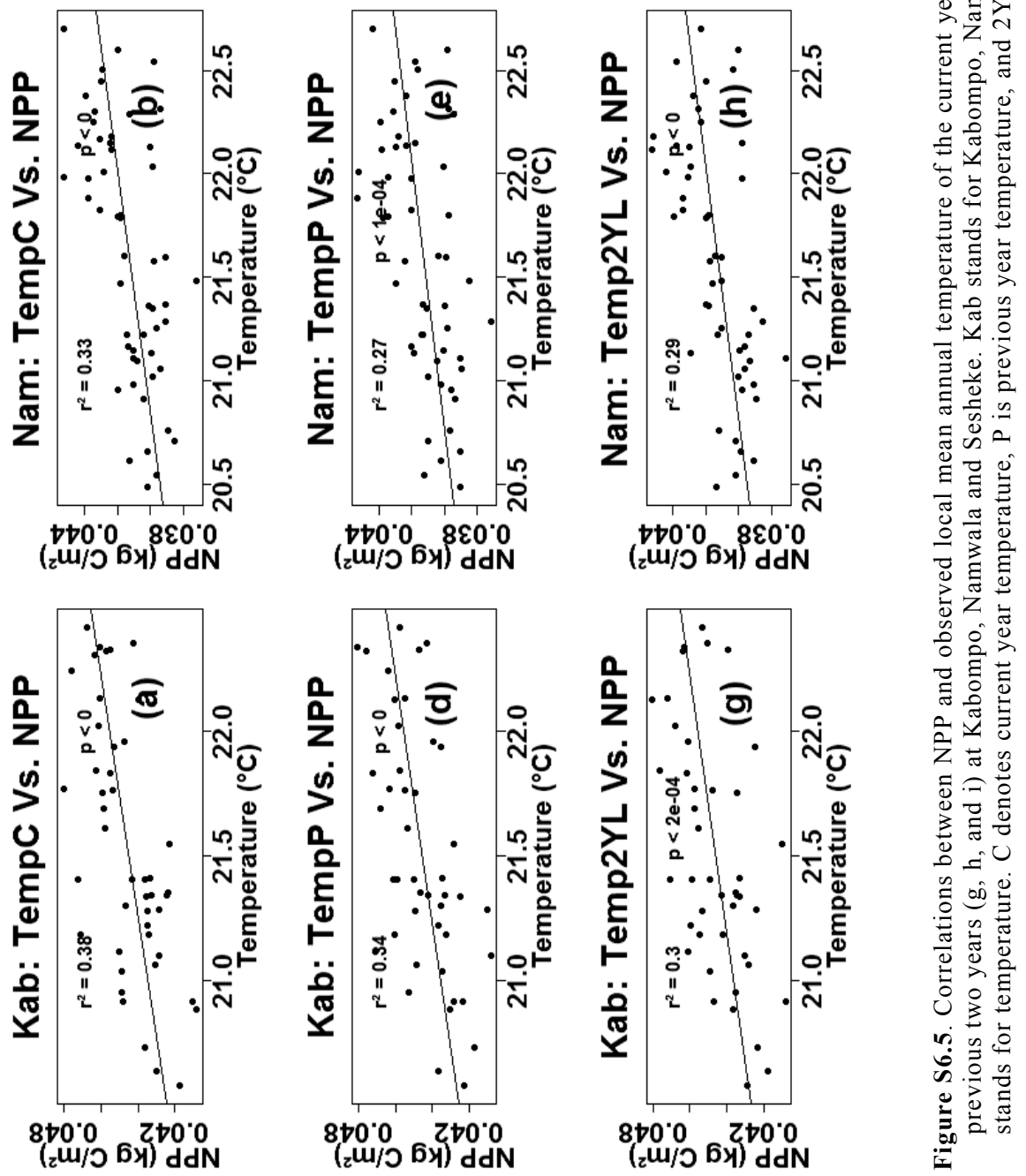

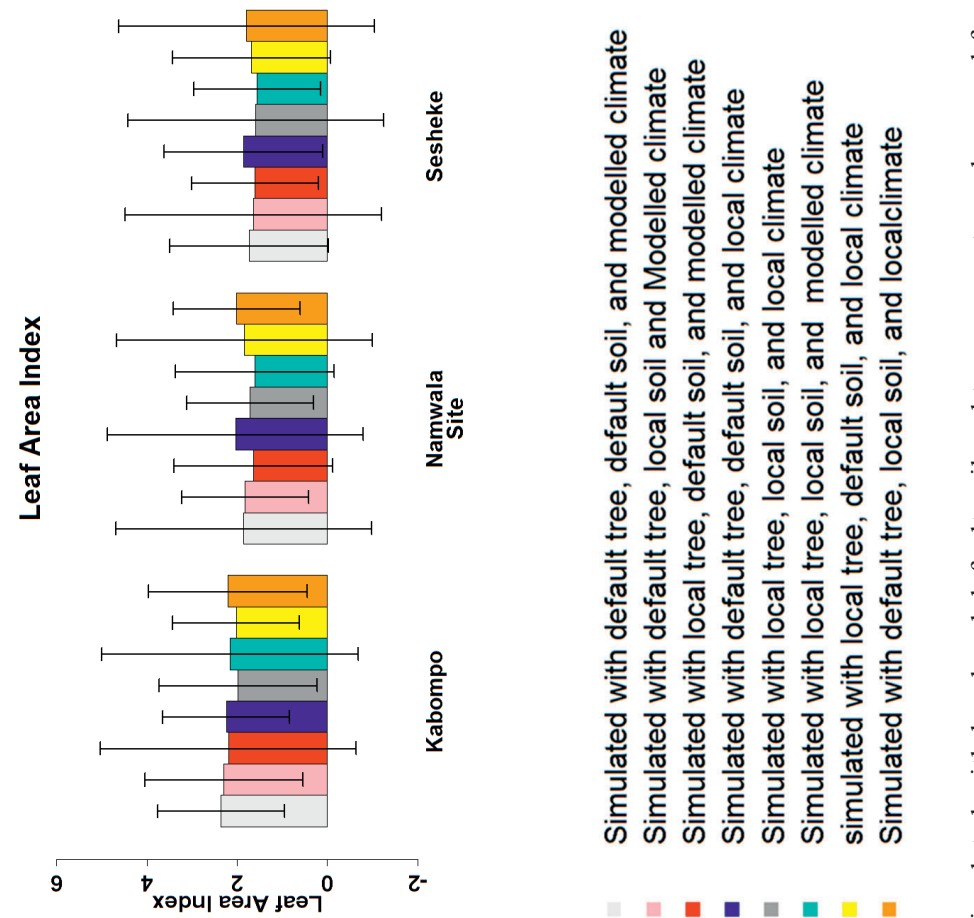

$\frac{\overrightarrow{0}}{0}$

ఏ

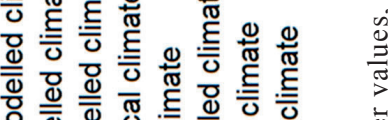

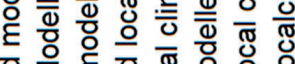
믈 음 엉 응으 응

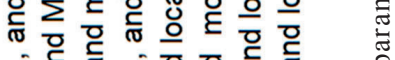

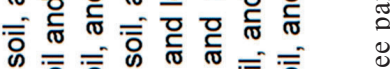

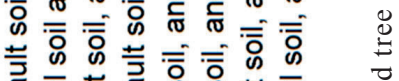
常 o 웡 0 으 응 ब

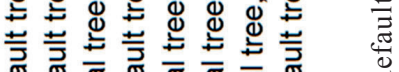
要

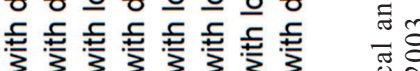

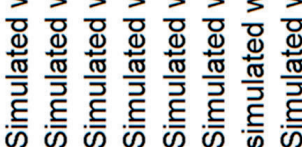
은 동 ग)

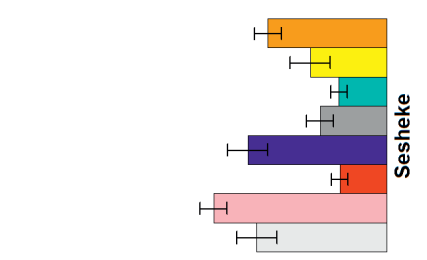

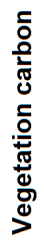

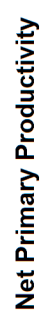

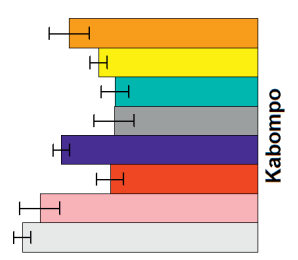

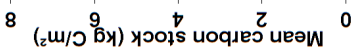

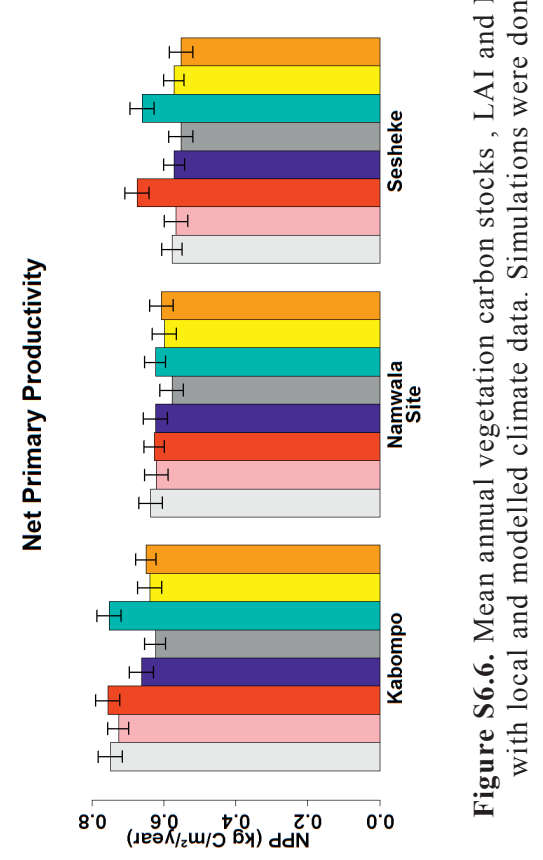


My study aims to determine the effects of climate change on the productivity of the Zambezi Teak forests along a rainfall gradient in Zambia. I addressed this aim by integrating information from biomass measurements, tree-ring analysis and a dynamic vegetation modelling. Chapter 2 presents data on total tree height, DBH, wood density, wood dry weight and carbon stock of each surveyed tree. This data was an input to Chapter $\mathbf{3}$ where biomass allometric models to estimate carbon stock were developed. Chapter 4 presents results of the review on Net Primary Productivity's (NPP) responses to climate change in Africa. In Chapter 5, I determined the climate-growth relationship through tree-ring analysis while in Chapter 6, I projected the response of NPP of the Zambezi teak forests to climate change in Zambia through the application of LPJ-GUESS vegetation model.

The review (Chapter 4) showed that NPP is highest in the wetter areas compared to drier areas. This was supported by simulated results that were presented in Chapter 6. The review also showed that NPP's sensitivity to climate is higher in the drier areas than in the wetter areas (Chapter 4). This sensitivity trend is contrary to the trends that are determined in Chapters 5 and $\mathbf{6}$ where the relationship between rainfall and productivity is higher in wetter areas than in drier areas. The biomass allometric models that are developed in Chapter 3 showed that only DBH had significant effects $(\mathrm{p}<0.0001)$ on tree biomass. Using these newly developed biomass models and carbon fractions that are presented in Chapters 2 and 3, I recorded the highest vegetation carbon stock at the wetter Kabompo site followed by the intermediate Namwala and then the drier Sesheke site (c.f. Chapters 2 and 3). Of the eighty tree species recorded, Baikiaea plurijuga Harms had the highest species specific carbon stock (Chapter 2).

I used local soil parameter values to characterize texture and measured local tree parameter values for maximum crown area, wood density, leaf longevity and allometry to adapt LPJ GUESS model and assess NPP at the Kabompo, Namwala and Sesheke sites. The model was validated by relating LPJ-GUESS simulated NPP and tree-ring indices. I further validated the model by comparing LPJ-GUESS simulated and measured vegetation carbon values. LPJGUESS simulated NPP and tree-ring indices were not correlated though the LPJ-GUESS simulated and measured vegetation carbon value compared reasonably well (Chapter 6). I 
thus conclude that using local parameter values is essential to obtaining reasonably reliable simulations.

Chapters 5 and 6 present the relationships between climatic variables and plants' productivity and I found a positive relationship between tree-ring indices and current years' rainfall at Kabompo, while tree ring indices positively correlated with rainfall of the previous two years at the Sesheke site (Chapter 6). No relationships were recorded between tree-ring indices and rainfall of the current year, previous year and previous two years at Namwala. I did not record any relationship between rainfall and NPP at all sites (Chapter 6).

Temperature of the current, previous and previous two years correlated positively with NPP at all sites. However, no significant relationships were recorded between tree-ring indices and mean annual temperatures of current, previous and previous two years at all sites apart from at the Namwala site where tree-ring indices correlated negatively with mean annual temperature of the previous two years (Chapter 6). A comparison of the climatic variables (i.e. temperature and rainfall) and evaporation at the three sites showed that tree-ring indices correlated best with the mean evaporation of November plus March $(r=-0.557)$ explaining $31 \%$ of the variance at the Namwala site and March value $(\mathrm{r}=-0.436)$ explaining $19 \%$ of the variance at the Sesheke site. However, at the Kabompo site the chronology correlated best with December temperature $(r=-0.540)$, explaining 29\% of the variance (Chapter 5).

In Chapter 6, I projected climate change effects on NPP under RCP4.5 and RCP8.5 following the changes in rainfall, temperature, incoming solar radiation, number of wet days and $\mathrm{CO}_{2}$ concentration. The results showed that by the end of the $21^{\text {st }}$ century, increased $\mathrm{CO}_{2}$ concentrations are projected to enhance NPP at the Kabompo and Namwala sites under both RCPs, while under RCP8.5 decreased precipitation coupled with increased temperature reduces NPP at the Sesheke site.

Chapter 1 indicated that the livelihood of $65 \%$ of the total population in Zambia is tied to forestry resources. This illustrates that adverse effects of climate change on forestry resources also affect the livelihood of these forestry dependent communities. To help the people prepare, the Government of the Republic of Zambia should come up with a deliberate program to disseminate this important information to these forestry dependent communities using local languages in the respective regions of the country. This would help local people to implement adaptation and mitigation measures following the diverse response of NPP to climate change that are assessed in this study. For example, while measures at the Kabompo 
and Namwala sites should focus on enhancing growth of the same species that are currently growing, measures at the Sesheke site should target those that promote planting of other tree species which can survive the projected higher temperatures and reduced rainfall. To obtain a holistic understanding of the fate of the forestry resources in Zambia, similar research should be carried out, both in the vast Miombo woodlands and in other forestry types to complement my results for the Zambezi teak forests. Only then comprehensive measures can be developed for all southern African forests. My data collection and analysis shows that this is possible and urgently needed. 
Pursuing a $\mathrm{PhD}$ would not have been possible without the support of many people. First, I would like to thank my promoter, Rik Leemans; co-promotors, Bart Kruijt, Eddy Moors and James H. Speer; and my local supervisor, Royd Vinya for accepting to supervise my work. You allowed me to express myself and develop as an independent scientist. This helped me to increase my confidence with time. I learned a lot from each one of you. A big 'thank you!' for your valuable comments and dedication to your work.

Rik Leemans: You were my promotor, but you were also working like my daily supervisor and teacher. Among your busy schedule as the Head of the Environmental Systems Analysis Group, you would always find time to look at my work and provide comments. You taught me how to construct short, but meaningful sentences when writing scientific papers. You taught me how to use Microsoft Word well. I troubled you several times, requesting for letters when looking for funds and extend my study leave with the Copperbelt University (my employer), but you never got tired of me frequenting your office. You even offered to pay Open Access Fees to ensure that one of the papers is published for me to successfully complete my studies. Truly, you did support me from the beginning to the end. I thank you for all the support that you gave me during my $\mathrm{PhD}$ journey. It is really amazing and truly appreciated.

Eddy Moors: I would like to thank you for your guide, flexibility and accommodativeness. From your tight schedule as the Head of the Altera climate team, you managed to find time to attend to my work. I would like to thank you for making me think critically during my $\mathrm{PhD}$ journey. Most of the time you would make short comments on my work which in the first instance, would look simple and needing very simple response. However, after thinking over them, I needed sometimes a lot of reading and studying and at times I would spend one week to attend to just one of your comments. I would like to thank you for guiding me on how to work as a $\mathrm{PhD}$ student and a researcher. Your guidance on how to accommodate divergent views as a student and a researcher helped me throughout my study period.

Bart Kruijt: I would like to thank you so much for your firmness on ideas. You helped me learn to stick to ideas and how to defend them. You made me realise that in science anything is achievable. Looking back to my work, incorporating tree ring analysis was a challenge after 
getting different views on how to combine modelling and tree-ring results, but through your persistence and different suggestions, we both achieved our objectives. Out of your busy schedule, you managed to find time to come down to Zambia and guided me in the field. Thank you so much for your flexibility and guide.

Royd Vinya: Thank you so much for your guidance and support throughout my PhD journey. From your busy schedule as the Dean of the School of Natural Resources, you still found time to look at my work and provided comments. Right from the beginning, you indicated to me that doing a $\mathrm{PhD}$ is hard work, of which truly it is. I would like to thank you for your support both towards my $\mathrm{PhD}$ work and at $\mathrm{CBU}$. Finishing this $\mathrm{PhD}$ would not have been possible without your support at CBU. You guided and defended me at work. Even after my study leave ended, you continued to support me by not allocating me courses to teach so as to give me enough time to finalise my PhD work. A big thank you to you.

James H. Speer: I would like to extend my sincere thank you for your guide and support. Since 2014 when we met in Australia during the field week which was combined with the $9^{\text {th }}$ International Conference on Dendrochronology, your support has continued. Out of your busy schedule with a lot of responsibilities, you found time to come down to Zambia and taught me how to analyse tree rings. Without your guidance, the tree ring analysis would have been a challenge to me. Your guidance and dedication to work is really appreciated. From your visit to Zambia, we planned to have a field week in Zambia, which did not work for several understandable reasons. Now that I am done with my PhD, I hope our collaborative ideas will become reality.

My further appreciation goes to Emmanuel Chidumayo for guiding me on how to collect and analysed data. Your contribution during data analysis and your valuable comments during the development of articles were greatly appreciated.

Maarten Braakhekke and Marleen Pallandt, you mentored me in the application of LPJGUESS model. Without your assistance, it would have been impossible for me to use this model in my work. I really want to thank you for your assistance and guide.

Iwan Supit, you guided me on how to work with Global Circulation Models to analyse climate data. I troubled you several times for guidance, but you never got tired of me. Thank you so much for your help. 
Sitwala Wamunyima, you introduced me to ArcGIS. You sacrificed the whole week-end to teach me the basics on how to use this too. I am really grateful for your help. My sincere thanks also go to Boniface Mbewe at Meteorological office in Lusaka for helping me with climate data from local weather stations in Zambia.

Kees Van 't Klooster, I would like to thank you for all the logistical support you provided to me. Every time I needed your hand, you were always there for me. You even went out of your way to negotiate with managers of HEART project to enable me access funds even after the closure of the project. Thank you for your kindness and support.

My heartfelt thanks also go to the Forestry Department for allowing me to get samples from the reserves in the respective study sites. The management and laboratory technicians at Forestry Research Division are greatly thanked for allowing me to use the laboratory facilities and assisting me to analyse the samples. Felix Chileshe at Copperbelt University and Jan Van Walsen at Wageningen University and Research, you are greatly thanked for your tireless guidance in the respective laboratories during the analysis of samples.

I would not have managed to collect samples without the help of field research assistants. These included, members of staff at Forestry Department and members of the local communities in the respective study sites. Your help in the field is greatly appreciated.

My fellow PhD students and members of staff of WSG group at Wageningen University and Research, I would like to thank you for your encouragement and support during my $\mathrm{PhD}$ journey. The PhD meetings and Monday morning meetings were so encouraging and helpful where specific problems facing $\mathrm{PhD}$ students were discussed and updates given.

To Phillimon Ng'andwe, thank you so much for your encouragement and support during my $\mathrm{PhD}$ journey. As the Head of my Department at Copperbelt University, you were always there for me and provided the necessary guidance and help right from the beginning to the end of my PhD journey. A big thank you to you.

To James Champion Tembo, Thank you so much for your encouragement. Yes, you are now physically very far, but spiritually, you have always been near me. Your encouragement has helped me to pull through this $\mathrm{PhD}$ journey. Your jokes and general communication with me was really appreciated. Sometime, I would feel so low, but after talking to you, I would feel 
like having life again. Yes, you have been a colleague, brother and friend, but also a father to me during this journey. Thank you for your support.

My PhD studies would not have been possible without the support of the HEART project, the Copperbelt University, International Foundation for Science, Schlumberger Foundation Faculty for the Future, and Wageningen University and Research. I want to thank these organisations for their financial support.

To my spiritual brothers and sisters of the English group in Wageningen, I want to thank you for your nice association and your kindness. You always made me feel at home every time I was in the Netherlands.

To Mum and my late Dad, I want to thank you for the good morals that you instilled in me. It is because of these good morals that I now can have this great achiement in my life. Sometimes I would be very far from you, mum, but you continued guiding me on how to live. Thank you for your prayers, guidance and support.

To the whole family, I want to thank you all for your moral, physical and spiritual support. Sometimes I would be away without seeing any of you when I was busy with my research activities, but you still encouraged me and gave me hope that one day, this activity will come to an end. Yes, it has now come to an end and I am fully available to the family. As the last born child in the family of eight, I have enjoyed the support from all of you. Thank you so much for understanding and trusting me. You have always been my pillar and I hope my achievement will encourage the young ones to aim higher. 
Justine Ngoma was born on $21^{\text {st }}$ November, 1975 in Chipata district, in eastern province of Zambia. In 1996, she completed her Secondary education at St. Monica's Secondary School. From 1998 to 2001, Justine studied forestry at the Copperbelt University in Zambia where she was awarded a BSc in Forestry. In 2002, Justine lectured at Zambia forestry college for one academic year before joining NFCA Africa Mining Plc in 2003 as a laboratory technician.

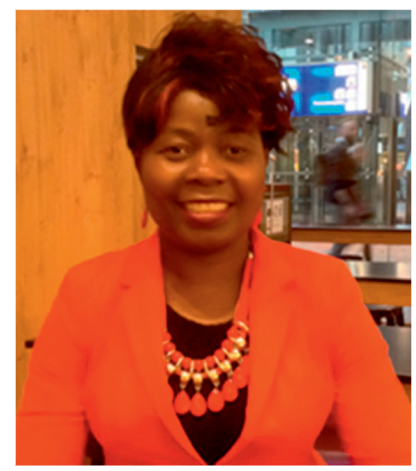

Being one of the best graduating female students, Justine was re-called by the Copperbelt University in 2005 to join the institution under the Staff Development Program. In 2006, she went to Sweden under the sponsorship of the Copperbelt University to pursue a Master's degree in Environmental Sciences at Linkoping University. Justine returned to the Copperbelt University in 2008 to continue working as a lecturer in the Department of Bio-material Science and Technology (the then Wood Science and Technology). In 2012, Justine was nominated by her Department to pursue a $\mathrm{PhD}$ at Wageningen University under the NUFFIC $\backslash$ NICHE funded project called HEART. She focused her research on vegetationclimate interaction, specifically looking at the response of the Zambezi teak forests to climate change.

After finishing her BSc. Forestry in 2001, Justine had been using some of her time to study accountancy (Association of Chartered Certified Accountants - ACCA) and she finished her professional level III in 2016. Justine is currently in Zambia working for the Copperbelt University as a lecturer and a researcher in the Department of Bio-material Science and Technology. 


\section{PUBLICATIONS}

\section{Peer reviewed papers}

Ngoma J, Braakhekke MC, Kruijt B, Moors E, Supit I, Speer JH, Vinya R, Leemans R. 2019. Modelling the response of Net Primary Productivity of Zambezi teak forests to climate change along a rainfall gradient in Zambia. Biogeosciences. "Under review"1-23.

Ngoma J, Moors E, Kruijt B, Speer JH, Vinya R, Chidumayo EN, Leemans R. 2018. Below and above-ground carbon distribution along a rainfall gradient. A case of the Zambezi teak forests, Zambia Acta Oecologica 87:45-57.

Ngoma J, Moors E, Kruijt B, Speer JH, Vinya R, Chidumayo EN, Leemans R. 2018. Data for developing allometric models and evaluating carbon stocks of the Zambezi Teak Forests in Zambia. Data in Brief 17:1361-1373.

Ngoma J, Speer JH, Vinya R, Kruijt B, Moors E, Leemans R. 2017. The dendrochronological potential of Baikiaea plurijuga in Zambia. Dendrochronologia 41:65-77.

Speer JH, Bräuning A, Zhang Q-B, Pourtahmasi K, Gaire NP, Dawadi B, Rana P, Dhakal YR, Acharya RH, Adhikari DL, Adhikari S, Aryal PC, Bagale D, Baniya B, Bhandari S, Dahal N, Dahal S, Ganbaatar N, Giri A, Gurung DB, Khandu Y, Maharjan B, Maharjan R, Malik RA, Nath CD, Nepal B, Ngoma J, Pant R, Pathak ML, Paudel H, Sharma B, Hossain MS, Soronzonbold B, Swe T, Thapa I, Tiwari A. 2017. Pinus roxburghii stand dynamics at a heavily impacted site in Nepal: Research through an educational fieldweek. Dendrochronologia 41:2-9.

\section{Conference papers}

Ngoma J, Braakhekke MC, Kruijt B, Moors E, Speer JH, Supit I, Vinya R, Leemans R. 2017. Modelling the sensitivity of the Zambezi teak forests to climate change, Zambia. iLEAPS International Science Conference. Oxford, UK.

Ngoma J, Speer J, H. , Vinya R, Kruijt B, Moors E, Leemans R. 2017. The climate-growth relationship of Baikiaea plurijuga in Zambia. 6th International Scientific Conference on Hardwood Processing. Helsinki, Finland. 
Ng'andwe P, Ncube E, Ngoma J, Malambo F, Chaamwe N. 2017. Web-based database for commercial and lesser-used hardwood timber species in Zambia. 6th International Scientific Conference on Hardwood Processing. Helsinki, Finland.

Ngoma J, Speer J, H. , Vinya R, Kruijt B, Moors E, Leemans R. 2015. The Dendroclimatological Potential of Baikiaea plurijuga in Zambia. The 4th International conference of Asian Dendrochronological Association. Kathmandu, Nepal.

Ngoma J. 2010. Adaptation measures implemented by agricultural sector in response to climate change in Zambia. 2nd International Conference: Climate, Sustainability and Development in Semi-arid Regions. Fortaleza-Ceará, Brazil: ICID+18. p 15pp. 


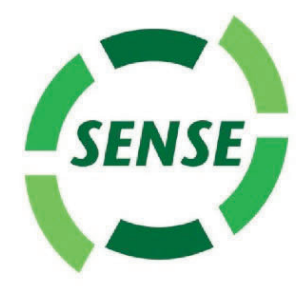

Netherlands Research School for the

Socio-Economic and Natural Sciences of the Environment

\section{I P L O M A}

For specialised PhD training

The Netherlands Research School for the Socio-Economic and Natural Sciences of the Environment (SENSE) declares that

\section{Justine Ngoma}

born on 21 November 1975 in Chipata, Zambia

has successfully fulfilled all requirements of the

Educational Programme of SENSE.

Wageningen, 11 June 2019
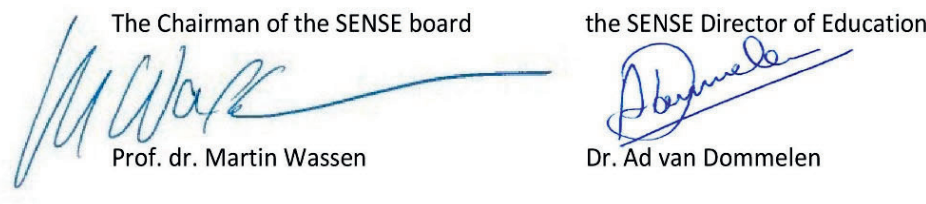

The SENSE Research School has been accredited by the Royal Netherlands Academy of Arts and Sciences (KNAW)

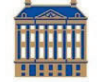

K O N I N K L I J K E N E D E R L A N D S E

A K A D E M I E V A N W E T E N S C H A P P E N 


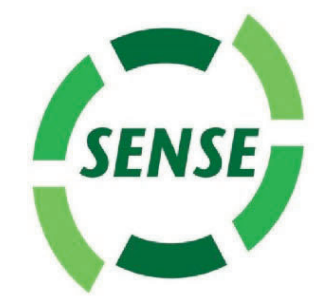

The SENSE Research School declares that Justine Ngoma has successfully fulfilled all requirements of the Educational PhD Programme of SENSE with a work load of $45.2 \mathrm{EC}$, including the following activities:

\section{SENSE PhD Courses}

- REDD Science governance: opportunities and challenges (2012)

- Information literacy (2012)

- Scientific writing (2012)

- Scientific publishing (2012)

- Linear models (2016)

- Generalized linear models (2016)

- Mixed linear models (2016)

- Basic statistics (2016)

- Environmental research in context (2016)

- Introduction to R for statistical analysis (2016)

- Research in context activity: 'Organizing PhD meetings for the Water Systems and Global Change (WSG) group and writing accessible press release on results of PhD

research'(2018)

\section{Other PhD and Advanced MSc Courses}

- Integrated ecosystem assessment, Wageningen University (2012)

\section{Management and Didactic Skills Training}

- Supervising eight BSc students at Copperbelt University with thesis (2014-2018)

- Teaching the BSc courses 'Environmental Management', 'Entrepreneurship' and 'Biomass Resource Assessment' at Copperbelt University (2018)

\section{Oral Presentations}

- Dendroclimatological potential of Baikiaea plurijuga in Zambia. The fourth International conference of Asian Dendrochronological society, 9-12 March 2015, Kathmandu, Nepal

- The vulnerability of the Zambezi teak forests and the forest's dependent communities to climate change. Heart project closing workshop, 18-19 June 2015, Ndola, Zambia

- The carbon stocks of Zambezi teak forests under a changing climate, Zambia. iLEAPS International Science Conference, 11-14 September 2017, Oxford, United Kingdom

- The climate-growth relationship of Baikiaea plurijuga in Zambia. $6^{\text {th }}$ International Scientific Conference on Hardwood Processing, 25-28 ${ }^{\text {th }}$ of September 2017, Helsinki, Finland

SENSE Coordinator PhD Education

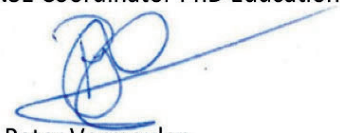

Dr. Peter Vermeulen 
Cover photos by Justine Ngoma

Cover designed by Justine Ngoma

Content designed by Justine Ngoma

Printed by Digiforce 

